\title{
Guide for Training Nuclear Power Plant Operators
}
J. A. Cox
C. D. Cagle
R. V. McCord
B. L. Corbett
W. H. Culbert
T. P. Hamrick
S. S. Hurt
K. H. Poteet
A. E. G. Bates
W. R. Casto
R. L. Scott

\section{OAK RIDGE NATIONAL LABORATORY}




\section{DISCLAIMER}

This report was prepared as an account of work sponsored by an agency of the United States Government. Neither the United States Government nor any agency Thereof, nor any of their employees, makes any warranty, express or implied, or assumes any legal liability or responsibility for the accuracy, completeness, or usefulness of any information, apparatus, product, or process disclosed, or represents that its use would not infringe privately owned rights. Reference herein to any specific commercial product, process, or service by trade name, trademark, manufacturer, or otherwise does not necessarily constitute or imply its endorsement, recommendation, or favoring by the United States Government or any agency thereof. The views and opinions of authors expressed herein do not necessarily state or reflect those of the United States Government or any agency thereof. 


\section{DISCLAIMER}

Portions of this document may be illegible in electronic image products. Images are produced from the best available original document. 
Printed in the United States of America. Available from National Technical Information Service

U.S. Department of Commerce

5285 Port Royal Road, Springfield, Virginia 22161

Price: Printed Copy $\$ 10.50$; Microfiche $\$ 3.00$

This report was prepared as an account of work sponsored by the United States Government. Neither the United States nor the Energy Research and Development Administration/United States Nuclear Regulatory Commission, nor any of their employees, nor any of their contractors, subcontractors, or their employees, makes any warranty, express or implied, or assumes any legal liability or responsibility for the accuracy, completeness or usefulness of any information, apparatus, product or process disclosed, or represents that its use would not infringe privately owned rights. 
Contract No. $W-7405-e n g-26$

OPERATIONS DIVIS ION

GUIDE FOR TRAINING NUCLEAR POWER PLANT OPERATORS
J. A. $\operatorname{Cox}$
C. D. Cagle
R. V. McCord
B. L. Corbett
W. H. Culbert
K. H. Poteet
T. P. Hamr ick
A. E. G. Bates
W. R. Casto
S. S. Hurt
R. L. Scott

Date Published: January 1977

OAK RIDCE NATIONAL LABORATORY

Oak Ridge, Tennessee 37830

operated by

UNION CARB IDE CORPORATION

for the

ENERGY RESEARCH AND DEVELOPMENT ADMINISTRATION

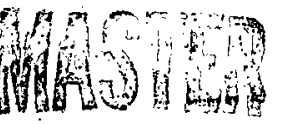


THIS PAGE

\section{WAS INTENTIONALLY LEFT BLANK}


CONTENTS

Page

INTRODUCTION . . . . . . . . . . . . . . . . . 1

Part A - Basic Preparation for Operator Training

SECTION I. Mathematics ............... 4

SECTION II. Chemistry and Radiochemistry . . . . . . 16

SECTION III. Basics of Heat Transfer and Fluid Flow . . . . . 25

SECTION IV. Basics of Instrumentation . . . . . . . . . 40

SECTION V. Basics of Elementary Control Diagrams,

Flow Diagrams, and Drawings . . . . . . . . . . 53

Part B - Operator Training Program

SECTION VI. Radiation Safety and Control . . . . . . . 60

SECTION VII. Principles of Reactor Operation . . . . . . . 80

SECTION VIII. General Operating Characteristics . . . . . . 99

SECTION IX. Features of Facility Design . . . . . . . . 123

SECTION X. Safety and Emergency Systems . . . . . . 143

SECTION XI. Instruments and Controls . . . . . . . . 163

SECTION XII. Standard and Emergency Operating Procedures . . . 221

Part. C. - Senior Cporator Training Progiam

SECTION XIII. Reactor Theory . . . . . . . . . . 244

SECTION XIV. Specific Operating Characteristics . . . . . 263

SECTION XV. Fuel Handling and Core Parameters . . . . . 306

SECTION XVI. Radioactive Material Handling, Disposal,
and Hazards

SECTION XVII. Administrative Procedures, Conditions,
and Limitations . . . . . . . . . . . . . 332

APPENDIX A. Bibliography . . . . . . . . . . . 343 


\section{INTRODUCTION}

The purpose of this training guide is to provide both the instructor and the student with an outline for training the operating staff of a nuclear facility. The subject material has been arranged in order of presentation so that the trainee will be provided with information in a logical sequence. Because it is assumed that operator trainees may require considerable review of basic mathematics, chemistry, heat transfer, and instrumentation before reactor or nuclear topics can be taught effectively, Part A, entitled "Basic Preparation for Operator Training" has been included. If the trainee is already sufficiently knowledgeable in these subjects, some or all can be omitted.

Part $B$ includes the topics required for operator training, which are the same as those used for licensing examination in the United States. Similarly, Part $\mathrm{C}$ includes the additional topics that are required for the senior operator licensing examination.

Upon completion of the training period, the student should (1) be prepared for a license examination for the position of reactor operator or senior operator and (2) possess the capability of performing these jobs efficiently.

The training guide is intended to include subject material applicable to all nuclear installations, whether they are simple research reactors or electrical-power-producing facilities, although much of the material may not apply to any specific reactor. Emphasis is placed primarily on the reactor and its associated systems; such subjects as reactor characteristics, cooling systems, safety systems, physics, emergency procedures, etc., for the reactor are covered in greater depth than are the turbine generator, electrical distribution systems, and auxiliary equipment. Since these last three subjects have been taught for years in fossil plant training, it is assumed that they will continue to be covered in the same manner.

No specified study time has been recommended for the lesson plans; this should be determined by the instructor. In general, the time required for training in each subject will depend primarily on the students' previous 
experience with nuclear reactors and/or electrical-power-producing plants, the complexity of the plant, the coordination of training sessions with practical training on a reactor, and the size of the group. Depending on the type and size of the facility, training periods at a nuclear facility may vary typically from six months to more than one or two years for operators and even longer for senior operators.

Many organizations have prepared training programs for nuclear power plant operators, and numerous reports have been written on the subject. Appendix $\mathrm{A}$ is a bibliography on training that could be helpful to any group during the initial stages of setting up a training program. 
Part A-Basic Preparation for Operator Training 
SECTION I. MATHEMATICS

Contents

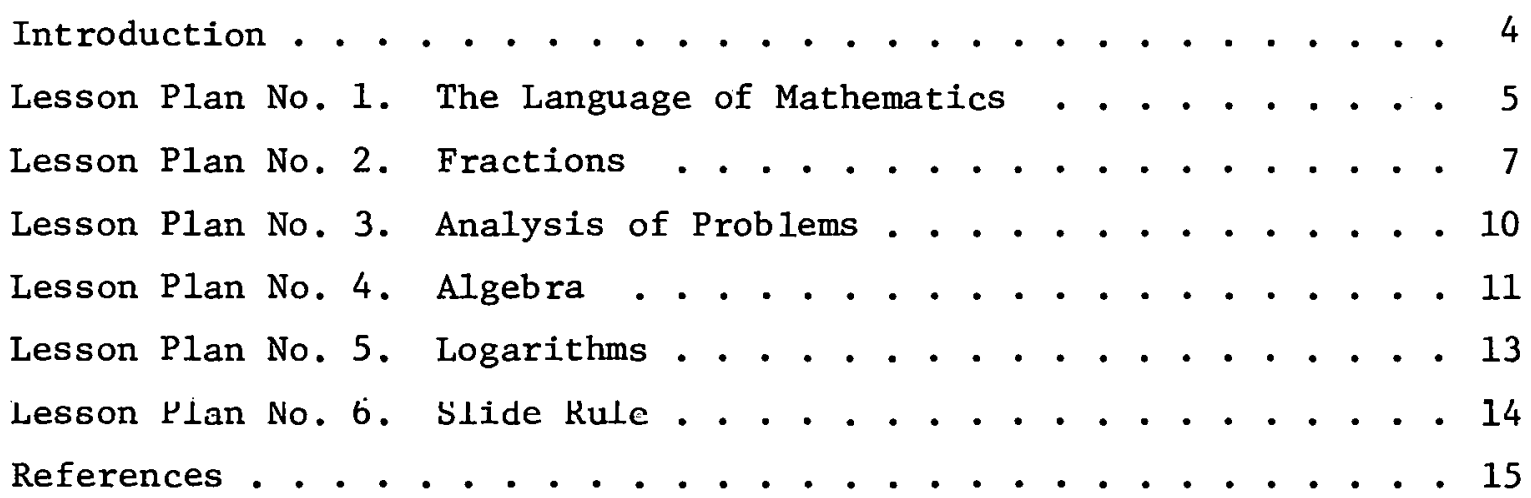

Introduction

Mathematics is the language of numbers and sizes. Just as rules of grammar must be studied to master English, so must certain concepts, rules, definitions, terms, etc., be studied to master mathematics. These basics form the vocabulary of the language. The more a language is studied and used, the greater its vocabulary becomes; 1ikewise, the more mathematics is studied and applied, the greater its usefulness becomes.

In all technical fields, regardless of level, a knowledge of some mathematics is necessary for understanding. Persons having this knowledge seem to be able to think and express themselves more confidently than those having no knowledge of mathematics. Without mathematical assistance, the reactor operator must be content with the process of accumulating bits of information, details of experience, etc., and he may never achieve an understanding of reactor operation.

Because of the emphasis on technical fields in the past several years, many mathematics texts have been prepared; the instructor needs only to find the proper one for his students. These texts range from teaching students simple addition to solving differential equations in performing highly complicated mathematical analyses. This is especially true in the programmed instruction style texts simply because mathematics is so 
adaptable to this type of presentation. For a bibliography of programed instruction courses, one should obtain a copy of Programed Instruction Guide, compiled by Northeastern University and published by Entelek, Inc. Regardless of the method of presentation, the student should receive a complete outline of the course material in the beginning so that he is aware of the overall objective result of his effort. The instructor must guard against progressing too rapidly. There is a tendency, especially in studying material whose contents are familiar, to hurry to the next subject. Proficiency in mathematics depends upon a thorough understanding of each step as it is encountered so that it can be used to its full advantage in each subsequent step.

This section is arranged in a series of lesson plans that can be used in a brief mathematics course for reactor operators. It must be emphasized that these lesson plans should be amplified to meet the needs of the training situation.

\section{Lesson Plan No. 1. The Language of Mathematics}

\section{Objective}

The purpose of the first lesson plan is to describe the course to the student. Emphasis should be placed on how the mathematics will be useful in other courses throughout the training program. This lesson can be used to hand out useful information such as that listed below.

\section{Plan Outline}

A. Common mathematical symbols

$$
\begin{array}{ll}
=\text { equals } & \times \text { or } \cdot \text { multiplied by } \\
\neq \text { is not equal to } & \div \text { or / divided by } \\
\equiv \text { is identical to } & >\text { greater than }
\end{array}
$$


+ plus

- minus

\pm plus or minus

$\sqrt[\mathrm{N}]{ } \mathrm{Nth}$ root

$\rightarrow$ or $\div$ approaches as

I a I absolute value of $a$

$\mathrm{n}$ ! or $\mathrm{n}$ fractional $\mathrm{n}=$ $n(n-1)(n-2) \ldots 1$

$\sum_{a}^{b}$ silm frnm a to $h$

$\angle$ angle

$\%$ percent $\geqslant$ or $\geqslant$ equal to or greater than

$<$ less than

$\leqq$ or $\leqslant$ equal to or less than

$\infty$ infinity

$\propto$ varies as

: ratio, is to

$\approx$ approximates

$\sim$ is similar to

b

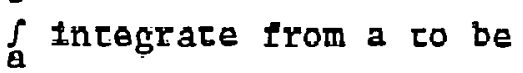

1 perpendicular

II parallel

Other symbols may be added for completeness. Each symbol should be defined and its use illustrated.

B. Greek alphabet

\begin{tabular}{|c|c|c|c|c|c|}
\hline \multirow[b]{2}{*}{ Name } & \multicolumn{2}{|c|}{ Symbol } & \multirow[b]{2}{*}{ Name } & \multicolumn{2}{|c|}{ Symbol } \\
\hline & Capilal & $\begin{array}{l}\text { Lower } \\
\text { Case }\end{array}$ & & Capital & $\begin{array}{l}\text { Lower } \\
\text { Case }\end{array}$ \\
\hline Alpha & A & $\alpha$ & $\mathrm{Nu}$ & $\mathrm{N}$ & $v$ \\
\hline Beta & B & $\beta$ & $\mathrm{Xi}$ & $\Xi$ & $\xi$ \\
\hline Gamma & $\Gamma$ & $\gamma$ & Omicron & 0 & 0 \\
\hline De1 ta & $\Delta$ & $\delta, \partial$ & $\mathrm{P} 1$ & $\pi$ & $\pi$ \\
\hline Epsilon & $\mathrm{E}$ & $\varepsilon$ & Rho & $\mathbf{P}$ & $\rho$ \\
\hline Zeta & $\mathrm{z}$ & $\zeta$ & Sigma & $\Sigma$ & $\sigma, s$ \\
\hline Eta & $\mathrm{H}$ & $n$ & Tau & $\mathrm{I}$ & $\tau$ \\
\hline Theta & $\theta$ & $\theta$ & Upsilon & $\mathrm{T}$ & $u$ \\
\hline Iota & I & $l$ & Phi & $\Phi$ & $\phi$ \\
\hline Kappa & $\mathrm{K}$ & $\kappa$ & Chi & $\mathrm{X}$ & $x$ \\
\hline Lamb da & $\Lambda$ & $\lambda$ & Psi & $\Psi$ & $\psi$ \\
\hline $\mathrm{Mu}$ & $\mathbf{M}$ & $\mu$ & Omega & $\Omega$ & $\omega$ \\
\hline
\end{tabular}


C. Metric system - prefixes

$$
\begin{array}{ll}
\text { pico }=10^{-12} & \text { tera }=10^{12} \\
\text { nano }=10^{-9} & \text { giga }=10^{9} \\
\text { micro }=10^{-6} & \text { mega }=10^{6} \\
\text { milli }=10^{-3} & \text { kilo }=10^{3} \\
\text { centi }=10^{-2} & \text { hecto }=10^{2} \\
\text { deci }=10^{-1} & \text { deka }=10^{1}
\end{array}
$$

Other terms and definitions should be added for completeness.

D. Conversion tables

The instructor should obtain or prepare a set of conversion tables to suit the needs of the student. Many are available in various handbooks. The tables are handed out for future use with a brief description of their use.

E. Fundamental constants

$$
\begin{aligned}
& \pi=3.141592653589793 \\
& e=2.1718281828459045 \\
& \log _{10} e=0.434294481903252 \\
& 1 \text { degree }\left(^{\circ}\right)=0.01745329 \text { radian } \\
& 1 \text { radian }=57.2957795^{\circ}
\end{aligned}
$$

There are many other useful items which can be handed out in this lesson or as the student has use for the information. In any case, the student should maintain a section in his notebook so that he can refer to it at any time, not only during his training period. However, he will not be able to use it if he does not understand it.

Lesson Plan No 2. Fractions

\section{Objective}

This lesson should refresh the trainee's memory on the use of fractions in various arithmetical operations. 
Plan Outline

A. Definitions

1. Fraction - an expression representing division of one number by another.

2. Mixed number - a number composed of an integer and a fraction.

3. Similar fractions - fractions having the same denominator.

4. Least common denominator - the least common multiple of the denominators of two or more fractions.

5. Equality of fractions - if two or more fractions yield the same quotlent when the indicated division is carried out, the fractions are equal (i.e., 1/2, 4/8,6/12).

6. Order of fractions - if two fractions have equal denominators, the one having the larger numerator is larger; if two fractions have equal numerators, the one having the smaller denominator is larger.

7. Cancellation - division of numerator and denominator of a fraction by the same number to simplify it.

B. Common fractions

1. Addition and subtraction

2. Multiplication and division

C. Decimal fractions

1. Addition and subtraction

2. Multiplication and division

3. Rounding off approximate numbers

4. Operations with approximate numbers

D. Percontage

\section{Sample Study Questions}

The only way to learn mathematics is by first learning the language and then using this language to work problems. Keep in mind that the people who have the most trouble with mathematics are those who are sloppy . 
1. Find the least common denominator of the following groups of fractions.
a. $3 / 7,2 / 3,5 / 6,1 / 2$
b. $3 / 11,2 / 9,3 / 10,4 / 7$
c. $1 / 2,1 / 4,1 \% 8,1 / 16$

2. Determine which two fractions in the following groups are equal.
a. $2 / 3,46 / 68,14 / 21$
b. $441 / 627,1287 / 1830,147 / 209$
c. $6271 / 103,601 / 11,661 / 121$

3. Put the following groups of fractions in ascending order.
a. $1 / 4,1 / 2,3 / 8,1 / 17,1 / 16$
b. $12 / 3,11 / 4,9 / 5,5 / 9$
c. $127 / 47,63 / 46,30 / 21,15 / 8$

4. Change the following common fractions to decimal fractions.
a. $2 / 3,4 / 3,6 / 3$
b. $1 / 2,1 / 4,1 / 8$
c. $2 / 11,3 / 12,4 / 13$

5. Perform the following operations.
a. $13 / 16+1 / 2-3 / 4$
f. $2-(3.8-1.2361 .498)$
b. $42 / 54-21 / 27$
g. $3.142 \div 100$
c. $3 / 8 \times(1 / 4+2 / 3)$
h. $3.142 \times 1000$
d. $1 / 2 \times 1 / 2 \div 1 / 4$
i. $2 / 3 \times 3.61$
e. $2.326+1.45-3.891601$
j. $3 / 4 \times 1.823 \div 14 / 15$

6. Change the following fractions to percentages.
a. $1 / 8$
d. $12 / 15$
b. 0.125
e. 0.00036
c. 3.21
f. $7 / 8$ 
Lesson Plan No. 3. Analysis of Problems

Objective

This lesson should provide a review of various algebraic operations and acquaint the trainee with dimensional concepts.

Plan Outline

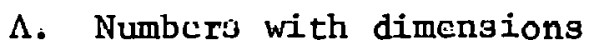

1. Cúnvensiun Lables

2. Multiplication and division

B. Ratio and proportion

1. Direct variation

2. Indirect variation

3. Joint variation

C. Graphs

1. Linear

2. Bar

3. Circle

4. Logarithmic

D. Signed numbers

Sample Study Questions

1. Convert the following.
a. $50 \mathrm{cals} / \mathrm{g}$ to Btu/lb
b. $14 \mathrm{~cm}$ to $\mathrm{ft}$
c. $95^{\circ} \mathrm{F}$ tu ${ }^{\circ} \mathrm{C}$

2. Perform the following operations.

a. $25 \mathrm{gal} /$ day $\times 275$ days $\times 8.3 \mathrm{lb} / \mathrm{gal}$

b. $5.3 \times 10^{13}$ neutrons $/ \mathrm{cm}^{2}-\mathrm{sec} \times 0.025 \mathrm{MeV} /$ neutron $\times 120 \mathrm{sec}$ 
3. Plot the following data.

\begin{tabular}{|c|c|}
\hline $\mathrm{X}$ & $Y$ \\
\hline 0 & 0 \\
\hline 3 & 4.38 \\
\hline 5 & 7.3 \\
\hline 10 & 14.6 \\
\hline 21 & 30.66 \\
\hline
\end{tabular}

Determine the slope of the line.

b. $x^{2}+y^{2}=25$

c. $\mathbf{x}=3 \mathrm{y}-2$

4. Plot the following on both linear and semilog paper.
a. $x=y^{2}$
b. $x=y^{3}$
c. $x=y^{4}$

What is the advantage of semilog paper?

5. Perform the following operations.
a. $-3.216+1.847+2.431-6.871$
b. $(-3.216) \times(1.847) \times(-6.871)$
c. $(-3.216) \times(1.847) \div(-6.871)$

Lesson Plan No. 4. Algebra

Objective

This lesson should provide a review of elementary algebra.

\section{Plan Outline}

A. Algebraic expressions

1. Symbols used in algebra

2. Addition and subtraction 
3. Multiplication and division

4. Powers and exponents

B. Algebraic equations

1. Simple

2. Simultaneous

3. Quadratic

C. Powers and powers of ten

D. Roots

Sample Study Questions

1. Simplify the following equations.
a. $7 a+3 a-a$
b. $-12 c-4 c+c+14 c$
c. $(5 a+14 b+10 c)+(2 b-6 c)-(3 a-9 c-3 x)$
d. $(3 a+2 b) \cdot(a-b)$
e. $\left(a^{3}+3 a^{2} b+3 a b^{2}+b^{3}\right) /(a+b)^{2}$

2. Solve the following equations for $x$.
a. $9 \mathrm{x}-18=6+3 \mathrm{x}$
b. $x^{2}=a^{2}+2 a b+b^{2}$
c. $x=(7+3 x) / 2$

3. Solve the equations for the two unknowns both algebralcally and graphically.
a. $2 \mathrm{x}+3 \mathrm{y}=7 ; \cdot 4 \mathrm{x}-5 \mathrm{y}=3$
b. $4 \mathrm{x}-6 \mathrm{y}=28 ; 2 \mathrm{x}-8 \mathrm{y}=24$

4. Solve the following quadratic equations.

$$
\begin{aligned}
& \text { d. } 8 x^{2}-64=0 \\
& \text { b. } 6 x^{2}-2 x^{2}=64 \\
& \text { c. } x^{2}+8 x+15=0 \\
& \text { d. } 2 x^{2}+4 x-70=0 \text { (complete the square) }
\end{aligned}
$$

5. A park which is in the form of a right triangle has one side $25 \mathrm{ft}$ longer than the other. If the area [1/2 (base $X$ height)] is $625 \mathrm{ft}^{2}$, find the length of the sides. 
6. Perform the following operations.
a. $5^{3}$
b. $10^{4}$
c. $10^{-4}$
d. $3^{5}$

7. Rewrite the numbers in scientific notation.
a. 4291
b. 0.00361
c. $10^{4}$
d. $30.12 \times 10^{2}$
e. 0.0000000682

8. Divide.

$$
\frac{3.7 \times 10^{10} \times 0.00182 \times 10^{12} \times 3.1 \times 10^{-7}}{2.842 \times 10^{-4} \times 4.7 \times 10^{3} \times 10^{2}}
$$

Lesson Plan No. 5. Logarithms

Objective

This lesson should provide a review of the properties and use of logarithms.

Plan Outline

A. Introduction

1. Definition

2. Notation

B. Common logarithms

1. Characteristic and mantissa

2. Use of tables

3. Multiplication and division

4. Powers and roots 
C. Natural logarithms

1. Base e

2. Exponential equations

\section{Sample Study Questions}

1. Find the common logarithms of the following numbers.
a. 3.14159
b. 10
c. 32496
d. U.UU12y3
e. 1

2. Find the natural logarithms of the numbers listed in Problem 1.

3. Work the following problems using common logarithms.
a. $27.381 \times 13.31$
b. $87 \div 326$
c. $\sqrt[3]{187}$
d. $(629)^{\circ}$
e. $16 \times 421 \div 342 \times \sqrt[6]{6873} \div(1269)^{3.21}$

4. Evaluate the following.
a. $e^{-3.3}$
b. $e^{-0.0012}$
c. $\mathrm{e}^{2.68}$
d. $e^{1.87}$
e. $e^{-1.87}$

Lesson Plan No. 6. Slide Rule

\section{Objective}

This lesson should provide a review on the use of the slide rule. 
Plan Outline

A. Introduction

B. Basic operations

1. Multiplication and division

2. Squares, cubes, and roots

3. Location of decimal points

C. Additional operations

1. Use of trigonometric scales

2. Use of $\log -\log$ scales

Sample Study Questions

The instructor can repeat the problems already given and add any number of his own. Practice increases proficiency.

\section{$\underline{\text { References }}$}

1. Samuel Slade and Louis Margolis, Mathematics for Technical and Vocational Schools, 4th ed., John Wiley \& Sons, Inc., New York, 1955.

2. E. E. Grazda, M. Brenner, and W. R. Minrath, eds., Handbook of Applied Mathematics, D. Van Nostrand Co., Inc., Princeton, N.J., 1966.

3. F. S. Merritt, Mathematics Manual, McGraw-Hill Book Co., Inc., New York, 1962.

4. J. P. Ellis, The Theory and Operation of the Slide Rule, Dover Publications, New York, 1961.

5. R. S. Burington, Handbook of Mathematical Tables and Formulas, 4th ed., McGraw-Hill, New York, 1965.

6. A. P. Sperling and M. Stuart, Mäthematics Made Simple, new rev. enl. ed., Doubleday \& Co., Inc., 1962. 
SECTION II. CHEMISTRY AND RADIOCHEMISTRY

Contents

Introduction . . . . . . . . . . . . . . . . . . . 16

Lesson Plan No. 1. Definitions and Fundamentals of Reactor

Chemistry . . . . . . . . . . . . . . . . . . . 17

Lesson Plan No. 2. Chemical Reactions . . . . . . . . . . . 18

Lesson Plan No. 3. Chemical Properties of Reactor Materials . . . 19

Lesson Plan No. 4. Chemical Operations at the Facility . . . . . 21

Lesson Plan No. 5. Hazards and Precautions . . . . . . . . . 22

Lesson Plan No. 6. Radiochemistry . . . . . . . . . . . . 23

Lesson Plan No. 7. Comprehensive Examination . . . . . . . . 24

\section{Introduction}

The purpose of this section is to provide the trainee with enough of the basics of chemistry and radiochemistry to enhance his understanding of some of the chemical processes that occur in the various systems of the facility (e.g., ion exchange in the water purification system). This knowledge will aid him in understanding the reasons for some of the imposed limitations on water quality and should also provide a foundation for understanding other concepts presented in later sections of the training program. 
Lesson Plan No. 1. Definitions and Fundamentals of Reactor Chemistry Objective

This lesson should provide an understanding of terminology and basic concepts.

$\underline{\text { Plan Outline }}$

A. Elements and atoms

1. Definitions

2. Symbols

3. Atomic structure (nucleus and orbital electrons)

4. Atomic weights

5. Periodic table, classification, characteristics

B. Compounds

1. Valence electrons

2. Ionic bonds

3. Covalent bonds

4. Combining weights

5. Simple formulas of compounds

6. Gram-molecular weight

7. Avogadro's number

C. States of matter

1. Gases

2. Liquids

3. Solids

4. Phase changes

\section{Sample Study Questions}

1. $\mathrm{H}_{2}+\mathrm{O}_{2}$ react to form what?

2. What is a gram-molecular weight?

3. What is the meaning of Avogadro's number? 
4. Can a compound exist in all three states - gas, liquid, and solid - at the same time? Give an example.

5. At what temperature does a phase change of water occur?

\section{$\underline{\text { References }}$}

1. Any standard chemistry handbook.

\section{Lesson Plan No. 2. Chemical Reactions}

\section{Objective}

This lesson should provide a basic understanding of chemical reactions to enhance the trainee's understanding of the subtle processes taking place within the reactor systems (e.g., corrosion and crud deposition.).

\section{$\underline{\text { Plan Outline }}$}

A. Liquids

1. Acids and bases

2. Chemical equilibrium

J. Solubility and concentration

4. pII

5. Conductivity and resistivity

6. Specific gravity

B. Chemical reactions of special interest

1. Corrosion

2. Electromotive forces

3. Oxidation potentials

4. Precipitation

5. Evaporation and distillation 
C. Purification of water

1. Ion exchange

2. Demineralization

3. Absorption

4. Desorption

5. Filtration

6. Coolant quality

D. Consequences of impurities in coolant

1. Excessive radioactivity in systems

2. Fouling of fuel elements

3. Corrosion of heat exchanger tubes

4. Jamming of mechanisms

Sample Study Questions

1. What is the meaning of $\mathrm{pH}$ ?

2. Does a high conductivity indicate almost pure water? Explain.

\section{$\underline{\text { References }}$}

1. Any standard chemistry handbook.

2. Paul Cohen, Water Coolant Technology of Power Reactors, an AEC Monograph, pp. 40-144 and 268-368, Gordon and Breach, Science Publishers, Inc., New York, 1969.

Lesson Plan No. 3. Chemical Properties of Reactor Materials

\section{Qbjective}

This lesson should introduce the trainee to the numerous materials in the reactor and provide an initial awareness of the different properties of these materials. 
$\underline{\text { Plan Outline }}$

A. Properties of reactor materials

1. Water

2. Stainless steel

3. Zirconium

4. Boron, cadmium, other poisons

5. Uranium and uranium dioxide

B. Important properties of materials affecting reactor operation

1. Decomposition in radiation fields

2. Radiolytic decomposition

3. Stress corrosion

4. Water boiling temperature vs pressure

5. Gas diffusion through cladding (or matertals)

6. Toxicity

7. Vaporization or volatility

8. Pyrophoricity

\section{Sample Study Questions}

1. What does radiolytic decomposition mean?

2. Are uranium, cadmium, and wator pyrophorici

\section{References}

1. Chemical Rubber Co., Handbook of Chemistmy and Physics, 55th ed., Cleveland, Ohio, 1975. 
Lesson Plan No. 4. Chemical Operations at the Facility

\section{Objective}

This lesson should alert the trainee to the chemical additives and operations which are necessary to minimize corrosion, control reactivity, purify coolant, etc.

\section{Plan Outline}

A. Main cooling system

1. Additives

2. Purpose

3. Quality specifications, limitations, and reasons for each

B. Purification systems

1. Filtration

2. Deaeration

3. Demineralization

4. Quality

C. Radwaste system chemical operations

1. Storage for decay

2. Sampling and analysis

3. Treatment

4. Disposition and limitations

Sample Study Questions

1. What processes are involved in purification of the main coolant water?

2. What limits are imposed on disposition of liquid wastes?

\section{$\underline{\text { References }}$}

1. Facility technical specifications.

2. Facility operating procedures. 
Lesson Plan No. 5. Hazards and Precautions

\section{Objective}

This lesson should introduce the trainee to the potential hazards associated with the use of chemicals and instill in him a desire to be continually alert for potential hazards.

\section{Plan Outline}

A. Chemical hazards

1. Potential burns

2. Addition of acid to water for dilution (never vice versa)

3. Inhalation of fumes

4. Toxicity

5. Potential explosions (e.g., oxygen and hydrogen)

6. Bases heavier than air (potential smothering)

Sample Study Questions

1. In diluting acids, is acid added to water or water added to acid? Explain.

\section{$\underline{\text { References }}$}

1. C. W. Kcilholtz, Chomioal Safoty, ORNL/TM-1884, Oak Ridge Nationa1 Laboratory, Oak Ridge, Tenn., June 6, 1967. 
Lesson Plan No. 6. Radiochemistry

Objective

This lesson should provide a basic understanding of the analytical technique for determining the presence of specific radionuclides, locating leaks, identifying sources of corrosion, and disposing of wastes.

$\underline{\text { Plan Outline }}$

A. Chart of nuclides

1. Element

2. Atomic number and mass

3. Characteristic decay energy

B. Technique of gamma spectroanalysis

1. Method, sampling, and precautions

2. Identifying spectra

3. Terminology ( $\mu \mathrm{Ci} / \mathrm{cc}, \mathrm{mCi} / \mathrm{ml}$, etc.)

C. Applicability of radiochemical analysis

1. Corrosion in coolant

2. Leaking fuel

3. Radwaste treatment methods

4. Normal and abnormal radionuclides in coolant and off-gas systems

\section{Sample Study Questions}

1. What is the predominant radionuclide in the coolant under normal conditions?

2. What is a curie?

\section{$\underline{\text { References }}$}

1. Plant final safety analysis report.

2. Paul Cohen, Water Coolant Technology of Power Reactors, an AEC Monograph, Gordon and Breach, Science Publishers, Inc., New York, 1969. 
Lesson Plan No. 7. Comprehensive Examination

\section{Objective}

This lesson should provide a review of the main points presented in the previous lessons and test the trainee's retention and understanding of the concepts.

\section{$\underline{\text { Plan Outline }}$}

A. A 1- to 2-hr examination

\section{Sample Study Questions}

1. What hazard exists if argon escapes from 1ts storage container into a poorly ventilated room?

2. Explain the difference between acid and base.

3. What quality limitations are imposed for the reactor coolant during operation?

4. Are the limitations (Question 3) different during nonoperation? Explain. 
SECTION III, BASICS OF HEAT TRANSFER AND FLUID FLOW

Contents

Introduction . . . . . . . . . . . . . . . . . . 25

Lesson Plan No. 1. Heat Terms . . . . . . . . . . . . 26

Lesson Plan No. 2. Heat Transfer . . . . . . . . . . . . 28

Lesson Plan No. 3. Heat Transfer (Continued) . . . . . . . . 30

Lesson Plan No. 4. Fluid Flow . . . . . . . . . . . . . . . 34

Lesson Plan No. 5. Comprehensive Examination . . . . . . . . 38

Int roduction

The objective of this chapter is to describe the basic principles of heat transfer and fluid flow and to show in a general way how they are important to the safe operation of nuclear reactors, particularly lightwater-cooled research and power reactors. Although fluid flow and heat transfer are covered separately for clarity, it should be realized that in most applications the two subjects are considered together. A general knowledge of the basic principles will be especially helpful to the operator in understanding why certain systems are designed as they are and why certain operating procedures are prescribed.

Detailed descriptions of how various processes and/or components are intended to function are not discussed. Rather, the approach is to concentrate on the basic principles of heat transfer and fluid flow. Some terms (such as minimum critical heat flux ratio) will be more applicable for certain types of reactors than for others. 
Lesson Plan No. 1. Heat Terms

\section{Objective}

This lesson should provide an understanding of the terminology of heat and its measurement. The student should be taught the difference between heat and temperature and should get some idea of how heat is generated in a reactor. If he can be taught to visualize heat as something tangible, moving and changing, he will be able to discuss and understand reactor problems better. He should already ditterentiate between heat and triction as a result of his own experfence; from thls polnt, he can progress: to understanding basic mechanics of heat sources in a reactor.

\section{$\underline{\text { Plan Outline }}$}

A. Definition of terms

1. Heat
a. Definition
b. Units

2. Specific heat
a. Definition
b. Unilss

3. "Word experiment" relating heat and specific heat

4. Heat power
a. Definition
b. Un1to

5. Temperature
a. Definition
h. Fahrenheit and centigrade scales
c. Temperature is not the same thing as heat

B. Application of terms

1. Nonflow process

2. Steady-flow process

a. General problem

b. Reactor heat balance problem 
C. Sources of heat in a nuclear reactor

1. Fission process

2. Beta heating

3. Gamma heating

4. Decay heat (afterheat, residual heat)

D. Detection of heat in reactor

1. Temperature-sensing devices

2. Delay in detection of heat released in fission

3. Common methods of measuring heat power

\section{Sample Study Questions}

1. How does a fission fragment produce heat? Where does this heat appear?

2. Explain how a nonfissionable material located near the reactor core can have heat produced within it.

3. Why must coolant be circulated through the core for some time after the reactor has been shut down?

4. Is a Btu of heat produced by fissioning of U-235 in a reactor larger than a Btu produced by burning coal? Explain.

5. What is the difference between MW and MW-days?

6. If $1 \mathrm{lb}$ of a certain material has a specific heat of

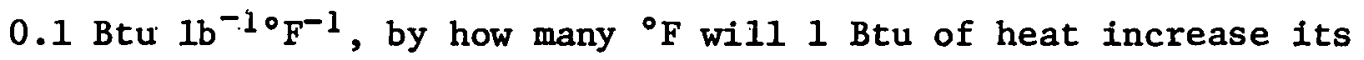
temperature?

7. Why are temperature-sensing devices not used for the main safety systems of a nuclear reactor?

\section{$\underline{\text { References }}$}

1. S. Glasstone and A. Sesonke, Nuclear Reactor Engineering, articles 1.44-1.48, 6.1-6.10,6.27-6.30, and 6.34-6.46, D. Van Nostrand, Inc., Princeton, N.J., 1963.

2. S. D. Sheppard, Reactor Operator Study Handbook (Programed Instruction Version). Vol. IV - Heat Theory and Fluid Flow, ed. C. D. Cagle, pp. 1-13, 20-21, 64-66, and 90-93, ORNL/TM-2034, Oak Ridge National Laboratory, Oak Ridge, Tenn., December 1968. 
Lesson Plan No. 2. Heat Transfer

\section{Objective}

This lesson should teach the student the language of heat transfer. He should gain an understanding of terms such as heat transfer coefficient and heat flux and should relate these terms to those he already knows, such as coolant velocity, interior temperature, and surface temperature. After learning definitions, the student should learn qualitatively how to use the terms in understanding the transfer of heat from the fissioning to 1 ts use or disposal. He should gain an understanding of how heat transfer is caused by differences in temperature, and he should develop a feeling for the effect of not transferring heat trom a tuel element. In other words, he should understand the heat flux curve and burnout. The questions at the end of the plan are quite typical, and the student should learn to answer similar ones for the reactor he will operate.

\section{Plan Outline}

A. Definition of terms (Fig. III.1)

1. Interior temperature of fuel rod or element

2. Burlace temperature of cladding

3. Coolant temperature

4. Coolant velocity

5. Coolant channel equivalent diameter

6. Critical heat flux

7. Heat transfer coefficient

8. Surface heat flux

9. Thermal conductivity

10. Fission-product decay after shutdown 


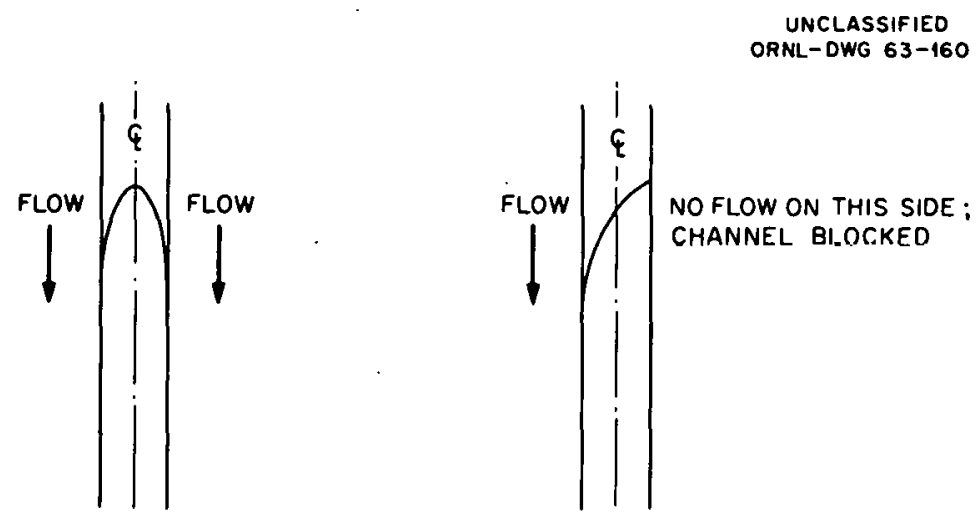

(a) FLOW ON BOTH SIOES (b) CHANNEL BLOCKED ON ONE SIDE

Fig. III.1. Temperature profile within a fuel plate.

B. Application of terms (illustrative problems)

1. Normal power level and normal flow

2. Reduced power level and normal flow

3. Normal power level and reduced flow

\section{Sample Study Questions}

1. Why is it important to limit surface temperatures of a fuel element? Why is it important to limit interior temperatures?

2. Define heat flux.

3. Describe one method for obtaining a value of heat transfer coefficicnt.

4. What one thing especially should one be careful about in using any correlation?

5. Explain how the surface temperature of a fuel element at reduced power could be higher than the surface temperature at full power.

6. Are all areas of the fuel element surface likely to be at the same temperature?

7. Are all areas of a fuel element likely to have the same heat flux?

8. Reactor fuel elements have a heat flux when the reactor operates. Do any other components? Explain. 


\section{$\underline{\text { References }}$}

1. S. Glasstone and A. Sesonke, Nuclear Reactor Engineering, articles 6.113-6.117 and 12.40-12.45, D. Van Nostrand, Inc., Princeton, N.J., 1963.

2. S. D. Sheppard, Reactor Operator Study Handbook (Programed Instruction Version). Vol. IV - Heat Theory and Fluid Flow, ed. C. D. Cagle, pp. 28-39 and 68-84, ORNL/TM-2034, Oak Ridge National Laboratory, Oak Ridge, Tenn., December 1968.

Lesson Plan No. 3. Heat Transfer (Continued)

\section{Objective}

Same as for Lesson Plan No. 2.

\section{Plan Outline}

A. Review of terms concerning water

1. Varluus slales of walei (jressure- and tempcraturc dependent)

d. Sulbcüled liqquid

b. Saturated liquid, saturated steam mixture

r. Superheated steam

d. Steam quality

2. Various processes
a. Boiling
b. Condensation
c. Flashing

B. Types of heat transfer

1. Nonboiling

2. Boiling
a. Subcooled nucleate boiling
b. Bulk boiling
c. Film boiling 
3. Heat flux vs surface temperature (Fig. III.2)

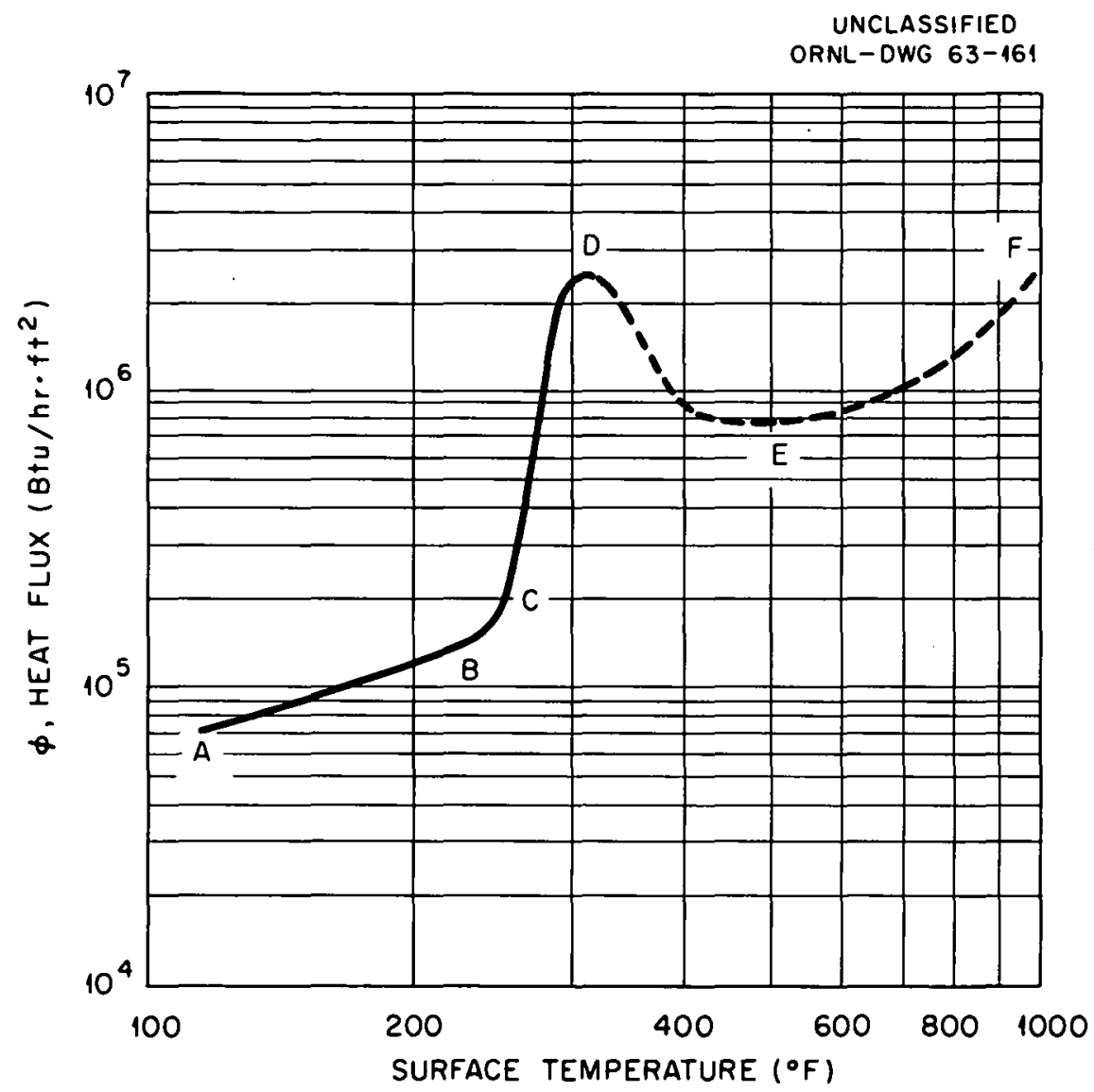

Fig. III.2. Relationship among heat flux, surface temperature, and heat transfer coefficient.

C. Incipient boiling

1. Definition

2. Location on heat flux vs surface temperature curve

D. Burnout

1. Definition

2. Location on heat flux vs surface temperature curve

3. Reasons to avoid 
4. Other names for

a. Departure from nucleate boiling

b. Critical heat flux

E. Safety factors

1. Hot-spot factor
a. Causes
b. Consequences

2. Hot channel factor
a. Causes
b. Consequences

3. Minimum eritical heat flux ratio

4. Effects of nonuniform heat flux distribution and limitations on power level

F. Gamma heating (Fig. III.3)

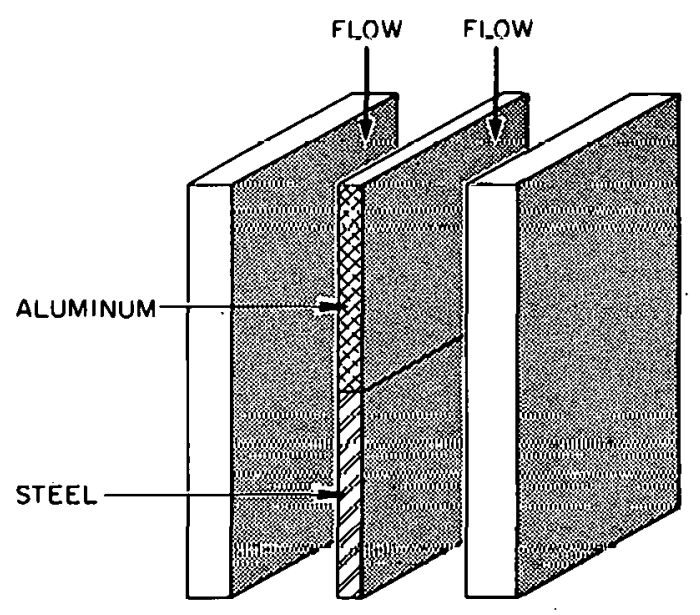

(a) NO HEATING IN PLATES

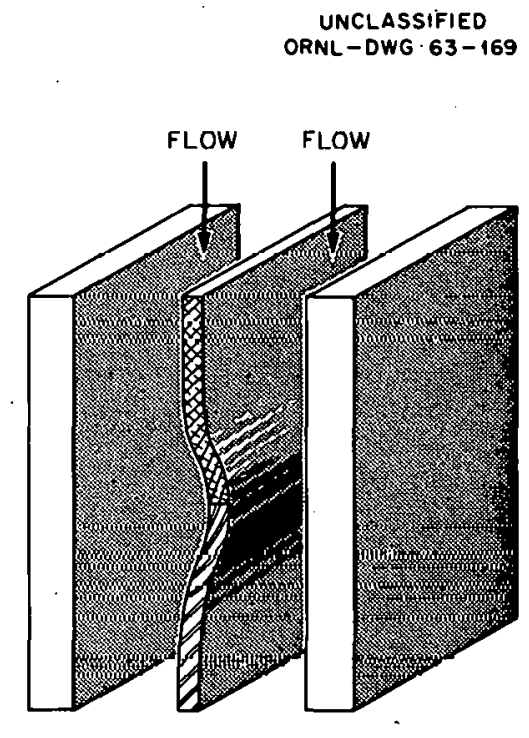

(b) PLATES hEATED, AND DISTORTED

Fig. III.3. Effect of gamma heating in a part made of two different materials. 
1. Nonfissionable materials

2. Examples

G. Shutdown (afterheat) cooling

1. Reasons for provision

2. Methods of production

H. Emergency cooling

1. Reason for provision

2. Methods of production

\section{Sample Study Questions}

1. If the pressure is 300 psia, at what temperature will water boil?

2. Compare the volume of $1 \mathrm{lb}$ of water at $70^{\circ} \mathrm{F}$ to that at $200^{\circ} \mathrm{F}$.

3. Compare the volume of $1 \mathrm{lb}$ of $\mathrm{H}_{2} \mathrm{O}$ when a saturated liquid at 100 psia to that when a saturated vapor at 100 psia.

4. Why must burnout be avoided?

5. Why can't we "turn off" decay heat?

6. Can a heat balance be used to detect a hot spot? A hot channel?

7. Describe a set of conditions that will cause water to flash. In what state is the water after it has flashed?

8. Identify the burnout point on a heat flux vs surface temperature curve. What happens to the surface temperature at this point?

9. W111 all materials undergo gamma heating while in an operating reactor core? Even the fuel element?

\section{$\underline{\text { References }}$}

1. S. Glasstone and A. Sesonke, Nuclear Reactor Engineering, articles 2.180-2.187, 6.102,6.129-6.140, and 12.46-12.49, D. Van Nostrand, Inc., Princeton, N.J., 1963.

2. S. D. Sheppard, Reactor Operator Study Handbook (Programmed Instmuction Version). Vol. IV - Heat Theory and Fluid Flow, ed. C. D. Cagle, pp. 85-90, ORNL/TM-2034, Oak Ridge National Laboratory, Oak Ridge, Tenn., December 1968.

3. H. J. Stoever, Engineering Thermodynomics, articles 14 and 50, John Wiley \& Sons, Inc., New York, 1951. 
Lesson Plan No. 4. Fluid Flow

\section{Objective}

The trainee should learn the mechanisms of fluid flow. He should understand pressure drop, $\Delta \mathrm{p}$, and how it can be developed by fluid flow as produced by pumps, fans, siphoning, convection, and gravity. The concept of how $\Delta p$ in a system can cause forces which rattle fuel elements and heatexchanger tubes should be learned along with the theory of water hammer. Questions included at the end of the lesson are typical and indicate the depth of understanding that the student should develop. He should learn the effects of friction on flow, the relationship between friction and velocity, the concept of fluid film on surfaces, the relationship between flow and heat transfer. After completing the course, the student should have a mental picture of what is happening in a pipe as he opens or closes a valve and starts or stops a pump. He should understand the sound he hears at an elbow, a heat exchanger, and an orifice.

\section{Plan Outline}

A. Definition of terms

1. Driving torce

2. Nominal velocity (Fig. III.4)

3. Coolant channel equivalent diameter (see also Lesson 2, Sect. A.5)

4. Reoiotance to flow

5. "Word experiment" relating above terms

6. Friction factor

7. Pressure drop

8. Power required

B. Classification of flow

1. By kind of driving force

a. Natural (free) convection

b. Forced convection 
ORNL-DWG $63-159$

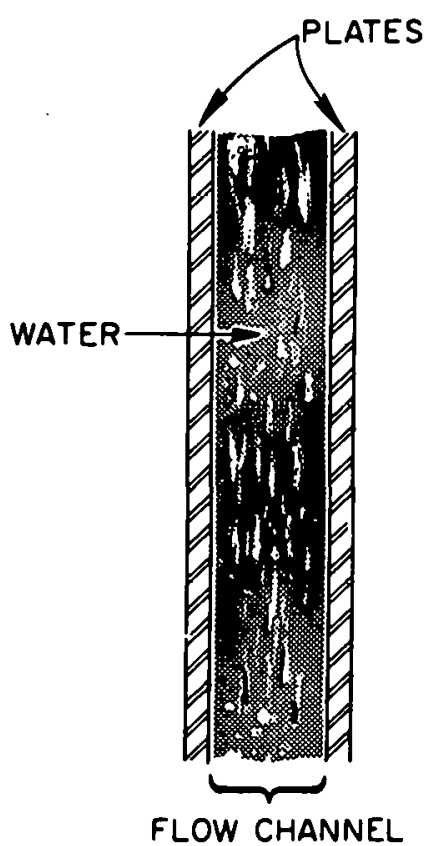

(a)

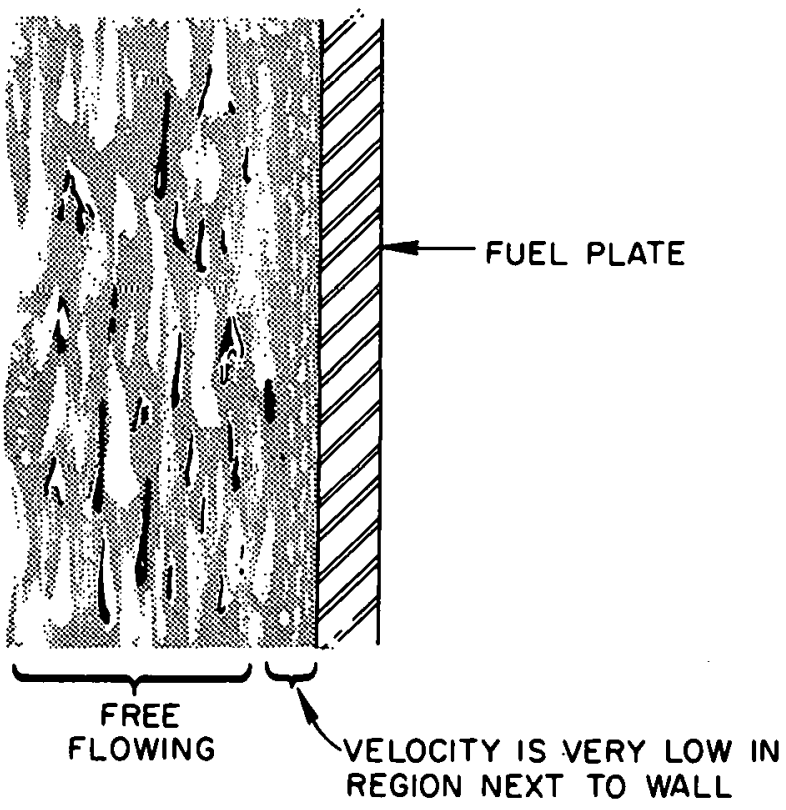

(b) PART OF " 0 " MAGNIFIED

Fig. III.4. Pattern of flow over a surface.

2. By amount of mixing (Fig. III.5)

a. Laminar

b. Turbulent

c. Stratification in pipes, pools, vessel, etc., and effects on sensors (both flow and temperature)

C. Special problems

1. Forces

a. At inlet and outlet nozzles of vessels

b. At pipe bends

c. Venturis, jets, etc.

d. On walls of parallel channel flow systems

e. In axial flow systems (Fig. III.6)

f. In main stream of channel 

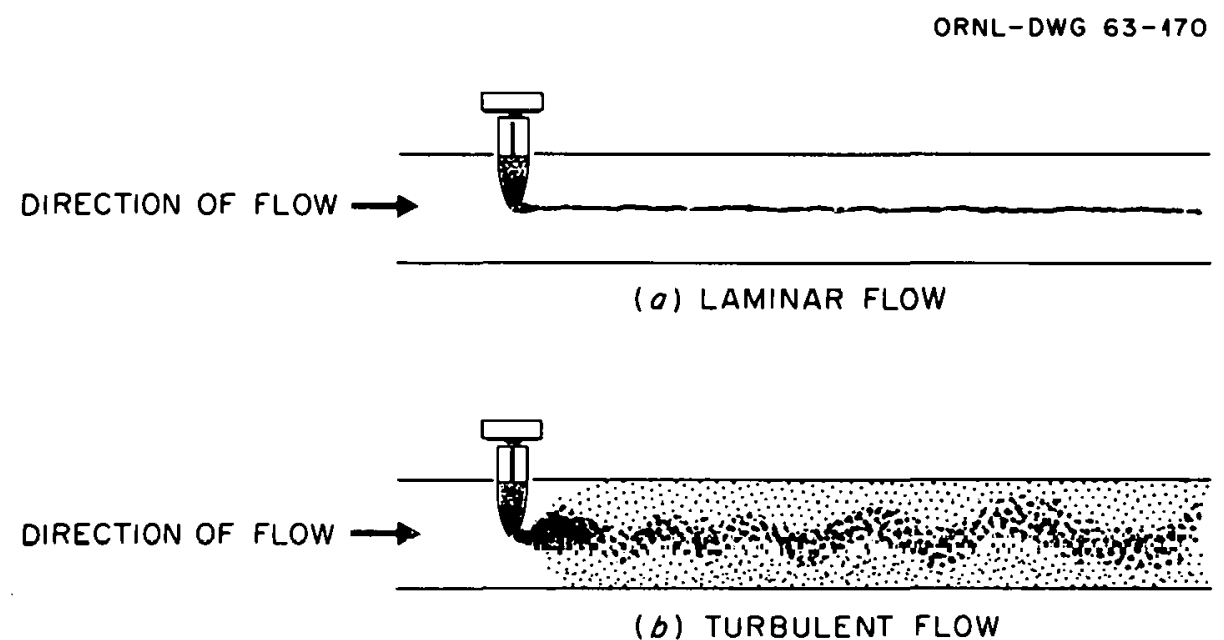

Fig. III.5. Mixing of a dye in laminar and turbulent flow.

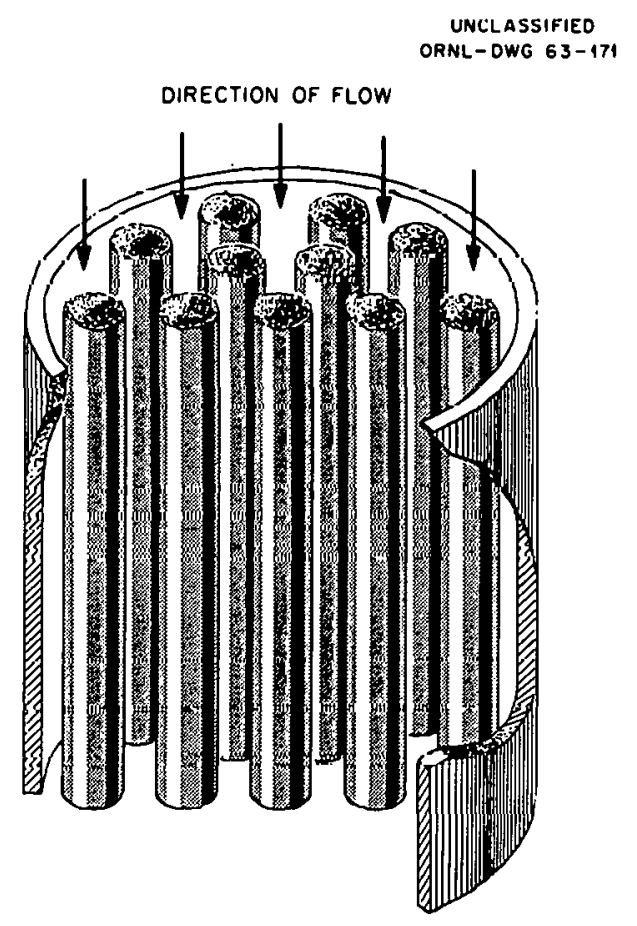

Fig. III.6. Axial flow system. 
2. Water hammer (Fig. III.7)

3. Vibration

UNCLASSIFIED

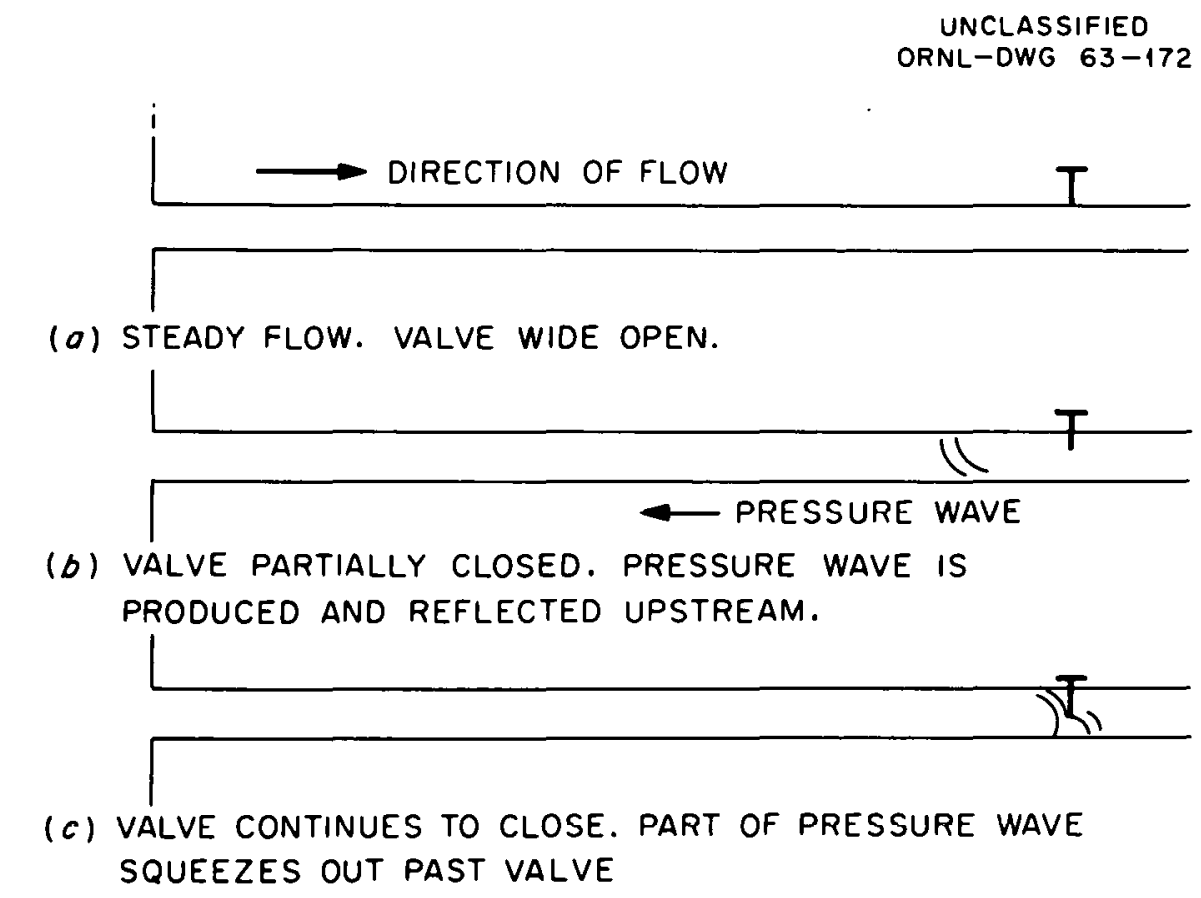

Fig. III.7. Water hammer in a pipe system.

\section{Sample Study Questions}

1. Why are pumps usually required as the driving force of water in a reactor? Compare with jets.

2. In what direction (upward or downward) is natural convection flow through the fuel element of a reactor?

3. In what direction (upward or downward) is forced convection flow through the fuel element of a reactor?

4. What could be the consequences of an extremely large flow force on a pipe bend of the main coolant line? 


\section{References}

1. S. Glasstone and A. Sesonke, Nuclear Reactor Engineering, articles 6.103-6.112, 6.153-6.161, 6.172-6.174, and 12.65-12.67, D. Van Nostrand, Inc., Princeton, N.J., 1963.

2. S. D. Sheppard, Reactor Operator Study Handbook (Prograrmed Instmuction Version). Vol. IV - Heat Theory and Fluid Flow, ed. C. D. Cagle, pp. 30-36, 56-60, and 99-102, ORNL/TM-2034, Oak Ridge National Laboratory, Oak Ridge, Tenn., December 1968.

Lesson P1an No. 5. Comprehensive Examination

\section{Sample Questions}

1. Define a Btu.

2. A Btu of heat produced by the fissioning of U-235 will raise the temperature of a given quantity of water about twice as high as a Btu produced from the burning of coal. True or false? Explain.

3. Explain how reactor fuel elements can produce heat even though the reactor has been shut down.

4. Why is the surface temperature of a fuel element usually controlled below a certain value?

5. Explain the term "heat flux."

6. List two parameters upon which the heat transfer coefficient depends.

7. If a reactor is operating at steady power, what parameter change will cause the surface temperature of the fuel elements to increase (a11 other parameters remaining unchanged)?

8. Explain how water can be prevented from boiling when its temperature reaches $212^{\circ} \mathrm{F}$.

9. What is a hot channel or hot-spot factor? 
10. For the same location in most reactors, a 1-in. cube of 304 stainless steel absorbing gamma rays from the fuel will have a lower average heat flux on its surface than will a 1-in. cube of 1100 aluminum. Explain.

11. List two items which cause resistance to flow in a piping system.

12. Reactor vessel internal components, in addition to fuel elements, depend upon adequate heat transfer. True or false? Explain.

13. With regard to water, discuss the terms "saturation temperature," "saturation pressure," "subcooled liquid," "superheated vapor," "steam quality," "carryover," and "carry under."

14. Describe a situation which could cause water to flash to steam.

15. At which point on the figure below does the burnout heat flux occur?

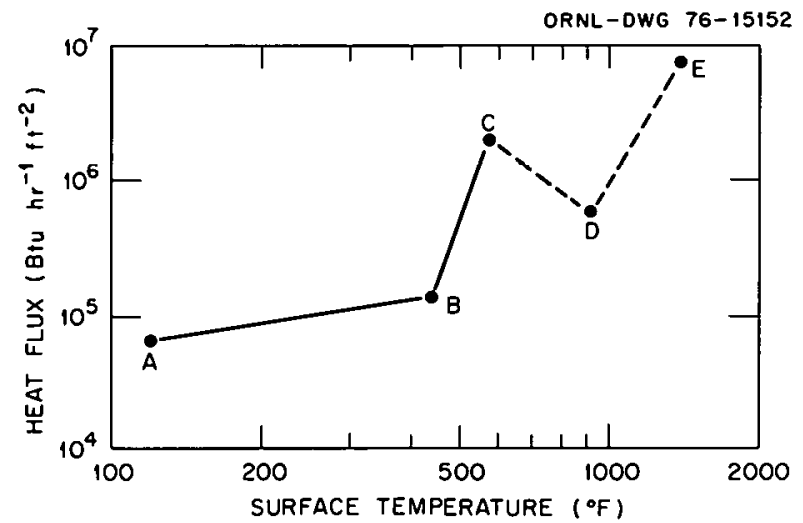

16. Describe two situations in which forces produced by coolant flow may cause problems. 
SECTION IV. BASICS OF INSTRUMENTATION

Contents

Introduction . . . . . . . . . . . . . . 40

Classroom Illustrations and Laboratory Experiments . . . . . . 40

Lesson Plan No. 1. Basic Concepts . . . . . . . . . . . . . 41

Lesson Plan No. 2. Electrical Circuit Elements . . . . . . 42

Lesson Plan No. 3. Electromagnetism . . . . . . . . . 45

Lesson Plan No. 4. Alternating Current . . . . . . . . 46

Lesson Plan No. 5. Radiation Detection . . . . . . . 47

Lesson Plan No. 6. Process Instrumentation . . . . . . . . 50

\section{Introduction}

The material presented in this section should provide the student with the fundamentals on the generation of signals, parameter measurement, channel components, transmission of signals, and utilization of these transmitted signals. Ihe student should adequately understand the information not only so that he can more readily interpret the information he will be monitoring as an operator, but more importantly, so that he will be able to recognize abnormal indications associated with instrument malfunctions and be able to take the necessary and appropriate action.

\section{Classroom Illustrations and Laboratory Experiments}

Potential classroom illustrations are listed below. $\Lambda$ dditional illustrations should be used throughout the training as they occur to the instructor. 
1. Demonstrate generation of static charges.

2. Demonstrate difference between $\mathrm{dc}$ and $\mathrm{ac}$.

3. Set up simple dc circuit with light bulb, switch, etc.

4. Demonstrate detection of radiation with G-M tube detector.

5. Demonstrate $\mathrm{pH}$ and/or conductivity measurement.

\section{Lesson Plan No. 1. Basic Concepts}

\section{Objective}

The trainee should learn the origin of static charges, potential difference (motive force), and flow of charges. An understanding of the basic concepts and terminology is expected.

\section{Plan Outline}

A. Static electricity

1. Charges and origin (atom, electrons, protons, and ions)

2. Creation of charges (by friction, light, heat, chemical reaction, and ionization)

3. Attraction and repulsion

4. Potential difference

5. Electrostatic induction

6. Electric fields

B. Electric current

1. Conductors, insulators, and resistors

2. Resistance and conductance

3. Ohm's Law

C. Terminology

1. Coulomb, ampere

2. Volt 
3. Ohm, mho

4. Milli, micro, kilo, mega

Sample Study Questions

1. How is current electricity different from static electricity?

2. State Ohm's Law in three different ways.

3. Do electrons attract or repulse electrons?

4. Which of the following are good conductors - copper, wood, glass, silver, water?

5. What is the difference between an ampere and a coulomb?

\section{References}

1. D. M. Considine, ed., Process Instruments and Controls Hondbook, McGraw-Hil1 Book Co., Inc., New York, 1957.

2. F. W. Kirk and N. R. Rimboi, Instrumentation, 2nd ed., American Technical Society, Chicago, 1962.

3. D. M. Considine, ed., Hondbook of Applied Instmumentation, pp. 5-5 to 5-20, McGraw-H111 Book Co., New York, 1964.

\section{Lesson Plan No. 2. Electrical Circuit Elements}

\section{objective}

The student should learn the application of electrical circuit elements and be introduced to the concept of watts.

\section{Plan Outline}

A. Simple series circuit

1. Circuit elements (switch, capacitors, breakers, fuses, batteries, rheostat, potentiometer, etc.) 
2. Application of elements

3. Circuit element and interconnecting conductor conventions

4. Current and electron flow conventions, polarities

5. Handling of circuits containing more than one resistor or potential source

B. Parallel circuit

1. Calculating "effective" resistance

2. Use of parallel potential sources

3. Calculating the "effective" resistance of circuits having both series and parallel connected resistors

C. Energy in circuits containing resistance

1. How is it calculated? Introduce "watts."

2. Where does it go? Where does it come from?

\section{Sample Study Questions}

1. Which way does electron current flow outside the source of potential (voltage)?

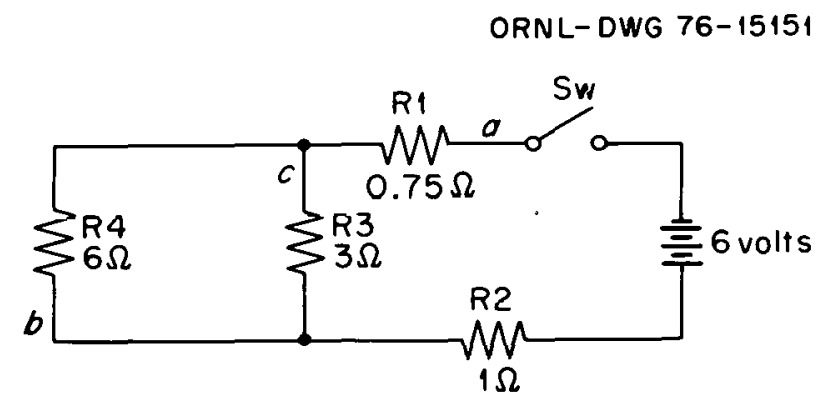

2. Answer the following questions about the circuit illustrated above, assuming the switch is closed.

a. What is the current in conductor $a$ ?

b. What is the current in conductor $b$ ?

c. What is the current in conductor $c$ ?

d. What is the voltage (IR drop) across R4?

e. What is the voltage (IR drop) across R3? 
f. What is the value of an equivalent resistor which could replace $R 1, R 2, R 3$, and $R 4$ and produce the same current flow in conductor $a$ ?

g. If a double flow of current were desired in conductor $a$, how would you connect or wire in another $6-V$ source?

h. Show the polarity of the voltages (IR drop) across each resistor.

i. How much power would be dissipated as heat in resistors $R 2$ and R3?

3. Name at least two uses to which resistors are put.

4. Name one use for a potentiometer and one for a rheostat.

5. Name two devices used for protecting electrical circuits from overloads, and describe how one functions.

6. Within a battery, which way does the electron current flow?

7. Express 0.001 volts (V) in millivolts (mV) and microvolts ( $\mu \mathrm{V})$.

8. Express 1,000,000 volts (V) in kilovolts ( $\mathrm{kV}$ ) and megavolts (MV).

9. Express 10 microamperes $(\mu \mathrm{A})$ in milliamperes $(\mathrm{mA})$ and amperes $(\mathrm{A})$.

\section{References}

1. D. M. Considine, ed., Process Instmuments and Controls Handbook, McGraw-Hill Book Co., Inc., New York, 1957.

2. F. W. Kirk and N. R. Rimboi, Instmumentation, 2nd ed., American Technical Society, Chicago, 1962.

3. D. M. Considine, ed., Ilandbook of Applied Instrumentation, pp. 5-5 to 5-20, McGraw-Hill Book Co., Inc., New York, 1964. 
Lesson Plan No. 3. Electromagnetism

\section{Objective}

The trainee should learn that current induces a magnetic field around the conductor and that a magnetic field can induce a current in a conductor; he should.also learn the applications of these effects.

A. Magnetic fields generated by current

1. Field around conductor and loop of wire

2. Elect romagnet

3. Left-hand rule for direction of field polarity

4. Applications (relays, solenoid actuators, etc.)

B. Current generated by magnetic fields

1. Effect of conductor motion in a magnetic field

2. Effects of rate of motion, strength of field, length of conductor

3. Effect on conductor in magnetic field if current is passed through it

4. Determination of polarity of induced electromotive force (emf) and direction of current

5. Explanation of how dc generators and motors work

Sample Study Questions

1. Describe two ways of increasing the magnetic field of an electromagnet.

2. Name two applications of an electromagnet.

3. Name two ways an emf may be induced in a conductor.

4. Why does the current in a coil tend to build up slowly when a potential is applied to it?

5. Inductance is measured in what units? 


\section{References}

1. D. M. Considine, ed., Process Instmments and Controls Handbook, McGraw-Hill Book Co., Inc., New York, 1957.

2. F. W. Kirk and N. R. Rimboi, Instmonentation, 2nd ed., American Technical Society, Chicago, 1962.

3. D. M. Considine, ed., Hondbook of Applied Instrumentation, pp. 5-5 to 5-20, McGraw-Hill Book Co., Inc., New York, 1964.

Lesson Plan No. 4. Alternating Current

\section{Objective}

The student should learn how alternating current is generated, the relationship between amplitude, phase, voltage, frequency, etc., and the fundamentals of transformers.

A. Induced emf in a rotating coil (wave form)

B. Induced emf in a 4-pole alternator

1. Wave form

2. Stator, rotor, cycle, amplitude, phase, reactance, two-phase, three-phase

3. Ohm's Law and simple circuits

4. Differentiation between an ac generator and an ac motor

5. Conversion of mechanical. energy to electriral energy (atcam gencracor)

C. Transformer

1. Interaction of primary and secondary coils

2. Voltage step-up and step-down

3. Standard transformer for voltage step-down to 220 and $110 \mathrm{~V}$ for home use 
Sample Study Questions

1. What wave shape does the alternating current generated by a public utility have? What is its frequency?

2. Make a simple sketch of a transformer and explain how it works.

3. Compare the input power with the output power of a transformer. What is the relationship between primary and secondary voltages and turns of windings? What is the relationship between primary and secondary current and turns of windings?

4. Explain briefly the purpose of a fuse. Identify several varieties of fuses and state where each type might be found at the plant or in your home.

5. Explain briefly how a thermal circuit breaker operates.

\section{$\underline{\text { References }}$}

1. D. M. Considine, ed., Process Instmonents and Controls Handbook, McGraw-Hill Book Co., Inc., New York, 1957.

2. F. W. Kirk and N. R. Rimboi, Instmontation, 2nd ed., American Technical Society, Chicago, 1962.

3. D. M. Considine, ed., Hondbook of Applied Instmontation, Pp. 5-5 to 5-20, McGraw-Hill Book Co., Inc., New York, 1964.

Lesson Plan No. 5. Radiation Detection

\section{Objective}

The student should learn the fundamentals of ionization and the basic principles of radiation detection with emphasis on detection of neutrons. 


\section{Plan Outline}

A. Ionization processes

1. Production of ionization

a. General

b. Alpha particles

c. Beta particles

d. Gamma particles

2. Production of electric currents in ionized gases

B. Chambers

1. General Factors

a. Arrangement

b. Operation at different potentials

2. Geiger-Mueller (G-M) tube

a. Construction

b. Operations (action in heavy fluxes)

c. Application

3. Ion chamber

a. Construction

b. Operation

c. Application

4. Yroportional counter

a. Construction

b. Operation

c. Application

5. Other detectors

a. Scintillation

(1) Construction and operation

(2) Applirntion

b. Solid state

(1) Construction and operation

(2) Application 
c. Neutron

(1) Fission chamber
(a) Construction
(b) Operation
(c) Application

(2) $\mathrm{BF}_{3}$ counter
(a) Construction
(b) Operation
(c) Application

(3) Boron-coated
(a) Construction
(b) Operation
(c) Application

\section{Sample Study Questions}

1. Explain briefly in what way a gas is different before and after it is ionized. How can an ionized gas be made to pass an electrical current?

2. Describe briefly how the different kinds of radiation - alpha, beta, gamma - produce ionization in a gas.

3. Make a sketch of an ionization chamber, showing only the working elements, and add the excitation and signal developing circuitry. Identify each part.

4. What are the unique features of a G-M tube, and for what types of radiation is it most suitable as a detector?

5. Is the output of a G-M tube a current or a series of pulses? Is the output signal size related to the energy of the radiation detected? Explain.

6. The ion chamber is suitable for detecting what kinds of radiation?

7. Is the ion chamber signal most of ten of pulse or current nature?

8. Describe the proportional counter briefly. Is it useful for detecting neutrons? 
9. What is the purpose of a fission chamber? Explain beiefly how a fission chamber functions in its principal role.

10. Explain why the fission chamber performs satisfactorily in the heavy gamma fluxes found in reactors.

11. Is the output signal from a fission chamber of current or pulse form? Explain.

12. Explain briefly how a $\mathrm{BF}_{3}$ counter operates. Would it be suitable for all the same applications as a fission chamber? Explain.

13. How does the boron-coated (or -lined) ion chamber detect neutrons? What is the principal application for such a chamber in a nuclear reactor installation?

\section{References}

1. D. M. Considine, ed., Process Instruments and Controls Handbook, McGraw-Hill Book Co., Inc., New York, 1957.

2. F. W. Kirk and N. R. Rimboi, Instmonentation, 2nd ed., American Technical Society, Chicago, 1962.

3. D. M. Considine, ed., Handbook of Applied Instromentation, pp. $5 \cdots 5$ to 5 20, McCraw-llill Book Co., Ine., New Yürk, 1964.

Lesson Plan No. 6. Process Instrumentation

\section{objective}

The student should learn the busic principlee of the various ucnsors used for process parameter measurement and, in particular, become aware of the many channel components required to utilize the signal (i.e., to provide readout for monitoring or to provide control signals). 
A. Parameters to be measured (description and fundamentals of sensors)

1. Temperature

2. Pressure

3. Liquid level

4. Flow

5. Vibration

6. $\mathrm{pH}$

7. Conductivity

B. Signal transmission

1. Electrical and pneumatic

2. Description and basics of channel components (converters, transducers, summers, dp cells, recorders, gauges, etc.)

C. Controllers

1. Description and basics of controllers such as level controllers, temperature, flow, switches, etc.

2. Local and remote control

a. Difference in channel components

b. Necessity and value of each

Sample Study Questions

1. List at least one type of sensor used to measure temperature, flow, pressure, vibration, liquid level

2. What are some of the basic differences between an electrical signal transmission channel and a pneumatic signal transmission channel?

3. Discuss the need for and advantages of remote recording, indication, and control.

4. Explain how a pressure gauge might be used to indicate the level of liquid in a tank.

5. Explain the difference between psig and psia. 


\section{References}

1. D. M. Considine, ed., Process Instmonents and Controls Handbook, McGraw-Hill Book Co., Inc., New York, 1957.

2. F. W. Kirk and N. R. Rimboi, Instmmentation, 2nd ed., American Technical Society, Chicago, 1962.

3. D. M. Considine, ed., Ilandbook of Applied Instrumentution, pp. 5-5 to 5-20, McGraw-Hill Book Co., Inc., New York, 1964. 
SECTION V. BASICS OF ELEMENTARY CONTROL DIAGRAMS, FLOW DIAGRAMS, AND DRAWINGS

Contents

Introduction . . . . . . . . . . . . . . . . . . 53

Lesson Plan No. 1. Flow Diagrams .............. 54

Lesson Plan No. 2. Electrical Wiring Diagrams and Pneumatic

Systems ..................... 55

Lesson Plan No. 3. Control Block Diagrams . . . . . . . . . 57

\section{Int roduction}

One of the greatest deterrents of information transmittal from a system designer to the plant operators is the inability of the operators to read and understand engineering drawings. For this reason, this section is included in the operator training outline.

The instructor should present the symbols and basic principles of instrumentation items used to transmit information about the various plant systems. The student need not understand the design details of individual components and instruments, but he should be familiar with their function and the symbols used to designate a particular item within the system. For example, the symbol and purpose of an emf-tocurrent converter, but not necessarily its details of design and inner workings, shmid he understond.

It is also important to understand the effect of the individual component on the rest of the system and its own function within a sensing channel. 
Lesson Plan No. 1. Flow Diagrams

\section{Objectives}

The student should learn (1) the basic theory that, in piping, fluid flows from a high- to a lower-pressure region and that the driving. force is pressure; (2) that, as fluid flows downstream, its pressure is reduced because of line and component losses; (3) that, in piping flow diagrams, major flow paths are usually shown as dark lines and minor flow paths are shown as lighter lines; (4) that all lines and components are systematically identitied; and (5) that components are identified also as to their physical location within the plant.

\section{$\underline{\text { Plan Outline }}$}

A. Description of the system diagrams

1. Symbols used to identify equipment on flow diagrams

2. Flow paths (major and minor)

3. Line identification

4. Numerical system used for different process systems

5. Valve identification, type, and operator

6. Designation of physical location of equipment

\section{Sample Study Questions}

1. Identify symbolically at least six different types of valves.

2. Identify symbolically solenoids, air operators, manual valve operators, transducers, dp cells, and remote valve operators.

3. What symbol is used to identify a pressure safety valve? 


\section{$\underline{\text { References }}$}

1. D. M. Considine, ed., Process Instmments and Controls Handbook, McGraw-Hill Book Co., Inc., New York, 1957.

2. F. W. Kirk and N. R. Rimboi, Instmonentation, 2nd ed., American Technical Society, Chicago, 1962.

3. D. M. Considine, ed., Handbook of Applied Instmumentation, pp. 5-5 to 5-20, McGraw-Hill Book Co., Inc., New York, 1964.

Lesson Plan No. 2. Electrical Wiring Diagrams and Pneumatic Systems

\section{Objectives}

The student should learn (1) the basic theory that, in electrical wiring, current flows from a high- to a lower-voltage source; (2) that voltage drop is distributed throughout the components and wiring itself; (3) that all wires and components are systematically identified; and (4) that individual components are usually identified as to their physical location.

\section{Plan Outline}

A. Description of electrical systems

1. One-line diagrams

2. Instrument symbols

3. Equipment symbols

4. Location identification

5. Wire identification

6. Control loops

7. Interconnection symbols 
8. Instrument application diagrams

9. Electrical control circuits

B. Description of pneumatic systems

1. Elementary pneumatic diagrams

2. Instrument symbols

3. Line identification

4. Pneumatically operated valves

5. Pneumatic instrument signals

\section{Sample Study Questions}

1. How are elementary electrical diagrams distinguished from pneumatic diagrams?

2. Identify the symbols used to indicate a pneumatic valve operator and an electrical valve operator.

3. What is meant by the term "signal pressure" in a pneumatic system?

\section{References}

1. D. M. Considine, ed., Process Instmments and Controls Handbook, McGraw-Hil1 Book Co., Inc., New York, 1957.

2. F. W. Kirk and N. R. Rimboi, Instmontation, 2nd ed., American Technical Society, Chicago, 1962.

3. D. M. Considine, ed., Handbook of Applied Instmmentation, pp. 5-5 to 5-20, McGraw-Hill Book Co., Inc., New York, 1964. 
Lesson Plan No. 3. Control Block Diagrams

Objective

The student should learn the purpose and practical usage of control block diagrams.

Plan Outline

A. Description of control block diagrams

1. Purpose

2. Condition designation

3. Function designation

4. Action designation

B. Instrument and control elementary diagrams

Sample Study Questions

1. What is the purpose of the control block diagram? In what way does it differ from the elementary diagram?

2. Name some limitations of the control block diagram.

\section{$\underline{\text { References }}$}

1. D. M. Considine, ed., Process Instruments and Controls Handbook, McGraw-Hill Book Co., Inc., New York, 1957.

2. F. W. Kirk and N. R. Rimboi, Instrumentation, 2nd ed., American Technical Society, Chicago, 1962.

3. D. M. Considine, ed., Handbook of Applied Instrumentation, pp. 5-5 to 5-20, McGraw-Hill Book Co., Inc., New York, 1964. 
THIS PAGE

WAS INTENTIONALLY

LEFT BLANK 
Part $B$ - Operator Training Program 
SECTION VI. RADIATION SAFETY AND CONTROL

Contents

Introduction . . . . . . . . . . . . . . . . . . 60

Lesson Plan No. 1. Structure of Matter . . . . . . . . . 61

Lesson Plan No. 2. Radiation and Interaction with Matter . . . . 62

Lesson P1an No. 3. Radioactivity Buildup and Decay . . . . . . . 64

Lesson Plan No. 4. Units of Measurement of Radiation . . . . . . 66

Lesson Plan No. 5. Biological Effects of Radiat1on . . . . . . 67

Lesson Plan No. 6. Radiation Attenuation . . . . . . . . . . 69

Lesson Plan No. 7. Radiation Detection . . . . . . . . . . . 71

Lesson Plan No. 8. Contamination . . . . . . . . . . . . . . 74

Lesson Plan No. 9. Sources of Radiation and Contamination

at the Facility . . . . . . . . . . . . . . . 75

Lesson Plan No. 10. Systems for Control of Radioactivity

Release from the Facility . . . . . . . . . . . . . 76

Lesson Plan No. 11. 10 CFR 20 - Standards for Protection

Against Radiation . . . . . . . . . . . . . . 78

Lesson P1an No. 12. Comprehensive Examination . . . . . . . . . 79

\section{Introduction}

The objective of this section is to outline the depth of understanding required by the operator with regard to radiation hazards, radiological safety practices, terminology, and radiation monitoring equipment.

Upon completion of this section in the training program, the operator should have an understanding of the structure of matter and the characteristics of atoms, elements, and nuclear particles; he should be able to use portable radiation monitoring equipment and describe the type, location, range, and alarms associated with fixed equipment; and he should know the facility regulations and be thoroughly familiar with the rules and regulations of $10 \mathrm{CFR}$, Part 20, "Standards for Protection Against Radiation." 
The lesson plans outlined in this section are to guide the instructor in presenting this material to the trainees and are recommendations only; additions, deletions, or modifications may be made on the basis of the requirements and characteristics of each specific facility.

Lesson Plan No. 1. Structure of Matter

\section{Objective}

The lesson should provide a basic understanding of the structure of matter - specifically, atoms and elements.

\section{Plan Outline}

A. Atom

1. Nucleus

2. Electrons

3. Protons

4. Neutrons

5. Ions

B. Elements

1. Naturally occurring

2. Radioactive vs stable

3. Artificlally produced

4. Atomic weight

5. Atomic number

6. Isotopes

7.. Avogadro's number

8. Periodic table

a. Significance

b. Chart of nuclides 


\section{Sample Study Questions}

1. What characteristics distinguish an electron from a proton?

2. What is an ion?

3. What are the isotopes of hydrogen?

4. What are the major isotopes of uranium?

5. What is the meaning of Avogadro's number?

\section{References}

1. H. D. Ricliaidsuí, Industriexz Radiography Manuaz, pp. 1-9, OE-84036, Ü.S. Office of Education, Washington, 1968.

2. R. A. Costner, Jr., E. N. Cramer, and R. L. Scott, Jr., Reactor Operator Study Handbook (Programmed Instruction Version). Vol. II - Radiation Safety and Control, Pp. 1-46, ORNL/TM-2034, Oak Ridge National Laboratory, Oak Ridge, Tenn., January 1968.

3. J. E. Wade and G. E. Cunningham, Radiation Monitoring, a Program of Self-Instruction, USAEC Rept. HW-SA-3671, General Electric Co., 1964.

4. Samuel Glasstone, Sourcebook on Atomic Energy, 3rd ed., pp. 1-23 and 96-197, D. Van Noetrand Company, Inc., Princeton, N.J., 1967.

Lesson Flä No. 2. Radiation and Interaction with Matter

\section{Objective}

The lesson should provide a basic understanding of the several types of radiation and the effects resulting from their interaction with atoms and matter. 


\section{Plan Outline}

A. Definition of radiation

B. Types and characteristics of radiation

1. A.lpha particles

2. Beta particles (positrons)

3. Gamma rays (X rays)

4. Protons

5. Neutrons

C. Interactions

1. Ions

2. Scattering

3. Ionization

4. Neutron moderation

5. Neutron absorption

6. Photoelectric effect

7. Compton scattering

8. Pair production

D. Fission

1. Fission process (induced, spontaneous)

2. Fission products

3. Energy release

4. Definition of $\mathrm{MeV}$

\section{Sample Study Questions}

1. How far would you expect an alpha particle to travel in air?

2. Will a proton or neutron produce more ions per centimeter of trave1? Why?

3. Why is a neutron more penetrating than a proton?

4. Is beryllium or light water more effective as a moderator? Why?

5. What products are released when fission of U-235 occurs? 


\section{References}

1. H. D. Richardson, Industrial Radiogrophy Manual, U.S. Office of Education, Washington, 1968.

2. R. A. Costner, Jr., E. N. Cramer, and R. L. Scott, Jr., Reactor Operator Study Handbook (Progrommed Instruction Version). Vol. II - Radiation Sa sety and Control, pp. 9-46, ORNL/TM-2034, Oak Ridge National Laboratory, Oak Ridge, Tenn., January 1968.

3. J. E. Wade and G. E. Cunningham, Radiation Monitoring, a Program of Self-Instmuction, USAEC Rept. HW-SA-3671, General Electric lo., 1964.

4. W. H. Stroschein and P. H. Maeser, eds., Health Physics Technician Training Manual, USAEC Rept. IDO-17182, Phillips Petroleum Co., Junc 1966 .

5. Samuel Glasstone, Sourcebook on Atomic Energy, 3rd ed., pp. 246-89 and 343-94, D. Van Nostrand Co., Inc., Princeton, N.J., 1967.

6. K. Z. Morgan and J. E. Turner, Principles of Radiation Protection, John Wiley \& Sons, Inc., New York, 1967.

Lesson Plan No. 3. Radioactivity Buildup and Decay

\section{Objective}

The lesson should provide a basic understanding of the activation, buildup, and decay of radioactive matter due to neutron absorption in matter.

\section{Plan Outline}

A. Neutron activation

1. Microscopic cross section

2. Macroscopic cross section 
3. Activity buildup equation: $\frac{\mathrm{dN}}{\mathrm{dt}}=\Phi-\lambda \mathrm{N}$

4. Definition of flux and decay constant

B. Radioactive decay

1. Decay equation: $\frac{d N}{d t}=\lambda N_{O}$

$$
N(t)=N_{0} e^{-\lambda t}
$$

2. Half-life: $t=\frac{\ln 2}{\lambda}=\frac{0.6931}{\lambda}$

3. Exponential decay curves

4. Definition of curie and microcurie

\section{Sample Study Questions}

1. What is the difference between a microscopic and macroscopic cross section?

2. What does thermal neutron flux mean?

3. If $40 \%$ of an isotope decays in one day, what is its decay constant?

4. What is a curie?

5. What is the half-life of an isotope having a decay constant of $0.35 \mathrm{dis} / \mathrm{sec}$ ?

\section{$\underline{\text { References }}$}

1. R. A. Costner, Jr., E. N. Cramer, and R. L. Scott, Jr., Reactor Operator Study Handbook (Programmed Instmuction Version). Vol. II - Radiation Sasely uricl Corltrol, pp. 65-146, ORNL/TM-2034, Oak Ridge National Laboratory, Oak Ridge, Tenn., January 1968.

2. H. W. Stroschein and P. H. Maeser, eds., Health Physics Technician Training Manual, IDO-17182, pp. 59-61, June 1966.

3. Samuel Glasstone, Sourcebook on Atomic Energy, 3rd ed., pp. 143-50, D. Van Nostrand Company, Inc., Princeton, N.J., 1967. 
Lesson Plan No. 4. Units of Measurement of Radiation

Objective

The lesson should provide a basic understanding of the terminology used to express the units and rates of radiation exposure and dose.

\section{Plan Outline}

A. Roentgen and m1111roenlgeil

1. Definition

2. Milliroentgen

B. Rad and millirad

1. Definition

C. RBE (relative biological effectiveness) factor

1. Definition

2. Factors of proton $\left(\mathrm{N}_{t h}, \mathrm{~N}_{\mathrm{f}}, \beta, \lambda, \alpha\right)$

D. Rem and millirem

1. Definition

E. Dose vs dose räle

F. Problems to show conversion of rads and roentgens to rems

G. Problems to convert dose rate and time to doses

\section{Sample Study Questions}

1. What are the RBE factors for $\beta, \lambda$, and $\mathrm{N}_{\mathrm{th}}$ ?

2. What is a rad?

3. What is a rem?

4. What is the meaning of RBE'?

5. What is the total dose if a man is continuously exposed tu $1 \mathrm{mrem} / \mathrm{hr}$ for seven days? 


\section{References}

1. R. A. Costner, Jr., E. N. Cramer, and R. L. Scott, Jr., Reactor. Operator Study Handbook (Programed Instmuction Version). Vol. II - Radiation Safety and Control, pp. 46-65, ORNL/TM-2034, Oak Ridge National Laboratory, Oak Ridge, Tenn., January 1968.

2. J. E. Wade and G. E. Cunningham, Radiation Monitoring, a Program of Self-Instruction, USAEC Rept. HW-SA-3671, General Electric Co., 1964.

3. H. W. Stroschein and P. H. Maeser, eds., Health Physics Technician Training Manual, IDO-17182, pp. 116-21, Phillips Petroleum Co., June 1966.

4. Samuel Glasstone, Sourcebook on Atomic Energy, 3rd ed., pp. 740-57, D. Van Nostrand Company, Inc., Princeton, N.J., 1967.

5. K. Z. Morgan and J. E. Turner, Principles of Radiation Protection, pp : 114-36, John Wiley \& Sons, Inc., New York, 1967.

Lesson Plan No. 5. Biological Effects of Radiation

Ob.jective

The lesson should provide an understanding of the effects and consequences resulting from personnel internal and/or external radiation exposure.

$\underline{\text { Plan Outline }}$

A. Exposure suurces

1. Background radiation

a. Cosmic radiation.

b. Materials in the earth 
c. Radioactive materials in the body

d. Exposure due to natural sources is about 0.5 millirem/ day or about 180 millirems/year.

B. Other sources

1. X-ray machines and other man-made devices (TV, etc.)

2. Radiation from reactors

3. Radiation from fission products and other radioisotopes

C. Internal vs external exposure

1. Alpha particles

2. Beta particles

3. Gamma rays

4. Neutrons

5. Noble gases

D. Recommended limits on exposure

1. 10 CFR 20.101

2. Facility regulations (weekly, quarterly, annual)

3. 10 CFR 20.105

4. Emergency dose

5. Definitions of radiation area and high-radiation area ( 10 CHK 20.103, 20.202, and 20.203)

6. Levels and symptoms of overexposure

\section{Sample Study Questions}

1. What is the daily and yearly exposure due to naturally occurring radioactive sources?

2. Why is the RBE of thermal neutrons greater than that of gamma rays?

3. What are the quarterly external limits listed in 10 CFR 20 ?

4. Why do the 10 CFR 20 external exposure limits have different values?

5. What are the facility limits for external exposure? 


\section{References}

1. R. A. Costner, Jr., E. N. Cramer, and R. L. Scott, Jr., Reactor Operator Study Hondbook (Programmed Instmuction Version). Vol. II - Radiation Safety and Control, pp. 65-93, ORNL/TM-2034, Oak Ridge National Laboratory, Oak Ridge, Tenn., January 1968.

2. H. W. Stroschein and P. H. Maeser, eds., Health Physics Technician Training Manual, pp. 76-114, IDO-17182, Phillips Petroleum Co., June 1966.

3. U.S. Council on Radiological Protection, Basic Radiation Protection Criteria, pp. 1-112, NCRP Report 39, Jan. 15, 1971.

4. N. A. Frigero, Your Body and Radiation, rev. ed., pp. 1-78, USAEC Division of Technical Information, October 1967.

5. I. Asimov and T. Dobzhansky, The Genetic Effects of Radiation, pp. 1-49, USAEC Division of Technical Information, September 1966.

Lesson Plan No. 6. Radiation Attenuation

\section{Objective}

The lesson should provide a basic understanding of the methods of decreasing radiation intensity and thus minimize personnel exposure doses.

$\underline{\text { Plan Outline }}$

(NOTE: In the majority of cases the operator will be confronted with gamma and/or beta radiation, and the sources generally may be considered point sources. Therefore, emphasis should be placed on these areas, although discussion of the other types of radiation and the other source configurations should be covered.) 
A. Attenuation

1. Definition

B. Decay time

1. $\mathrm{N}=\mathrm{N}_{\mathrm{O}} \mathrm{e}^{-\lambda t}$ or dose rate $=$ dose rate $_{\mathrm{o}} \mathrm{e}^{-\lambda t}$

2. $\lambda$, decay curves, half-life

C. Exposure time

1. Dose rate $X$ time $=$ dose

2. $\mathrm{R} / \mathrm{hr}$ at $1 \mathrm{ft}=6 \mathrm{CiE}$

3. Problems

D. Allenualdun by dislance

1. Inverse square Law $\mathrm{I}_{1} \mathrm{~d}_{1}^{2}=1_{0} \mathrm{~d}_{0}^{2}$

2. Explanation (using light bulb light emission as example)

3. Problems

4. $I=I_{0} e^{-M T}$

5. Problems

E. Shielding

1. Half-value layer (HVL) or thickness

2. HVL values of water, lead, concrete

3. Tenth-value layers (TVL)

4. Simple problems

5. Problems showing effect of both distance and shielding interposed between source and some point

F. Shiclding of alpha partielco, beta particleo, and neutronc

G. Effect of attenuation factors on personnel dosage

1. Allowable working time $=\frac{\text { permissible exposure }}{\text { exposure ratc }}$

2. Probleme combining affects of timb, dislance, and shielding

\section{Sample Study Questions}

1. What are the three major methods of reducing personnel exposure?

2. What is the dose rate at $3 \mathrm{ft}$ from a point source of $3 \mathrm{Ci}$ emitting $1-\mathrm{MeV}$ gamma rays?

3. What is the TVL for $1-\mathrm{MeV}$ gamma rays for water, lead, and concrete? 
4. If the initial dose rate from a $1-\mathrm{MeV}$ gamma point source having a half-life of $6 \mathrm{hr}$ is $10 \mathrm{rems} / \mathrm{hr}$, what is the dose rate $48 \mathrm{hr}$ later?

5. What is the relationship between half-value layers and tenthvalue layers?

\section{$\underline{\text { References }}$}

1. R. A. Costner, Jr., E. N. Cramer, and R. L. Scott, Jr., Reactor Operator Study Handbook (Progrommed Instruction Version). Vol. II - Radiation Safety and Control, pp. 93-146, ORNL/TM-2034, Oak Ridge National Laboratory, Oak Ridge, Tenn., January 1968.

2. J. E. Wade and G. E. Cunningham, Radiation Monitoring, a Program of Self-Instruction, pp. 62-88, USAEC Rept. HW-SA-3671, General Electric Co., 1964.

3. H. W. Stroschein and P. H. Maeser, eds., Health Physics Technician Training Manual, IDO-17182, pp. 59-75 and 159-67, Phillips Petroleum Co., June 1966.

4. Samuel Glasstone, Sourcebook on Atomic Energy, 3rd ed., pp. 143-50 and 273-75, D. Van Nostrand Company, Inc., Princeton, N.J., 1967.

5. K. Z. Morgan and J. E. Turner, Principles of Radiation Protection, pp. 105-13, John Wiley \& Sons, Inc., New York, 1967.

6. U.S. National Bureau of Standards, Safe Handling of Radioactive Materials, NBS Handbook 92, pp. 1-107, U.S. Government Printing Office, Washington, D.C., 1964.

Lesson Plan No. 7. Radiation Detection

\section{Objective}

This lesson should provide an understanding of the instruments and techniques for determining radiation intensity and personnel exposure doses. 
P1an Outline

A. Alpha detectors

1. Scintillation

a. Laboratory sample counters

b. Portable rate meters

c. Advantages and disadvantages

d. Situations in which they would be used

2. Gas proportional counters

a Laboratory sample counters

b. Yortable rate meters

c. Advantages and disadvantages

d. Situations in which they would be used

3. Limitations

a. Neutron sensitivity

b. Gamma sensitivity

B. Beta-gamma detectors

1. Geiger-Mueller (G-M) counters

a. Laboratory scalers

b. Portable rate meters

2. Ionization chambers

a. Fixed background monitors

b. Portable rate meters

3. Advantages

4. Situations favoring use of each type

C. Neutron detectors

1. Thermal

2. Intermediate

3. Fast

4. Limitations

a. Energy-dependent response

b. Gamma sensitivity 
D. Installed radiation monitoring instrumentation

1. Air monitors

2. Radiation monitors

a. Gamma-beta radiation monitors

b. Neutron monitors

c. Alpha

3. Use and limitations of installed monitors

E. Personnel monitoring devices

1. Film badges

a. Beta-gamma film

(1) Sensitivity (range)

(2) Energy dependence

b. Neutron film

(1) Sensitivity

(2) Gamma response

c. Hand exposure meter

2. Ionization chambers

a. Direct-reading dosimeters

b. Minometer (read)

3. Solid state detectors

a. Thermoluminescent dosimeter (TLD)

b. Thermally stimulated exoelectron emission (TSEE)

4. Faclltty procedures

a. Responsibility for personnel monitoring

h. Reporting of high=radiation fields

\section{Sample Study Questions}

1. What is the meaning of compensation?

2. What is the meaning of discrimination?

3. What types of instruments are used to detect neutrons?

4. What types of instruments are used at this facility?

5. Describe in detail the actions which take place in a G-M detector that indicate the presence of radiation. 


\section{References}

1. J. E. Wade and G. E. Cunningham, Radiation Monitoring, a Program of Self-Instruction, pP. 1-237, USAEC Rept. HW-SA3671, Genera1 Electric Co., 1964.

2. H. W. Stroschein and P. H. Maeser, eds., Health Physics Technician Training Monual, pp. 130-58, IDO-17182, Phillips Petroleum Co., June 1966.

3. J. Price, Nuclear Radiation Detection, 2nd ed., McGraw-Hil1 Book Co., Inc., New York, 1964.

Lesson Plan No. 8. Contamination

\section{Objective}

The lesson should provide an understanding of contamination, its mode of existence, safe limitations, and methods for minimizing the amount of contamination.

\section{Plan Outline}
A. Definition
B. Surface and airborne contamination
C. Detection methods
D. Decontamination mothods
E. 10 GFR. 20 limits
F. Facility limits

Sample Study Questions

1. What is contamination?

2. How would you decontaminate a tool that has been exposed to water from the main cooling system? 
3. What are the facility and $10 \mathrm{CFR} 20$ limits requiring contamination zone controls for surfaces contaminated with alpha and gamma sources?

4. Describe the technique used to determine the level of surface contamination.

5. How can you determine the difference between surface contamination and induced radioactivity?

\section{$\underline{\text { References }}$}

1. H. W. Stroschein and P. H. Maeser, eds., Health Physics Technicicn Training Manual, pp. 169-96, IDO-17182, Phillips Petroleum Co., June 1966.

2. U.S. National Bureau of Standards, Safe Handling of Radioactive Materials, NBS Handbook 92, pP. 1-107, U.S. Government Printing Office, Washington, D.C., 1964.

3. J. A. Ayres, Decontamination of Nuclear Reactors and Equipment, pp. 468-617, The Ronald Press Co., New York, 1970.

\section{Lesson Plan No. 9. Sources of Radiation and} Contamination at the Facility

\section{Objective}

This lesson should familiarize the trainee with the potential sources and levels of radiation and contamination which can be expected to exist at the facility.

\section{$\underline{\text { Plan Outline }}$}

A. Main cooling system

1. Major radioactive constituents

2. Sources and quantities normally expected 
3. Abnormal quantities and types

4. Monitoring instrumentation and setpoints

B. Secondary systems

C. Gaseous radioactivity and sources

1. Potential types and sources in reactor building

2. Stack effluents

3. Monitoring instrumentation and setpoints

4. Abnormalities

D. Sources during maintenance and equipment repair

Sample Study Questions

1. What are the major radioisotopes in the main cooling system?

2. What radioisotopes in the main cooling system would indicate a fuel cladding failure?

3. What are the major radioisotopes in the stack effluent?

4. What radioisotopes in the stack effluent indicate a fuel cladding failure?

5. List the radiation monftoring instruments and setpoints which are used at this facility.

\section{$\underline{\text { Keference }}$}

1. Facility safety analysis report.

Lesson Plan No. 10. Systems for Control of Radioactivity Release from the Facility

\section{Objective}

This lesson should familiarize the trainee with the systems available at the facility for treating radioactive wastes to minimize the amount 
released and acquaint the trainee with those instruments and systems available for measuring the quantities of radioactivity released to the environment.

Plan Outline

A. Radwaste treatment system

1. System description

2. Types and quantities of waste treated

3. Monitoring instrumentation and setpoints

4. Release limitations

5. Potential abnormalities

B. Gaseous waste treatment system

1. System description

2. Types and quantities of waste treated

3. Monitoring instrumentation and setpoints

4. Release limitations

5. Abnormalities

C. Solid waste treatment system

D. Environmental monitoring systems

\section{Sample Study Questions}

1. What are the facility license limits on liquid waste effluents from the facility?

2. What are the facility license limits on gaseous waste effluents from the facility?

3. Compare the expected normal quantities of radioactive effluents with the 10 CFR 29 limitations.

4. Describe in detail the liquid waste treatment system.

5. Describe in detail the gaseous waste treatment system.

\section{$\underline{\text { Reference }}$}

1. Facility safety analysis report. 
Lesson Plan No. 11. 10 CFR 20 - Standards for

Protection Against Radiation

\section{Objective}

This lesson should inform the trainee of the Federal regulations with regard to the control of radioactivity, personnel exposure, and limitations on the quantities released to the environment.

\section{Plan Outiline}

A. Complete review of $10 \mathrm{CH} 2 \mathrm{U}$

\section{Sample Study Questions}

1. What are the $10 \mathrm{CFR} 20$ quarterly external exposure 1imits (Par. 20.101)?

2. What are the $10 \mathrm{CFR} 20$ limits on radiation dose in unrestricted areas (Par. 20.105)?

3. What is the difference between Tables I and II of Appendix B to $10 \mathrm{CFR} 20$ ?

4. What is the meaning of "radiation area"?

5. What io the moaning of "high-radiation area"?

\section{Reference}

1. "Standards for Protection Against Radiation," U.S. Code of Federal Regulations, Title 10, Part 20, U.S. Government Printing Office, Washington, D.C., 1971. 
Lesson Plan No. 12. Comprehensive Examination

\section{Objective}

The examination should determine the adequacy of understanding of the trainee and provide further experience with taking examinations.

\section{$\underline{\text { Plan Outline }}$}

A comprehensive examination of the topics covered in this chapter should be given, graded, and then reviewed with the trainees - individually, if possible. Suggested questions are listed below.

\section{Sample Study Questions}

1. What is the difference between radiation and contamination?

2. List the types, locations, and setpoints of all radiationdetection instruments used or available at this facility.

3. Describe in detail the liquid, gaseous, and solid waste treat-. ment systems at this facility.

4. List those areas (specific spots) where radiation dose rates in excess of 2 millirems/hr exist, and give the nominal dose rate at these places.

5. List those areas (specific spots) where the potential exists for surface contamination, and give the expected degree of contamination and the radioisotopes expected.

6. List those areas (specific spots) where the potential exists for airborne radioactivity, and give the specific radioisotopes expected.

7. List the personnel exposure limits given in $10 \mathrm{CFR} 20$.

8. List the liquid and gaseous radioactive effluent limits at this facility.

9. Problems involving source strength, decay time, distance, and shielding. 
SECTION VII. PRINCIPLES OF REACTOR OPERATION

Contents

Introduction . . . . . . . . . . . . . . . . . . . 80

Classroom Illustrations and Laboratory Experiments . . . . . . 81

Lesson Plan No. 1. Neutron Reactions . . . . . . . . . . . . . 81

Lesson Plan No. 2. Nuclear Reactors . . . . . . . . . . . . 85

Lesson Plan No. 3. Reactivity and Reactor Period . . . . . . . 87

Lesson Plan No. 4. Fuel Burnup . . . . . . . . . . . . . 89

Lesson PLan No. j. Xenon and Samartum Koisoning Effects..... 90

Lesson Plan No. 6. Temperature and Other Coefficients . . . . . . 93

Lesson Plan No. $\overline{7}$. Neutron Flux Distribution . . . . . . . . 95

\section{Introduction}

This section contains information related to basic nuclear reactor behavior and elementary nuclear reactor theory, as well as terminology to provide an appreciation of the processes that take place in a reactor. Mathematical ability in excess of ordinary algebra is not required. Principles presented in this portion of the training program should be confined to reactors in general and to reactors of the appropriate class (i.e., power or research). 


\section{Classroom Illustrations and Laboratory Experiments}

Included in the lesson plans are a few examples of teaching illustrations. The training coordinator will find many others in the literature as he sets up his training program. If there is a low-power reactor available, experiments such as those listed below should be included in the teaching.

1. Scattering and absorption of neutrons

2. Thermal neutron capture cross sections

3. Period of delayed neutrons from fission

4. Fission propertles of U-235

5. Diffusion length of thermal neutrons

6. Moderation of neutrons

7. Neutron flux distribution

8. Fast neutron shielding

9. Critical mass of a nuclear reactor

10. Gamma and thermal neutron attenuations

\section{Lesson Plan No. 1. Neutron Reactions}

\section{Object1ve}

This lesson should give the trainee an understanding of the neutron. When he finishes the study, the trainee should believe that neutrons are real and should know where they come from, what happens to them, and how they live their short lives in a reactor. 


\section{$\underline{\text { Plan Outline }}$}

A. Reactions and characteristics of neutrons

1. Scattering

2. Neutron lifetime

3. Slowing-down time

4. Diffusion time

5. Absorption

6. Fission (Fig. VII.1)

B. Tast and thermal neutrons

1. Urigin

2. Moderation

C. Prompt and delayed neutrons

1. Origin

2. Prompt release time

3. Delayed release time

D. Multiplication factor (Fig. VII.2)

1. Generation of neutrons

2. $\mathrm{k}$

E. Cross sections

1. Microscopic and macroscopic

2. Absorption, $1 / \dot{v}$ law, resonance, tast region a. Neutron "poison"

3. Scattering

4. Fission

5. Nèutron flux

6. Fission rate and fissions per unit volume

F. Neutron energy spectrum

1. Fast

2. Intermediate

3. Slow 


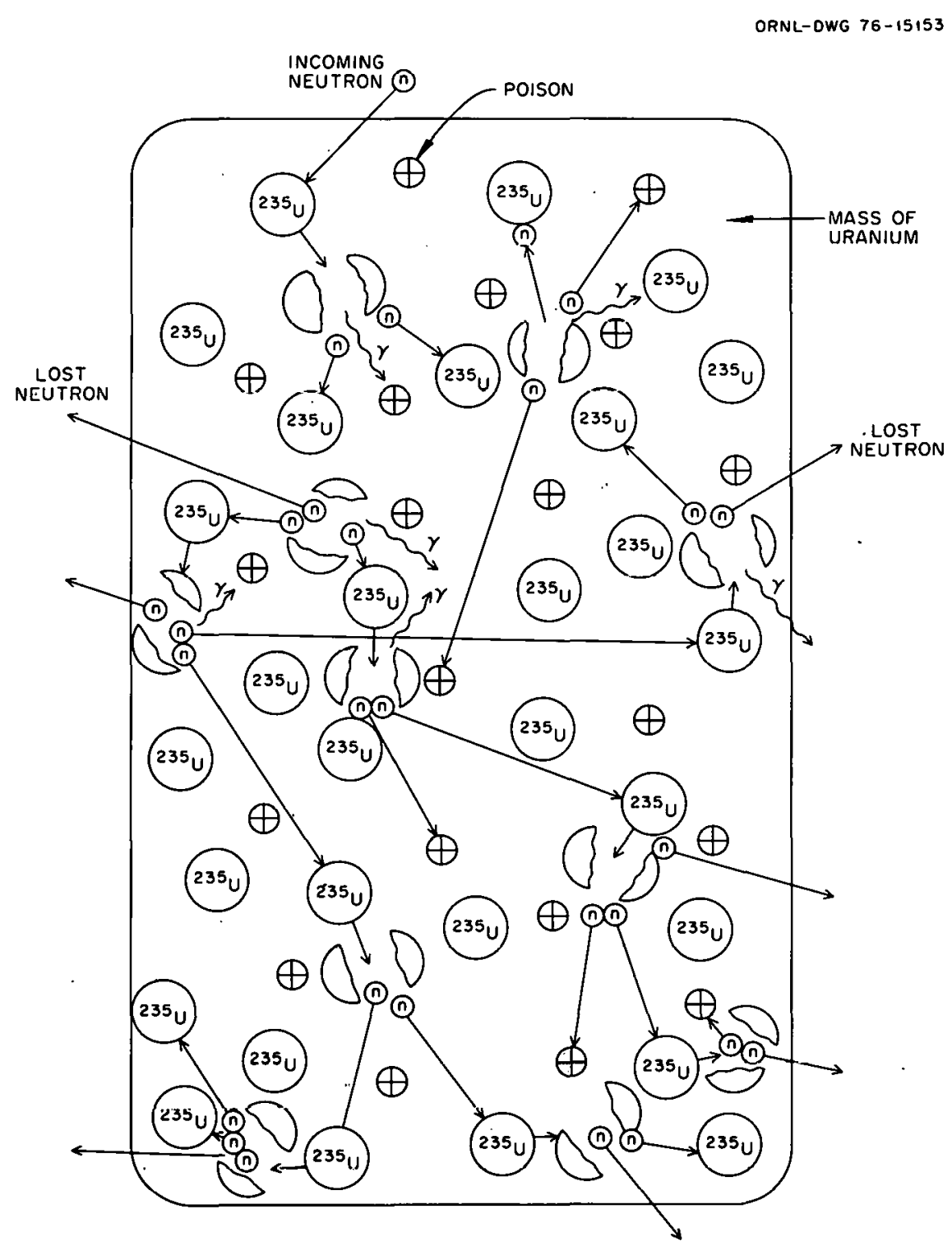

Fig. VII.1. Fission chain reaction. 


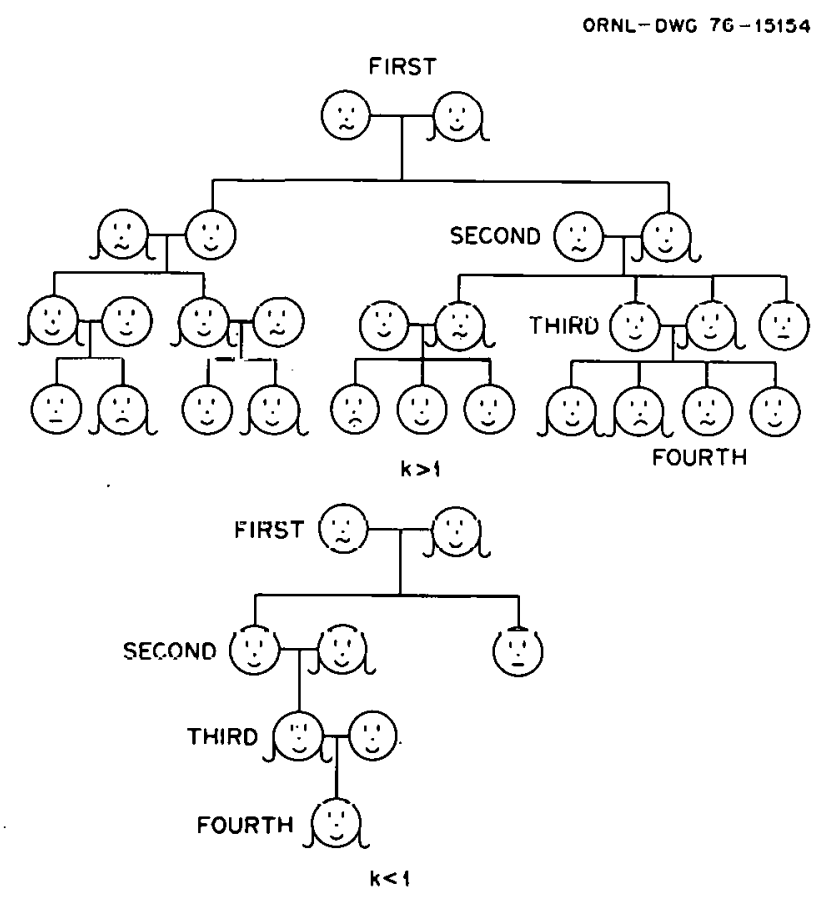

Fig. VII.2. Family trees.

\section{Sample Study Questions}

1. What is a neutron?

2. What is the difference between scattering and absorption cross sections?

3. What materials are effective neutron poisons?

4. Describe the properties of a good moderator.

5. How is the effect of delayed neutrons seen during reactor operation?

6. How does fission produce heat?

\section{References}

1. R. A. Costner, Jr., E. N. Cramer, and R. L. Scott, Jr., Reactor Operator Study Handbook (Programmed Instruction Version). Vol. III - Reactor Physics, Pp. 1-39, ORNL/TM-2034, Oak Ridge National Laboratory, Oak Ridge, Tenn., June 1968. 
2. E. G. Greenman, ed., Basic Nuclear and Reactor Information for the Reactor Operator, Pp. 9-22, ANL-6071, Argonne National Laboratory, February 1963.

3. D. F. Hanlen, G. N. Hamilton, and E. G. Taylor, Reactor Operator Training Manual, pp. 2-22 to 2-28, 3-1 to 3-14, 3-16 to 3-19, and 4-18 to 4-20, WCAP-2713 (rev.), Westinghouse Electric Corp., Atomic Power Division, P.O. Box 355, Pittsburgh, Pa., 1967.

4. S. E. Liverhant, EZementary Introduction to Nuclear Reactor Physics, pp. 30-266, John Wiley \& Sons, Inc., New York, 1960.

\section{Lesson Plan No. 2. Nuclear Reactors}

\section{Objective}

When the student finishes this lesson, he should have a basic understanding of how and why nuclear reactors work. This lesson will add to his knowledge of neutrons in a nuclear reactor so that he will understand subcritical multiplication and criticality and will be able to outline what happens to a generation of neutrons in a reactor.

\section{Plan Outline}

A. Description of reactor components

1. Fuel

2. Moderator

3. Reflector

4. Cooling system

5. Control system

6. Shielding

B. Reactivity and criticality

1. $\mathrm{k}$

2. $k_{\infty}$

3. $k_{e f f}$ 


\section{Criticality}

5. Subcritical multiplication

6. $1 / \mathrm{M}$ plot

C. Four-factor and six-factor formulas

1. Fast fission effect

2. Resonance escape probability

3. Thermal utilization factor

4. Eta

5. Fast nonleakage

6. Thermal nunleakage

D. Converșion

1. Fertile atoms to fissionable atoms

Sample Study Questions

1. What are the principle parts of a nuclear reactor?

2. What is an infinite reactor?

3. What are $k_{\infty}$ and $k_{\text {eff }}$ ?

4. What is nonleakage probability?

5. What arc the constituents of the four-factor formula?

6. Construct a typical approach-to-critical plot.

\section{$\underline{\text { References }}$}

1. R. A. Costner, Jr., E. N. Cramer, and R. L. Scott, Jr., Reactor Operator Study Handbook (Progrommed Instruction Version). Vol. III - ReG6.tor Physics, pp. 10-97, ORNL/TM-2034, Oak Ridge National Laboratory, Oak Ridge, Tenn., June 1968.

2. E. G. Greenman, ed., Basic Nuclear and Reactor Information for the. Rencetenr Operntenr, in, $16-21,23=30$, and $40=60, A \mathrm{NL}=6071$, Argonne National Labọatory, February 1963.

3. D. F. Hanlen, G. N. Hamilton, and E. G. Taylor, Reactor Operator Training Manual, pp. 4-18 to 4-25, WCAP-2713 (rev.), Westinghouse Electric Corp., Atomic Power Division, P.0. Box 355, Pittsburgh, Pa., 1967.

4. S. E. Liverhant, Elementary Introduction to Nuclear Reactor Physics, pp. 170-328, John Wiley \& Sons, Inc., New York, 1960. 
Lesson Plan No. 3. Reactivity and Reactor Period

\section{Objective}

In this lesson the student should learn to use some of the mathematics, such as period calculations. The concept of increasing and decreasing reactivity should be learned, and an understanding of prompt criticality should be attained.

\section{$\underline{\text { Plan Outline }}$}

A. Reactivity calculations

1. Reactivity

2. Positive changes in reactivity

3. Negative changes in reactivity

4. Neutron lifetime

B. Reactor period

1. Doubling time

2. Period

3. $N=N, e^{t} / T$

4. Power level = power level (start) $e^{t / T}$

5. Positive and negative periods

6. Calculation of period

7. Decades of power change per unit time

8. Stable and transient periods

9. Prompt and delayed neutrons

C. Prompt criticality

1. Delayed and prompt neutrons and reactor control

2. $\beta$ and $\beta$-effective

3. Stable periud for prompt criticality

4. Dollars and cents 
Sample Study Questions.

1. How are control rods used in controlling reactivity?

2. List changes in the reactor that cause positive reactivity changes. List those that cause negative reactivity changes.

3. What is the mathematical expression for reactivity?

4. Draw typical curves for control-rod reactivity worths.

5. What is neutron lifetime, and how does it affect reactor control?

6. If the neutron population now is $100 / \mathrm{cm}^{3}$ and the reactor is on a 10-sec perlod, what will. the population be $10 \mathrm{sec}$ from now?

\%. If the neutron flux increases from 1 to 100 , how many decades is this? If this flux increase occurs in $23 \mathrm{sec}$, what would the period be?

8. If the startup rate is 1 decade/min and the $\log \mathrm{N}$ is reading $5 \times 10^{-7}$, what will the power level be in $3 \mathrm{~min}$ ?

9. What does prompt criticality mean?

10. What is $\beta$ ?

\section{$\underline{\text { References }}$}

1. R. A. Costner, Jr., E. N. Cramer, and R. L. Scott, Jr., Reactor Operator Study Handbook (Progrommed Instruction Version). Vol. III Reactor Fhysius, PP, 98-140, ORNL/TM-2034, Uak Kidge National Laboratory, Oak Ridge, Teim., June 1968.

2. D. F. Hanlen, G. N. Hamilton, and E. G. Taylor, Reactor Operator Training Manual, pp. 3-24 to 3-31, WCAP-2713 (rev.), Westinghouse Electric Corp., Atowic Power Division, P.0. Box 355, Pittssburgh, Pa., 1967.

3. D. F. Hanlen and W. J. Morse, Nuclear Physics Made Very, Very, Easy, pp. III-15 to III-21, NTO-T-0026, Nevada Test Operations, Juiy 1968.

4. S. E. Liverhant, EZementary Introduction to Nuclear Reactor Physics, pp. 267-328, John Wiley \& Sons, Inc., New York, 1960. 
Lesson Plan No. 4. Fuel Burnup

\section{Objective}

In this lesson the student should learn to do the arithmetic involved with reactivity change and fuel addition and burnup. It is not expected that he fully understand the theory.

\section{Plan Outline}

A. Fuel requirements for operation

1. Critical mass

2. Extra fuel for operation

B. Effects of burnup

1. Burnup of U-235

2. Rate of loss of U-235

3. Reactivity

4. Fission products

\section{Sample Study Questions}

1. What is burnup?

2. Explain why, in loading a reactor, more fuel is needed than just the critical mass?

3. What is meant by the phrase "shutdown margin"?

4. How fast is $\mathrm{U}-235$ consumed? What happens to it? Give percentages.

5. What is the mathematical relationship between reactivity and fuel?

6. If the neutron flux at a particular position in the core of a reactor is the same as the average flux of the core and the fuel (a 190-g element) is replaced by one containing $10 \mathrm{~g}$ more U-235, what is the reactivity effect? Assume $\mathrm{M}=5000 \mathrm{~g}$ and $\mathrm{C}=0.35$. 


\section{References}

1. R. A. Costner, Jr., E. N. Cramer, and R. L. Scott, Jr., Reactor Operator Study Handbook (Programmed Instruction Version). Vol. III - Reactor Physics, pp. 141-49, ORNL/TM-2034, Oak Ridge National Laboratory, Oak Ridge, Tenn., June 1968.

2. E. G. Greenman, ed., Basic Nuclear and Reactor Information for the Operator, p. 36, ANL-6071, Argonne National Laboratory, February 1963.

3. S. E. Liverhant, EZementary Introduction to Nuclear Reactor Physics, pp. 311-28, John Wiley \& Sons, Inc., New York, 1960.

Lesson Plan No. 5. Xenon and Samarium Poisoning Effects

Objective

The student should learn to draw curves illustrating the production and loss of xenon and samarium in any type of operation. He should be able to explain the shape of the curves.

\section{Plan Outline}

A. Fission-product poisons

1. Fission fragments

2. Cross-section and reactivity effect

3. Xenon and samarium

B, Buildup and "removal" (Figs. VII.3 through VII.5)

1. Source of $\mathrm{Sm}-149$

2. Source of $\mathrm{Xe}-135$

3. Two methods of "removal"

4. Difference between "removal" of Sm-149 and Xe-135

5. Equilibrium and neutron flux

C. Effect of shutdown on poison equilibrium

1. Samarium concentration curves

2. Xenon concentration curves

3. Xenon transients 
ORNL-OWG $76-15155$

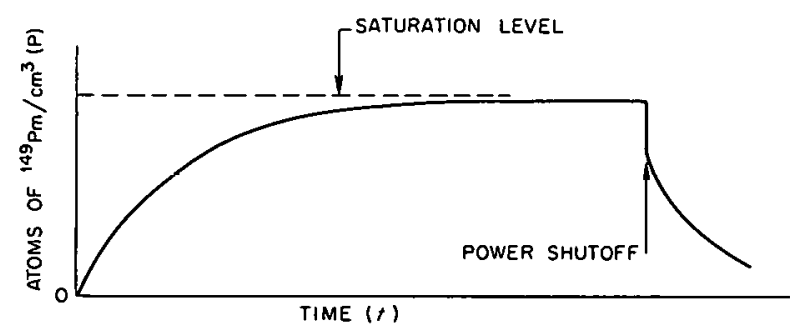

WATER TANK ANALOGY TO THE BUILDUP OF A RADIOACTIVE ISOTOPE

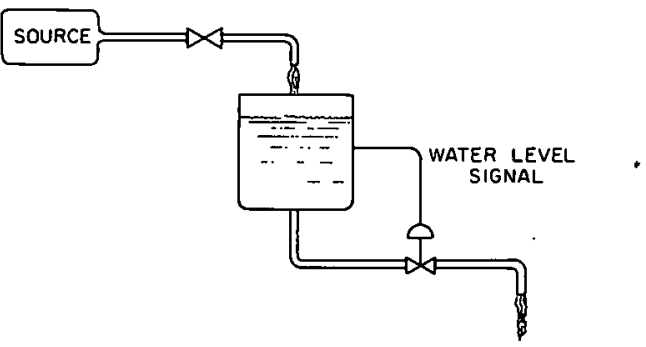

Fig. VII.3. Promethium-149 buildup and decay.
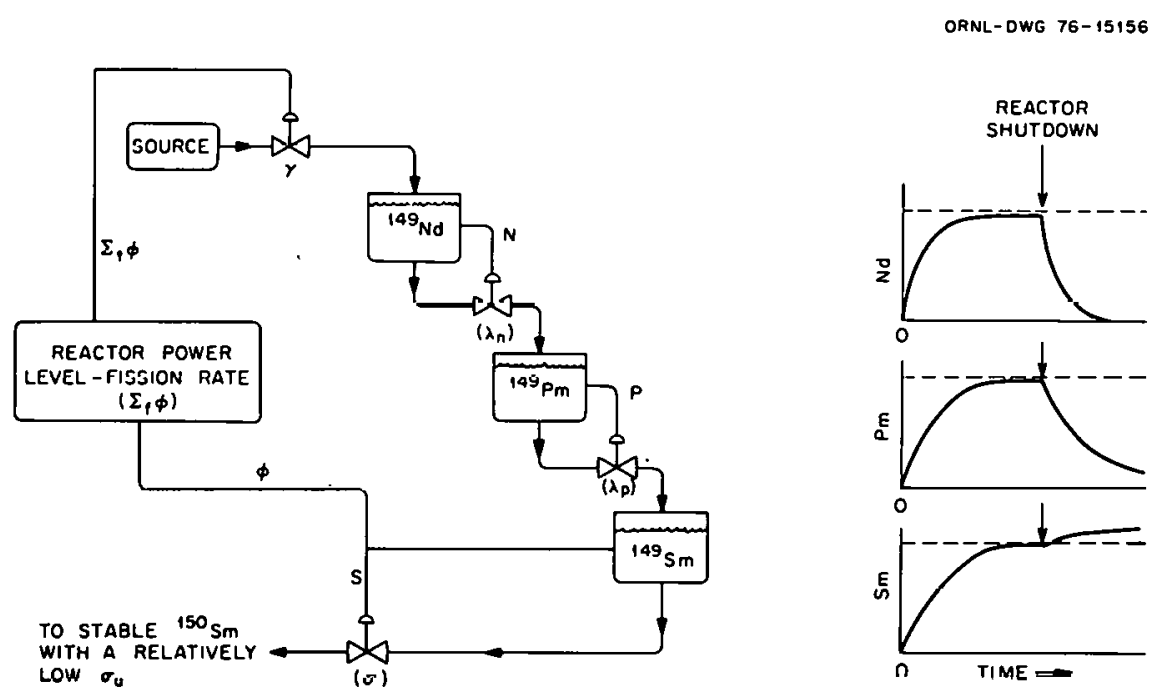

Fig. VII.4. Samarium-149 buildup. 

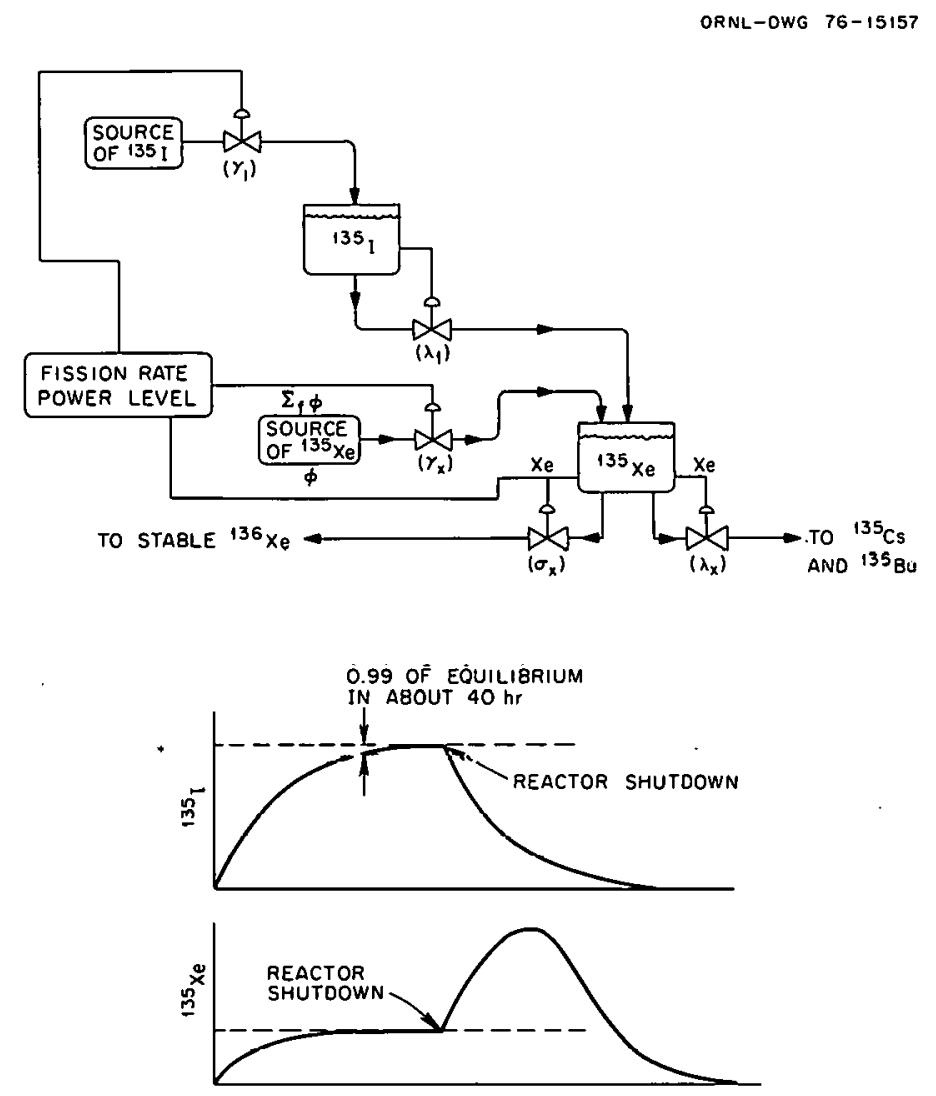

Fig. VII.5. Xenon-135 buildup and decay.

\section{Reactivity effects}

5. Peak xenon

6. Long-term effects of $\mathrm{Sm}-149$ and Xe-135

\section{Sample Study Questions}

1. Llow are Ke-135 and $\mathrm{Gm}-149$ formed?

2. What is the reactivity effect of Xe-135 and Sm-149?

3. What is the absorption cross section of Xe-135 and Sm-149?

4. How are Xe-135 and Sm-149 "removed" from the core?

5. What is meant by xenon equilibrium? Samarium equilibrium?

6. Draw a curve showing Xe-135 reactivity effects vs time from startm up to equilibrium, followed by a $50 \%$ power decrease unt11 equilibrium is again reached, followed by a three-day shutdown. 


\section{$\underline{\text { References }}$}

1. R. A. Costner, Jr., E. N. Cramer, and R. L. Scott, Jr., Reactor Operator Study Handbook (Programed Instmuction Version). Vol. III - Reactor Physics, pp. 150-71, ORNL/TM-2034, Oak Ridge National Laboratory, Oak Ridge, Tenn., June 1968.

2. E. G. Greenman, ed., Basic Nuclear and Reactor Information for the Reactor Operator, p. 15, ANL-6071, Argonne National Laboratory, February 1963.

3. D. F. Hanlen, G. N. Hamilton, and E. G. Taylor, Reactor Operator Training Manual, pp. 4-11 to 4-14, WCAP-2713 (rev.), Westinghouse Electric Corp., Atomic Power Division, P.0. Box 355, Pittsburgh, Pa., 1967.

4. S. E. Liverhant, Elementary Introduction to Nuclear Reactor Physics, pp. 311-28, John Wiley \& Sons, Inc., New York, 1960.

Lesson Plan No. 6. Temperature and Other Coefficients

\section{Objective}

The student should learn to estimate, qualitatively, reactivity effects which result from temperature changes. He should learn to evaluate the probable effect of temperature changes in various sltuations and explain the reason for the effect.

\section{Plan Outline}

A. Reactivity and temperature

1. Density

2. Moderator coefficient

3. Boron coefficient

4. Doppler

5. Power coefficient

6. Pressure coefficient

7. Void coefficient 
B. Reactor control

1. Temperature coefficient

2. Temperature variations in reactor (Fig. VII.6)
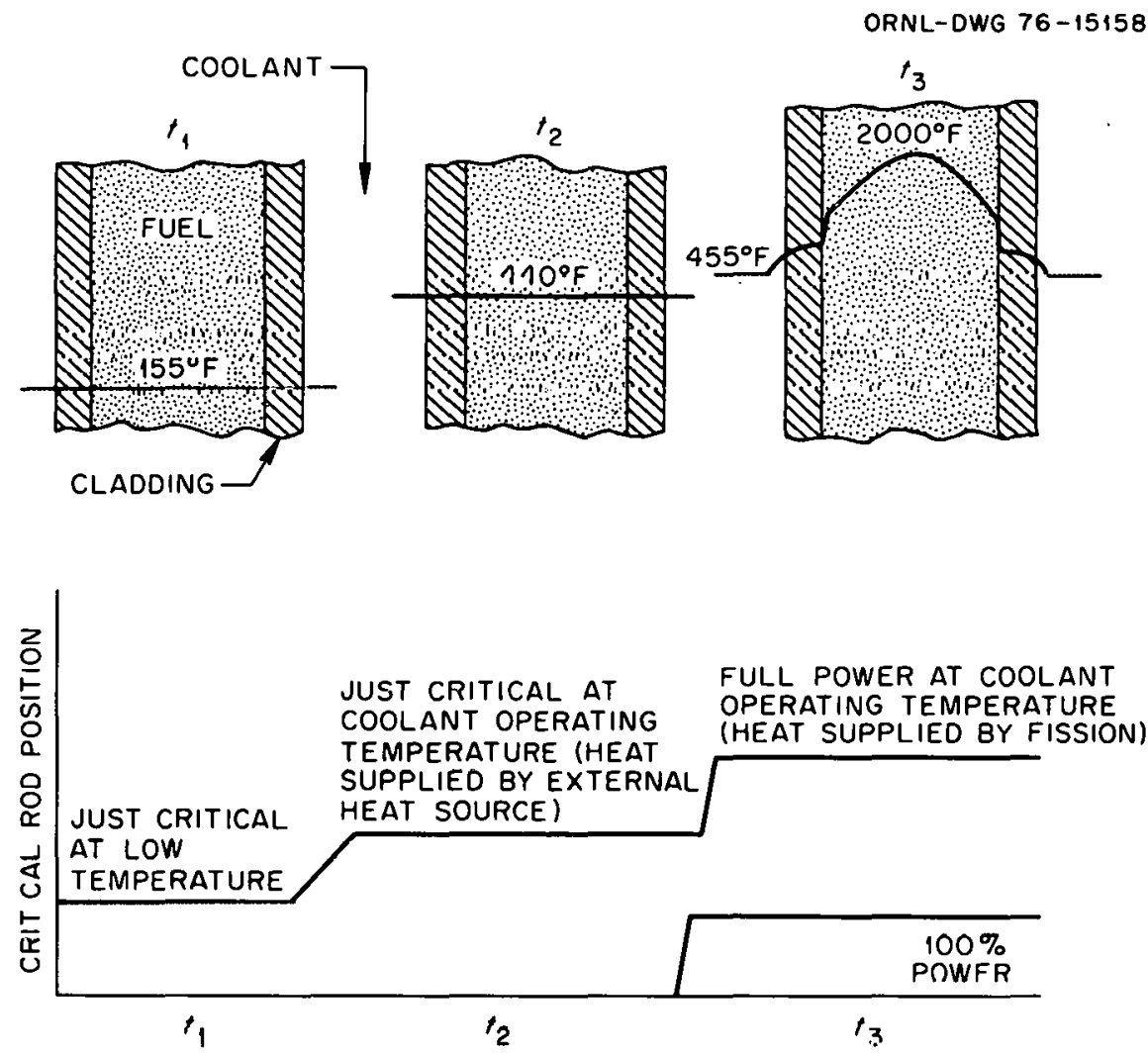

Fig. VII.6. Temperatures in rod-type fuel during startup of a reactor.

\section{Samplc Etudy Questions}

1. How does the concept of density changes enter into the explanation of moderator temperature coefficlents?

2. What is $\Delta t$ ? What are the units of temperature coefficients?

3. Why is the sign of the coefficlent important?

4. Which type of reactor is safer - one using an alloy fuel or one using an oxide fuel? Explain. 
5. What is the Doppler effect?

6. How can the temperature coefficient of a pressurized-water reactor (PWR) become positive? Is this good or bad? Why?

7. If the reflector temperature coefficient is $+0.008 \% \Delta \mathrm{k} / \mathrm{k} /{ }^{\circ} \mathrm{F}$ and the moderator coefficient is $-0.01 \Delta \mathrm{k} / \mathrm{k} /{ }^{\circ} \mathrm{F}$, what will be the reactivity change for these two for a $50^{\circ} \mathrm{F}$ increase?

\section{References}

1. R. A. Costner, Jr., E. N. Cramer, and R. L. Scott, Jr., Reactor Operator Study Handbook (Programmed Instruction Version). Vol. III - Reactor Physics, pp. 172-90, ORNL/TM-2034, Oak Ridge National Laboratory, Oak Ridge, Tenn., June 1968.

2. E. G. Greenman, ed., Basic Nuclear and Reactor Information for the Reactor Operator, p. 22, ANL-6071, Argonne National Laboratory, February 1963.

3. D. F. Hanlen, G. N. Hamilton, and E. G. Taylor, Reactor Operator Training Manual, pp. 3-32 to 3-37, WCAP-2713 (rev.), Westinghouse Electric Corp., Atomic Power Division, P.0. Box 355, Pittsburgh, Pa., 1967.

4. S. E. Liverhant, Elementary Introduction to Nuclear Reactor Physics, pp. 311-28, John Wiley \& Sons, Inc., New York, 1960.

Lesson Plan No. 7. Neutron Flux Distribution

\section{Objective}

The student should learn that the neutron flux varies in the core of a reactor. The reason for the variation and the way in which the variations affect reactivity, temperature distribution, burnup, and reactor control should be understood. 


\section{Plan Outline}

A. Definitions

a. Neutron flux

b. Distribution (Figs. VII.7 and VII.8)

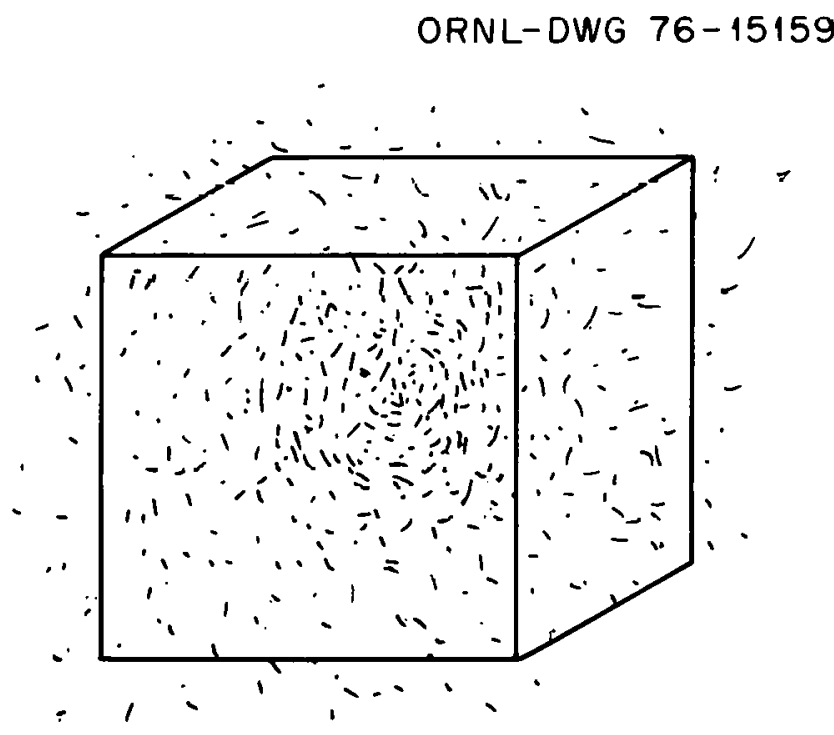

Fig. VII.7. Neutron distribution through the fuel region (core) of a reactor.

B. Reflector effects
a. Neutron leakage
b. Flat neutron flux distribution

C. Temperature effects

a. Hot spots

b. Uniform temperature distribution

D. Fuel burnup offocto

a. Neutron flux changes

b. Power distribution changes

E. Control-rod effects
a. Neutron flux distortion by rods
b. Chemical shim
c. Axial flux distribution
d. Radial flux distribution 


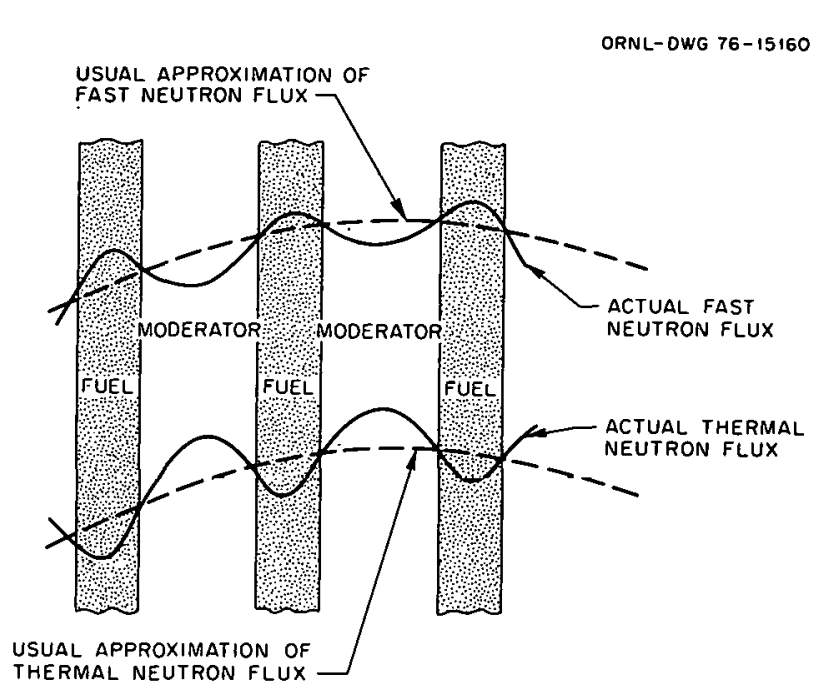

Fig. VII.8. Fine structure of neutron flux distribution.

F. Control-rod worth
a. Reactivity effects vs rod position
b. Calibration
c. Calibration curves

\section{Sample Study Questions}

1. What determines the maximum effectiveness of a given control rod?

2. What is the general shape of the plot of an integral control-rodworth curve? A differential worth curve?

3. What is the difference between chemical and rod shimming?

\section{$\underline{\text { References }}$}

1. R. A. Costner, Jr., E. N. Cramer, and R. L. Scott, Jr., Reactor Operator Study Handbook (Programmed Instruction Version). Vol III - Reactor Physics, pp. 191-221, ORNL/TM-2034, Oak Ridge National Laboratory, Oak Ridge, Tenn., June 1968. 
2. E. G. Greenman, ed., Basic Nuclear and Reactor Information for the Reactor Operator, pp. 31-36, ANL-6071, Argonne National Laboratory, February 1963.

3. D. F. Hanlen, G. N. Hamilton, and E. G. Taylor, Reactor Operator Training Manual, pp. 4-1 to 4-10, WCAP-2713 (rev.), Westinghouse Electric Corp., Atomic Power Division, P.0. Box 355, Pittsburgh, Pa., 1967.

4. S. E. Liverhant, EZementary Introduction to Nuclear Reactor Physics, pp. 194 and 286-93, John Wiley \& Sons, Inc., New York, 1960. 
SECTION VIII. GENERAL OPERATING CHARACTERISTICS

Contents

Introduction . . . . . . . . . . . . . . . . . . . . . 99

Lesson Plan No. 1. Nuclear Characteristics . . . . . . . . 100

Lesson Plan No. 2. Thermal-Hydraulic Characteristics . . . . . 103

Lesson Plan No. 3. Reactor Cooling Systems . . . . . . . . . 105

Lesson Plan No. 4. Reactor Instrumentation and Control . . . . 108

Lesson Plan No. 5. Utilities . . . . . . . . . . . . . . 110

Lesson Plan No. 6. Waste Systems . . . . . . . . . . . . 112

Lesson Plan No. 7. Turbines and Generators . . . . . . . . . 115

Lesson Plan No. 8. Operational Safety . . . . . . . . . . 120

\section{Introduction}

The primary objective of this section is to acquaint the student with those controlled and variable parameters used at this facility to evaluate and/or predict the operational status and performance of the reactor, steam generators, steam-driven turbine, and turbine-driven generators.

The first subject (A) listed under each lesson plan outline should be reviewed, with special emphasis on applicable parameters (specifically, the types and units of parameters, their limiting values, and the reason for their limits). Parameters discussed include

$\begin{array}{ll}\text { 1. Pressure } & \text { 14. Electric potential } \\ \text { 2. Temperature } & \text { 15. Electric current } \\ \text { 3. Flow } & \text { 16. Frequency } \\ \text { 4. Velocity } & \text { 17. Cycles } \\ \text { 5. Mass } & \text { 18. Resistivity } \\ \text { 6. Volume } & \text { 19. Radiation leve1 } \\ \text { 7. Density } & 20 . \text { Concentration } \\ \text { 8. Time } & 21 . \text { Rate } \\ \text { 9. Heat } & 22 . \text { Ratio } \\ \text { 10. Power } & 23 . \text { Efficiency } \\ \text { 11. Energy } & 24 . \text { Coeffictent } \\ \text { 12. Flux } & 25 . \text { Period } \\ \text { 13. Reactivity } & 26 . \text { pH }\end{array}$


By then studying the cause and effect ( $B$ and $C$, respectively, in the plan outline) of changes in those parametric values, the interrelationship of the systems and subsystems will be more readily understood, and the operating characteristics of a nuclear facility will be learned.

Some subjects in this section are covered in greater depth in other sections (e.g., Instrumentation and Control, and Safety and Emergency Procedures). Section IX (Features of Facility Design) also describes al1. the equipment in the reactor complex with the common objective of teaching the interrelationship of the various systems and subsystems; hence, the material in both chapters is presented in much the same manner. The instructor should give consideration to presenting this section immediately after that on features of the facility design (rather than in the order of section listings) since it would be more beneficial to familiarize the student initially with the design features of the various systems and, after a basic knowledge of the plant is obtained, to review all the systems and study their operating characteristics.

Study questions, which are included for each lesson plan, reflect the depth of understanding of the material that the student should develop.

Lesson Plan No. 1. Nuclear Characteristics

\section{Objective}

In addition to providing a brief review of definitions, this lesson should familiarize the student with the behavior of those parameters associated with the nuclear characteristics of the reactor. The cause and effect of changes in normal parametric values should be emphasized. The student should develop a thorough understanding of the nuclearoriented data obtained during the operating cycle, and he should become competent in recognizing significant deviations in such data. 


\section{Plan Out1ine}

A. Parameters (types, normal magnitudes, limiting values, and reason for limits) associated with

1. Control rods
a. Reactivity worth
b. Withdrawal speed (rod-worth minimizer)
c. Reactivity insertion (per unit time)
d. Scram speed
e. Release time
f. Worth vs core life

2. Fuel elements
a. BOL (beginning of life) internal pressure, EOL (end of life) internal pressure
b. Axial and radial temperature distribution of cladding and meat
c. Fission product buildup (U-235 burnup)
d. Burnable-poison burnup
e. Cladding ductility change with burnup
f. Plutonium buildup

3. Temperature coefficients

4. Void coefficients

5. Fuel coefficients

6. Shutdown margins

7. Criticality measurements

8. Liquid shim

9. Poisons

B. Causes of changes in parametric values (for each of the above items)

C. Effects of changes in parametric values (for each of the above items)

1. In regard to component

2. In regard to overall system 
1. Plot the control-rod motion (i.e., the inches withdrawn vs operating time during the fuel depletion cycle), and plot the boron concentration vs operating time. Discuss the causes of any changes in the curve. What is the value of such data?

2. Discuss the temperature coefficient for different locations in the core; list values. How does the temperature coefficient change if there is an increase in temperature? What is the value of such data?

3. Discuss the void coefficient for different locations in the core at BOL and EOL. What is the value of such data?

4. Discuss the fuel coefficients of reactivity. What is the value of such data?

5. What is a "fuel cycle analysis"? of what value are such studies?

6. Discuss the shutdown margin; give values.

7. Discuss the purpose of minimizing flux perturbations during operation of the reactor. What control features and actions are involved? List any setpoints.

8. What materials are used as "burnable poisons?" What is their function?

$\underline{\text { RuILRUHLLU }}$

1. Vendor's literature.

2. Design reports.

3. Procedures manuals.

4. Safety analysis reports. 
Lesson Plan No. 2. Therma1-Hydraulic Characteristics

\section{Objective}

In addition to providing a brief review of definitions, this lesson should familiarize the student with the behavior of those parameters associated with the thermal-hydraulic characteristics of the various reactor systems. The cause and effect of changes in normal parametric values should be emphasized. The student should develop a thorough understanding of the heat transfer requirements of the various systems and/or components, and he should become competent in diagnosing changes in normal operating conditions.

\section{Plan Outline}

A. Parameters (types, normal magnitudes, limiting values, and reason for limits) associated with

1. Core cooling (normal and emergency conditions)
a. Coolant flow rates through fuel region
b. Velocity of flow at fuel, reflector, control rods, experiments, in-core monitoring, dummy core pieces, etc.
c. Differential pressure across core under various flow conditions

2. Core voids

3. Power (levels and densities)

4. Heat fluxes

5. Vessel stress loads

6. Pressurization of the reactor water system

7. Minimum critical high flux ratio variations

B. Causes of changes in parametric values (for each of the above items)

C. Effects of changes in parametric values (for each of the above 1tems)

1. In regard to component

2. In regard to overall system 


\section{Sample Study Questions}

1. Define the "average power density." What is it for this reactor?

2. Briefly discuss any changes that the power density may undergo during a fuel cycle.

3. Define and give values of the "power density ratio." What is done to control it?

4. Define and give values of the minimum critical high flux ratio. What is done to control it?

5. Discuss the flow distribution through the various sections of the core; 11st values. Dlscuss the effect on the reactor if any flow channel is blocked during normal operation. (Note to instructor: Selection of channels is optional.)

6. List the specific data, applicable to this category, that the console operator records.

7. How do temperature fluctuations affect the equilibrium condition of the reactor? What might have caused such changes? What change in reactivity occurred?

8. Briefly discuss the basic factors considered for the "heatremoval analysis."

9. Does the core-cooling flow rate vary during a fuel depletion cycle? Why? Draw a curve showing the magnitude of such changes.

10. List all the curves plotted during a fuel depletion cycle, and explain the value of such data.

11. What precautions are associated with pressurizing and depressurizing the reactor primary water system (in regard to thermal and/or hydraulic load problems)?

12. What are the average and hot-spot heat flux values in the fuel region of the core?

\section{References}

1. Vendor's literature.

2. Design reports.

3. Procedures manuals.

4. Safety analysis reports. 
Lesson Plan No. 3. Reactor Cooling Systems

\section{Objective}

This lesson should familiarize the student with the behavior of those parameters associated with the reactor cooling systems. The cause and effect of changes in normal parametric values should be emphasized. The student should become acquainted with the cooling system parameters to the extent that, when given a certain set of varying conditions, he should be able to (1) predict the changes that would occur in system readouts and (2) effect appropriate corrective action when needed.

\section{$\underline{\text { Plan Outline }}$}

A. Parameters (types, normal magnitude, limiting values, and reason for limits) associated with

1. Primary coolant system

a. Reactor vesse1

(1) Temperature distribution upstream of the core

(2) Differential temperature and pressure across the core

(3) Temperature of coolant for nonfuel pieces (percentage of flow distribution)

b, Heat. exchangers

c. Primary coolant pumps (recirculation and feedwater pumps)

(1) Capacity

(2) Amperage

(3) Seal-water flow and temperature

(4) Lubrication (oil flow and temperature)

(5) Heat input to primary water

d. Pressurizer pumps (and/or pressurizer systems)

(1) Normal pressure, fluid level, and temperature of system 
(2) Setpoints and control action

(3) Transients of level, pressure, and temperature with load change

(4) Spray flow

e. Purification and volume control systems

(1) Filters, deaerators, demineralizers

(2) Letdown and/or cleanup flows

(3) Temperature in and out of regenerative heat exchanger

(4) Pressure change in let-down system

(5) Temperature in and out of nonregenerative heat exchanger

(6) $\mathrm{pH}$, conductivity, total solids, and concentrations of chlorine, lithium, hydrogen, and oxygen

(7) Boric acid concentration (from beginning to end of core life)

(8) Level in volume control tank

f. Chemical addition systems

g. Makeup, fill, and drain systems

h. Emergency cooling systems

i. Temperature control systems

j. Poison injection systems, safety injection systems, accumulators, and/or liquid control systems

k. Steam systems

2. Secondary coolant systems

a. Cooling tower capacity

b. C1rculation pumps

c. Chemical addition oyotemo

d. Emergency cooling systems

e. Temperature control system

3. Storage (pool coolant system)

a. Overflow and surge tanks

b. Heat exchangers

c. Filters, deaerators, and demineralizer

d. Makeup, fill, and drain systems

e. Temperature control systems 
B. Causes of changes in parametric values (for each of the above items)

C. Effects of changes in parametric values (for each of the above items)

1. In regard to component

2. In regard to overall system

Sample Study Questions

1. List the monitored and calculated parameters of (1) the reactor primary water system (include the cleanup system), (2) the pool primary water system, (3) the reactor secondary water system, and (4) the pool secondary water system; include the normal operating values, their limiting values, and the reason for such limits.

2. In the event of a 30-min electrical power failure, show as a function of time the effect on (1) the reactor power level, (2) the reactor primary coolant flow rate, (3) the pressure, (4) the steam turbine, and (5) the generator. Discuss the sequence of events when such a failure occurs (in regard to the automaticstart features of emergency equipment).

3. Describe the routine testing requirements of all standby emergency equipment (e.g., pony motors, pressurizer systems, diesel-driven generators, poison injection system).

4. Describe the effect on the reactor inlet-water temperature in the event of (1) a failure of one or all of the primary water pumps, (2) a failure of the pressurizer pumps, and (3) an increase in speed of the steam-driven generator.

5. List three different pipe diameters in the reactor primary water system, and discuss the reason for the magnitudes and variations.

6. List all chemicals added to the reactor water systems and the reason for such additions. List the normal concentrations and the limiting values for each chemical. How do extremes in the concentrations of each affect the system? 
7. List the radioactive gases removed by the deaerators and steamgenerator blowdowns. List the radioactive ions removed by the cation and anion demineralizer columns. List the half-life and method of production of each of the above radioactive nuclides.

8. Describe the sequence of events that would occur if the reactor vessel's exit-cooling line ruptured.

9. How would the operating crew become aware of a primary-to-secondary water leak in the heat exchangers? What are the consequences of such a leak? What action should be taken?

10. Describe the steam separators and driers. What are their functions?

11. What is the purpose of the "jet-pumps"?

12. What is the core-coolant flow rate in both gpm and $1 \mathrm{~b} / \mathrm{hr}$ ?

13. Describe the conditions and/or setpoints that will actuate the emergency cooling systems.

\section{References}

1. Vendor's literature.

2. Design reports.

3. Procedures manuals.

4. Safety analysis reports.

Less on Plan No. 4. Reactor Instrumentation and Control

\section{Ubjéctive}

This lesson should familiarize the student with the behavior of those parameters associated with the various nuclear and process instrument channels used for reactor startup and power operation. Control room readouts and annunciator alarm and action setpoints should be 
taught so that the student may learn to evaluate a particular condition when one or more annunciator alarms are initiated from any of the various systems. The parametric setpoints and/or conditions at which all standby and/or emergency equipment is actuated should be thoroughly learned by the student.

\section{Plan Outline}

A. Parameters (types, normal magnitudes, limiting values, and reason for limits) associated with

1. Shim and control-rod drives (position and condition indicator)

2. Reactor-startup channels

3. Intermediate-range channels

4. Power-operation channels

5. Safety system (scram and rod insertion parameters)

6. Control system [power reduction (setback) parameters]

7. Radiation (monitoring equipment)

a. Reactor systems (cooling, liquid waste, off-gas systems)

b. Building

c. Personne1

8. Coolant-monitoring equipment ( $\mathrm{pH}$, resistivity, chromate, calcium, and radionuclides)

9. Automatic-start features of standby and/or emergency equipment

10. Temperature, pressure, and flow control systems

B. Causes of changes in parametric values (for each of the above items )

C. Effects of changes in parametric values (for each of the above items )

1. In regard to component

2. In regard Lu uverall system

\section{Sample Study Questions}

1. From the standpoint of instrument readouts, describe reactor startup after a refueling and after the dropping of one or more control rods. Which instrument readouts are of prime importance? 
2. Discuss the methods by which the reactor safety and control systems accomplish their corrective action.

3. Discuss the reasons for the specific scrams, reverses, and setbacks; list setpoints. Discuss the procedures for returning the reactor to full power after a shutdown initiated by each of the above control actions.

4. Discuss the effect of a loss of instrument air on the (1) reactor heat power, (2) nuclear instrumentation, and (3) pressure. What action should be taken by the operating crew?

5. Describe how components and/or channels in the safety system are tested to eneure reliability? What is the frequency of such tests?

6. Discuss the parameters of the startup and power-operation channels; list setpoints of alarm and control action.

7. Discuss the significance of (1) reset gain, (2) flux-to-flow ratio, and (3) reactivity change.

\section{$\underline{\text { References }}$}

1. Vendor's 11 cerature.

2. Design reports.

3. Prucedures manuals.

4. Safety analys1s reports,

Lesson Plan No. 5. Utilities

\section{Objecelve}

This lesson should familiarize the student with the behavior of those parameters associated with the process utilities at the reactor complex. The cause and effect of changes in normal parametric values should be emphasized. The student should learn the systems well enough to diagnose any deviations from normal operating conditions. 
$\underline{\text { Plan Outline }}$

A. Parameters (types, normal magnitudes, limiting values, and reason for limits) associated with

1. Electrical systems
a. Normal power
b. Emergency power
c. Instrument power
d. Failure-free (battery-operated)

2. Water systems
a. Potable water
b. Process water
c. Demineralized water
d. Fire sprinkler

3. Process steam systems

4. Instrument air system

5. Alarm and annunciation systems

a. Building and plant public address

b. Area fire alarm

c. Evacuation alarms

d. Area intercommunications

B. Causes of changes in parametric values (for each of the above items)

C. Effects of changes in parametric values (for each of the above items)

1. In regard to component

2. In regard to overall system

\section{Sample Study Questions}

1. Draw a schematic diagram of the instrument air distribution system, and show normal operating pressures indicated at the various subsystems. Describe the effect on the reactor readouts in the control room when an operating air compressor fails. 
2. Draw a schematic diagram of the potable water distribution system, and show normal flow rates of the various subsystems.

3. Draw a schematic diagram of the process steam distribution system, and show normal pressures indicated at the various subsystems .

4. Discuss the function of the various electrical systems, and list the sequence of events when there is a loss in the normal source of electrical power to each.

5. Describe any automatic action that results when a fire alarm at the reactor complex is sounded.

\section{$\underline{\text { References }}$}

1. Vendor's literature.

2. Design reports.

3. Procedures manuals.

4. Safety analysis reports.

Lesson Plan No. h. Waste Systems

\section{Objective}

This lesson should familiarize the student with the special significance of handling and disposing of waste materials generated at the reactor facility (as compared with a nonnuclear industry) and the responsibility the licensor has to the NRC in regard to limiting wastes discharged to the environment. The limiting radiation levels, etc., of all waste materials and the efficiency requirements of stack filters, action setpoints, effects on reactor operation, etc., should be emphasized. 
Plan Outline

A. Parameters (types, normal magnitudes, limiting values, and reason for limits) associated with

1. Gaseous waste disposal systems
a. Building ventilation containment
b. Experiment and other off-gas
c. Filtering (efficiency checks)
d. Holdup
e. Containment inerting
f. Containment spray
g. Standby gas treatment (recombiners)
h. Condenser, air ejector
i. Radiation monitoring

2. Liquid waste disposal systems
a. Categories (radiation levels, types of wastes, etc.)
b. Holdup or retention (equipment, sampling, etc.)
c. Subsystems (treatment and release)
d. Radiation monitoring

3. Solid waste disposal systems

a. Categories (radiation levels, types of wastes, etc.)

b. Storage

c. Compacting

d. Shipping container

e. Burial

f. Radiation monitoring

B. Causes of changes in parametric values (for each of the above items)

C. Effects of changes in parametric values (for each of the above items)

1. In regard to component

2. In regard to overall system 
Sample Study Questions

1. What is the importance of building containment? List the setpoints of any alarms and/or control actions that occur if the exhaust fans that control the negative pressures fail. What are the normal negative pressures in the various areas throughout the reactor complex?

2. Draw a schematic diagram of the process liquid waste system. List the normal flow rates and radiation levels of fluids discharged into the system for each contributing subsystem. List any automatic control action and discuss lie reasuin fór such action.

3. Draw a schematic diagram of the gaseous waste disposal systems. List the normal flow rates and radiation levels of fluids discharging into the systems for each contributing subsystem. List any automatic control action and discuss the reason for such action.

4. Discuss the various types of filters used in the off-gas systems. List their required particle removal and/or iodine retention efficiencies and their normal values. Describe the efficiency tests. How often are such tests performed? What materials are removed by each filter?

5. List the radiation and contamination limits for shipping carriers. How are these carriers decontaminated? What radionuclides are usually encountered in the cleaning process?

\section{References}

1. Vendor's literature.

2. Design reports.

3. Procedures manuals.

4. Safety analysis reports. 
Lesson Plan No. 7. Turbines and Generators

\section{Objective}

The objective of this lesson plan is to familiarize the student with the behavior of those parameters associated with the steam-producing equipment, steam-driven turbines, and turbine-driven generators. The cause and effect of changes in normal parametric values should be emphasized. By the time the student completes this section, he should be relatively familiar with the entire plant complex, and he should be familiar with control room instrumentation and other readouts to the extent that, when given an abnormal set of conditions, he can diagnose the cause and initiate the appropriate corrective action.

\section{Plan Outline}

A. Parameters (types, normal magnitudes, limiting values, and reason for limits) associated with

1. Steam generators

a. Boiling-water reactors

(1) Steam production and flow

(2) Separators and driers

(3) Flow paths to the steam-driven turbine

(4) Auxiliary and pumping systems

(5) Pressure control

(6) Reactor control

(7) Safety systems

(8) Radiation-monitoring systems

b. Pressurized-water reactors

(1) Steam production and flow in the steam generator

(2) Separators and driers

(3) Pressurizer systems

(4) Auxiliary and pumping systems 

(5) Pressure control
(6) Reactor control
(7) Safety systems
(8) Radiation monitoring systems

2. Steam-driven turbines
a. Shaft (speed, thrust, vibration, eccentricity, position, and load)
b. Reactor control
c. Inlet steam (flow paths, flow rates, and pressures)
d. Condenser vacuum
e. Exhaust pressures
f. Reheat systems (preheaters, superheaters, etc.)
g. Lubrication systems
h. Cooling systems
i. Condensing systems
f. Feedwater systems
k. Economizers
1. Reliability and/or performance tests
m. Efficiency ratings
n. Critical and normal speeds
o. Metal temperatures and rate of change
$\mathrm{p}$ : Shell and differentlal expansion
q. Generator excitation
r. Turning gear
s. Low load operation
t. Turbine irlys
u. Radiation monitoring systems
v. Control system
w. Safely devices

3. Iurbine-driven generaturs
a. Ratings
b. Rotor (speed, vibration)
c. Load
d. Excitation system 
e. Voltage, current, and frequency output

f. Lubrication systems

g. Cooling systems

h. Reliability and/or performance tests

i. Efficiency ratings

j. Leaving loss

k. Load rejections

1. Control systems

m. Safety devices

4. Electrical power transmission

a. Transformers, switchgears, circuit breakers

b. Voltage control

c. Protective-relay systems

d. Systems control

e. Transmission systems

f. Subtransmission systems

g. Distribution systems

h. Power for auxiliary systems

i. Safety devices

j. Stability

B. Causes of changes in parametric values (for each of the above items)

C. Effects of changes in parametric values (for each of the above items)

1. In regard to component

2. In regard to overall system

Sample Study Questions

1. Explain how a change in the load on the turbine effects a change in the reactor power level. Include parametric values in your discussion.

2. Discuss the possible consequences of a failure in the pressurizers and/or steam generators. What corrective action should be taken? 
3. Describe the startup and shutdown procedures for the steamdriven turbine. Discuss any special precautions applicable to a startup that was preceded by an emergency shutdown. Include parametric values in your discussion.

4. List the conditions for which the operator should manually shut down the turbine. List the conditions for which the turbine is automatically shut down.

5. What are the conditions that will result in the bowing of the shaft? How are these conditions avoided? Include parametric values in your discussion.

6. What may be the result of "foaming" of the lubricating oil?

7. Describe the startup and shutdown procedures for the turbinedriven generator. Discuss any special precautions applicable to a startup that was preceded by an emergency shutdown. Include parametric values in your discussion.

8. What condition develops when there is an over-saturation of generator components with high magnetic flux? How is this condition detected and avoided? What do saturation curves show?

9. During a planned shutdown, is the excitation current for the gencrator 1cft on or turned of $I$ ? Why? Should the generator casing be closed or left open during a prolonged shutdown? Why?

10. What precautions must be taken when filling and/or purging the gonorator with hydrogen?

11. With a potential difference of __ volts across the primary windings of a power transformer, it carries a current of amperes. What is the voltage across the secondary windings when there is a current of amperes drawn from it? (Assume a transformer efficiency of $93 \%$, and use values in the blanks typlcal of this facility's power output.)

12. Complete Table VIII-1 (for the turbine-driven generator).

\section{$\underline{\text { References }}$}

1. Vendor's literature.

2. Design reports.

3. Procedures manuals

4. Safety analysis reports. 
Table VIII-1

\begin{tabular}{|c|c|c|c|}
\hline Sondition & $\begin{array}{l}\text { Instruments that } \\
\text { indicate condition }\end{array}$ & $\begin{array}{l}\text { Consequences of } \\
\text { abnormal condition }\end{array}$ & $\begin{array}{l}\text { Corrective } \\
\text { action }\end{array}$ \\
\hline a. Overload & & & \\
\hline b. High vibration & & & \\
\hline c. Loss of excitation & & & \\
\hline d. Abnormal frequency & & & \\
\hline e. Overvoltage & & & \\
\hline f. Unbalanced current & & & \\
\hline g. Overcurrent & & & \\
\hline h. Differential current & & & \\
\hline i. Stator-winding ground & & & \\
\hline j. Field-winding ground & & & \\
\hline k. Reverse power & & & \\
\hline 1. Field-winding high temp. & & & \\
\hline m. Stator-winding high temp. & & & \\
\hline n. Loss of bearing oil & & & \\
\hline
\end{tabular}


Lesson Plan No. 8. Operational Safety

\section{Objective}

Operational safety is covered in greater depth in another chapter; however, its importance warrants reiteration. This lesson should further indoctrinate the student with the relationship between safety and the operating characteristics of a nuclear facility. In essence, this section serves as a review of certain systems to emphasize their safety parameters and emphasizes those items checked by review and/or safety committees.

$\underline{\text { rlan OutLine }}$

A. License requirements by the NRC prior to construction and/or operation of the reactor

B. Engineered safeguards

1. Control and safety systems

a. Redundancy in systems and/or instrumentation

b. Poison injection systems

2. Emergency systems

a. Diesel-operated electric generator and electrical distribution system

b. Battery-operated equipment

3. Building containment

4. Stack filtering systems

5. Shielding

C. Radiation and contamination monitoring

1. Health physics

2. Gaseous waste

3. Liquid waste

4. Solid waste

D. Review committees

E. Cont1nuous-type training programs for operating personnel 
F. Internal and external distribution of literature on operational experiences

G. Plant and/or building evacuation criteria (limits, procedures, drills, etc.)

\section{Sample Study Questions}

1. Discuss the safety precautions taken during a reactor startup and a reactor shutdown.

2. Discuss administrative safety procedures.

3. What are the tenth-value layers for water, lead, and concrete? How much of each of these shielding materials is required to shield a fuel element (assume $6 \times 10^{6} \mathrm{R} / \mathrm{hr}$ )?

4. List the job title of those individuals required to approve personnel working in radiation zones. List the radiation levels for each approval criterion. What are the normal radiation doses received by reactor operating personnel each year?

5. Discuss the various inspections that a reactor operating crew is subjected to (e.g., internal and external review committees, training and testing programs).

6. (a) What subjects are covered in the contractual agreement with the NRC that permit operation of this reactor? (b) Discuss the items that are generally studied by the experiment review committee. What are the reasons for such studies? (c) Discuss the items that are generally studied by the reactor safety review committee. What are the reasons for such studies?

7. Discuss the precautions that must be taken when loading a carrier over a storage pool. What are the reasons for such precautions? Describe the action that the operating crew should take in the event of a fuel meltdown.

8. Describe a core refueling in detail, and discuss the safety precautions applicable for each step. List a few human errors that might be made by an operating crew and the consequences of each error. 
9. Discuss the precautions taken at this reactor facility (either design or administrative) to minimize, if not eliminate, industrial pollution of the surrounding area.

\section{$\underline{\text { References }}$}

1. Vendor's 1iteraure.

2. Design reports.

3. Procedures manuals.

4. Safety analysis reports. 
SECTION IX. FEATURES OF FACILITY DES.IGN

Contents

Introduction . . . . . . . . . . . . . . . . . . 123

Lesson Plan No. 1. Reactor Site. . . . . . . . . . . . 124

Lesson Plan No. 2. Buildings . . . . . . . . . . . . 125

Lesson Plan No. 3. Reactor Vessel and Core Components . . . . . 127

Lesson Plan No. 4. Reactor Cooling Systems . . . . . . . . . . 129

Lesson Plan No. 5. Reactor Instrumentation and Control . . . . 132

Lesson Plan No. 6. Utilities . . . . . . . . . . . . . . 134

Lesson Plan No. 7. Waste Systems . . . . . . . . . . . 136

Lesson Plan No. 8. Turbines and Generators . . . . . . . . . . 137

Lesson Plan No. 9. Operational Safety . . . . . . . . . . . . 141

Introduction

The primary objective of this section is to acquaint the student with the design features of the reactor, steam generators, steam-driven turbines, and turbine-driven generators.

When studying the topics listed in each less on plan, emphasis should be placed on (1) the functional requirements and safety features of the various systems, subsystems, and/or components; (2) the criteria used in determining the size, relative location, and materials of construction of various equipment; (3) the methods by which any control action is accomplished; and (4) the minimum and maximum values of monitored parameters .

Upon completion of this chapter, the student should have a basic understanding of the overall plant and equipment layout, and he should have a relatively good understanding of the design features of the facility.

Some subjects in this section are covered in greater depth in other sections (e.g., Instrumentation and Control, and Safety and Emergency 
Procedures). Section VIII (General Operating Characteristics) also deals with all the equipment in the reactor complex with the common objective of teaching the interrelationship of the various systems and subsystems; hence, the material in both sections is presented in much the same manner.

The instructor should give consideration to presenting this section before the section on operating characteristics (rather than in the order of section listings) since it may be more beneficial to familiarize the student initially with the design features of the various systems and, after a basic knowledge of the plant is obtained, to revlew all the systems and study their operaling characteristics.

Study questions, which are included for each lesson plan, reflect the depth of understanding of the material that the student should develop.

Lcooion Plan No, 1. Reactor Site

Objective

This lesson should familiarize the student with those criteria used to select an acceptable location for a reactor facility from the standpoint of engineering and economlc practicality and also from the stand= point of local environmental effects.

\section{Plan Uutline}

A. Location

B. Geophysical features (meteorology, temperature, precipitation, geology, hydrology, selsmology, atmospheric diffusion characteristics) 
C. Discharge of radioactive waste material to the environment 1. Liquid

2. Gaseous

3. Solid

D. Practicality of location for electrical power distribution

E. Environmental impact

1. Effect on local residence

2. Effect on general area

Sample Study Questions

1. Discuss the factors considered in the selection of this particular area for this reactor complex.

2. Why are environmental impact studies so important? Discuss such studies made at this facility.

3. Discuss the requirements for discharging radioactive waste materials to the environment. How does this facility conform to such requirements? Who ensures that these requirements are acknowledged?

\section{$\underline{\text { References }}$}

1. Vendor's literature.

2. Design reports.

3. Procedures manuals.

4. Safety analysis reports.

Lesson Plan No. 2. Buildings

\section{Objective}

This lesson should familiarize the student with the functional layout of the reactor buildings. Emphasis should be placed on the 
ventilation, air-conditioning, and off-gas systems. After completing the lesson, the student should be able to draw schematic diagrams of these systems and be familiar with the containment criteria.

\section{$\underline{\text { Plan Outline }}$}

A. Reactor building

1. Size, construction materials, relative location

2. Equipment location

3. Containment criteria

4. Ventilabion, air-cundiliuning, and off-gas systems

a. Filtering equipment (efficiency requirements)

b. Stack monitoring requirements

B. Turbine and generator buildings

1. Size, construction, relative location, floor loadings

2. Equipment location

3. Containment criteria

4. Ventilation, air-conditioning, and off-gas systems

a. Filtering equipment (efficiency requirements)

b. Stack monitoring requirements

C. Auxiliary buildings (electrical, pump, chemical storage, and office buildings and cooling towers)

1. Size, construction, relative location

2. Equipment location

3. Containment criteria

4. Ventilation, air-conditioning, and off-gas systems

a. Filtering cquipment (efficicncy requirements)

b. Stack monitoring requirements

\section{Sample Study Questions}

1. Describe the buildings at this reactor complex, and discuss the location of various equipment in each building. 
2. Draw a schematic diagram of the off-gas systems. What relationship do they have with the ventilation and airconditioning systems? List any automatic action that is taken if an exhaust fan fails.

3. Discuss the filtering equipment for the stack. What materials are filtered? What are the efficiency requirements of the filters?

4. Discuss the radiation monitoring equipment for the off-gas systems.

5. Discuss the containment criteria. What are the negative pressures in each section of the reactor building? Discuss any control action to be taken if containment is not maintained.

\section{$\underline{\text { References }}$}

1. Vendor's literature.

2. Design reports.

3. Procedures manuals.

4. Safety analysis reports.

Lesson Plan No. 3. Reactor Vessel and Core Components

\section{Objective}

Th1s lesson should familiarize the student with functional descriptions of the reactor vessel and the core components. Emphasis should be placed on how the various components are designed so that replacement and/or maintenance can be accomplished. The student should become thoroughly familiar with the techniques and tools used for refueling the reactor and for performing other in-vessel tasks. 
$\underline{\text { Plan Outline }}$

A. Reactor vesse1

1. Materials of construction

2. Dimensions of vessel, posts, etc.

3. Pressure, temperature, and flow requirements

4. Shielding

5. Installation and inspection

6. Instrumentation

7. Filters and/or strainers

8. Acléssibilily of cure

9. Experiment facilities

10. Maintenance (provisions for)

11. Safety devices (rupture disc, vents, etc.)

12. Special tools for removal

B. Core components

1. Fuel elements (materials, dimensions, enrichments, poisons, etc.)

2. Control rods

3. Reflector assembiy

4. Special tools for removal

Sample Study Questions

1. Describe the reactor vessel (include dimensions, the location of any instrumentation, and the designed safety features). What are the limiting values of preseure, temperature, and flow rate? What control action ensures that these parameters are maintained within safe limits?

2. Describe the fuel elements. What are the tolerances on cladding dimensions? What are the tolerances on fuel content and distribution in each fuel plate? What are the cooling requirements?

3. Describe the control rods. What functional and/or performance tests are the rods subjected to? What parameters are monitored during such tests? List their normal and limiting values. 
4. Describe the reflector assembly. What are the cooling requirements and/or temperature limitations for the reflector?

5. Describe the step-by-step procedure for a refueling operation (i.e., list the order in which the various core components must be removed).

\section{References}

1. Vendor's literature.

2. Design reports.

3. Procedures manuals.

4. Safety analysis reports.

Lesson Plan No. 4. Reactor Cooling Systems

\section{Objective}

This lesson should familiarize the student with functional descriptions of the various components of the reactor cooling system. Emphasis should be placed on safety and/or control devices, design limits and actual values for pressure, temperature, flow, and other parameters. After completing this lesson, the student should be able to draw schematic diagrams of the main and auxiliary cooling loops showing details of sensor locations, control valve locations, and the location of any special equipment.

\section{Plan Outline}

A. Primary coolant system

1. Reactor vessel
a. Flow distribution methods for core components
b. Pressure 
2. Heat exchangers
a. Capacity
b. Maintenance (provisions for)

3. Pumps (recirculation, pressurizer, and feedwater)
a. Lubrication systems
b. Pumping capacity
c. Emergency power supplies
d. Control systems
e. Setpoints and safety features
f. Spray flow
g. Stean separalion and driers. ... . . .
h. Safety devices (rupture discs, vents, etc.)

4. Purification and volume control systems

a. Filters, deaerators, demineralizers

b. Letdown and/or cleanup flows

C. Surge and/or overflow tanks

d. Systems for analysis and/or control of $\mathrm{pH}$, conductivity, $\mathrm{Cl}, \mathrm{Li}, \mathrm{H}_{2}, \mathrm{O}_{2}$, and/or boric acid

5. Chemical addition systems

6. Makeup, fill, and drain systems

7. Emergency cooling systems

8. Temperature control systems

9. Poison injection systems, safety injectinn systems, accumulators, and/or liquid control systems

10. Process steam systems

11. Types and locations of sensing elements

B. Secondary coolant systems

1. Heat exchangers

2. Coullng towers

3. Circulation pumps

4. Chemical addition systems

5. Emergency cooling systems

6. Temperature control systems

7. Types and location of sensing elements

8. Safety devices (rupture discs, vents, etc.) 
C. Storage (pool coolant system)

1. Overflow and surge tanks

2. Heat exchangers

3. Filters, deaerators, and demineralizer

4. Temperature control systems

5. Types and location of sensing elements

\section{Sample Study Questions}

1. Draw a schematic diagram of the primary water system, and include the location of all sensing elements. List the normal coolant flow rates through various sections in the core and through each heat exchanger.

2. Draw a schematic diagram of the secondary water system, and include the location of all sensing elements.

3. Discuss the temperature control system, the pressure control system, and the flow control system. List normal operating values and those limiting values at which some control action occurs.

4. Discuss the effect on the cooling system when there is an electrical power failure. What are the emergency cooling requirements for the core? Describe the emergency cooling equipment and list the setpoints and/or conditions at which the equipment is energized.

5. Discuss the control action that occurs when there is (1) a failure of one or all of the primary water pumps; (2) a failure of the pressurizer pumps; and (3) an increase in the speed of the steamdriven generator.

6. Why are some of the pipe diameters in the primary water system the size they are? Give three pipe diameters and explain the reas on for the sizes.

7. Explain the reason why various chemicals are added to the water systems. Draw a schematic diagram showing this type of auxiliary system, and list the setpoints at which some automatic control action occurs. 
8. What design features were incorporated into the cooling system to combat the consequences of a major rupture in the exit cooling line from the core?

9. What design features were incorporated into the cooling system to remove radioactive materials? Describe how each radionuclide is produced and removed; to what waste system is each discharged?

\section{References}

1. Vendor's literature.

2. Design reports.

3. Procedures manuals.

4. Safety analysis reports.

Lesson Plan No. 5. Reactor Instrumentation and Control

\section{objective}

This lesson should familiarize the student with the instrumentation used in the nuclear and process systems to ensure safe operation. Emphasis should be placed on the various types of instrument channels used for startup and full-power operation of the reactor, the methods of pressure, temperature, and flow control, and any auxiliary systems that are automatically energized if certain parameters are exceeded.

\section{$\underline{\text { Plan Outline }}$}

A. Shim and control rod drives

B. Instrument channels

1. Types and location of chambers

2. For reactor startup

3. For power operation 
C. Safety system

1. Performance criteria (for normal operation and fast excursion)

2. Scram and rod insertion parameters

D. Control system

1. Performance criteria

2. Power reduction (setback) parameters

E. Radiation monitoring equipment

1. Reactor systems. (cooling, liquid waste, off-gas, etc.)

2. Building

3. Personne1

F. Coolant-monitoring equipment ( $\mathrm{pH}$, resistivity, chromate, calcium, and radionuclides)

G. Automatic-start features of standby and/or emergency equipment

H. Temperature control systems

I. Pressure control systems

J. Flow contro1 systems

\section{Sample Study Questions}

1. List the normal (1) flux and/or power level, (2) inlet water temperature, (3) differential temperature, (4) pressure and flow rate, and (5) radiation level of the core's exit water; for each, describe the control systems which ensure that these levels are maintained, and discuss the action that occurs when there is a deviation from the normal values.

2. Discuss the mechanism by which setbacks, reverses, and scrams are effected. List the setpoints for each control action.

3. What safety features are incorporated in the instrumentation to ensure reliable readouts if there is an electrical power failure and/or loss of Instrument dit?

4. Discuss the instrument readouts in the reactor startup channels and the full-power channels. What is the significance of each readout?

5. Discuss all automatic-start features of standby and/or auxiliary systems. List their action setpoints. 


\section{$\underline{\text { References }}$}

1. Vendor's literature.

2. Design reports.

3. Operating procedures.

4. Safety analysis reports.

\section{Lesson Plan No. 6. Utilities}

\section{Objective}

This lesson should familiarize the student with the general layout of the various electrical, water, steam, and air systems used at the reactor complex. After completing the lesson, the student should be able to draw schematic diagrams of the various systems showing the location of main breakers and main control valves.

\section{Plan Outline}

A. Electrical systems

1. Normal puwer

2. Emergency power

3. Instrument power

4. Battery-operated

B. Water systems

1. Potablc water

2. Hrocess water

3. Demineralizer water

4. Fire sprinkler

C. Process steam system

D. Instrument afr systems 
E. Alarm and annunciator systems

1. Building and plant public address

2. Area fire alarm

3. Evacuation alarms

4. Area intercommunication

Sample Study Questions

1. Draw a schematic diagram of the potable water system, and show the equipment serviced by this system. List the setpoints at which any control action occurs. Repeat the same for the process water system and the demineralized water system.

2. Draw a schematic diagram of the process steam system, and show the equipment serviced by this system. List the setpoints at which any control action occurs.

3. Draw a schematic diagram of the air supply system, and show the equipment serviced by this system. List the setpoints at which any contro1 action occurs.

4. Discuss the various electrical systems. Discuss the safety features incorporated in the electrical system to ensure that certain systems remain in operation when there is a failure in the main incoming lines. List any action setpoints and the sequence of events when such a failure occurs.

\section{$\underline{\text { References }}$}

1. Vendor's 1iterature.

2. Design reports.

3. Procedures manuals.

4. Safety analysis reports. 


\section{Objective}

This lesson should familiarize the student with the overall plan to categorize, process, and dispose of waste material. Emphasis should be placed on monitoring systems, efficiency requirements of the filtering. systems, and any automatic action that occurs if any radiation and/or contamination level exceeds specified safety limits. After completing the lesson, the student should be able to draw schematic diagrams of the various systems and explain which reactor and/or steam-producing system is serviced by the various waste systems.

\section{Plan Outline}

A. Gaseous waste disposal systems

1. Building ventilation containment

2. Experiment and other off-gas

3. Filtering

4. Holdup

5. Containment inerting

6. Containment spray

7. Standby gas treatment (recombiners)

8. Condenser, air ejector

9. Radiation monitoring

B. Liquid waste disposal systems

1. Holdup and/or retention equipment

2. Subsystems (treatment and release)

3. Radiation monitoring

C. Solid waste disposal

1. Storage

2. Compacting

3. Burial

4. Shipping

5. Radiation monitoring 
Sample Study Questions

1. Draw a schematic diagram of the process liquid waste system, and show the equipment serviced by this system. List the setpoints at which any control action occurs.

2. Draw a schematic diagram of the gaseous waste disposal system, and show the equipment serviced by this system. List the setpoint at which any control action occurs. Discuss the function of the various types of filter used in the systems, and list their particle removal and/or iodine retention efficiencies.

3. Discuss the safety features incorporated in the waste disposal systems to ensure that the surrounding area is not contaminated with radioactive waste materials.

4. Discuss the facilities used for decontaminating equipment. What are the radiation and contamination limits for shipping carriers?

\section{$\underline{\text { References }}$}

1. Vendor's literature.

2. Design reports.

3. Procedures manuals.

4. Safety analysis reports.

Lesson Plan No. 8. Turbines and Generators

\section{Objective}

This lesson should familiarize the student with design features of the steam-producing equipment, the steam-driven turbines, and the turbinedriven generators. Emphasis should be placed on the function of the various auxiliary systems, the design and/or safety limits, and the actual values for pressure, temperatures, rotor speeds, and other parameters. 
After completing the lesson, the student should be able to draw schematic diagrams of the various systems and be familiar with the control instrumentation.

\section{$\underline{\text { Plan Outline }}$}

A. Steam generators

1. Boiling-water reactors
a. Steam production and flow
b. Separators and driers
c. Flow paths to the steam-driven firbine
d. Auxiliary and pumping systems
e. Pressure control
f. Reactor control
g. Safety systems
h. Radiation monitoring systems

2. Pressurized-water reactors

a. Steam production and flow in the steam generator

b. Separators and driers

c. Pressurizer systems

d. Auxiliary and pumping systems

e. Pressure control

f. Reactor control

g. Safety systems

h. Radiation monitoring systems

B. Steam-driven turbines

1. Shaft (speèd, thrust, vibration, eccentrlc1ty, posttion, and load)

2. Reactor control

3. Inlet steam (flow paths, flow rates, and pressures)

4. Condenser vacuum

5. Exhaust pressures

6. Reheat systems (preheaters, superheater, etc.)

7. Lubrication systems 
8. Cooling systems

9. Condensing systems

10. Feedwater systems

11. Economizers

12. Reliability and/or performance tests

13. Efficiency ratings

14. Critical and normal speeds

15. Metal temperatures (and rate of change)

16. Shell and differential expansion

17. Generator excitation

18. Turning gear

19. Low load operation

20. Turbine trips

21. Radiation monitoring systems

22. Control system

23. Safety devices

C. Turbine-driven generators

1. Ratings

2. Rotor (speed, vibration

3. Load

4. Excitation system

5. Voltage, current, and frequency output

6. Lubrication systems

7. Cooling systems

8. Reliability and/or performance tests

9. Efficiency ratings

10. Leaving loss

11. Load rejections

12. Control system

13. Safety devices

D. Electrical power transmission

1. Transformers, switchgears, circuit breakers

2. Voltage control

3. Protective-relay systems

4. Systems control

5. Transmission systems 
6. Subtransmission systems

7. Distribution systems

8. Power for auxiliary systems

9. Safety devices

10. Stability

\section{Sample Study Questions}

1. Explain how a change in the load on the turbine effects a change in the reactor power level. Include parametric values in your discussion.

2. Discuss the engineered safeguards associated with the production of steam (e.g., rupture discs, radiation monitoring equipment). Include parametric values in your discussion.

3. Discuss any safety features incorporated in the design to combat the consequences of a failure in the pressurizer and/or steam generators.

4. Draw a schematic diagram of the steam-driven turbine showing the flow paths, normal flow rates, and normal steam pressures. Indicate the plus and minus values for varying load conditions. List the conditions for which the turbine is automatically or manually shut down.

5. Draw a schematic diagram of and/or discuss the cooling system and lubricating system for the turbine-driven generator. List the setpoints at which any control action occurs. What is the function of a synchroscope during the startup of the generator?

6. How is the electrical output of the turbine-driven generator controlled? Include parametric values in your discussion.

7. Discuss the safety features incorporated in the design of the turbine-driven generator (and/or instrumentation) to contro1 and/or correct (1) overload, (2) high vibration, (3) loss of excitation, (4) abnormal frequency, (5) overvoltage, (6) unbalanced current, (7) overcurrent, (8) differential current, (9) statorwinding ground, (10) field-winding ground, (11) reverse power, 
(12) field-winding high temperature, (13) stator-winding high temperature, (14) loss of bearing oil.

\section{$\underline{\text { References }}$}

1. Vendor's literature.

2. Design reports.

3. Procedures manuals.

4. Safety analysis reports.

Lesson Plan No. 9. Operational Safety

Objective

This lesson should indoctrinate the student with the safety requirements as they relate to instrumentation at a nuclear installation. Certain systems should be reviewed in detail to ensure complete comprehenston of the safety-oriented design features.

\section{Plan Outline}

A. License requirements by the NRC prior to construction and/or operation of the reactor

B. Englneered safeguards

1. Control and safety systems

a. Redundancy in systems and/or instrumentation

b. Poison injection and/or liquid control systems

2. Emergency systems

a. Diesel-operated electric generator and electrical distribution system

b. Battery-operated equipment 
3. Building containment

4. Stack filtering systems

5. Shielding

C. Radiation and contamination monitoring

1. Health physics

2. Gaseous waste

3. Liquid waste

4. Solid waste

Sample Study Questions

1. List three radioactive materials for each physical state (i.e., gaseous, liquid, and solid) that are of concern at this reactor facility. Describe how each of the nine materials are produced; 11st their half-lives; explain when they are encountered; and discuss how each is handled or disposed of.

2. Discuss the safety features incorporated in the design to combat the consequences of a ruptured fuel element. How is one to be removed from the reactor vessel?

3. Discuss the probable annual radiation exposure of the reactor operating s.rew.

4. Discuss the radiation monitoring of the various process systems. Include parametric values in your discussion.

5. Discuss the radiation monitoring of general working areas. Include parametric values in your discussion.

6. Discuss some safety hazards not associated with the nuclear aspects of this facilily. Whit safeguards àre incorporated in the design to combat each potential hazard?

\section{$\underline{\text { References }}$}

1. Vendor's literature.

2. Design reports.

3. Procedures manuals.

4. Safety analysis reports. 
SECTION X. SAFETY AND EMERGENCY SYSTEMS

\section{Contents}

Introduction . . . . . . . . . . . . . . . . . . 143

Lesson Plan No. 1. Engineered Safeguards (General) . . . . . . 144

Lesson Plan No. 2. Emergency Core-Cooling System (General) . . . 145

Lesson Plan No. 3. Containment System . . . . . . . . . . 147

Lesson Plan No. 4. Standby Liquid Control System . . . . . . . 148

Lesson Plan No. 5. Reactor Core Isolation Cooling System (BWR) . 150

Lesson Plan No. 6. Chemical and Volume Control System (PWR). . . 151

Lesson Plan No. 7. Core Spray System . . . . . . . . . . 153

Lesson Plan No. 8. Residual-Heat Removal System . . . . . . . 154

Lesson Plan No. 9. High-Pressure Coolant Injection System . • 157

Lesson Plan No. 10. Semiautomatic Blowdown System . . . . . . . 158

Lesson Plan No. 11. Emergency Electrical System . . . . . . . 160

Lesson Plan No. 12. Review of Safety and Emergency Systems . • 161

Lesson Plan No. 13. Examination .. . . . . . . . . . . 162

\section{Introduction}

This section deals with the design, operation, and interrelationships of the systems most directly associated with reactor safety. The reactor operator should become familiax with the conditions that require the use of these systems and why such systems are required.

The first two lesson plans are to give the student an overall view of engineered safeguards and emergency core-cooling systems. The specific functional requirements of any system discussed will depend on the reactor design, and no attempt has been made to consider every different design here. The inctructor should add, delete, or alter lesson plans to meet. the specific functional requirements of the particular systems under consideration. 
Lesson Plan No. 1. Engineered Safeguards (Genera1)

\section{Objective}

This lesson should present the student with engineered safeguards. The presentation to the student should be made in a general fashion to acquaint him with the overall subject.

\section{Plan Outline}

A. Introduetiun

1. Objectives of engineered safeguards

a. Design to preclude accidents

b. Location to restrict dispersal

c. Location to minimize exposure

2. Concepts of engineered safeguards
a. Operation
b. Functional requirements
c. Dependability

B. Specific systems

1. Containment
a. General deseription
b. Purpose

2. Core spray and safety injection
a. General description
b. Purpose

3. Containment spray oyotem

a. General description

b. Purpose

4. Atmosphere recirculation cooling and filtration
a. General description
b. Purpose 
Sample Study Questions

Since this is designed as a general discussion topic, there are no questions appearing in this lesson plan. Questions regarding specific systems appear in the appropriate lesson plan.

\section{References}

1. U.S. Nuclear Regulatory Commission, Standard Format and Content of Safety Analysis Reports for Nuclear Power Plants, U.S. NRC Regulatory Safety Guide 1.70 (rev. 2), September 1975.

2. Final safety analysis report.

3. Vendor's training material.

4. Procedures manuals.

5. Piping and instrument drawings.

6. Technical specifications.

Lesson P.1an No. 2. Emergency Core-Cooling System (Genera1)

\section{Objective}

This lesson should present the emergency core-cooling system. The presentation to the student should be made in a general fashion to better acquaint him with the overall picture of the subject.

Plan Outline

A. Functional performance requirements

1. Limit peak-clad temperatures

2. Limit clad temperature before geometry changes prohibit cooling of the core 
3. Restrict the maximum energy and oxide content of the total clad mass

4. Remove the core-stored energy

B. Design and fabrication requirements

1. General redundancy

2. Redundancy for repair and surveillance

3. Coolant delivery

4. Power

5. Isolation

6. Structural design

7. Eharing

8. General

C. Failure mode and reliability analysis

D. Control and instrumentation requirements

E. Testing requirements

1. Component proof test

2. Preoperational system tests

3. Periodic system tests

F. Evaluation guidelines

1. Emergency core-cooling definitions

2. Functional performance requirements

\section{Sample Study Questions}

Since this lesson plan is designed as a general discussion topic, there are no questions. Questions regarding specific systems appear in the appropriate lesson plan.

\section{References}

1. U.S. Nuclear Regulatory Commission, Standard Format and Content of Safety Analysis Reports for Nuclear Power Plants, U.S. NRC Regulatory Safety Guide 1.70 (rev. 2), September 1975.

2. Final safety analysis report. 
3. Vendor's training material.

4. Procedures manua.1.s.

5. Piping and inștrument drawings.

6. Technical specifications.

Lesson Plan No. 3. Containment System

\section{Objective}

This lesson should acquaint the student with the containment system as it exists for the particular reactor. The system was first introduced in Lesson Plan No. 1 in a general manner.

Plan Outline

A. Containment system structure

1. Design basis

2. Containment system structure design

B. Containment-isolation system

1. Penetrations

2. Isolation valves

3. Leakage monitoring system

C. Pressure-suppression system

1. General description

2. Equipment

3. Operation

D. Containment spray

1. General description

2. Equipment

3. Operation 
E. Containment inerting and ventilation system

1. General description

2. Equipment

3. Operation

F. Tests and inspections

1. Requirements

G. Procedures

(Procedures are covered in a separate section. It may be beneficial for the instructor to point out to the student the location of pertinent procedures in the procedures manual.)

\section{Sample Study Questions}

1. What is the basic reason for inerting the primary containment?

2. Describe how the primary containment limits the pressure resulting from the design basis loss-of-coolant accident.

3. List the signals which cause primary containment isolation and the resultant actions which take place.

\section{$\underline{\text { References }}$}

1. Final safety analysis report.

2. Vendor's training material.

3. İrocedures manual.

4. Piping and instrument drawings.

5. Technical specifications.

Lesson Plan No. 4. Standby Liquid Control System

Objective

This lesson should acquaint the student with a means of shutting down the reactor in an emergency situation. The title reflects the 
terminology often used for boiling-water reactors; another term often used is safety injection system.

Plan Outline

A. Description of the system

1. Functional requirements

2. Influence or dependence on other systems

B. Flow diagram of the system

1. Equipment location

2. Principle of operation

C. System design

1. Design parameters

2. Equipment characteristics

D. Procedures

1. Normal operating

2. Abnormal operating

3. Testing and reliability

(The procedures are discussed in a separate lesson plan. The instructor, if he wishes, can insert that lesson plan at this point for completeness or present the section later.)

E. Administrative

1. Safety analysis report

2. Technical specifications

\section{Sample Study Questions}

1. Draw a simple flow diagram of the standby liquid control system.

2. Why is it necessary to heat the sodium-pentaborate solution?

3. What are the technical specification limits concerning the boron concentration contained in the storage tank?

4. Describe the manner in which the standby liquid control system is tested? How often 1s this done? 


\section{References}

1. Final safety analysis report.

2. Vendor's training material.

3. Procedures manual.

4. Piping and instrument drawings.

5. Technical specifications.

Lesson Plan No. 5. Reactor Core Isolation Cooling System (BWR)

\section{Objective}

This lesson should acquaint the student with the reactor core 1solation cooling (RCIC) system.

\section{Plan Outline}

A. Description of the system

1. Functional requirements

2. Influence or dependence on other systems

B. Flow diagram of the system

1. Equipment location

2. Principle of operation

C. Syatem design

1. Design parameters

2. Equipment characteristics

3. Methods of actuation

D. Procedures

1. Normal operating

2. Abnormal operating

3. Testing and reliability

(The procedures are discussed in a separate lesson plan. The instructor, if he wishes, can insert that lesson plan at this point for completeness or present the section later.) 
E. Administrative

1. Safety analysis report

2. Technical specifications

\section{Sample Study Questions}

1. Draw a simple flow diagram of the RCIC system.

2. What is the primary purpose of the reactor core isolation cooling system, and how does it accomplish this objective?

3. How is operation of the RCIC system initiated?

4. What other systems are affected by or depend on the RCIC?

\section{$\underline{\text { References }}$}

1. Final safety analysis report.

2. Vendor's training material.

3. Procedures manual.

4. Piping and instrument drawings.

5. Technical specifications.

Lesson Plan No. 6. Chemical and Volume Control System (PWR)

\section{Objective}

This lesson should acquaint the student with the type of liquid control used to maintain the water at the correct volume and chemical composition.

\section{Plan Qutline}

A. Description of the system

1. Functional requirements

2. Influence or dependence on other systems 
B. Flow diagram of the system

1. Equipment location

2. Principle of operation

C. System design

1. Design parameters

2. Equipment characteristics

D. Procedures

1. Normal operating

2. Abnormal operating

3. Testing and reliability

(The procedures are discussed in a separate lessnn plan. The instructor has the option of inserting that lesson plan at this point for completeness or presenting the section later.)

E. Administrative

1. Safety analysis report

2. Technical specifications

\section{Sample Study Questions}

1. List the four functions of the chemical and volume control system.

2. Draw a flow diagram of the chemical and volume contrni system.

3. What are the technical specification limits conrerning pump malfunction?

\section{References}

1. Final safety analysis report.

2. Vendor's training material.

3. Procedures manual.

4. Plping and instrument drawings.

5. Technical spectfications. 
Lesson Plan No. 7. Core Spray System (BWR)

Objective

This lesson should acquaint the student with the core spray system.

$\underline{\text { Plan Outline }}$

A. Description of the system

1. Functional requirements

2. Influence or dependence on other systems

B. Flow diagram of the system

1. Equipment location

2. Principle of operation

C. System design

1. Design parameters

2. Equipment characteristics

3. Methods of actuation

D. Procedures

1. Normal operating

2. Abnormal operating

3. Testing and reliability

(The procedures are discussed in a separate section. The instructor has the option of inserting the pertinent lesson plan at this point for completeness or presenting the section later.)

E. Administrative

1. Safety analysis report

2. Technical specifications

Sample Study Questions

1. What conditions automatically initiate the core spray system?

2. Draw a simple flow diagram of the core spray system. 
3. What are the technical specification limits as to the operability of the core spray system?

4. What are the objectives of the core spray system?

\section{References}

1. Final safety analysis report.

2. Vendor's training material.

3. Procedures manual.

4. Piping and instrument drawings.

5. Technical specifications.

Lesson Plan No. 8. Residual-Heat Removal System

Objective

This lesson should acquaint the student with the multiple functions of the residual-heat removal system.

\section{$\underline{\text { Plan Out line }}$}

A. General description

1. Subsystems
a. Low-pressure coolant injection
b. Containment cooling
c. Shutdown cooling

2. Functional requirements

3. Influence or dependence on other systems

B. Low-pressure coolant injection subsystem

1. Flow diagram of the subsystem
a. Equipment location
b. Principle of operation 
2. Subsystem design
a. Design parameters
b. Equipment characteristics
c. Methods of actuation

3. Procedures
a. Normal operating
b. Abnormal operating
c. Testing and reliability
(The procedures are discussed in a separate lesson plan. The instructor has the option of inserting that lesson plan at this point for completeness or presenting the section later.)
4. Administrative
a. Safety analysis report
b. Technical specifications

C. Containment cooling subsystem

1. Flow diagram of the subsystem
a. Equipment location
b. Principle of operation

2. Subsystem design
a. Design parameters
b. Equipment characteristics
c. Methods of actuation

3. Procedures
a. Normal operating
b. Abnuriual operating
c. Testing and relliability
(The procedures are discussed in a separate section. The instructor has the option of inserting the pertinent lesson plan at this point for completeness or presenting the section later.)

4. Administrative
a. Safety analysis report
b. Technical specifications 
D. Shutdown cooling subsystem

1. Flow diagram of the subsystem

a. Equipment location

b. Principle of operation

2. Subsystem design

a. Design parameters

b. Equipment characteristics

3. Procedures

a. Normal operating

b. Ahnormal opernting,

(The procedures are discussed in a ecparatc ocction. The instructor has the option of inserting the pertinent lesson plan at this point for completeness or presenting the section later.)

4. Administrative

a. Safety analysis report

b. Technical specifications

E. Other subsystems

F. Combined system features

1. Equipment

a. Heat exchangers

b. Pumps

c. Other

2. Secondary system

3. Interlock.e

Sample Study Questions

1. What are the various functions of the reeidual-heat removal system? Which subsystems are provided for these various functions?

2. Which of the subsystems are actuated automatically, and what initiates the automatic actuation?

3. What are the technical specification limits concerning the operability of the ECC subsystems? 


\section{$\underline{\text { References }}$}

1. Final safety analysis report.

2. Vendor's training material.

3. Procedures manual.

4. P1ping and 1nstrument diagrams.

5. Technical specifications.

Lesson Plan No. 9. High-Pressure Coolant Injection System (BWR)

Objective

This lesson should acquaint the student with the high-pressure coolant injection (HPCI) system and its operation.

\section{Plan Outline}

A. Description of the system

1. Functional requirements

2. Influence or dependence on other systems

B. Flow diagram of the system

1. Equipment location

2. Principle of operation

C. System design

1. Design parameters

2. Equipment characteristics

3. Methods of actuation

D. Procedures

1. Normal operating

2. Abnormal operating

3. Testing and reliability 
(The procedures are discussed in a separate section. The instructor has the option of inserting the pertinent lesson plan at this point for completeness or presenting the section later.)

E. Administrative

1. Safety analysis report

2. Technical specifications

\section{Sample Study Questions}

1. What are the operational objectives of the HPCI system, and how are these objectives accomplished?

2. Draw a simple flow diagram of the HPCI system.

3. What conditions automatically initiate operation of the HPCI system?

4. What are the technical specification limits concerning operability of the HPCI system?

\section{$\underline{\text { References }}$}

1. Final safety analysis report.

2. Vendor's training material.

3. Procedures manual.

4. Piping and instrument diagrams.

5. Technical specifications.

Lusioul Plin No. 10. Scmlautomar1c Blowdown Syatem

\section{Objective}

This lesson should acquaint the student with the semiautomatic blowdown system and its operation. 
Plan Outline

A. Description of the system

1. Functional requirements

2. Influence or dependence on other systems

B. Flow diagram of the system

1. Equipment location

2. Principle of operation

C. System design

1. Design parameters

2. Equipment characteristics

3. Methods of actuation

D. Procedures

1. Normal operating

2. Abnormal operating

3. Testing and reliability

(The procedures are discussed in a separate lesson plan. The instructor has the option of inserting that lesson plan at this point for completeness or presenting the section later.)

E. Administrative

1. Safety analysis report

2. Technical specifications

Sample Study Questions

1. Draw a simple flow diagram of the semiautomatic blowdown system.

2. What conditions actuate the system?

3. What are the technical specification limits concerning operability of the system?

\section{References}

1. Final safety analysis report.

2. Vendor's training material.

3. Procedures manual.

4. Piping and instrument diagrams.

5. Technical specifications. 
Lesson Plan No. 11. Emergency Electrical System

\section{Objective}

This lesson should acquaint the student with the emergency electrical system.

Plan Outline

A. Electrical system design

1. Network interconnections
a. Single-line diagrams

b. Reliability

2. Station distribution

a. Single-line diagrams

b. Load distribution

B. Emergency power

1. Source of power
a. Equipment location
b. Performance

2. Procedures

a. Normal opcrating

b. Abnormal operating

c. Testing and reliability

(The procedures are discussed in a separate lesson plan.

The instructor has the option of insenting Llat lessun

plan at this point for completeness or presenting the section later.)

C. Administrative

1. Final safety analysis report

2. Technical specifications 
Sample Study Questions

1. Briefly describe the sources of emergency power available.

2. What are the technical specification limits concerning the availability of emergency power?

\section{$\underline{\text { References }}$}

1. Final safety analysis report.

2. Vendor's training material.

3. Procedures manual.

4. Electrical distribution diagrams.

5. Technical specifications.

Lesson Plan No. 12. Review of Safety and Emergency Systems

\section{Objective}

This lesson should review all safety and emergency systems throughout the plant. Emphasis should be placed on the influence or dependence on other systems. Technical specification limits and their relation to operability should be stressed. 
Lesson Plan No. 13. Examination

Objective

The trainee's retention and understanding of the concepts presented during this portion of the program should be tested.

Plan Outline

A. Two-hour examination

B. Typical questions as presented in the individual lesson plans 
SECTION XI. INSTRUMENTATION AND CONTROLS

\author{
Contents
}

Introduction . . . . . . . . . . . . . . . . . 164

Basic Section

Lesson Plan No. 1. Controlling Small Nuclear Reactors,

Part I . . . . . . . . . . . . . . . . . . . . 165

Lesson Plan No. 2. Controlling Small Nuclear Reactors,

Part II . . . . . . . . . . . . . . . . . . . 167

Lesson Plan No. 3. Unique Requirements of Power Reactors . . . 171

Lesson Plan No. 4. Counting Channels Including an Introduction to Nuclear Instrumentation . . . . . . . . . . . . . . 173

Lesson Plan No. 5. Intermediate and Power Range Channels . . . . 176

Lesson Plan No. 6. Other Nuclear Control Instrument

Channels . . . . . . . . . . . . . . . 179

Lesson Plan No. 7. Some Auxiliary Systems . . . . . . . . . . . 182

Lesson Plan No. 8. Introduction to Process

Instrumentation . . . . . . . . . . . . . . . . . . . 186

Lesson Plan No. 9. Temperature Instrumentation, Part I . . . . 189

Lesson Plan No. 10. Temperature Instrumentation, Part II . . . . 191

Lesson Plan No. 11. Pressure Instrumentation . . . . . . . . . . 194

Lesson Plan No. 12. Level Instrumentation . . . . . . . . . 197

Lesson Plan No. 13. Flow Instrumentation . . . . . . . . . . 200

Lesson Plan No. 14. Instrument Signal Transmission Systems . . . 203

Lesson Plan No. 15. $\mathrm{pH}$ and Conductivity Instrumentation . . . . 206

\title{
Practical Section
}

Lesson Plan No. 16. Principles, Philosophy, and Design Bases .. . . . . . . . . . . . . . . . . 207

Lesson Plan No. 17. Reactor Protection System . . . . . . . . 210

Lesson Plan No. 18. Engineered Safety Feature Actuation . . . . . 212

Lesson Plan No. 19. Reactor Control System . . . . . . . . . . 214

Lesson Plan No. 20. Supplementary Reactor Control System . . . 216

Lesson Plan No. 21. Control-Rod Drive Mechanism . . . . . . . . 217

Lesson Plan No. 22. Balance of Plant Systems . . . . . . . . . . 219 


\section{Introduction}

This section deals with the principles and hardware items found in typical nuclear reactor instrumentation. The intent is to provide the student with enough guidance to basic information to allow him to concentrate on understanding overall operation of instrumentation and control systems when these are encountered in the design and operations sections of the course.

The actual hardware and arrangements found in the instrumentation of a nuclear reactor or power plant will appear in many forms since each installation represents the preferences of the individual designer in meeting the specific and often unique requirements of the particular installation's systems as well as some of the preferences of the owner and, in general, the state-of-the-art. Fortunately, the student need acquaint himself only with the small number of basic principles included here to prepare himself for study of those systems.

Regardless of the complexity of the instrumentation found at nuclear reactors and power plants, they embody only a limited number of principles. The purpose of the material presented in this section is to acquaint the student with these principles and some typical hardware items embodying each of them. Systems, as such, are considered in other sections of the course, principally in design and operations.

- The instructor will, of course, adjust the emphasis on the various principles to suit the need of his students with respect to their particular future assignments and to their background. 
Lesson Plan No. 1. Controlling Small Nuclear Reactors, Part I

Objective

The student should become familiar with the overall requirements and makeup of the control and instrumentation systems of a small reactor and the principal parameters which require monitoring and control. He is expected to gain an understanding of the relative importance of the various parameters and to learn appropriate terms and names.

Furthermore, he should understand the function of the rod drives and the importance of knowing the position of the rods accurately and at all times.

Finally, he is expected to learn the principal purpose of the protection system and to begin to understand the difference between the requirements for the protection and control systems.

\section{Plan Outline}

A. Control

1. Purpose (control, orderly operation, etc.)

2. Reasons for making measurements

B. Range of control

1. Comparison with other control problems

2. Determinant of range of measurement

C. Parameters

1. F1ux

a. Rate

b. Power proportionality

c. Time constants

2. Temperature and flow

a. Temperature change

b. $\Delta t$ flow

c. Heat power

d. Time constant

e. Relationship between flux power and heat power

f. Necessity of fast response (use of flux calibrated to heat power) 
3. Position information (rods, valves, level, trolley, tools; direct and indirect)

D. Flow diagrams (with instrumentation)

1. Flow

2. Temperature

3. Coolant leve1

4. Pressure

5. Vibration

6. Flux

7. $\mathrm{pH}$

8. Conductivity

9. $\Delta t$

10. Radiation (1iquid and gas)

11. Rod position

12. Control system interconnections and various inputs including operator

E. Flux conditions

1. Shutdown level (source level)

2. Various stages of criticality

3. Control and delayed neutrons

4. Rate of changes of flux

F. Interactions of systems

1. Cold slugglng

2. Cooling and heat dumping systems

3. Pressure

Sample Study Questions

1. Give two requirements a reactor control system must meet.

2. From the standpoint of instrumentation and control, what is unusual about a nuclear reactor?

3. When are flux measurements important?

4. When is heat power information needed?

5. How is heat power determined?

6. Heat power information is used to calibrate what other instrumentation? 
7. Name two purposes of the control rods.

8. Name three nuclear instrument channels, and explain briefly the purpose of each.

9. In addition to power, what other information about flux is needed?

10. Why is it important for the control system and the operator to have continuous information of existing conditions within the reactor?

11. What measurements (nonnuclear) are necessary in the heat removal system?

12. Do control actions in one part of a system interact with or cause actions in another, or are the system actions usually quite independent of each other? Explain.

\section{$\underline{\text { References }}$}

See list of references for Lesson Plan No. 2.

Lesson Plan No. 2. Controlling Small Nuclear Reactors, Part II

\section{Objective}

The student should become familiar with the differences between the purposes of the control and protection systems. He should be made aware of the importance of avoiding unnecessary scrams and should gain an understanding of the effects of safe and unsafe equipment failures and learn how the protection systems are arranged to prevent scrams from such failures.

The student should understand that, in practice, sensors seldom can be placed in optimum locations, and he should understand the effect which position has on the information supplied by the instrumentation and on reactor operation. 
Plan Qutline

A. Reactor protection system

1. Purpose

2. Importance

3. Reliability

a. Need

b. Multiple-channel approach

c. Independence required of channels and system from control and hardware

B. Flux sensor locations

1. Requirements

a. Provision of needed information when required

b. Accessibility for sensor replacement

c. Suitable protection of sensor from physical damage

2. Problems of selecting suitable locations

a. Flux distribution and effects of changes in power level

b. Effects of rod position (shading)

c. Effects of burnup

d. Effects of experiments, beam holes, etc.

e. Environmental effects

f. Minimum transport delay

C. Other sensors (locatiuns)

1. Temperature

a. Time constant

b. Sensor-response delay selected to sult cond1tions

$\therefore$ Avuld transport delayo

d. Environmental effects

e. Physical damage

f. Accessibility for replacement

2. Flow sensors

a. Location

b. Environmental sensitivity

3. Pressure

a. Location

b. Environmental sensitivity 


\section{Sample Study Questions}

1. Briefly explain the purpose of the reactor control system and the reactor protection system.

2. Assuming the highest grade of equipment is being used to build a protection system, how may its reliability be further increased?

3. With respect to protection systems, what is meant by the following terms?
a. Trip
b. Scram
c. Safe failure
d. Unsafe failure
e. Coincidence

4. Explain briefly how a 2-of-3 coincidence protection system (a) tends to minimize the number of spurious scrams and (b) permits on-line testing and repair.

5. Give one reason for providing physical and electrical separation of individual protection system channels.

6. Give two requirements which should be met by an acceptable nuclear sensor installation.

7. A number of factors must be evaluated when selecting a location for installing a nuclear sensor; name two.

8. State two problems encountered when determining a suitable location for a temperature sensor.

9. Both nuclear and temperature instrumentation channels are needed as part of the protection system. State the unique purpose of each.

10. Explain briefly why the siting of pressure and flow sensors is appreciably less critical than that for nuclear and temperature channels. 
1. S. Glasstone, "Control of Nuclear Reactors," pp. 318-35 in Principles of Nuclear Reactor Engineering, D. Van Nostrand Co., Inc., Princeton, N.J., 1955.

2. S. Glasstone, "Design of Safety Systems," pp. 346-49 in Principles of Nuclear Reactor Engineering, D. Van Nostrand Co., Inc., Princeton, N.J., 1955.

3. T. E. Cole, "Design of a Control System for a Low-Cost Research Reactor," Nucleonics 11(2): 32-37 (1953).

4. S. H. Hanauer and C. S. Walker, Design Principles of Reactor Frotection systems, UKNL/NSLC-SL, Uak Kidge National Läboratóry, Oak Ridge, Tenn., September 1968.

5. A. E. G. Bales, Desuription and Operating Instruations for the LITR Reactor Control and Instmomentation Systems, ORNL/TM-1190, Oak Ridge National Laboratory, Oak Ridge, Tenn., July 1965.

6. L. C. Oakes, A Second Generation of Reactor Control Systems as Applied to the High Flux Isotope Reactor, ORNL/TM-1259, Oak Ridge National Laboratory, Oak Ridge, Tenn., September 1965.

7. M. A. Schultz, "Reactor Control Philosophies," Nucleonics 16(5): 62-65 (1958)

8. J. M. Harrer, Nuclear Reactor Control Engineering, pp. 8-31 and 8-34 through 8-39, D. Van Nostrand Co., Inc., Princeton, N.J., 1963.

9. C. S. Walker, "Criteria and Requirements for RDT Plant Protection Systems," Nucl. Safety 11(5) (1970).

10. D. M. Considine, ed., Sect. 14 in Handbook of Applied Instrumentation, McGraw-Hi11, New York, 1964. 
Lesson Plan No. 3. Unique Requirements of Power Reactors

\section{Objective}

The student is expected to become familiar with the unique features of power reactors which affect control and other instrumentation. Further, he should develop an understanding of how these features affect the selection and forms of the control and instrumentation logic and hardware.

\section{$\underline{\text { Plan Outline }}$}

A. Differences between power and research reactor installations

1. Size

2. Complexity

3. Differences in problems of making meaningful measurements

4. Relative accuracy

B. In-core instrumentation

1. Necessity

2. Problems

a. Environment and life expectancy

b. Quantity

c. Wiring

d. Installation and replacement

C. Temperature measurements

1. Problems with multiple primary loops

2. Stratification
a. Definition
b. Origin
c. Accuracy in temperature measurements

D. Flow measurements

1. Economics

2. Accuracies

3. "Inferred" methods

E. Typical systems of nuclear steam plants

1. Primary heat removal

2. Secondary (steam or other) heat sink 
3. Makeup

4. Blowdown

5. Emergency core cooling system

F. Rod position information

1. Multiple rods
a. Worth
b. Travel
c. Position information

G. System interactions

H. Containment and other engineered safeguards

1. Needs

2. Problems

3. False actuation

\section{Sample Study Questions}

1. Explain briefly two major differences between the instrumentation problems in research and power reactors.

2. Explain briefly why large numbers of flux sensors are of ten installed in power reactor cores.

3. Why is it necessary to know coolant temperatures and flow in all loops of a mult1loop primary heat removal system?

4. Discuss briefly the problem of determining meaningful temperatures in the large pipes found in nuclear power plants.

5. What does temperature stratification mean when speaking of the primary coolant piping of a nuclear power plant? How can 1 c occur?

6. Although accurate methods of measuring coolant flow are known and instrumentation can be built, why are such systems oflen umLLLed in power reactor installations?

7. Name several places outside the reactor core where radiation instrumentation would be found in a nuclear power station.

8. Why are less accurate rod-position measurements needed in power than in research reactors?

9. Name several engineered safeguards. 


\section{References}

1. A. J. Spurgin, "Some Aspects of the Process Control and Protection Systems of a Westinghouse PWR," IEEE Trans. Nucl. Sci. 17(1): 599-607 (1970).

2. W. R. Morgan, "In-Core Neutron Monitoring System for the General Electric Boiling Water Reactors," IEEE Trans. Nucl. Sci. NS-17(1): 564-671 (1970).

3. L. E. Phillips, "In-Core Instrumentation for Power Reactors," React. Fuel-Process. Technol. 12(2): 195-204 (1969).

4. W. C. Coppersmith et al., Sects. A and B in Reactor Protection System Diversity, USAEC Rept. CENPD-11, Combustion Engineering, Inc., February 1971.

5. H. A. O'Brien and C. S. Walker, Protection Instrument Systems in Light-Water-Cooled Power Plants, ORNL/NSIC-29, Oak Ridge National Laboratory, Oak Ridge, Tenn., October 1969.

6. L. M. Johnson, "Palisades PWR: Station Control and NSSS Instrumentation," Nucl. Eng. Int. 15(164): 40-42 (1970).

7. W. Patalon and R. Pierce, "Instrumentation System for the Sequoyah Nuclear Plant," Nucl. Eng. Int. 16: 860-64 (1971).

8. R. S. Stone, "The Design Basis for Nuclear Power-Plant Protection Systems," Nucl. Safety 11(1): 2-24 (1970).

9. A. E. G. Bates, "Control Rods and Control-Rod Drives in Nuclear Reactors," Nuci. Safety 2(4): 16-37 (1961).

\section{Lesson Plan No. 4. Cumting Channels Including an}

Introduction to Nuclear Instrumentation

\section{Objective}

The student should become aware of the problems of making useful flux measurements over the wide range of values encountered in nuclear reactors. These problems include varying gamma backgrounds and elevated temperature environments. He 1s expected to understand the relative usefulness and importance of the information obtained from each type of channel under various operating conditions. 
The student should learn in some detail the composition of a counting channel and its capabilities and limitations. He is to learn what output signals are available, the typical purposes to which these are put, and the system logic. He is to begin practice in reading and using instrument block diagrams.

\section{$\underline{\text { Plan Outline }}$}

A. Introduction

1. Exleill of cuverage of lessons

2. Source range

3. Intermediate range

4. Power range

B. Problems in providing information in various parts of flux range

1. Gamma background

2. Temperature

3. Siting problems

C. Other channels

1. General area monitors

2. Process monitoro

D. Source range channel

1. Purpooc

2. Simple system

3. General system

4. Capabilities and limitations

a. Gamma tilux toleration

b. Short range due to statistical nature of flux

c. Fold-over of electronics

d. Ways of increasing range

e. Discriminator

f. Period information generation

5. Application to control system

a. Block withdrawàl

(1) No source or too low a count rate

(2) Too rapid a power rise 
b. Reverse or scram due to too rapid a rate of rise

6. Not suitable for protection system applications

7. Noise problems

8. Compare fission and boron trifluoride chambers (includes construction) and systems

9. Sensor life

10. Use of a plurality of channels

11. Difficulties due to capacity nf chamber signal cable and alternate use of pulse transformers for cable impedance matching

\section{Sample Study Questions}

1. Explain briefly why more than one kind or type of nuclear instrument channel is needed in a reactor installation.

2. What is the principal problem of nuclear instrumentation employed at the source and intermediate flux levels with a nuclear reactor? Why is this not a problem in the power range ( 1 to $150 \%$ of full power)?

3. Describe briefly how a fission chamber works. What is the form of its output signal within its counting range?

4. Why is a discriminator necessary in a counting channel? Explain briefly how it operates to perform its function.

5. In addition to count rate (flux level), what other information is obtained from counting instrumentation?

6. What use is made of the two kinds of information supplied by the counting channel?

7. Why is the counting channel ordinarily not made a part of the reactor protection system?

8. What are some differences between fission and boron trifluoride chambers?

9. The nature of the signal from a counting chamber makes its transmission difficult. Explain two ways in which the problem may be handled, and give some merits of each. 


\section{$\underline{\text { References }}$}

1. A. Pearson and C. G. Lennox, "Sensing and Control Instrumentation," The Technology of Nuclear Reactor Safety, Vol 1 - Reactor Physics and Control, ed. T. H. Thompson and J. G. Beckerley, MIT Press, Cambridge, Mass., 1964.

2. L. C. Oakes, A Second Generation of Reactor Control Systems as Applied to the High Flux Isotope Reactor, ORNL/TM-1259, Oak Ridge National Laboratory, Oak Ridge, Tenn., September 1965.

3. F. T. Binford and E. N. Cramer, eds., The High Flux Isotope Reactor - a Functional Description (Vol. 1A, Text; Vol. 1B, Illustrations), ORNL-3572, Oak Ridge National Laboratory, Oak Ridge, Tenn., May 1964.

Lesson Plan No. 5. Intermediate and Power Range Channels

\section{Objective}

The student should become famlliar with the purpose, capabilities, limitations, and hardware of typical intermediate $(\log N)$ and power range (linear or safety) instrument channels and gain an understanding of their place in the scheme of neutron flux measurement. He should develop an understanding of the need for routine recalibration of the power range channels during regular operation in some installations and the reason for use of heat power as the reference. He should know why both types of power measuring channels are required.

The student should also gain additional experience with block diagrams of instrument channels.

\section{Plan Outline}

A. Review

1. Place of intermediate range channel in whole system

2. Problem of measuring neutron flux in heavy gamma fields

3. Introduction of the $\log -\mathrm{N}$ instrument 
B. Log-N channel

1. Block diagram

2. Sketch of a compensated chamber

a. Function and purpose of arrangement of both cup and plate types

b. Signal-developing circuitry

c. Problems of compensation in practice and date on practical systems

d. Advantage of current signals over pulse signals for handling

3. Thermionic log diode and development of $\mathrm{log}$ and flux signal

4. Brief description of electronics and outputs

5. Compensation

6. Solid-state $\log$ system

7. Readout instrument scales ( $\log N$ and period)

8. Power supply requirements

C. Power range channels

1. General

a. Need for linear and accurately calibrated instruments

b. Range

c. Protection system assignment and ramifications

d. Need for both flux and heat power instrumentation

2. Block diagram

a. Chamber and characteristics

b. Electronics

(1) Protection signal output (safety)

(2) Control signal, alarm, and corrective actions

(3) Signal isolation

c. Slow and fast scrams

3. Importance of

a. Separation

b. Identification

c. Recognitioin of protection and control systems

d. Attitude toward protection and control systems 
Sample Study Questions

1. Explain briefly why the detection of neutrons in a heavy gamma flux is difficult.

2. Describe one type of construction of a compensated ion chamber, and explain briefly how it detects neutrons in a gamma background.

3. Identify the type of compensated chamber that is currently most popular, and explain briefly why it is preferred.

4. What is the function of the thermionic log diode?

5 . What ranges of power and period are covered in typical $\log -\mathrm{N}$ jinstrument channels?

6. The typical $\log -\mathrm{N}$ channel inetallation does not include a preamplifier as does a counting channel. Explain.

7. What is the power range when speaking of a nuclear reactor? Why is it preferable to use linear instrumentation and readouts in the power range?

8. The linear instruments (question 7) are primarily part of what system? Why are they used in multiple?

9. Explain briefly the purpose of continuous monitoring of these channels (question 7)?

10. What is meant by a coincidence system? Give two of its important features.

11. Since these instruments (question 7) are calibrated against nonnuclear power measuring channels and give the same information (power), why are they needed?

12. Draw a simple block diagram of a linear channel, and explain its operation briefly. Why is an uncompensated neutron-sensitive ion chamber suitable?

13. What signal outputs are available from the instrument that records the reactor power as determined by a linear channel?

14. What is the function of the isolation provided between the control and protection signal circuits of the linear instrument channels?

15. Explain slow and fast scram. 


\section{References}

1. A. Pearson and C. G. Lennox, "Sensing and Control Instrumentation," The Technology of Nuclear Reactor Safety, Vol. 1 -Reactor Physics Control, pp. 285-99, 304-06, 308-12, and 318-42, ed. T. J. Thompson and J. G. Beckerly, MIT Press, Cambridge, Mass., 1964.

2. L. C.. Oakes, A Second Generation of Reactor Control Systems as Applied to the High Flux Isotope Reactor, ORNL/TM-1259, Oak Ridge National. Laboratory, Oak Ridge, Tenn., September 1965.

3. W. R. Morgan, "In-Core Neutron Monitoring System for General Electric Boiling Water Reactors," IEEE Trans. Nucl. Sci. NS-17(1): 564-71 (1970).

4. L. E. Phillips, "In-Core Instrumentation for Yower Reactors," React. Fuel-Process. Technol. 12(2): 195-204 (1969).

5. W. H. Jordan, H. B. Frey, and G. Kelly, An Instrument for Measuring the Logarithm of Neutron Level and the Period of a Pile, ORNL-110, Oak Ridge National Laboratory, Oak Ridge, Tenn., November 1948.

6. L. M. Johnson and C. J. Meijer, "A Two Range System for Ex-Core Neutron Flux Monitoring," IEEE Trans. Nucl. Sci. 1(17): 552-60 (1970).

7. R. M. Ball and L. M. Lovallo, "Automatic-Ranging Picoammeter for Reactor Control and Protection," IEEE Trans. Nucl. Sci. 1(18): 435-37 (1971).

8. J. L. Anderson, "Role of Log-N Period Meter in. Reactor Protection," Nucl. Safety 4(3): 48-50 (1963).

Lesson Plan No. 6. Other Nuclear Control Instrument Channels (CIC)

\section{Objective}

The student should become familiar with the servo system and its instrumentation, the Campbelling system flux channel, the wide-range counting channel and counting-Campbelling wide-range channel. The extent of coverage is equivalent to that of lesson plans Nos. 4 and 5. 


\section{Plan Outline}

A. Servo system

1. Purpose

2. General description (block diagram)

a. Major components

b. Signals, error reference, and feedback

c. Dead band (excessive and insufficient feedback)

d. On-off and continuous types

3. Error signal sources

a. Separate channel with range change picoammeter

b. Dual power range channcl

c. Dual wide-range channel

4. General philosophy (rod worth, etc.)

5. Rods, shim-safety

B. Campbelling system (reactor flux)

1. General description (block diagram)

a. Major components

b. Features

c. Comparison of input signal with that used for counting or power range operation

2. Comparison with $\log -\mathrm{N}$ (CIC) system (capabilities and limitationo)

3. Ilistorical note

C. Wide-range channels using fission chambers

1. Automatically positioned chamber

a. General description

(1) Range

(2) Outputs

(3) Mechanical and electrical arrangement

b. Capabilities and limitations

c. Other approaches (multiple and repositionable chambers)

2. Counting-Campbelling system

a. General description

b. Low-range operation 

c. High-range operation
d. Crossover problem
e. Period information
f. Capabilities and limitations

\section{Sample. Study Questions}

1. What is the function of the reactor control servo system?

2. Draw a simple block diagram of such a system, and briefly explain how it operates.

3. Define "setpoint" (demand). Discuss feedback briefly, explaining why it is needed and the effects of too much or too little.

4. Name two types of servo systems, and explain the principal differences in action.

5. Should the reactivity controlled by the servo be limited for any reason or reasons? Explain your answer.

6. Discuss briefly the Campbelling system ${ }_{r}$ comparing it feature by feature with the $\log \mathrm{N}$ (intermediate-range) channel.

7. Explain briefly how the wide-range counting channel operates. What output information does it furnish?

8. Describe briefly other methods employed to extend the range of a counting channel.

9. Draw a block diagram showing the major parts of a countingCampbelling wide-range system. State briefly the purpose or function of each block.

10. Approximately how many decades of tlux (or power) are handled by (1) the counting section, (2) the Campbelling section, and (3) both?

11. Compare the principal features of the counting-Campbelling widerange systems.

12. Explain why, from the operator's point of view, a single widerange channel is or is not preferable to a number of shorter but overlapping range instruments. 


\section{References}

1. F. T. Binford and E. N. Cramer, eds., The High FZux Isotope Reactor - a Iunctional Description (Vol. 1A, Text; Vol. IB, Illustrations), ORNL-3572, Oak Ridge National Laboratory, Oak Ridge, Tenn., pp. 8-16 and 130, May 1964.

2. L. E. Stanford, T. P. Hamrick, and F. T. Binford, Description and Safety Analysis of Significant Change of the Bulk Shielding Reactor for 2-MW Operation, ORNL/TM-2231, Oak Ridge National Laboratory, Oak Ridge, Tenn., pp. 104-06, May 1968.

3. A. E. G. Bates, Description of the BSR 2-MW Reactor Control and Instriment Systems, ORNL/TM-2400, Oak Ridge National Laboratory, Oak Ridge, Tenn., October 1968.

4. S. Glasstone, Principles of Nuclear Reactor Engineering, D. Van Nostrand Company, Inc., Princeton, N.J., 1955.

5. D. P. Rouiri, "Wide-Ránge Nuclcảr Chảnnçlo," Nuar. Safoty $9(6)$ : 486-93 (1968).

Lesson Plan No. 7. Some Auxiliary Systems

\section{Objectivc}

The student should become familiar with the ${ }^{16} \mathrm{~N}$ and gamma channels, but to less depth than that of lesson plans Nos. 4 and 5 . The student should also develop an understanding of the annunciator system, its operation and its usefulness, and he should become familiar with the purpose and use of remote position indicating systems and how the more popular ones operate.

\section{$\underline{\text { Plan Outline }}$}

A. ${ }^{16} \mathrm{~N}$ channe1

1. Purpose and features

2. Block diagram and description 
B. Gamma channel

1. Purpose and features

2. Block diagram and description

C. Fission break monitoring

1. Purpose and problems

2. Block diagram of typical system

3. Tie to annunciator and protection system

D. General site radiation monitoring system

1. Purpose and features

2. Block diagram of typical system

3. Readouts and information displays

4. Individual channels

a. Working areas

(1) Air monitors (particulate and gaseous activity)

(2) Radiation from various sources

b. Effluents

(1) Stack gas

(2) Liquid wastes

c. Radiolytic gas in coolant system

E. Annunciator

1. Purpose and applications

2. General description of multi-unit systems

3. Data logging or computer monitoring of annunciator system

F. Position indicators

1. General discussion

a. Purposes and types

b. Applications at reactor installations

c. Rod-drive systems capabilities and limitations

2. Potentiometric system

a. Theory and operation

b. Features and applications

3. Synchro system

a. Theory and operation

b. Fine and coarse systems

c. Features and applications 
4. Linear magnetic system

a. Theory and operation

b. Features and applications of

(1) Continuous system

(2) Step-by-step system

5. Position switches

a. Theory and operation

b. Features and application

c. Travel limit

6. Digital-to-analog converters

\section{Sample Study Questions}

1. Explain briefly the purpose of ${ }^{16} \mathrm{~N}$ channel and how it operates.

2. Explain brief $\perp y$ the purpose of a gamma channel and what output signals it might supply.

3. Explain briefly the general purpose of an area monitoring system. What means are employed to detect (a) gaseous activity and (b) particulate activity?

4. What kinds of chambers may be used for monitoring the activity of the primary coolant of a PWR or BWR?. Why? Would it be necessary to monitor both sides of a heat exchanger? Name two other processtype systems (associated with a reactor) that require monitoring.

5. Explain briefly the purpose of an annunciator system. Do you consider it an operating aid? Explain.

6. Why is an annunciator often monitored by a data logger or computer?

7. How important is it for the positions of control rods to be known at a11 times? Explain.

8. Are the indicated and actual rod positions always the same? Explain.

9. Draw simple block diagrams of two continuous position indication systems, and explain briefly how they operate.

10. Explain why noncontinuoue (otep) rod-position-indicating oyotemo are quite adequate for some reactor arrangements.

11. Describe briefly how two different noncontinuous rod-positionindicating systems operate. 
12. Name two or more applications for travel-limit position-indicating systems besides control rods.

\section{$\underline{\text { References }}$}

1. F. T. Binford and E. N. Cramer, The High Flux Isotope Reactor - a Functional Description (Vol. 1A, Text; Vo1. 1B, Illustrations), ORNL-3572, Oak Ridge National Laboratory, Oak Ridge, Tenn., pp. 8-18 and 8-19, May 1961.

2. Phillips Petroleum Company, Fundomentals in the Operation of Nuclear Test Reactors. Vol. 2. Materials Testing Reactor Design and Operation, p. 76, IDO-16871-2, 1963.

3. D. P. Roux, "Some Problems of Nuclear Radiation Detection in Light Water Research Reactors," Trans. Am. Nucl. Soc. 6, Suppl.: 51 (1963).

4. D. P. Roux and S. H. Hanauer, "Use of Reactor Gamma Radiation as a Reactor Control and Safety Parameter," Trans. Am. Nucl. Soc. 6(1): 74 (1963).

5. J. L. Kaufman, "Fuel-Element Leak Detection," Nucl. Safety 1(3): 3 (1960).

6. R. A. Rohrbacher, "Sample and Control for Fast Detection of Fuel Failure in a Pressurized Water Reactor," ISA Trans. 4(2): 189-97 (1965).

7. C. D. Bauman, "Fission-Product Detection Systems in High-Temperature Gas-Cooled Reactors," Nucl. Safety 12(2): 90-91 (1971).

8. L. C. Oakes, A Second Generation of Reactor Control Systems as Applied to the High Flux Isotope Reactor, ORNL/TM-1259, Oak Ridge National Laboratory, Oak Ridge, Tenn., pp. 13, 14, 26-28, September 1965.

9. D. J. Knowles, "Monitoring of Gaseous Wastes," Nucl. Safety 2(2): 25-27 (1960).

10. A. Pearson and C. G. Lennox, The Technology of Nuclear Reactor Safety. Vol. 1 - Reactor Physics and Control, ed. T. J. Thompson and J. G. Beckerly, pp. 389-99, MIT Press, Cambridge, Mass., 1964.

11. S. Glasstone, Principles of Nuclear Reactor Engineering, pp. 557-59, D. Van Nostrand Company, Inc., Princeton, N.J., 1955.

12. J. A. Russell, Jr., and D. J. Knowles, Description of Facility Radiation and Contamination Alarm Systems Installed in the Bulk Shielding Facility (Building 3010), ORNL/TM-1874, Oak Ridge National Laboratory, Oak Ridge, Tenn., August 1967.

13. T. P. Hamrick and J. H. Swanks, The Oak Ridge Research Reactor a Functional Description, ORNL-4169 (vol. 1), pp. 147-50, Oak Ridge National Laboratory, Oak Ridge, Tenn., September 1968. 
14. A. E. G. Bates, Description of the BSR 2-MW Reactor Control and Instrument Systems, ORNL/TM-2400, pp. 28-29, Oak Ridge Nationa1 Laboratory, Oak Ridge, Tenn., October 1968.

15. J. M. Harrer, Nuclear Reactor Control Engineering, pp. 189, 192, 193, 201, 204, 207, 223, and 224, D. Van Nostrand Co., Inc., Princeton, N.J., 1963.

16. R. D. Bryden and K. J. Simm, "Indication of Control Rod Position," GEC At. Energy Rev. 2: 34-37 (1959).

17. R. C. Floyd and J. M. Ruether, "A Rod Position Indicating System for Pressurized Water Reactors," Commun. Electron. 45: 614-18 (19.59).

18. E. Medal, "Magnetic Position Indicators for Reactor Control Rods," Autom. Control 13(3): 29-31 (1960).

Lesson Plan No. 8. Introduction to Process Instrumentation

\section{Objective}

This lesson should help the student understand what process instrumentation is, why it is necessary, and how it can help him in the operation of a nuclear reactor and its power plant. The student should also become familiar with the makeup of a few typical measuring, recording, and control systems, identification of components, and further use of block diagrams.

\section{l'Lan Uut line}

A. General

1. Definition of process instrumentation

2. Automatic systems

a. Reference to experience as a successful car driver

b. Importance of predictability and uniformity of control in industry, etc.

c. Advantage to operator 
3. System block diagrams

4. Sensors and other hardware operation

B. Typical control schemes (block diagrams)

1. Temperature of liquid in tank - steam heating

2. Temperature of liquid in tank - electrical scheme with level protector for heating elements

(NOTE: This combines two control systems.)

3. Heat exchanger systems (outlet temperature of primary fluid held constant by controlling secondary flow)

4. Maintaining level in head tank

5. Combined schemes and illustrations with heat-power system for nuclear reactor

C. Facts of life

1. Placement of sensors
a. Optimum
b. Practical limitations

2. Effects of lags

a. Sensor

b. Controller

c. Inherent delays on process following controller action

D. Types of control
a. On-off
b. Continuous and variations

\section{Sample Study Questions}

1. What do you think the term "process instrumentation" identifies or refers to?

2. Give some reasons for using process instrumentation and controls schemes in a nuclear reactor or power plant installation that you consider important.

3. Considering the variables that are monitored in the control and protection of a nuclear reactor, name three that are also of primary interest in ordinary process instrumentation systems.

4. Name two applications for nuclear or radioactivity instrumentation in process systems at a nuclear reactor installation. 
5. The water level in a head tank must be maintained within close limits even though the rate of water flow out of the tank varies appreciably with time. The scheme employed includes an instrumentcontrolled valve which automatically adjusts the rate of water flow from the makeup pump. What general type of automatic controller is used? Suppose the water level in a heat tank was considered to be adequate as long as it was above the half-full point; what kind of automatic control would be appropriate, and would the flow control valve be used? Explain.

6. When a variable such as temperature must be held relatively constant, where would the sensor be placed! Explain. In practice, are such sensors always placed in the ideal location? Explain.

1. What is meant by the term "Lag" when referring to an automatic control scheme? Where may such lags occur, and what is their effect?

8. In a vessel heating system employing automatically controlled electrical immersion heaters, why are both temperature and level sensors required?

\section{$\underline{\text { References }}$}

1. D. M. Considine, Process Instrmentation and Controts Handbook, pp. 1-2 to 1-5 and 11-1 to 11-26, McGraw-Hil1 Book Co., Inc., New York, 1957.

2. F. W. Kirk and N. R. Rimboi, Instrumentation, 2nd ed., chaps. 1 and 15, American Technical Society, Chicago, 1966.

3. M. Considine, ed., Handbook of Applied Instrumentation, pp. 10-4 to $10-34,10-46$ to $10-54,13-27$ to $13-30$, and 14-25 to 14-44, McGraw-Hill Book Co., Inc., New York, 1964. 
Lesson Plan No. 9. Temperature Instrumentation, Part I

\section{Objective}

The student should become familiar with the operation, capabilities, limitations, and typical applications of the liquid-in-glass, bimetallic, and thermocouple temperature-measuring devices.

\section{$\underline{\text { Plan Outline }}$}

A. Introduction

1. Typical systems and means of measuring tmeperature

2. Typical systems in nuclear power plants

B. Liquid-in-glass thermometer

1. Description and operation

2. Typical liquids and temperature ranges

3. Practical design arrangements

4. Applications

C. Bimetal thermometry

1. Description and operation

2. Typical operating ranges and limitations

3. Practical designs of hardware

4. Applications

D. Thermocouple thermometry

1. Simple circuit (two junctions and no indicator)

2. Indicator and effect

3. Various meta1 combinations

a. Temperature ranges

b. Ambient atmosphere effects

4. Proulems

a. Speed of response and how optimized

b. Locating sensors

c. Cold junction

d. Extension wire

e. Connectors 
5. Physical arrangements
a. Unsheathed
b. Sheathed
c. Grounded
d. Ungrounded

6. Reliability and life expectancy

7. Readout devices
a. Direct indicating
b. Direct recording
c. Problems
d. Potentiometric
(1) Manual
(2) Electrical

8. Typical hardware description
a. We11s
b. Couple assemblies
c. Portable instruments for readout
d. Panel-mounted instruments

\section{Eample Study Questiuns}

1. Briefly describe the construction of a liquid-in-glass thermometer, and explain its operation.

2. Is the liquid-in-glass thermometer relatively rugged or relatively fragile? Is it suitable for reading direst.ly or for reading from remote locations?

3. Explain briefly how the bimetal thermometer operates.

4. Is the bimetal thermometer relatively rugged or relatively fragile? Is it suitable for reading directly or for reading from remote locations?

5. Make a sketch to illustrate a thermocouple temperature-measuring system including the hot and cold junctions and the readout device. Explain briefly how it operates.

6. Identify three common types of thermocouples, and give the typical temperature ranges for which each is used. 
7. Are thermocouples most frequently used for making local measurements or measurements at remote locations? Explain.

8. Are thermocouple extension lead wires made of the same materials as the couples? Explain.

9. Give three reasons why thermocouples are suitable for use in reactor installations.

10. Would a thermocouple installation in a reactor coolant pipe respond relatively rapidly or slowly to changes in temperature of the coolant? Explain. Would it sense the temperature at its junction or automatically average the temperature across the whole pipe area? Explain.

\section{References}

1. D. M. Considine, ed., Process Instmuments and Controls Handbook, pp. 4-20 and 85-92, McGraw-Hill Book Co., Inc., New York, 1957.

2. F. W. Kirk and N. R. Rimboi, Instmumentation, 2nd ed., pp. 12-16 and 106-14, American Technical Society, Chicago, 1966.

3. D. M. Considine, ed., "Temperature," pp. 2-3 through 2-27 in Handbook of Applied Instrumentation, McGraw-Hill Book Co., Inc., New York, 1964.

Lesson Plan No. 10. Temperature Instrumentation, Part II

\section{Objective}

The student should become familiar with the operation, capabilities, limitations, and typical applications of resistance-thermometry, and liquid-, vapor-, and gas-filled temperature-measuring systems and equipment. 


\section{Plan Out line}

A. Resistance thermometry

1. Wheatstone bridge

2. Temperature resistance effect in metals

3. Comparison of accuracies of typical resistance and thermocouple systems and sensitivity to nuclear radiation

4. Readout problem

a. Direct system limitations

b. Manually adjusted bridge

c. Elcetrical servo arrangemenl

5. Typical appllcallons in nuclear powè plants

6. Typical hardware

B. Filled systems

1. Sketch of typical system with parts identified

2. Problems

a. Temperature effects on long capillaries

b. Physical size of sensors

c. Leak repair

3. Three types of filling

a. Typical filling materials and operating ranges

b. Individual characteristics and selection for use

4. Hardware

a. Indicating types

b. Recording types

C. Comparison of the various types of thermometry and basis for colcction and use

\section{Sample Study Questions}

1. The resistance thermometer system depends upon what property of a metal for its operation? Identify two metals frequently used for this application, and give the approximate temperature range covered by each. 
2. Name the electrical network into which the resistance bulb is connected, and explain briefly how the temperature can be determined with it.

3. Is the resistance thermometer used in making temperature measurements within a reactor? Explain.

4. Explain briefly how a "filled-system" thermometer operates. Make a sketch of a simple instrument, and identify the active components. Identify three types of fillings used in practical systems.

5. Is the filled-system thermometer suitable for measuring reactor core temperatures? Explain.

6. If a filled system were to develop a leak, would the temperature readings be affected? Explain. How would repairs be affected?

7. Liquid-filled-system performance may be degraded when long capillaries are required. Explain and describe one method for minimizing the effect.

8. Give typical operating ranges for each of the three types of filled systems.

9. Name one type of temperature-measuring device or system that is suitable and adequate for (a) local room temperature, (b) hot water heating system header, (c) primary cooling system of a water reactor, (d) fuel element in a reactor, (e) air in cooling system ducts, and (f) condensate returning to steam generator.

\section{$\underline{\text { References }}$}

1. D. M. Considine, ed., Process Instruments and Controls Handbook, pp. 47-59 and 68-84, McGraw-Hill Book Co., Inc., New York, 1957.

2. F. W. Kirk and N. R. Rimboi, Instrumentation, 2nd ed., pp. 16-18 and 114-17, American Technical Society, Chicago, 1966.

3. D. M. Considine, ed., Handbook of Applied Instmumentation, pp. 2-3 to 2-27, McGraw-Hill Book Co., Inc., New York, 1964. 
Lesson Plan No. 11. Pressure Instrumentation

\section{Objective}

The student should become familiar with the functioning, capabilities, and limitations of pressure instrumentation and should learn to identify typical applications of such instrumentation in nuclear reactor and power plant installations.

\section{Plan Outline}

A. Int roduction

1. General purpose tor procouro meaourcmento

2. Gauge, vacuum, and absolute scales

3. Typical applications in a nuclear reactor and power plant installations.

B. U-tube manometer

1. Sketch simple device

2. Inclined tube version

3. We11 version

4. Different filling liquids and practical ranges obtainable

5. Scales and units of calibration

6. Practical devices

a. Typical applications

b. Suitability

G. Limitations

c. Mechanical elements

1. Diaphragm and bellows

a. Principle of operation

b. Typical applicatione

2. Bourdon tube

a. Operating principle

b. "C"-type element

c. Helical-type element

d. Spiral-type element

e. Typical applications 
3. Pointer and pen-driving arrangements

a. Lever, cable, etc.

b. Gearing

c. Others

4. Charts and drives

5. Calibration

D. Strain gauges

1. Operating principle

a. Resistance change

b. Electrical bridge

2. Practical forms of elements

3. Typical applications

E. Vacuum measurements

1. Manometers and working ranges

2. Mechanical elements and working ranges

3. High-vacuum measuring equipment

F. Differential pressure measurement

1. Description

2. Some applications

3. Importance in level and flow applications

G. General comments

1. Speed of response of various practical systems

2. Measurement and readout accuracies required and obtained in practice

H. Pressure switches

1. Purpose

2. Actuating mechanisms

3. Adjus tments

4. Performance

\section{Sample Study Questions}

1. Sketch a simple U-tube manometer showing the connection to the pressure or vacuum source to be measured and the scale. Explain briefly how it operates and how the scale is read. 
2. Manometers may be filled with any one of several liquids. Name the two most common of these. In what terms is each calibrated? What principal characteristic of the manometer is determined by its filling liquid?

3. Name one pressure (or vacuum) measurement which may be made in a nuclear reactor installation with a manometer and another for which it is not suitable or practical.

4. Sketch a diaphragm or bellows-type pressure element, and describe how it operates a pointer to give a pressure indication. Explain briefly how the system functions.

5. Explain briefly the principle of operation of the Bourdnn tube.

6. Identify three versions of the Bourdon tube element. In terms of relative pressures, when might each version be used?

7. Sketch the simplest form of the Bourdon tube element, and show a mechanism by means of which it is made to drive a recorder pen. Use a mechanism which operates in a fashion different from that described in the answer to question 4.

8. Explain briefly how the strain gauge element operates. What auxiliary equipment is usually required with the element to produce a complete pressure-measuring and readout system. Why is this system particularly useful for remote operation?

9. Approximately what is the highest vacuum that is read with practical mechanical elements? Which mechanical element has this capability?

10. Explain briefly how the manometer or bellows system is used to measure differential pressure.

11. Which is "O" (zero) on (a) a vacuum scale, (b) a gauge pressure scale, and (c) the absolute pressure scale? If the pressuresensing element of an instrument is a Bourdon tube, what is its "O" (zero) calibration point?

12. What is a pressure switch? Name two applications for this device in a reactor or power plant installation. 


\section{References}

1. D. M. Considine, ed., Process Instmments and Control Handbook, pp. 4-24, 30-45, 64-69, and 72-81, McGraw-Hill Book Co., Inc., New York, 1957.

2. F. W. Kirk and N. R. Rimboi, Instrumentation, 2nd ed., pp. 24-32 and 118-30, American Technical Society, Chicago, 1966.

3. D. M. Considine, ed., Handbook of Applied Instrumentation, pp. 10-22, McGraw-Hill Book Co., Inc., New York, 1964.

Lesson Plan No. 12. Level Instrumentation

\section{Objective}

The student should become familiar with the functioning, capabilities, and limitations of level instrumentation, as well as with typical applications for such instrumentation to be found at nuclear reactors and their power plants.

\section{$\underline{\text { Plan Outline }}$}

$\Lambda$. Introduction

1. The what and why of level information

2. Applications and special problems

3. Definition of direct and indirect indications

B. Direct level instrumentation

1. Tape or calibrated rod

a. Suitable applications

b. Limitations

2. Sight glass

a. Suitable applications

b. Limitations 
3. Float

a. Buoyant

(1) Operating mechanisms

(2) Suitable applications

b. Magnetic float

(1) Mechanism

(2) Suitable applications

4. Displacer

a. Operating mechanisms

b. Suitable applications

5. Conductivity probe

a. Operating principle

b. Applications

C. Indirect level instrumentation

1. Pressure gauge

2. Trapped or diaphragm gas pressure

a. Operating principle

b. Applications

3. Nir bubbler

a. Opcrating principle

b. Applications

4. Differential pressure

a. Review principle

b. Applications

5. Weight of container

a. Operating principle

b. Applications

6. Other methods

a. Radioactive source

b. U1trasonics

D. Step-by-step or incremental methods

1. Min-max level sensing

2. Additional intermediate sensors

3. Applications 
E. Capabilities and limitations

1. Acceptability of measurements

2. Capability of practical instruments

3. Operator's contributions

\section{Sample Study Questions}

1. From the standpoint of protection of personnel and/or equipment, the level of the liquid in one or more tanks or other containers at a nuclear reactor or power plant installation must be known at all times during operation. Name one instance and explain its importance.

2. Explain why the sight-glass direct-level instrument is suitable for either open or closed tank or vessel use.

3. Sketch the magnetic float arrangement. Explain how it and its readout system operate. Name one application for which it is particularly suitable.

4. Describe the operating principle of the displacer-type level sensor. How is the indicating pointer driven by the displacer? For what type of level measurement is it particularly suited?

5. Explain how a pressure gauge might be used to indicate the level of liquid in a tank. How do the trapped and diaphragm gas pressure systems differ from it?

6. Explain the difference between direct and indirect methods of measuring liquid levels.

7. Sketch and explain the air-bubbler-type of level-measuring system. Where might it be found around a reactor or power plant installation?

8. Where might each of the following be used?

a. Conductivity probe level system

b. Differential pressure level system

c. High and low level switches

9. Explain how the difference in level between the liquids in two tanks might be determined. Draw a simple sketch of the arrangement. 


\section{$\underline{\text { References }}$}

1. D. M. Considine, ed., Process Instmuments and Control Handbook, pp. 5-3 to 5-7, 5-10 to 5-12, 5-14,5-15, 5-20 to 5-25, and 5-43 to 5-45, McGraw-Hill Book Co., Inc., New York, 1957.

2. F. W. Kirk and N. R. Rimboi, Instmomentation, 2nd ed., pp. 33-39 and 5-23 to 5-25, American Technical Society, Chicago, 1966.

3. D. M. Considine, ed., Handbook of Applied Instmmentation, pp. 5-55 to 5-78, McGraw-Hill Book Co., Inc., New York, 1964.

Lesson Plan No. 13. Flow Instrumentation

\section{Objective}

The student should become familiar with the functioning, capabilities, and limitations of flow instrumentation and should learn to identify and describe some typical applications of such instrumentation in nuclear reactor and power plant installations.

\section{Plan Uutline}

A. Introduction

1. Needs for, and importance of, flow measurements

2. Definitions
a. Pressure
b. Density
c. Vioconity
d. Velocity
e. Turbulent flow
f. Laminar flow
g. Reynolds number 
B. Head or differential pressure measurement

1. Sketch showing operation of
a. Pipe orifice arrangement
b. Flow tube
c. Venturi

2. Comparison of major features of each

3. Square root scale problem and difficulty of making accurate low end measurements

4. Typical applications

5. $\Delta \mathrm{p}$ across any restriction

C. Pitot tube system

D. Variable area system

1. Sketch showing operation of

a. Rotameter

b. Piston-type sensor

2. Major features including linear scale

3. Typical applications

E. Flow volume measurements

1. Need

2. Sketch of an intermittent mechanical integrator for differential pressure sensors

3. Nutating piston flowmeter

4. Turbine wheel (or other) flowmeter

5. Applications of these volume devices

F. Weir and flume systems

1. Sketches

2. Float leve1-measuring system

3. Application

G. Magnetic flowmeter

1. Sketch explaining operation with stainless steel pipe (Henry Faraday principle)

2. Reactor application

H. Review of reactor coolant flow and temperature rise measurements 
Sample Study Questions

1. Describe the principle on which the differential pressure (head) flow measuring system is based.

2. Describe three devices used to develop a pressure differential for flow measurement.

3. Name one important feature of each of the three devices identified in question 2 .

4. How is the scale of the readout device of a differential pressure flow instrument calibrated? Does this affect the readability of any part of the scale? Explain.

5. Name two flow-measuring devices which depend upon the "variable area" principle. Sketch one and explain briefly how it operates.

6. How is the scale of a variable area flowmeter calibrated? Would you expect to find one of these devices used to measure the flow of coolant through a main heat exchanger for a large nuclear reactor? Explain.

7. What is the purpose of an integrating device when used with a flowmeter? Name two other devices which are used to make the same kind of flow measurement. Which of these would most likely be used where flow rates are large? Which would be used where they are sma1l?

8. Explain (using sketch) one arrangement for measuring the flow in open streams. What kind of instrument is used to convert the measured variable into flow?

9. Make a simple sketch of a magnetic flowmeter, and explain its operation. In what kind of nuclear reactor coolant system might such a flowmeter be found?

10. Reactor heat power is determined by combining what measurements? Why is the accurate determination of heat power considered of major importance in many nuclear reactor installations? 


\section{$\underline{\text { References }}$}

1. D. M. Considine, ed., Process Instruments and Controls Handbook, pp. 4-5 to 4-16, 4-36 to 4-45, 4-57 to 4-69, 4-76 to 4-79, 4-82 to 4-84, and 4-92 to 4-95, McGraw-Hill Book Co., Inc., New York, 1957.

2. F. W. Kirk and N. R. Rimboi, Instmmentation, 2nd ed., pp. 40-49 and 131-38, American Technical Society, Chicago, 1966.

3. D. M. Considine, ed., Handbook of Appilied Instmumentation, pp. 5-5 to 5-20, McGraw-Hill Book Co., Inc., New York, 1964.

Lesson Plan No. 14. Instrument Signal Transmission Systems

\section{Objective}

The student should become familiar with the functioning of the electric and pneumatic data transmission systems employed in process instrumentation. Features of the two systems should be learned. Also, the student should become familiar with typical applications for each type of system in nuclear reactors and their power plants.

\section{$\underline{\text { Plan Outline }}$}

\section{A. Introduction}

1. Limitations of "local only" readout in practical installations

2. Needs for and advantages of remote recording, indication, and control

3. Special problems where monitored fluids are hazardous, etc.

B. Pneumatic system

1. Block diagram

a. Define transducer and transmitter

b. Remote indicator or recorder

C. Control switch 
d. Air supply system (driers and regulators)

e. Reason for 3- to 15-1b signal system

2. Flapper nozzle operation

3. Attachment of flapper to typical sensing elements

4. Internal mechanisms of typical indicators and recorders and review operation

5. Review of pressure switch operation

6. Features of system and control switches

a. Identical readout and record hardware for different variables

b. Accuracy, reliability, and ruggedness

c. Relative treedom trom etfects of power outages

d. Practical signal tubing runs and system response

C. Electronic system

1. Block diagram

a. Purpose of each block

b. Reason for series 10-50 mA (or equivalent) system

2. Mechanical to electrical transducer (e.g., balanced bridge)

3. Amplifier

a. Conversion of bridge output to dc related sigmal

b. Conversion of output of electrical sensors to dc related signals

4. Töwer supply

5. Indicator and recorder mechanisms

6. Switch mechanism

7. Features

a. Identical hardware

b. Speed of response

c. Transmission distances

d. Electrical to pneumatic transducers

e. Accuracy, reliability, and ruggedness

Sample Study Questions

1. Give at least two reasons why it would be difficult, if not impossible, to operate a nuclear power plant in absence of continuous and reliable instrument signal transmission means. 
2. Temperature can be measured by several different methods. Describe one that lends itself directly to remote readout and one that is limited to local readout only.

3. Draw a block diagram of a pneumatic transmission system, including the instrument air supply.

4. What is the function of the flapper nozzle? Explain how it operates.

5. Why is it preferable to use a 3- to 15-1b signal system instead of one which operates from 0 to $151 \mathrm{~b}$ ?

6. The pen or pointer driving mechanism in the readout instrument of a 3- to 15-1b pneumatic system may be practically identical to that of an instrument used with the measurement of what other variable studied so far?

7. What form of electrical signal is transmitted in the electronic system discussed in class?

8. Explain how a balanced bridge (electrical) is used to convert the motion of a Bourdon tube (for example) to a proportional electrical signal.

9. What is the purpose of (a) the power supply and (b) the amplifier of the electronic transmission system?

10. If it were necessary to bring signal lines through the containment of a reactor, which type of instrument data transmission system would be less likely to cause containment leakage?

11. If a rapidly changing parameter was being monitored from a relatively remote location, would the pneumatic or electronic signal transmission system be preferred for that service? Explain.

\section{$\underline{\text { References }}$}

1. D. M. Considine, ed., Process Instmuments and Control Handbook, pp. 8-7 to 8-33 and 9-13 to 9-16, McGraw-Hill Book Co., Inc., New Yurk, 1957.

2. F. W. Kirk and N. R. Rimboi, Instmumentation, 2nd ed., pp. 17, 18, 27-35, 58-62, 108, 112, 113, and 119-29, American Technical Society, Chicago, 1966. 
3. D. M. Considine, ed., Handbook of Applied Instrumentation, pp. 1-36 to 1-46, McGraw-Hi11 Book Co., Inc., New York, 1964.

Lesson Plan No. 15. $\mathrm{pH}$ and Conductivity Instrumentation

\section{Objective}

The student should become familiar with the functioning, capabilities, and limitations of $\mathrm{pH}$ and conductivity instrumentation. Also, he should learn to identify and describe typical applications for such instrumentation in nuclear reactor and power plant installations.

\section{Plan Outline}

A. Parameters

1. $\mathrm{pH}$

a. Definition

b. Scale used

c. Values of some typical liquids

d. Typical instrument system

2. Conductivity

a. Definition

b. Typical values for several liquids (including natural and reactor cooling water)

c. Typical instrument system

B. Applications for instrumentation

1. Background

a. Characteristics and composition of natural and potable water

b. Reactor primary cooling water specifications and reasons

c. Appearance of sodium and iodine in primary coolant water 
d. On-line demineralizer

e. Secondary system problems

2. $\mathrm{pH}$ and conductivity instrumentation

a. Makeup water

b. Routine monitoring of primary and secondary systems

c. Routine monitoring of output of on-line demineralizers

d. Other applications

e. Care and handling of sensors, etc.

\section{Sample Study Questions}

1. What does the $\mathrm{pH}$ instrument measure? What scale is used, and what is its range of values?

2. What does the conductivity instrument measure? What scale does it use?

3. What is meant by buffering?

4. Why is cleanliness so important in each instrumentation system?

\section{$\underline{\text { References }}$}

1. F. W. Kirk and N. R. Rimboi, Instrumentation, 2nd ed., pp. 148-51, American Technical Society, Chicago, 1966.

2. D. M. Considine, ed., Process Instmments and Controls Handbook, pp. 6-96 to 6-121 and 6-159 to 6-172, McGraw-Hill Book Co., Inc., New York, 1957.

Lesson Plan No. 16. Principles, Philosophy, and Design Bases

\section{Objective}

In this section the trainee should review some of the principles of monitoring core flux, power, and process variables; he should be made 
aware of some of the philosophy and design bases which prescribe the requirements of the various instrument channels.

$\underline{\text { Plan Outline }}$

A. Terminology

1. Discrimination

2. Compensation and compensated ion chamber

3. Uncompensated ion chamber

4. Overcompensation (and effect)

5. Undcreompensation (and $E\left[\int_{e c L}\right.$ )

6. Trips

7. Interlocks

8. Calibration (flux vs heat power)

9. Redundancy

10. Independence of protection and control channels

11. Coincidence (1-of-2 2-of-3, and 2-of-4 logic)

12. Fail-safe criterion

13. Single-failure criterion

B. Principles of detection of neutrons and nther radiation

1. Pulse signals

2. Current signals

3. emf Signals

4. Campbelling

C. Types of detectors

1. Cource range

2. Intermediate range

3. Power range

1. Ovorlap

5. Limitaliuns

D. Channel conponents

1. Summer

2. Amplifier

3. Preamplifier

4. Miscellaneous 
Sample Study Questions

1. Describe a compensated ion chamber, and compare it with an uncompensated chamber.

2. Describe the manner in which a fission chamber provides a signal related to the neutron flux.

3. Why are nuclear instruments calibrated to agree with the heat power?

4. What effect does core burnup have on the signal obtained from the nuclear instrument channels?

5. What is meant by the term fail-safe criterion?

6. What two materials are generally used in ionization chambers to detect slow neutrons? What material is used to detect fast neutrons?

7. List, in order of pulse strength, the four types of radiation that will cause ionization in a detection chamber.

8. Why, for reactor operation, is the most important ionization chamber that which detects neutrons?

9. What is the advantage of an integrated-type circuitry, which some radiation monitors utilize?

10. Describe a multiple-section ionization chamber.

\section{$\underline{\text { References }}$}

1. Facility final safety analysis reports.

2. Vendor information.

3. Technical specifications. 
Lesson Plan No. 17. Reactor Protection System

Objective

The trainee should acquire adequate knowledge to recognize and respond to abnormalities and situations resulting in actuation of the protection system.

\section{$\underline{\text { Plan Outline }}$}

A. Purpose or functional performance requirements

B. Description and block diagram

C. Scram functions

1. Source range

a. Trip settings

b. Bases for trip settings

2. Intermediate range

a. Trip settings

b. Bases for trip settings

3. Power range

a. Trip settings

b. Bases for trip settings

4. Manual scram capability

D. Annunciators

1. Immediate action

2. Hollow-up action

3. Administrative controls

E. Instrumentation

1. Type of detectors and principles of operation

2. Netector Locations

3. Recorder indications

a. Norma1

b. Abnormal 
F. Bypasses

1. Manual

2. Automatic

3. Administrative limitations

G. Power supply

1. Normal

2. Emergency

H. Limiting conditions for operation

Sample Study Questions

1. Describe the purpose of the reactor protection system.

2. List the scram functions and trip settings.

3. What are the limitations on bypassing scram functions?

4. Name three annunciators, and list the immediate operator action expected.

5. Describe the normal power supply to the protection system.

6. Briefly describe the expected changes in readouts of the startup channels as the reactor is being started up.

7. How does the reactor protection system accomplish its purpose?

8. How does the reactor protection system function when there is an electrical power outage?

9. Describe the abnormal instrument indications that might be expected if boiling occurs in the core.

10. Describe the emergency electrical power supply for the protection system.

11. List the minimum number of protection channels required for reactor startup.

\section{References}

1. Facility final safety analysis report.

2. Vendor information.

3. Technical specifications. 
Lesson Plan No. 18. Engineered Safety Feature Actuation and Instrumentation

Objective

The trainee should acquire adequate knowledge so that he can intelligently respond to abnormalities and situations wherein engineered safety features (ESH) are actuated.

\section{Plan Outline}

A. Purpose of ESF actuation system

B. System description

C. Trip settings

1. Setpoints and coincidence

2. Feature actuated and its purpose

D. Annunciators

1. Immediate action

2. Follow-up action

3. Administrative controls

E. Instrumentation

1. Type of detector and principles of operation

2. Detector locations

3. Recorder indication
a. Normal
b. Abnormal

F. Bypasses

1. Mariua1

2. Automatic

3. Administrative limitations

G. Power supply

1. Norma1

2. Emergency

H. Limiting conditions for operation (minimum instrumentation) 


\section{Sample Study Questions}

1. Describe the purpose of the ESF actuation system.

2. List the trip settings, coincidence, and feature actuated for this system.

3. List those ESF systems which can be manually actuated and the conditions which might require this action.

4. What are the administrative restrictions concerning the use of bypasses?

5. Describe the indications (for both normal and abnormal conditions) available to the operator in the control room which indicate the status of the ESF systems.

6. Describe the engineered safety features associated with radiation levels.

7. Describe the emergency electrical power supply for the ESF actuation system.

8. How does the ESF accomplish its intended purpose?

9. Briefly discuss the engineered safety features associated with the steam generator.

10. Briefly discuss the engineered safety features associated with the turbine and generator.

\section{$\underline{\text { References }}$}

1. Facility final safety analysis reports.

2. Vendor information.

3. 'lechnical specifications. 


\section{Lesson Plan No. 19. Reactor Control System}

\section{Objective}

The trainee should learn to effectively operate and control the reactor at all times in a safe manner. The ability to recognize and respond to abnormalities and unusual conditions is also a necessity.

\section{Plan Outline}

A. Purpose

B. Description and block diagrams

C. Instrumentalton

1. Detector types and principles of operation

2. Location

3. Range coverage (degree of overlap)

4. Interlocks and modes

5. Purpose of interlocks

6. Control room indication

7. Malfunctions and abnormal indications

8. Bypasses

D. Annunciators

1. Immediate action

2. Follow-up action

3. Administrative controls

E. Manual vs automatic modes

F. Interaction of other systems

1. Feedwater flow increase or decrease

2. Feedwater temperature change effect

3. Generator output changes

4. Other

G. Power supply

1. Nurwal

2. Emergency

H. Limiting conditions for operation (minimum instrumentation) 
Sample Study Questions

1. List the rod block interlocks for each mode of operation.

2. Explain how the neutron instruments are calibrated to actual heat power.

3. Why is this method of control desirable in this reactor (BWR bottom entry control rods; PWR - chemical shim)?

4. What means are available to shut down the reactor if the control room becomes uninhabitable due to smoke and fire?

5. Why are the source range monitors fully withdrawn after the reliability of the intermediate range monitors is established?

6. List the minimum number of control channels required for reactor startup and full-power operation.

7. How does the reactor control system accomplish its intended task?

8. Briefly explain the relationship of the steam generator with the reactor control system.

9. Briefly explain the relationship of the turbine-driven generator with the reactor control system.

10. Briefly describe the control action if one of the primary water cooling pumps falls during normal operation.

11. What control action is intended to minimize undesirable peaking of the power density?

\section{$\underline{\text { References }}$}

1. Facility final safety analysis reports.

2. Vendor information.

3. Technical specifications. 
Lesson Plan No. 20. Supplementary Reactor Control Systems

\section{Objective}

The trainee should gain knowledge of the supplementary control systems which interact with the control of the reactor. Such systems include the rod-block monitor, rod-worth minimizer, feedwater controls, recirculation flow controllers, turbine generator controls, pressure controllers, process computer, etc.

Plan Outline
A. Puspuse
B. Description and block diagram
C. Instrumentation
1. Detection
2. Operable ranges
3. Interlocks and modes
4. Purpose of interlocks
5. Control room indications
6. Malfunctions and abnormalities
7. Administrative controls
D. Interactions with reactor control and other systems
E. Limiting conditions for operation

\section{Sample Study Questions}

1. Describe the method for switching from manual to automatic for each of the applicable systems.

2 . Nescribe the purpose of each system.

3. Describe the modes (or power level ranges) in which each system is operable, and give the bases.

4. List the interlocks for the applicable system.

5. Describe the annunciators for a system, and list the immediate action expected. 
6. Describe the administrative controls applicable to the startup of the steam-driven turbine, and describe the changes in instrument readouts expected when the turbine is started.

7. Describe the administrative controls applicable to the startup of the turbine-driven generator, and describe the changes in instrument readouts expected when the generator is started.

8. Select a few possible malfunctions that could affect the steam generator; describe the consequential changes in instrument readouts, and describe the corrective action.

9. Select a few possible malfunctions that could affect the steamdriven turbine; describe the consequential changes in instrument readouts, and describe the corrective action.

10. Briefly describe the interactions of the steam generator, turbine, and electric generator with each other and the reactor.

\section{$\underline{\text { References }}$}

1. Facility final safety analysis reports.

2. Vendor information.

3. Technical specifications.

Lesson Plan No. 21. Control-Rod Drive System

\section{$\underline{\text { Objective }}$}

The operator should become proficient enough to respond properly to control-rod movement and abnormalities associated with this system.

\section{$\underline{\text { Plan Outline }}$}

A. Design bases 


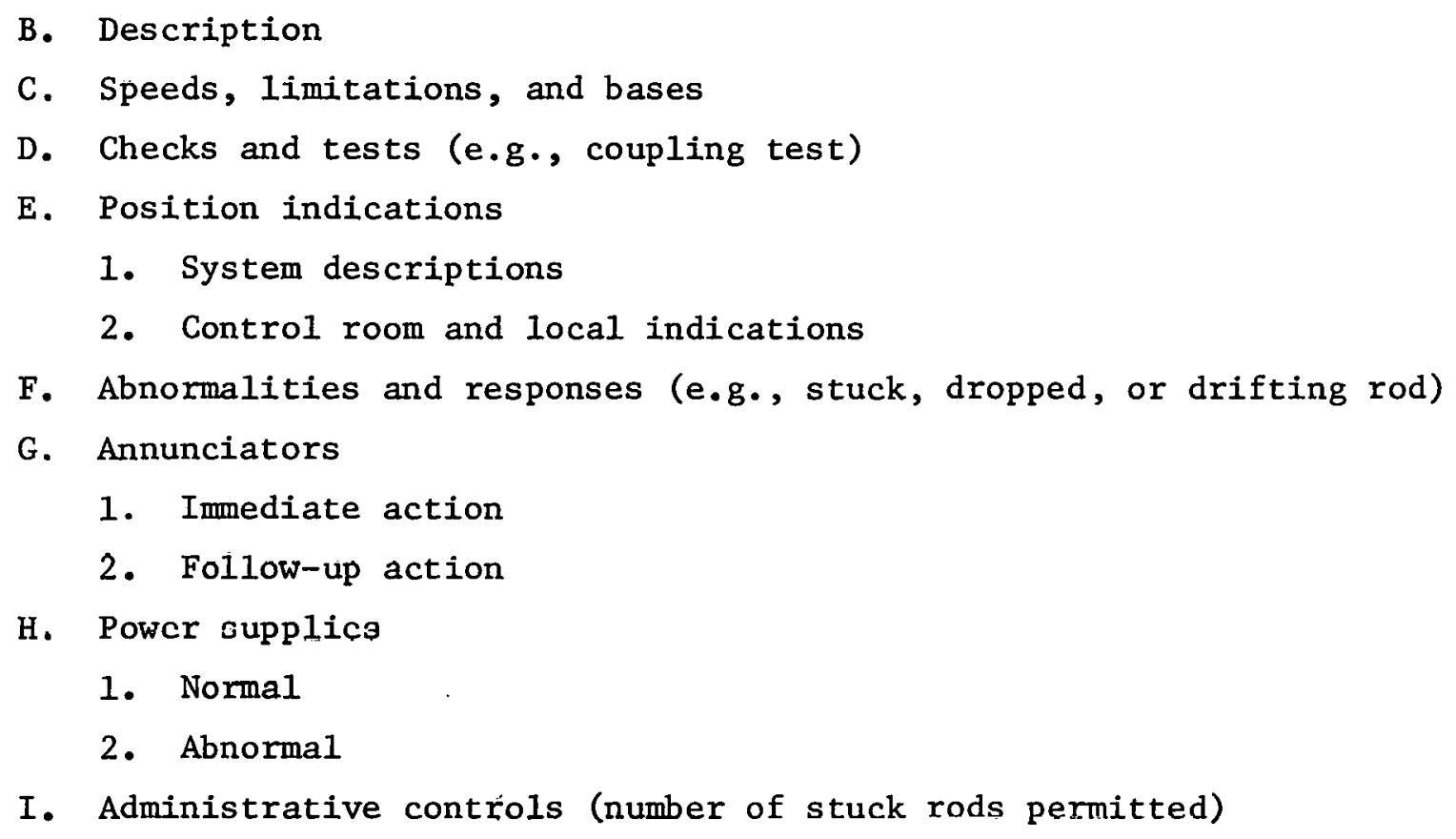

\section{Sample Study Questions}

1. What is the maximum speed at which control rods can be withdrawn?

2. What physical provisions have been made to limit the speed of control-rod ejection?

3. Describe the procedure for assuring that the control rod is coupled to the drive mechanism.

4. What is the maximum number of stuck rods permitted before shutdown is required?

5. Describe the control-rod position indication system.

6. Describe the emergency electrical power supply for the control-rod motors.

7. What is the importance of maintaining rod asymmetry, and how is it ensured?

8. Describe how control rods are checked for proper release and scram time.

9. Describe the servo controlled rods, action setpoints, and the limit of travel.

10. Describe how the control-rod drives (only) are raised. When is this manipulation necessary? 


\section{$\underline{\text { References }}$}

1. Facility final safety analysis reports.

2. Vendor information.

3. Technical specifications.

Lesson Plan No. 22. Balance of Plant Systems

\section{Objective}

All remaining control systems required to be manipulated by operators should be presented. Systems requiring local control should be reviewed from the control and instrumentation aspect at this point in the training program and/or when each individual system is discussed. Items for review should cover at least those listed in the following lesson plan, and the systems should include those such as process monitoring, process radiation monitoring, electrical distribution system, coolant purification system, air supply system, etc. Emphasis should also be placed on any and all control room indications and alarms and the expected control room operator response.

\section{Plan Outline}
A. Design basis
B. System description
C. Checks and tests to be performed
D. Indications (meters, recorders, etc.)
E. Manual and automatic actuation
F. Power supply
G. Administrative controls 
$\underline{\text { References }}$

1. Facility final safety analysis reports.

2. Vendor information.

3. Technical specifications. 
SECTION XII. STANDARD AND EMERGENCY OPERATING PROCEDURES

Contents

Introduction . . . . . . . . . . . . . . 221

Lesson P1an No. 1. Primary Coolant System . . . . . . . . 222

Lesson Plan No. 2. Secondary Coolant System . . . . . . 223

Lesson Plan No. 3. Reactor Cleanup System . . . . . . . 224

Lesson Plan No. 4. Residual-Heat Removal System . . . . . 226

Lesson Plan No. 5. Emergency Core Coolant System . . . . . . 228

Lesson Plan No. 6. Radioactive Waste Disposal Systems . . . . 229

Lesson Plan No. 7. Containment System . . . . . . . . 230

Lesson Plan No. 8. Fuel Handling and Storage . . . . . . 231

Lesson Plan No. 9. Cold Startup Procedure . . . . . . . 233

Lesson Plan No. 10. Reactor Operation . . . . . . . . 235

Lesson Plan No. 11. Evacuation, Fire Alarm, and Radiation and

Contamination Procedures . . . . . . . . . . 237

Lesson Plan No. 12. Standby Liquid Control System . . . . . 238

Lesson Plan No. 13. Turbine-Generator . . . . . . . . 239

Introduction

The purpose of this section is obvious; it is included here to provide an outline of the various reactor systems and standard and emergency operating procedures. A thorough knowledge of the subject procedures is essential to the well-trained reactor operator.

The operator should be sufficiently familiar with the plant and auxiliary systems to be able to follow the detailed procedures without hesitation and to outline, generally, the standard procedures in a broad sense.

Emergency procedure for evacuations, fire alarms, radiation and contamination emergencies, and abnormal operating conditions should be thoroughly ingrained in the operator so that he will be able to perform the necessary functions immediately upon their occurrence. 
While all possible procedures cannot be covered, it is hoped that enough of the more important ones will be found in this outline to give instructors adequate assistance in planning a training course on individual reactors.

Leeson Plan No. 1. Primary Coolant System

Objective

The trainee should learn (1) the purpose and operation of individual. components within the system and the effects of their operation on the system, (2) the purpose and operation of the system within the overall reactor complex and the effects of system operation on the reactor complex, and (3) the limitations associated with the systems operation.

P1an nut1ine

A. Normal nperation

1. Operating limitations

2. Preparation for startup

3. Startup checklist

4. Heating and pressurizing the system

5. Routine operation and checks

6. System shutdown

7. Shut duwn check11st

B. Abnormal operation

1. Operating 1imitations

2. Leak detection

3. Loss of feedwater flow

4. Loss of system pumps

5. Loss of primary cooling capacity

6. Annunciator procedures 
Sample Study Questions

1. What operating limitations are placed on coolant flow with the reactor at full-power operation?

2. Explain in general terms the procedure used to start up the primary coolant system.

3. What are the limits placed upon the primary coolant chemistry?

4. How is the temperature of the system controlled? Explain the procedure for adjusting this temperature.

\section{References}

1. Final safety analysis reports.

2. Technical specifications.

3. Vendor information.

Lesson Plan No. 2. Secondary Coolant System

\section{Objective}

The student should learn (1) the operation of individual components w1thin the system, (2) the operation of the system within the overall reactor complex, and (3) limitations associated with the system's operation.

\section{$\underline{\text { Plan Outline }}$}

A. Normal operations

1. Operating 1imitations

2. Preparation for startup

3. Startup checklist 
4. Placement of system in service

5. Routine operation and checks

6. Chemical treatment

7. Removal of system from service

8. Shutdown checklist

B. Abnormal operations

1. Operating Iimitations

2. Loss of system pumps

3. Emergency operating procedures

4. Annunciator procedures

\section{Sample Study Questions}

1. Explain the chemistry control method used in the secondary coolant system.

2. Explain the general procedure for placing the secondary system in service.

3. What is the minimum secondary system flow rate during full-power reactor operation?

4. Explain the general procedure for placing the emergency secondary coolant system in operation.

Lesson Plan No. 3. Reactor Cleanup System

\section{Objective}

The student should learn (1) operation of the system using normal operating procedures, (2) precautions and prerequisites to system operation, (3) system malfunctions and abnormal operating procedures, and (3) operating limitations. 


\section{Plan Outline}

A. Normal operation

1. Prerequisites

2. Precautions

3. Operating limitations

4. Placing the system in service

5. Routine operation and checks

6. Removing the system from service

7. Demineralizer regeneration and backwashing

8. Resin replacement

B. Abnormal operation

1. Demineralizer bypassing

2. System alarms and malfunctions

3. Loss of system pumps

\section{Sample Study Questions}

1. Explain the procedure for bypassing one or both of the demineralizer columns.

2. What are the operations limitations placed on coolant chemical quality of the cleanup system?

3. Explain the procedure for disposal of radioactive spent resins and replacement with new resin.

4. Explain the procedure for regenerating a demineralizer.

\section{$\underline{\text { References }}$}

1. Final safety analysis report.

2. Technical specifications.

3. Vendor information. 
Lesson Plan No. 4. Residual-Heat Removal (RHR) System

\section{Objective}

The trainee should learn (1) operating limitations, (2) normal operation with the systems in standby, (3) operation of the systems during emergency situations, (4) accepted procedures during possible system malfunctions, and (5) system test and checkout procedures.

\section{Flan Outline}

A. Normal operation

1. Prerequisites

2. Precautions

3. Normal standby

4. Normal LPCI mode operational sequence

5. Torus cooling

6. Containment spray

7. Torus spray

8. Eystem shutdown from LPCI operation

9. RHR system flush

10. Shutdown cooling

11. Head epray

12. Shutdown from head spray operation

13. Fuel pool cooling

B. Abnormal operation

1. Operational sequence with a loss of AC concurrent with an emergency core coolant (ECC) 5 initiate signal

2. E'mergency reactor vessel cooling

3. Pump trip

4. High seal leakage

5. Low flow

6. Infection valve overload

7. System valve overload 
8. Pump power failure

9. High conductivity

10. High header pressure

11. Loss of cooling to heat exchanger

12. Low header pressure

C. Surveillance testing

1. Pump and valve operability test

2. RHR full-flow test

3. Simulated automatic actuation test

4. Core spray and LPCI test

5. Containment spray operability test

\section{Sample Study Questions}

1. Describe the method of automatic actuation of the low-pressure coolant injection system.

2. Describe the flow path of water after actuation of the LPCI system. How can this flow path automatically be selected?

3. What is the flow path of the RHR system when used for shutdown cooling? What initiates this mode of operation?

4. How is the RHR system used to assist the fuel pool cooling system during periods of high heat loads?

5. During what periods are the containment cooling spray loops required to be operable?

\section{References}

1. Final safety analysis report.

2. Technical specifications.

3. Vendor information. 
Lesson Plan No. 5. Emergency Core Coolant System

\section{Objective}

The student should learn (1) operating limitations, (2) normal operation with system in standby, and (3) system malfunctions and abnormal operating procedures.

\section{Plan Outline}

A. Uperating procedures

1. Prerequisites

7. Preraitrinns

3. Initiation signals for system components

4. Operational sequence with normal power available

5. Operational sequence with normal power not available

6. Operational sequence on gas turbine generator

7. Alarms and system malfunctions

8. System tests and checkouts

0. Eyatcm chcekliats

\section{Sample Study Questions}

1. What reactor conditions require that one core spray subsystem be operable? Both systems? What action must be taken if these conditions are not met?

2. Describe the sequence of automatic actuation of the core spray system.

\section{$\underline{\text { References }}$}

1. Final safety analysis report.

2. Technical specifications.

3. Vendor information. 
Lesson Plan No. 6. Radioactive Waste Disposal System

\section{Objective}

The student should learn (1) procedures for normal disposal of wastes, (2) system operating 1imitations, and (3) procedures for emergency control and disposal of wastes.

\section{Plan Outline}

A. Operating procedures - 1iquid waste system

1. Prerequisites

2. Precautions

3. Processing waste collector tank

4. Waste demineralizer operation

5. Neutralizing waste

6. Concentrating waste

7. Alarms and malfunctions

8. System checklists

B. Operating procedures - solid waste system

1. Prerequisites

2. Precautions

3. Placing centrifuge and hopper in service

4. Removing centrifuge and hopper from service

5. Processing spent resins

6. Processing cleanup filter sludge tank

7. Radwaste conveyor system operation

\section{Sample Study Questions}

1. What are the radioactivity limits for discharging wastes into the canal?

2. What are the limits for determining that the radwaste demineralizer resin is depleted? 


\section{References}

1. Final safety analysis report.

2. Technical specifications.

3. Vendor information.

Lessoin Plan Nu. 7. Contalnment System

\section{Objective}

The student should learn (1) operating limitations, (2) procedures for systems normal operation, (3) procedures for systems emergency operation, and (4) automatic isolation functions.

\section{Plan Outline}

A. System procedures

1. Prerequisites

2. Precautions

3. Functions of the system

4. Drywell cooling and ventilation

5. Secondary containment ventilation

6. Nitrogen inerting

7. Standby gas treatment system

8. Automatic initiation signals

9. System testing and checkout

10. Operating limitations

11. Alarms and system malfunctions

12. System checklists 
Sample Study Questions

1. What reactor operating conditions dictate containment integrity?

2. How are tests made to ensure containment integrity?

3. What actions must be taken during reactor operation if containment integrity is compromised?

4. List the signals which cause primary containment isolation. What action do these signals initiate?

\section{References}

1. Final safety analysis report.

2. Technical specifications.

3. Vendor information.

Lesson Plan No. 8. Fuel Handling and Storage

Objcctive

The trainee should learn (1) procedures for safe and efficient handling of new and irradiated fuel, (2) storage limitations, and (3) precautions against hazards involved in fuel handling.

\section{$\underline{\text { Plan Outline }}$}

A. Preparation for refueling

1. Authorization

2. Use of equipment

3. Instrumentation requirements for refueling

4. Plant operating requirements

5. Nuclear considerations 
6. Precautions

7. Pre-shutdown preparations

8. Reactor shutdown

B. Refueling

1. Communications

2. Fue1 shipping

3. Unloading a fuel assembly

4. Loading a new fuel assembly

5. In-core transfer of a fuel assembly

C. Depleted fuel element

1. Storage location

2. Hazards Involved

3. Disposal of depleted fuel

D. Defective fuel element

1. Hazards involved

2. Handling precautions

3. Disposal methods

4. Detection of defective fuel elements

Sample Study Questions

1. What are three potential hazards involved in reạctor rofueling? What procedures protect against these hazards?

2. Describe the procedure used to inspect new fuel elements prior to their insertion in the reactor.

3. Describe the procedure used to dispose of spent fuel assemblies.

4. Explain the importance of installing new fuel assemblies in their assigned location.

References

1. Final safety analysis report.

2. Technical specifications.

3. Vendor information. 
Lesson Plan No. 9. Cold Startup Procedure

Objective

The student should learn (1) procedures for safe programmed reactor startup, (2) procedures for emergency or abnormal situations, and (3) operating limitations.

\section{Plan Outline}

A. Plant conditions preparatory to plant startup

1. Electrical system

2. Primary and secondary containment

3. Nuclear steam supply system and auxiliaries

4. Turbine generator and auxiliaries

5. Circulating water and condenser

6. Condensate and feedwater system

7. Instrumentation systems

8. Auxiliary systems

9. ECCS standby

10. Keactor water cleanup systems

11. Fuel pool cooling and filtering system

12. Reactor building cooling water system

13. Blowdown system

B. Cold startup preparation

1. Pre-startup checks and operations

2. Starting recirculating pumps

3. Starting feedwater and condensate pimps

4. Venting of noncondensible gases from the reactor

5. Securing shutdown cooling mode

C. Approach-to-critical and pressurization of reactor

1. Approach-to-critical

2. Determining criticality

3. Heating and pressurization of the reactor 
D. Startup and synchronization of the unit

1. Increasing power by control rod withdrawal

2. Turbine startup

3. Transfer of reactor mode to "Run"

4. Transfer house loads from startup transformer to the station auxiliary transformer

E. Increase of power to rated

1. Increase of power to $10 \%$ of rated

2. Transfer of vessel level control to automatic

3. Increase of power to $20 \%$ of rated

4. Placing recirculation system on master control

5. Increasing power to $50 \%$ of rated

6. Increasing power to $100 \%$ of rated

7. Abnormal operation

8. System checklists

\section{Sample Study Questions}

1. During scheduled rod withdrawal to criticality, one rod is withdrawn past its predicted critical rod position and all others are at critical position. What response is expected of the opcrator?

2. Assuming normal cold startup during rod withdrawal to criticality, what is the fastest period allowed?

3. What is the difference between attaining criticality and heating pnwer?

4. What is meant hy the term "half-perind"?

5. During power escalation, the flux scram switch is moved from noncoincident to coincident. Why? What does this mean?

6. During the heating period, the temperature increase between 180 and $212^{\circ} \mathrm{F}$ should be passed through quickly. Why?

7. During the heating period, the control rods must be withdrawn to keep the power level constant. Why? 
8. When boiling begins in the core, the period scram must be bypassed. Why? How is boiling detected?

9. The $\log -\mathrm{N}$ and in-core flux measuring instruments show increases as turbine load increases. Why? What has this to do with reactivity increases?

\section{$\underline{\text { References }}$}

1. Final safety analysis report.

2. Technical specifications.

3. Vendor information.

\section{Lesson Plan No. 10. Reactor Operation}

\section{Objective}

The student should learn (1) established procedures in all phases of normal reactor operation, (2) actions and operations which must be followed during emergencies, and (3) operating limitations.

\section{Plan Outline}

A. Startup

1. Operating limitations

2. Startup checklist

3. Minimum instrumentation required

4. Minimum equipment required

5. General startup procedures

6. Power escalation

7. Startup following accidental shutdown

8. Annunciator procedures 
B. Routine operation

1. Control rod manipulation

2. Minimum instrumentation required

3. Minimum equipment required

4. General operating procedures

5. Routine operational checks

6. Annunciator procedures

C. Shutdowns

1. Accidental

2. Administrative

3. Eule ryenticy

4. Shutdown checklist

5. Annunciator procedures

\section{Sample Study Questions}

1. Explain briefly the cold startup procedure.

2. What instrumentation, in particular, should be closely observed during startup?

3. What procedures are used for startup following an accidental shutdown?

\section{References}

1. Final safety analysis reports.

2. Technical specifications.

3. Vendor information. 
Lesson Plan No. 11. Evacuation, Fire Alarm, and Radiation and Contamination Procedures

\section{Objective}

The trainee should learn (1) to perform those actions required during emergencies in such a way as to minimize exposure to personnel and equipment from radiation and radioactive contamination and (2) to safely secure equipment during building evacuations.

\section{Plan Outline}

A. Evacuation

1. Conditions requiring evacuation

2. Evacuation paths

3. Partial evacuation

4. Total area-wide evacuation

5. Actions required during evacuation

6. Emergency equipment

7. Evacuation drills

B. Fire alarm

1. Fire-fighting procedures

2. Building area isolation during fire alarm

3. Use of fire-fighting equipment

4. Fire alarm in areas requiring evacuation

C. Radiation and contamination emergencies

1. Fission product release

2. Immediate action required

3. Personnel exposure

4. Contamination cleanup and isolation

5. Health physics measures required

6. Reactor operation during emergencies

7. Emergencies requiring reactor shutdown 
Sample Study Questions

1. What immediate action is required by the operator upon receipt of a fire alarm?

2. Describe the total building evacuation procedure.

$\underline{\text { References }}$

1. Final safety analysis report.

2. Technical specifications.

3. Vendor information.

Lesson Plan No. 12. Standby Liquid Control System

\section{Objective}

The student should learn (1) the purpose of the system, (2) when it should be activated manually or automatically, (3) operating limitations, and (4) test and checkout procedures.

\section{Plan Outline}

A. Operating procedures

1. Plant operating requiremenes

2. Precautions

3. Prerequisites

4. Charging the standby liquid control tank

5. Placing the system in standby readiness

6. Injecting the solution into the reactor vessel

7. Alarms and system malfunctions

8. System checklists 


\section{Sample Study Questions}

1. What is the purpose of the standby liquid control system? How does one determine when to use the system?

2. Describe the procedure for placing the liquid control system in use.

3. What concentration of the solution is required in the storage tank?

4. Describe what routine checks are necessary to ensure the dependability of the liquid control system.

\section{References}

1. Final safety analysis report.

2. Technical specifications.

3. Vendor information.

Lesson Plan No. 13. Turbine-Genèrator

Objective

Procedures for efficient and safe operation of the equipment should be learned.

\section{Plan Outline}

A. Turbine-generator warmup (synchronizing and loading)

1. Prerequisites

2. Precautions

3. Preparation before producing steam in reactor

4. Preparation for starting and warming up

5. Starting and bringing up to speed

6. Loading 
B. Shutting down turbine-generator

1. Reducing load

2. Removing unit from the line

C. Turning gear operation

1. Prerequisites

2. Precautions

3. Turning gear automatic operation

4. Return of turning gear to service after shutdown of cooled turbine

5. Removal of turning. gear from service

6. Kemoval of turning gear from service on turbine startup

D. Hydrogen shaft seal oil system

1. Prerequisites

2. Precautions

3. Starting the seal oil system

4. Shutting down the seal oil system

5. Alarms and system malfunctions

6. Sys tem checklists

E. Generator stator cooling water system

1. Prerequisites

2. Precautions

3. Stator cooling water normal operation

4. Alarms and system malfunctions

5. System checklists

F. Initial pressure regulator

1. Placing inflial pressure regulator in service

2. Removing initial prescure regulator from eervice

3. Transferring to mechanical pressure regulator

4. Test operation of IPR

5. Alarms and system malfunctions

G. Test operation of emergency governor

1. Oil trip and lockout:

2. 0il trip testing of the emergency governor 
H. Turbine oil purification system

1. Prerequisites

2. Precautions

3. Filling turbine oil reservoir and oil purifier

4. Alarms and system malfunctions

5. System checklists

I. Starting and loading turbine-generator

1. Prerequisites

2. Precautions

3. Starting the turbine

4. Shutting down the turbine

5. Load removal

6. Turning gear operation

\section{Sample Study Questions}

1. What primary concern dictates the speed of loading the turbine generator?

2. What is meant by the rotor critical speeds?

3. How much vibration of the generator journal is allowed while increasing the speed of the generator? What adverse effects are caused by excessive vibration?

4. Why must the generator be synchronized before placing it on stream?

5. Why must the turbine generator be placed on the turning gear immediately after its removal from service?

\section{References}

1. Final safety analysis reports.

2. Technical speciflcations.

3. Vendor information. 


\section{THIS PAGE}

\section{WAS INTENTIONALLY \\ LEFT BLANK}


Part C - Senior Operator Training Program 
SECTION XIII. REACTOR THEORY

Contents

Introduction . . . . . . . . . . . . . . . . . 244

Classroom Illustrations and Laboratory Experiments . . . . . . 245

Lesson Plan No. 1. Fission . . . . . . . . . . . . . . . . 246

Lesson Plan No. 2. Chain Reaction . . . . . . . . . . . . . 249

Lesson Plan No. 3. Subcritical Multiplication . . . . . . . . 252

Lesson Plan No. 4. Supercriticality . . . . . . . . . . . 254

Lesson Plan No. 5. Reactor Control . . . . . . . . . . . . 257

Lesson Plan No. 6. Types of Reactors . . . . . . . . . . 260

Introduction

Most of the material in this section is based on the topics treated in Section VII (Principles of Reactor Operation), but the senior operator will be expected to learn the subject material in greater depth and to have a more quantitative understanding of the fundamental principles of reactor theory applicable to the fission process, including criticality, kinetic response of the core, effects of control rods, and flux distribuclon. Although it is difficult to specify exactly how much more the senior operator should know, examples will be indicated in the objectives and questions of each lesson plan to convey a feeling for the degree of understanding that is necessary, More spectflcally, the reactor operator 1s expected to be able to recognize what is happening from observation, whereas the senior reactor operator is expected to be able to explain why it is happening.

The objectives of this section on reactor theory are

1. To develop the basic concepts of neutron fission, neutron multiplication, and the kinetic response of the core.

2. To develop some of the formulae used to calculate power level, period reactivity, flux levels, critical rod positions, etc. 
3. To develop a practical knowledge of the effect of changes in reactivity caused by such things as changes in temperature, rod position, and addition of an in-core experiment, etc.

4. To develop an understanding of the objectives and advantages of the specific design features of the reactor core, control system, safety system, cooling systems, etc.

5. To help the student become relatively familiar with reactor physics terminology to develop his appreciation and understanding of publications in the field of nuclear technology.

Classroom Illustrations and Laboratory Experiments

Included in the lesson plans are a few examples of teaching illustrations. The training coordinator will find many others in the literature as he sets up this training program. If there is a low-power reactor available, experiments such as those listed below could be included in the program.

1. Scattering and absorption of neutrons.

2. Thermal neutron capture cross sections.

3. Period of delayed neutrons from fission.

4. Fission propertles of U-235.

5. Diffusion length of thermal neutrons.

6. Moderation of neutrons.

7. Neutron flux distribution.

8. Fast neutron shielding.

9. Critical mass of a nuclear reactor.

10. Gamma and thermal neutron attenuations. 
Lesson Plan No. 1. Fission

Objective

The treatment of the effect of burnup on the delayed neutron fraction and the reactor is an example of the depth of knowledge that is expected of the senior reactor operator, as opposed to that expected of the reactor operator.

In Section VII the trainee was expected to learn that the value of the delayed neutron fraction will change over the core life of a power react or because $\mathrm{Pu}-239$ is formed in the slightly enriched core. Since each of these radionuclides fission with a smaller beta-fraction than $\bar{U}-235$, the beta-fraction for the core decreases as the life of the core increases. In this section he should learn that this change has an effect on reactor response to reactivity and should be able to explain the reason for the response by use of the inhour equation, $T=\frac{\beta-\rho}{\lambda \mu}$. As $\beta$ decreases, the numerator approaches zero and the reactor period becomes shorter for a given reactivity insertion.

Other subjects in this lesson plan should be accorded similar depth

of treatment.

Plan Outline

A. Types of reactions (review)

1. Cross sections

a. Units of medsurtutin

b. Microscopic and macroscopic

2. Absorption

a. Variation with energy

b. Comparison of materials

3. Scattering

a. Heavy vs light isotopes

4. Fission

a. U-235, U-238, Pu-239 
B. Fission process

1. Fission cross sections

a. Energy dependence

b. Isotope dependence

c. Fissile vs fertile material

d. Fast vs thermal fission

e. Fission of U-235, U-238, and $\mathrm{Pu}-239$

2. Fission reaction and energy release

a. Moderation

b. Energy release

c. Fisssion products

d. Neutron balance

e. Energy deposition distribution (i.e., in fuel, clad, and coolant)

3. Fission neutrons
a. Prompt
b. Delayed
c. Fast
d. Slow
e. Number released for U-235, U-238, Pu-239
f. Neutron lifetime
g. Importance of delayed
h. $\beta$ and $\beta$-effective
i. Effect on reactor control

Sample Study Questions

1. What is fission?

2. What is the difference between fast neutrons and prompt neutrons? What is the difference between slow neutrons and prompt neutrons?

3. What is meant by the fission spectrum?

4. What is meant by enrichment?

5. What are the properties of a good moderator? 
6. Explain the meaning of nuclear cross section. What are the units of cross section? What does the product of flux and cross section give?

7. If $1 \%$ excess reactivity is added to a critical reactor, the resulting period is very short. Explain in detail why the addition of $1 \%$ negative reactivity to a critical reactor results in a long stable period.

\section{References}

Since anyone selected to conduct a training program for nurlear reactor operators will already have a knowledge of reactors, we have included only one of the many standard textbooks available on the subject.

1. R. A. Costner, Jr., E. N. Cramer, and R. L. Scott, Jr., Reactor Operator Study Handbook (Programmed Instruction Version). Vol. III - Reactor Physics, ORNL/TM-2034, Oak Ridge National Laboratory, Oak Ridge, Tenn., June 1968.

2. D. F. Hanlen, G. N. Hamilton, and E. G. Taylor, Westinghouse Reactor Evaluation Center: Reactor Operator Training Manual, USAEC Rept. WCAP-271.3 (rev.), Westinghouse Electric Corp., October 1967.

3. D. F. Hanlen and W. J. Moroc, Nuclear Physies Made Very, Ver'y Easy, USAEC Rept. NTO-T-0026, Nevada Test Operations, July 1968.

4. S. E. Liverhant, Elementary Introduction to Nuclear Reactor Physics, John Wiley \& Sons, Inc., New York, 1960.

5. U.S. Nuclear Regulatory Commission, Operating Experience Information on Inspections and Enforcement Bulletins and Replies, Washington, D.C.

6. Congressional Information Bureau, Inc., Atomic Energy Clearing House, Washington, D.C.

7. Nuclear Safety, Superintendent of Documents, U.S. Government Printing Office, Washington, D.C. 20402.

8. Nuclear News, American Nuclear Soclety, 244-A East Ogden Avenue, Hins dale, III:- 60521 .

9. Power, P.0. Box 521, H1ghtstown, N.J. 08520. 


\section{Lesson Plan No. 2. Chain Reaction}

\section{Objective}

In this lesson plan the treatment of the six-factor formula is an example of the depth of understanding expected of the senior reactor operator as opposed to the reactor operator. Other topics should receive similar increased depth of treatment.

In Section VII the student was expected to learn the principal processes by which neutrons are generated (thermal and fast fission) and lost (by leakage and by absorption in U-238, control rods, and core materials). A senior reactor operator is expected to be able to explain. such things as how temperature affects each term of the six-factor formula.

\section{Plan Outline}

A. Description of reactor components

1. Fuel

2. Moderator

3. Reflector

4. Cooling system

5. Control system

6. Shielding

B. Dependence on core material

1. Fue.1.
a. Pu vs U
b. Amount
c. Enrichment

2. Coolant

a. Temperature effects

b. Void effects

3. Control system 
C. Neutron Balance

1. The six-factor formula

a. Fast fission effect

b. Resonance escape probability

c. Thermal utilization factor

त. Fita

e. Nonleakage probability (fast)

f. Nonleakage probability (therma1)

2. Effects of core materials and parameters on the six-factor formula

a. 'lype of fuel

b. Amount of fuel

c. Fuel burnup effect

d. Coolant

e. Control system

f. Reflector,

g. Chemical poison

h. Burnable poison

i. T'emperature

j. Voids

3. ko vis $k_{\text {eff }}$

4. Excess reactivity

5. Subcritical, critical, and supercritical

\section{Sample Srudy Questions}

1. Explain the difference between k-infinity and k-eftective.

2. What effects contribute to the balance of neutrons in an operating reactoor?

3. Write the formula for k-effective, and define each term.

4. List and briefly describe or explain the processes taking place in an operating reactor which compete with fission in "consuming" neutrons. 
5. Consider a bare thermal reactor that is in outer space and is just critical. If it were then completely surrounded with cadmium, would the reactor remain critical, become supercritical, or become subcritical? Explain your answer.

\section{$\underline{\text { References }}$}

Since anyone selected to conduct a training program for nuclear reactor operators will already have a knowledge of reactors, we have included only one of the many standard textbooks available on the subject.

1. R. A. Costner, Jr., E. N. Cramer, and R. L. Scott, Jr., Reactor Operator Study Handbook (Programmed Instruction Version). Vol. III-Reactor Physics, ORNL/TM-2034, Oak Ridge National Laboratory, Oak Ridge, Tenn., June 1968.

2. D. F. Hanlen, G. N. Hamilton, and E. G. Taylor, Westinghouse Reactor Evaluation Center: Reactor Operator Training Manual, USAEC Rept. WCAP-2713 (rev.), Westinghouse Electric Corp., October 1967.

3. D. F. Hanlen and W. J. Morse, Nuclear Physics Made Very, Very Easy, USAEC Rept. NTO-T-0026, Nevada Test Operations, July 1968.

4. S. E. Liverhant, Elementary Introduction to Nuclear Reactor Physics, John Wiley \& Sons, Inc., New York, 1960.

5. U.S. Nuclear Regulatory Commission, Operating Experience Information on Inspections and Enforcement Bulletins and Replies, Washington, D.C.

6. Congressional Information Bureau, Inc., Atomic Energy Clearing House, Washington, D.C.

7. Nuclear Safety, Superintendent of Documents, U.S. Government Printing Office, Wash1ngton, D.C. 20402.

8. Nuclear News, American Nuclear Society, 244-A East Ogden Avenue, Hinsdale, I11. 60521.

9. Power, P.0. Box 521, Hightstown, N.J. 08520. 
Lesson Plan No. 3. Subcritical Multiplication

Objective

Approach-to-criticality is an example of the depth of knowledge expected of the senior reactor operator as opposed to the reactor operator.

In Section VII the student learned to take data, construct a $1 / \mathrm{M}$ plot, and predict criticality. In this section he should learn to use the formula $k_{\text {eff }}=1-1 M$ in calculating the effect of count-rate changes on $k_{\text {eff }}$ and vice versa. Other topics in the lesson plan should receive similar depth of treatment.

$\underline{\text { Plan Outline }}$

A. Approach-to-critical fuel loading

1. Importance function

a. Fue1

b. Geometry

2. Source neutrons, subcritical multiplication, location effect, distribution, purpose

3. Calculations using $1 / M=1-k_{\text {eff }}$

4. Shutdown margin

B. Approach-to-critical rod withdrawal

1. Location of control rods

2. Burnable poison

3. Calculations using $1 / M$ and plotting exercise

C. Achleving critical,i,ty

1. Indications

a. Period indications and recnricr plnten

b. Power level indications and recorder plots

2. Reactivity coefficients effect

a. Temperature

b. Degree of fuel burnup

c. Xenon buildup and decay

d. Other 
Sample Study Questions

1. What mathematical relationship exists between subcritical multiplication and the multiplication factor for a subcritical reactor?

2. Discuss the geometrical positioning of the source and the detector in relation to the core or an approach-to-critical fuel loading.

3. A reactor has a count rate of $30 \mathrm{cps}$ when it has a $k_{\text {eff }}$ of 0.95 . Is $40 \mathrm{cps}$ the proper count rate when $k_{\text {eff }}$ is 0.975 ? Show how you arrived at your answer. If the ganged rod positions are 16 and 19 in. withdrawn when $k_{\text {eff }}$ is 0.95 and 0.975 , respectively, what ganged rod position would you estimate for criticality?

4. During a core loading, the count rate is 1000 counts/min when $\mathrm{k}_{\text {eff }}=0.9$. Sometime later during the loading the count rate is 2000 counts/min. What is $k_{\text {eff }}$ ?

\section{References}

Since anyone selected to conduct a training program for nuclear reactor operators will already have a knowledge of reactors, we have included only one of the many standard textbooks available on the subject.

1. R. A. Costner, Jr., E. N. Cramer, and R. L. Scott, Jr., Reactor Operator Study Handbook (Programmed Instmuction Version). Vol. III - Reactor Physics, ORNL/TM-2034, Oak Ridge National Laboratory Uak Ridge, Tenn., June 1968.

2. D. F. Hanlen, G. N. Hämilton, and E. G. Taylor, Westinghouse Reactor Evaluation Center: Reactor operator Training Manual, USAEC Rept. WCAP-2713 (rev.), Westinghouse Electric Corp., October 1967.

3. D. F. Hanlen and W. J. Morse, Nuclear Physics Made Very, Very Easy, USAEC Rept. NTO-T-0026, Nevada Test Operations, July 1968.

4. S. E. Liverhant, Elementary Introduction to Nuclear Reactor Physies, John Wiley \& Sons, Inc., New York, 1960. 
5. U.S. Nuclear Regulatory Commission, Operating Experience Information on Inspections and Enforcement Bulletins and Replies, Washington, D.C.

6. Congressional Information Bureau, Inc., Atomic Energy Clearing House, Washington, D.C.

7. Nuclear Safety, Superintendent of Documents, U.S. Government Printing Office, Washington, D.C. 20402.

8. Nuclear News, American Nuclear Society, 244-A East Ogden Avenue, Hinsdale, Ill. 60521 .

y. Hower, P.0. Box 521, Hightstown, N.J. 08520.

Lesson Plan No. 4. Supercriticality

Objective

An example of the greater depth of understanding expected of the senior reactor operator, as opposed to the reactor operator, is shown in the treatment of reactor period.

The reactor period knowledge needed by reactor operators is that required to estimate the reactor power at the end of a given time interval, a given period, or vice versa. In addition to understanding the periodtime-power relationship, a senior reactor operator is expected to be able. to understand the relationship between reactivity period and beta and to make estimates of period for insertions of reactivity and vice versa. Other topics in this lesson plan should be given similar depth of treatment.

\section{$\underline{\text { Plan Outline }}$}

A. Supercritical vs prompt critical

1. Reactor kinetics

a. Inhour equation

b. $B$ and $B$ eff 
2. Exponential behavior

3. Neutron lifetime

a. Fuel burnup effect

b. Plutonium buildup effect

B. Time behavior

1. Prompt jump and delayed response

2. Calculation of reactor period

3. Period vs reactivity

C. $k_{\text {eff }}$ and beta

1. Mathematical relationships

a. Inhour equation

b. $P=P o(e) \frac{t}{\tau}$

c. Calculations (problems based on above-listed topics similar to study questions)

Sample Study Questions

1. What will be the resultant reactor period for a reactivity insertion of $0.001 \Delta \mathrm{k} / \mathrm{k}$ and $0.01 \Delta \mathrm{k} / \mathrm{k}$ ?

2. Suppose your reactor had a $\beta$ fraction of $1.0 \%$ rather than.its actual value. If a reactivity insertion of $0.1 \% \Delta \mathrm{k} / \mathrm{k}$ were made to the critical reactor, would the resultant period be shorter or longer than that resulting from the actual beta fraction? Explain.

3. The reactor is critical at very low power. A step increase in reactivity of $0.002 \Delta \mathrm{k} / \mathrm{k}$ is added. What will be the resulting period with and without delayed neutrons?

4. Explain the difference in $k_{\text {excess }}$ and reactivity.

5. Explain the difference between beta and beta-effective. Explain why these values change from beginning of life (BOL) to end of life (EOL) in a fuel loading of a power reactor. How will this affect reactor response to reactivity insertions? Explain. 
6. Write the inhour equation for your facility. To obtain a good approximation of the reactor period, would it be necessary to use the complete equation for the following reactivity insertions?

a. $0.001 \Delta \mathrm{k} / \mathrm{k}$.

b. $0.01 \Delta \mathrm{k} / \mathrm{k}$.

Explain.

\section{References}

Since anyone selected to conduct a training program for nuclear reactor operators will already have a knowledge of reactors, we have included only one of the many standard textbooks available on the subject.

1. R. A. Costner, Jr., E. N. Cramer, and R. L. Scott, Jr., Reactor Operator Study Handbook (Programmed Instruction Version). Vol. III - Reactor Physics, ORNL/TM-2034, Oak Ridge National Laboratory, Oak Ridge, Tenn., June 1968.

2. D. F. Hanlen, G. N. Hamilton, and E. G. Taylor, Westinghouse Reactor Evaluation Center: Reactor Operator Training Manual, USAEC Rept. WCAP-2713 (rev.), Westinghouse Electric Corp., October 1967.

3. D. F. Hanlen and W. J. Morse, Nuclear Thysies Made Very, Very Easy, USAEC Rept. NTO-T-0026, Nevada TeEt Operatione, July 1968.

4. S. E. Liverhant, Elementary Introduction to Nuclear Reactor Physics, John Wiley \& Sons, Inc., New York, 1960.

5. U.S. Nuclear Regulatory Commission, Operating Experienee Information on Inspections and Enforcement Bulletins and Replies, Washington, D.C.

6. Longressional Intormation Bureau, Inc., Atomic t'nergy l'Learing Hulveis, Washington, D.C.

7. Nuclear Safety, Superintendent of Documents, U.S. Government Printing Office, Washington, D.C. 20402.

8. Nuclear News, American Nuclear Society, 244-A East Ugden Avenue, Hinsdale, I11. 60521.

9. Power, P.0. Box 521, Hightstown, N.J. 08520. 
Objective

In this lesson plan the treatment of temperature coefficient illustrates the added depth of understanding expected of. the senior reactor operator. Other topics should be given similar treatment. Reactor operators are expected to understand the effect of the temperature coefficient of reactivity on their reactor. They are expected to understand that, as the moderator becomes less dense, moderation is decreased and leakage increases. A senior reactor operator also should understand the concept of over- and under-moderation and how it affects the temperature coefficient.

\section{Plan Outline}

A. Effect of control rods

1. Composition

2. Rod worth

3. Separation from fuel

4. Position effects (radial and axial)

5. Burnup

6. Coolant chemistry effects.

7. Overmoderation effect

8. Avoidance of positive coefficient

9. Variation with core lifetime

B. Reactivity coefficients

1. Temperature coefficient

2. Void coefficient

3. Doppler coefficient

4. Power coefficient

5. Under-moderation effect on coefficients

C. Flux and power distribution

1. Importance function

2. Burnable poisons 
3. Liquid control

4. Normal flux variation through core lifetime

5. Reason for flat power distribution

6. Effect of fuel enrichments

7. Radial and axial

D. Systems affecting reactor control

1. Chemical shim (PWR)

2. Recirculation system (BWR)

3. Turbine load

4. Abnormal effects such as loss of feedwater heaters

5. Pressure variation effects

6. Temperature variation effects

Sample Study Questions

1. Does a control rod's worth vary with its radial position in a reactor? Explain. Does it vary if another rod is placed adjacent to it? Explain. If the moderator temperature increases? Explain. If the voids in the core increase? Explain.

2. Explain how the selection of the moderator-fuel ratio can affect the temperature coefficient:

3. Vuid formation in a reactor produces three major reactivity effects. Briefly describe these and indicate whether each by itself has a positive or negative effect.

4. Define radial flux distribution and axial flux distribution.

5. Why are bottom entry control rods desirable in a BWR?

6. Explain why, or why not, each of the following is dependent on neutron flux.
a. Power level
b. Xenon equilibrium
c. Samarium equilibrium 


\section{$\underline{\text { References }}$}

Since anyone selected to conduct a training program for nuclear reactor operators will already have a knowledge of reactors, we have included only one of the many standard textbooks available on the subject.

1. R. A. Costner, Jr., E. N. Cramer, and R. L. Scott, Jr., Reactor Operator Study Handbook (Programmed Instruction Version). Vol. III - Reactor Physics, ORNL/TM-2034, Oak Ridge National Laboratory, Oak Ridge, Tenn., June 1968.

2. D. F. Hanlen, G. N. Hamilton, and E. G. Taylor, Westinghouse Reactor Evaluation Center: Reactor Operator Training Manual, USAEC Rept. WCAP-2713 (rev.), Westinghouse Electric Corp., October 1967.

3. D. F. Hanlen and W. J. Morse, Nuclear Physics Made Very, Very Easy, USAEC Rept. NTO-T-0026, Nevada Test Operations, July 1968.

4. S. E. Liverhant, Elementary Introduction to Nuclear Reactor Physics, John Wiley \& Sons, Inc., New York, 1960.

5. U.S. Nuclear Regulatory Commission, Operating Experience Information on Inspections and Enforcement Bulletins and Replies, Washington, D.C.

6. Congressional Information Bureau, Inc., Atomic Energy Clearing House, Washington, D.C.

7. Nuclear Safety, Superintendent of Documents, U.S. Government Printing Office, Washington, D.C. 20402.

8. Nuclear News, American Nuclear Society, 244-A East Ogden Avenue, Hinsdale, I11. 60521.

9. Power, P.O. Box 521, Hightstown, N.J. 08520. 
Lesson Plan No. 6. Types of Reactors

\section{Objective}

The purpose of this lesson is to review other types of reactors and learn the basic differences. While a senior reactor operator may not have to know anything about other types to supervise the operation of his reactor, the realization that the reactor theory he has learned can be used to explain the differences will afford considerable satisfaction, and there are other gains. For instance, there is a wealth of information in various publications such as Nuclear Safety, Power, ANS News, and Reactor Experiences. Reactor operating experiences, unusual occurrences, and Incldent reports from licensed reactors in the United States are available to the U.S. Nuclear Regulatory Commission, can be found in the Nuclear Regulatory Commission Public Document Room, and are of ten reported in the Atomic Energy Clearing House. Since this information is from many reactor types, a general understanding of reactors is helpful in keeping abreast of current developments and occurrences and in applying this experience to the plant at which the senior reactor operator is working. Furthermorè, different types of reactors are often purchased by an operating organization and it is advantageous for the senior reactor operator to be aware of the differences and problems which he might expect to encounter in uther reactors.

Plan Out,line

A. Variations in reactors

1. Fuel (moderator arrangement)

a. Heterogeneous

b. Homogeneous

c. Fuel

(1) Uranium

(2) Plutonium

(3) Future 
2. Coolant
a. Pressurized water
b. Boiling water
c. Liquid metal
d. Gas cooled
e. Organic cooled

3. Neutron energy
a. Thermal
b. Fast

4. Breeders

B. Concepts of operation

1. Pressurized water

2. Boiling water

3. Homogeneous

4. Liquid metal

5. Gas cooled

$\underline{\text { References }}$

Since anyone selected to conduct a training program for nuclear reactor operators will already have a knowledge of reactors, we have included only one of the many standard textbooks available on the subject.

1. R. A. Costner, Jr., E. N. Cramer, and R. L. Scott, Jr., Reactor Operator Study Handbook (Programed Instruction Version). Vol. III - Reactor Physics, ORNL/TM-2034, Oak Ridge National Laboratory, Oak Ridge, Tenn., June 1968.

2. D. F. Hanlen, G. N. Hamilton, and E. G. Taylor, Westinghouse Reactor Evaluation Center: Reactor Operator Training Manual, USAEC Rept. WCAP-2713 (rev.), Westinghouse Electric Corp., October 1967.

3. D. F. Hanlen and W. J. Morse, Nuclear Physics Made Very, Very Easy, USAEC Rept. NTO-T-0026, Nevada Test Operations, July 1968.

4. S. E. Liverhant, Elementary Introduction to Nuclear Reactor Physics, John Wiley \& Sons, Inc., New York, 1960. 
5. U.S. Nuclear Regulatory Commission, Operating Experience Information on Inspections and Enforcement Bulletins and Replies, Washington, D.C.

6. Congressional Information Bureau, Inc., Atomic Energy Clearing House, Washington, D.C.

7. Nuclear Safety, Superintendent of Documents, U.S. Government Printing Office, Washington, D.C. 20402.

8. Nuclear News, American Nuclear Society, 244-A East Ogden Avenue, Hinsdale, I11. 60521.

9. Power, P.0. Box 521, Hightstown, N.J. 08520. 
SECTION XIV. SPECIFIC OPERATING CHARACTERISTICS

Contents

Introduction . . . . . . . . . . . . . . . . 263

Lesson Plan No. 1. Introduction to System Behavior . . . . . . 265

Lesson Plan No. 2. Nuclear Characteristics . . . . . . . . 270

Lesson Plan No. 3. Thermal-Hydraulic Characteristics . . . . . 273

Lesson PIan No. 4. Characteristics of Reactor Systems . . . . 278

Lesson Plan No. 5. Characteristics of Steam-Production

and Turbine Systems . . . . . . . . . . . . . 283

Lesson Plan No. 6. Characteristics of Generators and

Electrical Power Transmission Systems . . . . . . . . . 287

Lesson Plan No. 7. Characteristics of Site Utility Systems . . 290

Lesson Plan No. 8. Characteristics of Waste Systems . . . . . 293

Lesson Plan No. 9. Characteristics of Instrumentation and

Control . . . . . . . . . . . . . . . . 296

Lesson Plan No. 10. Operational Safety . . . . . . . . 303

Introduction

The training guide topics and the presentation of material for the senior operators' program on the subject of specific operating characteristics is, in essence, the same as for the operators' program on the subject of general operating characteristics. However, the senior operator trainees will be expected to learn the study material to a greater depth and subsequently display a greater knowledge of

1. The reason for the behavior of the various systems.

2. The reason for the particular design features of the various systems.

3. The overall system response to various postulated failures and/or emergency situations.

4. The reasons for suggested responses to correct abnormal conditions. 
5. The reasons for, and application of, specific NRC and companyoriginated administrative controls.

6. The reasons for obtaining the required operating data.

7. The relatively nonroutine-type tasks (e.g., calibration of control rods, criticality tests, special experiment work, etc).

8. The trouble-shooting-type jobs.

9. The overall operation of the plant site (e.g., chemical processing of radioactive isotopes after they are removed from the reactor, etc.).

The purpose of this section is to teach the operating characteristics of the various systems by familiarizing the student with those controlled, vartable, and/or calculated parameters used at a facility to evaluate the operational status, performance, and safety of the various systems under normal and abnormal operating conditions. The primary objectives are:

1. To learn the types of parameters associated with each system (A list of types is provided).

2. To learn the normal magnitude of parametric values associated with each system.

3. To learn the limiting parametric values and/or action setpoints associated with each system and the reason for the limits.

4. To learn the variations in parametric values that will be encountered during normal operation and those variations that may be expected during various postulated failures and/or abnormal conditions.

5. To learn the cause of changes in parametric values.

6. To learn the effects of changes in parametric values, both in regard to the subsystems and the overall system.

7. To learn the corrective astion and/nr response, initiated either automatically by system control action or manually by operator response, to postulated failures and/or abnormal conditions.

8. To learn the overall interrelationship of the reactor, steamproducing, turbine, generator, and electrical power transmission systems. 
The types of parameters discussed are:

$\begin{array}{ll}\text { 1. Pressure } & \text { 14. Electrical poten } \\ \text { 2. Temperature } & \text { 15. Electrical curren } \\ \text { 3. Flow } & \text { 16. Frequency } \\ \text { 4. Velocity } & 17 . \text { Cycles } \\ \text { 5. Mass } & \text { 18. Resistivity } \\ \text { 6. Volume } & \text { 19. Radiation level } \\ \text { 7. Density } & 20 . \text { Concentration } \\ \text { 8. Time } & 21 . \text { Rate } \\ \text { 9. Heat } & 22 . \text { Ratio } \\ \text { 10. Power } & 23 . \text { Efficiency } \\ \text { 11. Energy } & 24 . \text { Coefficient } \\ \text { 12. Flux } & 25 . \text { Period } \\ \text { 13. Reactivity } & 26 . \text { pH }\end{array}$

As a study guide for the senior operator candidate, questions are provided with each lesson plan; these questions are typical, and they reflect the added depth of learning to be achieved by the senior operator candidate.

The instructor should consider presenting this section after the section on the features of the facility design, rather than in the order of section listings, since it may be more beneficial to familiarize the student initially with the design features of the various systems and, after a basic knowledge of the plant is obtained, to review all the systems and study their operating characteristics as presented in this section.

Lesson Plan No. 1. Introduction to System Behavior

Objective

Since it is realized that individual systems become involved and relatively complicated, the objective of this lesson plan is to facilitate 
comprehension by initially familiarizing the student with the fundamental behavior of some of the more important systems as entities. The behavior of the systems from an integrated viewpoint will be covered in greater detail in lesson plans to follow.

The student should learn (1) the general layout and function of the individual systems; (2) the parameters used to evaluate the performance of the systems; and (3) the normal parametric values associated with each system during normal operation. A basic understanding of the interrelationship of the reactor, steam-producing, steam-driven turbine, turbine-driven generator, and electrical power transmission systems should be gained during this first lesson plan; a more thorough understanding of the interrelationships will be gained later.

Plan Outline

A. Reactor systems

1. Core coolant (flow rates, temperatures, pressures, levels, and quality)

2. Water to heat exchangers, pressurizer, steam generator, and/or cleanup systems (flow rates, temperatures, pressure levels, etc.)

3. Pumps circulation, pressurizer, etc. (capactey, current, control)

4. Power level and rate of change

5. Flux level

6. Boron recycle, recovery, and thermal regeneration systems

7. Chemical addition ayatcms (acid, etc.)

8. Poison injection system (safety)

9. Volume, level, and/or pressure control system

10. Waste systems (liquid and of $f$-gas requirements)

11. Secondary water systems

a. Flow rates, temperature, pressure, levels, etc.

b. Tower (capacity, control, blowdown, makeup, etc.)

c. Chemical addition 
12. Safety systems
a. Containment spray
b. Containment isolation
c. Containment ventilation and nitrogen-inerting
d. Annulus (ventilation)
e. Ice condenser and refrigeration
f. Blowdown
g. High-pressure coolant injection
h. Pressure-relief valves
i. Scram accumulator

13. Reactor control
a. Variables affecting the reactor power level
b. Modes of control
c. Computer control

B. Fuel storage (pool cooling) system

1. Flow rates, temperatures, pressures, levels, and quality of coolant

2. Pumps (capacity, current, control, etc.)

3. Heat exchangers and secondary water cooling

4. Chemical addition systems

5. Volume- and level-control systems

6. Waste systems (1iquid and off-gas requirements)

7. Safety systems and parametric values

8. Radiation monitoring systems

C. Steam-producing systems (reactor and/or steam generator)

1. Flow rates, temperatures, and pressures of steam

2. Water leve1

3. Preheat, reheat, and superheat systems

4. Feedwater system

5. Pressurizer system

6. Condensing system

7. Cooling system

8. Lubrication system

9. Waste system (liquid and off-gas requirements) 
10. Radiation monitoring system

11. Safety systems and parametric values of action setpoints

12. Control of steam production

D. Steam-driven turbine

1. Flow rates, temperatures, and pressure of steam

2. Speed, thrust, vibration, eccentricity, position, and load of shaft

3. Cooling system

4. Lubrication system

5. Radiation monitoring system

6. Safcty systems and paramelric values of arrinn setpoints

7. Turbine control

E. Turbine-driven generators

1. Speed and vibration of rotor

2. Excitation system

3. Voltage, current, and frequency output

4. Cooling system

5. Lubrication system

6. Safety systems and parametric values of action setpoints

7. Generator control

F. Electrical power transmission system

1. I'ranstormer, switchgear, and circuit-breaker

2. Voltage control

3. Current control

4. Frequency control

5. Transmission

6. Jubleansmlssion

7. Distribution

8. Power and auxiliary

9. Cooling

10. Lubrication

11. Safety systems and parametric values of action setpoints

12. Transmission control 
Sample Study Questions

1. Draw a schematic diagram of the reactor primary water system, and show normal flow rates, temperatures, and pressures applicable to the various components and subsystems. Show the location of sensing elements.

2. List the radioactive gases removed by the deaerator and systemgenerator blowdown. List the radioactive ions removed by the cation and anion demineralizer columns.

3. Discuss the methods by which the temperature and pressure of the core coolant is controlled.

4. List three different pipe diameters in the reactor primary-water system, and discuss the reason for the magnitudes and variations.

5. Discuss the reasons for the reactor safety and control action setpoints (i.e., list scram and rod insertion parameters and values).

6. Draw a schematic diagram of the steam loop (through generator and steam-driven generator, etc.), and show normal flow rates, temperatures, and pressures of the steam through each component.

7. Discuss the control of the steam generator, the steam-driven turbine, and the turbine-driven generator. Include parametric values in your discussion.

8. Briefly discuss the interrelationship of the reactor power level, the steam-driven turbine, the turbine-driven generator, and the electrical power transmission system.

9. Discuss the generator excitation system. Discuss the oversaturation of generator components with high magnetic flux.

10. Draw a schematic diagram of the fuel storage (pool cooling) system, and show the normal flow rates and temperatures applicable to the various components and subsystems.

\section{$\underline{\text { References }}$}

1. Vendor's li.terature.

2. Safety analysis report.

3. Technical specificatione.

4. Procedures manuals. 
Lesson P1an No. 2. Nuclear Characteristics

Objective

In addition to providing a brief review of definitions, this lesson should familiarize the student with the behavior of those parameters associated with the nuclear characteristics of the reactor. The topics presented in each lesson plan should be reviewed, as applicable, with three basic objectives in mind: (1) to learn the parametric values (types, normal magnitudes, limiting values, and reason for the limits) associated with each topic; (2) to learn the cause of changes in parametric values: and (3) to learn the effects of changes in parametric values in regard to both the component and the overall system). The senior operator candidate should become relatively competent in diagnosing the reason for changes in nuclear readouts and/or computed parametric values, and he should develop a good understanding of the reactor physics that wi.11 be used to explain various anomalies.

\section{Plan Outline}

A. Neutron properties

1. Energy clasoifications

2. Production and reactions

3. Flux (levels, anomalies, etc.)

B. Criticality

1. Reactor variables and the four-factor formula

2. Fiffertive multiplioation factor

3. Prompt criticality

4. Reactor period

5. Criticality measurements

C. Reactivity

1. Fue1

2. Poisons (xenon, samarium, boron)

3. Fission products 
4. Excess reactivity distribution

5. Shutdown margin

D. Reactivity coefficients

1. Doppler

2. Moderator void

3. Moderator temperature

4. Moderator density

5. Moderator pressure

6. Power

E. Control rods

1. Differential and integral rod worths

2. Withdrawal and insertion rates

3. Rod-worth minimizers

4. Worth vs core life

5. Safety parameters (scram and release times, etc.)

6. Dropped rod (effect on flux, power level, temperatures, pressures)

F. Fuel elements

1. BOL (beginning of life) and EOL (end of life) internal pressure

2. Axial and radial temperature distribution in tuel and in cladding

3. Fission product buildup

4. U-235 and poison burnup

5. Cladding ductility changes with burnup

G. Reactivity control

1. Rod cluster control assemblies

2. Chemical poisons

3. Burnable poisons

H. Power-level control

1. Individual variables initiating action

2. Methods of control 
I. Safety analysis

1. Loss-of-coolant accident

2. Damage from earthquake, tornado, lightning

3. Loss of electrical power

J. Nuclear data (indicated, plotted, computed) associated with the above topics

\section{Sample Study Questions}

The questions provided in Sect. VIII (General Operating Characteristics) should be reviewed.

1. Give the analysis and result of a rod ejection accident; include curves on "peak neutron power vs control-rod worth" and "peak thermal power vs control-rod worth" in your discussion.

2. Discuss the reactivity control limits and the nuclear limits. Discuss the control of the reactor by soluble boron.

3. Discuss the procedure for flux mapping the reactor core. What is the value of such data? Include parametric values in your discussion .

4. Discuss the degree to which certain water systems are borated. Include parametric values in your discussion.

5. Fill in the blanks on the following table.

Nuclear design parameter Magnitude Units

Cladding weight

Core height

Core diameter

Feed enrichment

Effective multiplication

Cold, zero,power, clean

Hot, full power, poisoned

Boron concentration

Hot, poisoned, $k_{\text {eff }}=1$

Boron worth, hot 
Kinetic characteristics

Moderator temperature coefficient

Moderator pressure coefficient

6. Discuss the initial criticality testing program and the postcriticality testing program. List the tests and their objectives.

7. Discuss the effects of fast-neutron reactions in the beryllium reflector. Draw and discuss the xenon and samarium production and decay curves. Include parametric values in your discussion.

8. Draw a cross section of the reactor core and show the therma1and fast-neutron flux levels in each section at the start and end of an operating cycle.

9. Discuss the procedure for calibrating a control rod. Draw and explain two reactivity rod-worth curves (differential and integral curves).

10. Discuss NRC and company-originated administrative controls associated with the handling of fissionable material at this facility.

\section{References}

1. Vendor's literature.

2. Safety analysis report.

3. Technical specifications.

4. Procedures manuals.

Lesson Plan No. 3. Thermal-Hydraulic Characteristics

Objective

This lesson should familiarize the student with the thermal-hydraulic characteristics of the reactor systems, the steam-producing equipment, 
the steam-driven turbine, the turbine-driven generator, and electrical power transmission equipment. Emphasis should be placed on cooling requirements during normal and emergency conditions, safety limits as pertaining to temperatures and pressures, and safety tests required.

The senior operator candidate should learn (1) the reason for the various thermal-hydraulic operating limits; (2) the necessity of periodic testing of hydraulic components and the tests performed; and (3) the consequences of failures, such as metal fatigue and rupture, resulting from thermal and/or pressure cycling and oyerloads.

\section{Plan Outline}

A. General operating characteristics

1. Thermal output

2. Power level for engineered safeguards

3. Sleam flow rates, temperatures, and pressures

4. Core-coolant flow rates, temperatures, and pressures

5. Feedwater flow rates

6. Average power density

7. Average and maximum thermal output

8. Average, maximum, and critical heat flux

9. Core inlet enthalpy

10. Core maximum exit voids within assemblies

11. Peaking factors (local, gross, axial, total)

12. Core voids

13. Minimum critical high-flux-ratio variations

B. Safety parameters and/or limits for each of the above items, as applicable

C. Reactor systems (thermal-hydraulic requirements and limits)

1. Reactor vessel

2. Core components

a. Fuel

b. Reflector

c. Control rods

d. Other equipment (jet pumps, separators, etc., for BWR) 
3. Drywe11 and torus

4. Pumping systems (seal lubrication and general cooling)

5. Purification systems
a. Filtering
b. Degassing
c. Demineralizer

6. Volume control systems

7. Interconnecting piping

8. Boron recycle, recovery, and thermal regeneration systems

9. Heat exchanger

10. Cooling tower

11. Experiment facilities

12. Safety systems
a. Containment spray
b. Containment isolation
c. Containment ventilation
d. Annulus ventilation
e. Ice condenser and refrigeration
f. Scram accumulator
g. Pressure relief

13. Corrosion problems (metal-water reaction, etc.)

14. Perlodic tests required

15. Thermal-hydraulic data (indicated, plotted, computed)

D. Steam-producing equipment (thermal-hydraulic requirements and limits)

1. Separators and driers

2. Pressurizer systems

3. Preheat, reheat, and superheat systems

4. Steam generators

5. Cooling systems

6. Lubrication systems

7. Condensing systems

8. Corrosion problems

9. Periodic tests required

10. Thermal-hydraulic data (indicated, plotted, computed) 
E. Steam-driven turbines

1. Components (thermal-hydraulic requirements and limits)

2. Corrosion problems

3. Periodic tests required

4. Thermal-hydraulic data (indicated, plotted, computed)

F. Turbine-driven generators

1. Components (thermal-hydraulic requirements and limits)

2. Corrosion problems

3. Periodic tests required

4. Thermal-hydraulic data (indicated, plotted, computed)

G. Electrical power transmission systems

1. Components (thermal-hydraulic requirements and limits)

2. Periodic tests required

3. Thermal-hydraulic data (indicated, plotted, computed)

\section{Sample Study Questions}

The questions provided in Sect. VIII (General Operating Characteristics) should be reviewed.

1. Discuss the thermal-hydraulic limits.

2. Define:
a. The power-peaking factor.
b. The flow-area-reduction factor.
c. The local heat flux factor.
d. The maximum/average power ratio.
e. The minimum critical heat flux ratio.

3. Discuss the mechanical limits of the fuel assemblies, the controlrod assemblies, and the orifice-rod assemblies. Discuss some of the problems that might be encountered with the reactor vessel over its projected lifetime because of temperature and pressure cycling.

4. Name three types of missiles that might be generated as a result of a pustulated accident. List a few of their characteristics (e.g., weight, area of impact, velocity, etc.). Discuss the consequences of the three types of accidents, and discuss the safety features intended to minimize the consequences. 
5. Draw and explain the following

a. A "peak pressure vs rod-withdrawal-rate" curve for a rodwithdrawal accident from rated power.

b. A "percent reactor flow vs time" curve after a loss of pump power.

c. A "pressure, power, temperature, flow rate vs time" curve after the dropping of one or more control rods.

6. Discuss a loss-of-reactor-coolant accident; include an environmental analysis in your discussion. Discuss the "maximum hypothetical accident."

7. Discuss the effects of $\mathrm{pH}$, velocity (of coolant), and temperature on corrosion of various metal components in the reactor system.

8. Discuss the hydraulic tests that were performed on this reactor before criticality was achieved and that are now performed on a routine basis.

9. List the operating variables applicable to this category and discuss how their limits were established (e.g., a high-temperature scram at $\left.{ }^{\circ} \mathrm{F}\right)$.

10. Discuss some of the studies made of, and/or the safety features incorporated in, the design of the reactor vessel, the steam generator, the interconnecting piping, and the valving to ensure minimum consequences in the event of (a) a loss-of-coolant accident, (b) an earthquake, and (c) a sudden increase in pressure and/or temperature.

\section{$\underline{\text { References }}$}

1. Vendor's literature.

2. Safety analysis report.

3. Technical specifications.

4. Procedures manuals. 
Lesson Plan No. 4. Characteristics of Reactor Systems

Objective

In addition to providing a brief review of the systems' description and function, this lesson should familiarize the student with the behavior of those parameters associated with the reactor cooling systems and the various subsystems. The topics presented in each lesson plan should be reviewed, as applicable, with three basic objectives in mind: (1) to learn the parametric values (types, normal magnitudes, limiting values, and the reason for the limits) associated with each topic: (2) to Learn the cause of changes in parametric values; and (3) to learn the effects of changes in parametric values (both in regard to the component and the overall system).

The senior operator candidate should become competent in evaluating the cause of variations in reactor system readouts and in initiating corrective action when applicable. He should learn the methods by which automatic and manual corrective action accomplishes the intended tasks, and he should become very familiar with the administrative safety procedures applicable to this category.

Plan Mutline

A. Reactor primary water system (operation under normal and emergency conditions)

1. Keactor vesse1

a. Flow rates, velocity, and temperature distributions for various core components

ᄂ. Temperalure of core components

c. Temperature distribution upstream of the core

d. Pressure differentials across the core

e. Fluid transit times

f. Water level and contrul (BWR)

g. Separators (BWR) 
h. Jet pumps (BWR)

i. Postulated failures and/or abnormal conditions (cause, system response, and corrective action)

2. Heat exchangers

a. Flow rates and velocities

b. Temperature differentials

c. Pressure differentials

d. Postulated failures and/or abnormal conditions (cause, system response, and corrective action)

e. Radiation monitoring systems

3. Pumps (recirculating, pressurizer, feedwater, booster, jet, etc.)

a. Capacity

b. Amperage

c. Seal water flow and temperature

d. Lubrication system (oil flow and temperature)

e. Transients of level, pressure, and/or temperature with load change

f. Heat input into systems

g. Cooling system

h. Pump control

i. Emergency electric power

f. Setpoints and control action

k. Radiation monitoring system

1. Postulated failures and/or abnormal conditions (cause, system response, and corrective action)

4. Purification and volume control systems

a. Filtering (flow rates, temperature, and contro1)

b. Demineralizer ( $f$ low rates, temperature, and control)

c. Degassing systems ( $f$ low rates, temperature, and control)

d. Pressure-reducing

e. Water-quality monitoring

f. Volume contro1

g. Radiation monitoring 
h. Safety systems and parametric values of action setpoints

i. Postulated failures and/or abnormal conditions (cause, system response, and corrective action)

5. Boron recycle system (operation under normal and emergency conditions)

6. Boron recovery system (operation under normal and emergency conditions)

7. Boron thermal regeneration (operation under normal and emergency conditions)

8. Chemical addition systems (acid, oxygen, etc.)

a. Volume and/or rate of addition

b. Concentration monitoring systems

9. Makeup, fill, and drain systems

10. Safety system (operation under normal and emergency conditions)

a. Poison injection

b. Liquid control

c. Scram accumulator

d. Pressure-relief valves

c. Containment spray

f. Contailumel ventilarton and nitrogen-inerting

g. Anmulus ventilation

h. Ice condenser and refrigeration

i. Radiation monitoring

j. High-pressure coolant injection

k. Blowdown

11. Control syst.ems

a. Variables affecting controlled parameters and action setpoints

b. Methods of control

c. Computer function

12. Data used to evaluate the performance of the reactor primarywater system and subsystems (indicated, plotted, computed) 
B. Reactor secondary water system (operation under normal and emergency conditions)

1. Flow rates and temperatures of secondary water

2. Blowdown and makeup flow rates

3. Basin level control system

4. Chemical addition system

5. Quality monitoring systems

6. Radiation monitoring system

7. Safety systems and parametric values of action setpoints

8. Interrelationship with other systems

9. Postulated failures and/or abnormal conditions (cause, system response, and corrective action)

10. Data used to evaluate the performance of the secondary water system (indicated, plotted, computed)

C. Fuel storage (pool cooling) system (operation under normal and emergency conditions)

1. Primary water flow rates, temperatures, and control

2. Pumping system (capacity, current, control, etc.)

3. Heat exchangers and secondary water cooling

4. Chemical addition system

5. Quality monitoring system

6. Waste system (1iquid and of $f$-gas requirements)

7. Radiation monitoring system

8. Safety systems and parametric values of action setpoints

9. Interrelationship with other systems

10. Postulated failures and/or abnormal conditions (cause, system response, and corrective action)

11. Data used to evaluate the performance of the pool cooling system (indicated, plotted, computed)

D. Summary of emergency condition requirements

1. Emergency electrical power (during total and partial power failures)

2. Emergency cooling requirements

3. Other emergency services required 
Sample Study Questions

The questions provided in Sect. VIII (General Operating Characteristics) should be reviewed.

1. List six heat sources, and explain how cooling is provided to each source during both normal operation and emergency situations; include parametric values in your discussion. Discuss the cause and effect of variations in heat removal requirements of each source.

2. Complete the following table, showing the quality of the reactor

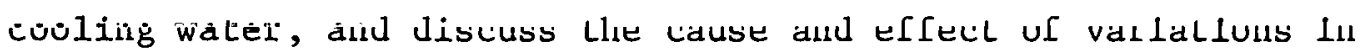
the parameters.

Item $\begin{gathered}\text { Allowable } \\ \text { content (ppm) }\end{gathered}$
a. Total solids
b. Boron
c. Lithium as ${ }^{7} \mathrm{Li}$
d. $\mathrm{pH}$
e. Dissolved $\mathrm{O}_{2}$
f. $\mathrm{H}_{2}$
g. Fluoride as $\mathrm{F}^{-}$
h. Hydrazine as $\mathrm{N}_{2} \mathrm{H}_{4}$

3. Discuss the water chemistry of the various systems. Include the chemicals added, method of monitoring for, changes expected during both normal operations and certain emergency situations, etc.)

4. Discuss the thermal regeneration, boron recovery, and boron recycle systems. Include parametric values in your discussion.

5. Discuss the production of the various radioactive nuclides found in the reactor primary water cooling system. Include the method and usual rate of production in your discussion.

6. Discuss the "downcomer water level vs steam generator load" curve. Include parametric values in your discussion. 
7. Discuss the operation of the high-pressure injection system during normal and emergency conditions. Include parametric values in your discussion.

8. Discuss the response of the primary containment system to a loss-of-coolant accident (drywell, torus response, if applicable).

\section{References}

1. Vendor's literature.

2. Safety analysis report.

3. Technical specifications.

4. Procedures manuals.

\section{Lesson Plan No. 5. Characteristics of Steam Production and Turbine Systems}

\section{Objective}

In addition to providing a brief review of the systems' description and function, this lesson should familiarize the student with the behavior of those parameters associated with steam production and the steam-driven turbines. The topics presented in each lesson plan should be reviewed, as applicable, with three basic objectives in mind:

to learn the parametric values (types, normal magnitudes, limiting values, and reason for limits) associated with each topic; (2) to learn the cause of changes in parametric values; and (3) to learn the effect of changes in parametric values (in regard to both the component and the overall system).

The senior operator candidate should become relatively competent in evaluating the cause of variations in system readouts and in initiating corrective action when applicable. He should also learn the methods by which automatic and manual corrective action accomplishes the intended 
task. He should have a good understanding of (1) heat-transfer problems, (2) load limits and the basis for such limits, and (3) the reasons for administrative safety controls as applicable to this category.

\section{Plan Outline}

A. Steam generators

1. Boiling-water reactors

a. Steam production and flow

b. Separators and driers

c. Flow paths to the steam-driven turbines

d. Safety devices and/or systems

e. Pressure, temperature, level, and flow (control and safety limits)

f. Reactor power level (control and safety limits)

g. Pumping and auxiliary systems

h. Radiation monitoring systems

i. Facility utilities (cooling, electrical power, etc.) required during normal and emergency conditions

j. Postulated failures and/or abnormal conditions (cause, system response, and corrective action)

2. Pressurized-water reactors

a. Steam production and flow in the steam generator

b. Separators and driers

C. Pressurizer systeins

d. Safety devicee and/or syjatems

e. Pressure, temperature, and flow (control and safety limits)

f. Feedwater system

g. Pumping and auxili.ary systems

h. Radiation monitoring systems

i. Reactor power level (control and safety limits)

j. Facility utilities (cooling, electrical power, etc.) required during normal and emergency conditions

k. Postulated failures and/or abnormal conditions (cause, system response, and corrective action) 
B. Steam-driven turbine

1. Pressure, temperature, flow paths, and rates of inlet and exit steam

2. Preheat, reheat, and superheat systems

3. Condensing systems

4. Cooling systems

5. Economizer

6. Shell and differential expansion

7. Lubrication systems

8. Speed, thrust, vibration, eccentricity, position, and load of shaft

9. Metal temperatures and rate-of-temperature changes

10. Efficiency ratings

11. Turning gear

12. Low-load operation

13. Safety devices and/or systems and startup limits

14. Turbine trips

15. Radiation monitoring systems

16. Control system (variables and safety limits)

17. Reactor power level (control and safety limits)

18. Site utilities (cooling, electrical power, etc.) required during normal and emergency conditions

19. Postulated failures and/or abnormal conditions (cause and system response)

c. Date (indicated, plotted, and computed) on the production of steam and the performance of the steam-driven turbines

\section{Sample Study, Questions}

The questions provided in Sect. VIII (General Operating Characteristics) shnuld he reviewed.

1. Discuss the control function of the turbine bypass under both normal operating conditions and emergency situations. Include parametric values in your discussion: 
2. Give the analysis and results of a steam-generator tube failure. Give the analysis and results of a rupture in the steam line from one of the steam generators. Include reactivity effects in your discussion.

3. Discuss the effect of a change in frequency on the control of steam pressure.

4. Discuss the feedwater control system during normal operations and during emergency conditions. Include parametric values in your discussion.

5. Discuss the conditions that would alter the heat-transfer characteristics of the steam generator.

6. Draw and discuss a "unit demand vs temperature" curve.

7. Discuss the variables that determine the amount of energy available from the steam generator. Discuss what would result if the system should try to remove more energy from the steam generator than is available.

8. Draw and discuss a "wide-range reactor water level vs reactor water temperature" curve (BWR).

9. Discuss the variables that will alter the rate of steam production and the speed of the turbine. Include parametric values i.n your discussion.

\section{References}

1. Vendor's 1iterature.

2. Safety analysis report.

3. Technical specifications.

4. Procedures manuals. 
Lesson Plan No. 6. Characteristics of Generators and Electrical Power Transmission Systems

\section{Objective}

In addition to providing a brief review of the systems' description and function, this lesson should familiarize the student with the behavior of those parameters associated with the turbine-driven generator and the electrical power transmission equipment. The topics presented in each lesson plan should be reviewed, as applicable, with three basic objectives in mind: (1) to learn the parametric values (types, normal magnitudes, limiting values, and the reason for the limits) associated with each topic; (2) to learn the cause of changes in parametric values; and (3) to learn the effect of changes in parametric values (both in regard to the component and in regard to the overall system).

The senior operator candidate should become competent in evaluating the cause of variations in electrical system readouts and in initiating corrective action when needed. He should learn the methods by which automatic and manual corrective action accomplishes the intended task. He should also become very familiar with the administrative safety procedures applicable to this category.

Plan Outline

A. Turbine-driven generators

1. Speed and vibration of the rotor

2. Cooling system

3. Lubrication system

4. Excitation system

5. Normal load and load rejection

6. Voltage, current, and frequency output

7. Safety devices and/or protection systems

a. Station overheating and short circuit

b, Loss of excitation synchronism

c. Phase current unbalance 
d. Overspeed and overvoltage

e. Bearing overheating

f. External fault

8. Control system (variables and safety and startup limits)

9. Reactor power level (control and safety limits)

10. Site utilities (cooling, electrical power, etc.) required during normal and emergency conditions

11. System stability

12. Postulated failures and/or abnormal conditions (cause and system response)

B. Electrical power transmission systems

1. Transformer, switchgear, and circuit-breaker

2. Protective relay (response time, sensitivity, etc.)

3. Voltage control

4. Current control

5. Frequency control

6. Cooling

7. Lubrication

8. Control (variables and safety limits)

9. Transmission

10. Subt rancmiesion

11. Distribution

a. Load (demands and types)

b. Devices peculiar to the distribution systems

12. Power and auxiliary

13. Safety and/or protective (1ightning protection, overheating protection, etc.)

1.4. Startup 1imits

15. Reallue puwer lovel (cuntrul and bufety limitc)

16. Site utilities (cooling, electrical power, etc.) required during normal and emergency conditions

17. System stability

18. Postulated failures and/or abnormal conditions (cause and system response) 
C. Data (indicated, plotted, computed) on the performance of the turbine-driven generator and the electrical power transmission sys tems

Sample Study Questions

The questions provided in Sect. VIII (General Operation Characteristics) should be reviewed.

1. Discuss the precautions that are taken to maintain the integrity of the vital bus supplies. Discuss the probability of a power failure due to faults in the network interconnections and the associated switching.

2. Discuss the modes of operation of the unit load control station.

Discuss the conditions that create a load-limiting situation. Include limits and a "unit load demand vs time" curve in your discussion.

3. Discuss the conditions that cause tracking.

4. Discuss the methods of control and the modes of operation for the control system that provides coordination between the turbine, steam generator, and reactor.

5. Complete the "comments and consequences" column of the singlefailure analysis for $125-\mathrm{V}$ dc switching station power system.

Component

480-V ac power supply

Battery charger

$125-V$ dc battery

dc Switchgear busses

$125-V$ dc bus

dc Switchgear load feeder cables

$125-V$ dc primary or backup panelboards
Comments and consequences

Loss of power to one

Loss of power from one

Loss of power from one

Bus shorted

Grounding a single bus and a gradual decay of voltage on one bus

Cables shorted

Bus shorted in one 
6. Discuss how failures in the following systems would be indicated. a. 690-V auxiliary system.

b. 4160-V engineered safety power distribution system.

c. 60-V engineered safety power distribution system.

d. 600-V engineered safety power distribution system.

e. $125 / 250-V$ dc system.

f. 125-V dc switching station power system.

How are these systems tested for reliability?

7. Describe the computer and auxiliary control power ac-dc supply system.

8. Draw and label a site transmission map.

\section{$\underline{\text { References }}$}

1. Vendor's literature.

2. Safety analysis report.

3. Technical specifications.

4. Procedures manuals.

Loccon Plan No. 7. Characteriotico of Eite Utility Eyotem

\section{Objective}

This lesson should familiarize the student with the various utilities available at the reactor complex and with their functions relative to the reactor systems, the steam production systems, the turbines, the generators, and the electrical power transmission systems.

The senior operator candidate should become competent in evaluating the cause of variations in utility system parameters and the effects of such variations and in initiating corrective action when applicable. He should learn the methods by which automatic and manual corrective 
action accomplishes the intended task. He should also become very familiar with the administrative safety procedures applicable to this category.

\section{Plan Outline}

A. Electrical systems (description, function, systems serviced)

1. Normal power

2. Emergency power

3. Instrument power

4. Battery-operated

5. Safety systems or devices and parametric action setpoints

6. Postulated failures and/or abnormal conditions

a. Effect on electrical system

b. Effect on system supplied with electrical power

c. Effect on overall system

d. Corrective action

7. Tests required

B. Water systems (description, function, systems serviced)

1. Potable water

2. Proceso water

3. Demineralized water

4. Fire sprinkler

5. Safety system or devices and parametric action setpoints

6. Postulated failures and/or abnormal conditions

a. Effect on water system

b. Effect on system supplied with water

c. Effect on overall system

d. Corrective action

7. Testa required

C. Process steam system

1. Description

2. Function

3. Flow rates 
4. Systems serviced

5. Safety system or devices and parametric action setpoints

6. Postulated failures and/or abnormal conditions

a. Effect on steam supply system

b. Effect on overall system

c. Corrective action

7. Tests required

D. Compressed-air system

1. Description

2. Function

3. Hlow rates, pressures, temperatures

4. Systems serviced

5. Safety system or devices and parametric action setpoints

6. Postulated failures and/or abnormal conditions

a: Effect on instrument air. system

b. Effect on overall system

c. Corrective action

7. Tests required

E. Alarm systems

1. Faclilly radialiun and cunlaminaliun alar'll

a. Description

b. Parametric values of action setpoints

2. Fire alarm

a. Description

b. Parametric values of action setpoints

3. Buflding and area evacuation alarm

F. Television surveillance systems (operating requirements)

G. Telemetering systems

H. Summary of utilities needed during emergency conditions

1. Electrical power outage

2. Loss-of-coolant accident resulting from mechanical failure 
Sample Study Questions

The questions provided in Sect. VIII (General Operating Characteristics) should be reviewed.

1. Discuss the fire protection system for the various systems (e.g., the turbines, the hydrogen seal-oil units, the main power transformers, etc.)

2. Discuss the effect on the reactor power level if there is a rupture in the air supply line to any three pneumatic control units .

3. Discuss the sequence of equipment startup that is used to minimize surges in the electrical system following an electric power outage.

4. Discuss the systems affected by a loss of potable and/or process water, and discuss the consequences of such a loss.

5. Discuss the systems affected by a loss of the steam supply system, and discuss the consequence of such a loss.

\section{$\underline{\text { References }}$}

1. Vendor's literature.

2. Safety analysis report.

3. Technical specifications.

4. Procedures manuals.

Lesson Plan No. 8. Characteristics of Waste Systems

\section{Objective}

The objective of this lesson plan is to familiarize the student with the behavior of those parameters associated with the liquid, solid, and gaseous waste disposal systems. 
The parametric values (types, normal magnitude, limiting values, and reason for limits) associated with each waste system should be learned, including the effects of changes in parametric values (both in regard to the component and to the overall system), the causes of changes, and the corrective action needed. The administrative safety procedures and limits should be thoroughly understood.

\section{Plan Outline}

A. Gaseous waste disposal system

1. Description, function, flow rates, pressures of various systems
a. Building ventilation containment
b. Drywe11 ventilation
c. Torus ventilation
d. Containment inerting
e. Standby gas treatment
f. Air ejector
g. Experiment and other off-gas
h. Holdup gas

2. Radiation monitoring

3. Reactor and other systems served by oft-gas systems

4. Normal effluents (volume and radiation levels)

5. Safety systems and/or devices and parametric action setpoints

6. Postulated failures and/or abnormal conditions

a. Effect on individual system

b. Effect on overall system

c. Corrective action

7. Tesl sequirements

a. Etficiency of various filter media

B. Liquid waste disposal system

1. Categories (radiation levels, types of waste, etc.)

2. Description and function of various liquid waste systems

3. Holdup or retention systems 
4. Reactor and other main systems serviced by liquid waste systems

5. Normal influents (volume and radiation levels)

6. Radiation monitoring

7. Safety systems and/or devices and parametric action setpoints

8. Postulated failures and/or abnormal conditions

a. Effect on liquid waste system

b. Effect on system being serviced

c. Corrective action

9. Test requirements

C. Solid waste disposal

1. Categories (radiation levels, types of waste, etc.)

2. Storage requirements

3. Shipping requirements

4. Burial requirements

5. Radiation monitoring

\section{Sample Study Questions}

The questions provided in Sect. VIII (General Operating Characteristics) should be revilewed.

1. Discuss the removal of hydrogen by the gaseous waste system. Discuss tritium production and its removal from the reactor water system.

2. Discuss the operating parameters associated with the (a) hydrogen recombiners, (b) waste-gas separators, and (c) retention tanks.

3. Discuss the annual liquid and gaseous releases of radioactive materials to the environment.

4. List three radioactive materials for each state (i.e., gaseous, solid, and liquid) that are found in the waste systems. Discuss how they were produced, their source, and their treatment before being released to the environment.

5. Discuss the reason for the various types of filters used in the off-gas system. Discuss their particle and iodine removal 
efficiencies; include parametric values in your discussion.

Discuss any tests required on these filters.

\section{$\underline{\text { References }}$}

1. Vendor's literature.

2. Safety analysis report.

3. Technical specifications.

4. Procedures manuals.

Lesson Plan No. 9. Characteristics of Instrumentation and Control

\section{Objective}

In addition to providing a brief review of those parameters that are displayed locally and in the control room, this lesson should familiarize the student with variations in the main control room readouts that might be expected during normal operation and during emergency conditions.

Control room readouts, annunciator alarm setpoints, and control action setpolnts should be learned to the extent that the student may become competent in evaluating a particular situation when one or more abnormal conditions are indicated by the control room instrumentation. The appropriate corrective action should be learned as we1.1.

\section{$\underline{\text { Plan Outline }}$}

A. Control room (familiarization with location of specilic Leaduuls and controls)

1. Console

2. Annunciatin

3. Panel readouts

4. Other control panels 
B. Shim and control-rod drives

1. Position and rod-condition indications

2. Test requirements

3. Normal and abnormal variations (cause, effect, and corrective action)

C. Reactor power level

1. Startup channels

2. Intermediate-range channels

3. Power operation channels

4. Variables that affect the reactor power level

5. Normal and abnormal variations (cause, effect, and corrective action)

D. Reactor safety system

1. Scram variables and action setpoints

2. Rod-insertion variables and action setpoints

3. Normal and abnormal variations (cause, effect, and corrective action)

E. Reactor control system

1. Modes of control

2. Variables that affect the power level and action setpoints

a. Neut ron $=$ Ilux level

b. Effect from steam production

c. Effect from turbine

d. Effect from generator

e. Effect from electrical power load requirements

3. Normal and abnormal variations (cause, effect, and corrective action)

F. Reactor systems

1. Core coolant (flow rates, temperatures, pressures, levels, and quality)

2. Water to heat exchangers, pressurizers, steam generators, and/or cleanup systems (flow rates, temperatures, pressures, levels, etc.)

3. Pumps - circulation, pressurizer, etc. (capacity, current, control) 
4. Power levels and rate of change

5. Flux level

6. Chemical addition (acid, boron, etc.)

7. Poison injection

8. Volume, level, and/or pressure control systems

9. Waste systems (1iquid and off-gas requirements)

10. Secondary water system

a. Flow rates, temperatures, pressures, levels, etc.

b. Tower (fan control, etc.)

c. Chemical, addition

11. Safety systems and parametric values of action setpoints

a. Containment spray

b. Containment isolation

c. Containment ventilation and nitrogen-inerting

d. Annulus ventilation

e. Ice condenser and refrigeration

f. Pressure-relief valve

g. Scram accumulators

12. Normal and abnormal variations (cause, effect, and corrective action)

G. Fuel storage (pool cooling) system

1. Flow rates, temperatures, pressures, levels, and quality of coolant

2. Pumps (capacity, current, control, etc.)

3. Heat exchangers and secondary water cooling

4. Chemical addition

5. V̄olume and level contrul

6. Waste (liquid and off-gas requirements)

7. Radiation monitoning

8. Safety systems and parametric values of action setpoints

9. Normal and abnormal variations (cause, effect, and corrective action) 
H. Steam-producing systems (reactor and/or steam generator)

1. Flow rates, temperatures, and pressures of steam

2. Water leve1

3. Preheat, reheat, and superheat

4. Feedwater

5. Pressurizer

6. Condensing

7. Cooling

8. Lubrication

9. Waste (liquid and off-gas requirements)

10. Radiation monitoring

11. Safety systems and parametric values of action setpoints

12. Control of steam production

13. Effect on reactor power level and other systems

14. Normal and abnormal variations (cause, effect, and corrective action)

I. Steam-driven turbines

1. Flow rates, temperatures, and pressures of steam

2. Speed, thrust, vibration, eccentricity, position, and load shaft

3. Cooling

4. Lubrication

5. Radiation monitoring

6. Safety systems and parametric values of action setpoints

7. Turbine control

8. Effect on reactor power level and other systems

9. Normal and abnormal variations (cause, effect, and corrective action)

J. Turbine-driven generators

1. Speed and vibration of rotor

2. Excitation system

3. Voltage, current, and frequency output

4. Cooling systems

5. Lubrication systems 
6. Safety systems and parametric values of action setpoints

7. Generator control

8. Effect on reactor power level and other systems

9. Normal and abnormal variations (cause, effect, and corrective action)

K. Electrical power transmission

1. Transformer, switchgear, and circuit breaker

2. Voltage control

3. Frequency control

4. Transmission

5. Subtransmission

6. Distribution

7. Power and auxiliary

8. Cooling

9. Lubrication

10. Safety systems and parametric values of action setpoints

11. Transmission control

12. Effect on reactor power level and other systems

13. Normal and abnormal variations (cause, effect, and corrective action)

L. Utilities

1. Electrical systems

a. Normal power

b. Emergency power

c. Instrument power

d. Tajluye-free (battery-operated)

2. Water systems

a. Potable water

b. Process water

C. Demineralized water

d. Fire sprinkler

3. Process steam systems

4. Instrument air

5. Television monitoring 
6. Telemetering

7. Alarm

a. Facility radiation and contamination alarm

b. Fire alarm

c. Building and area evacuation alarm

d. Area intercommunication

M. Waste systems

1. Gaseous waste disposal

a. Building ventilation containment

b. Reactor off-gas and/or ventilation

c. Experiment off-gas

d. Containment spray

e. Containment inerting

f. Air ejector

g. Holdup

h. Filtering

i. Standby gas treatment (recombiners)

j. Radiation monitoring

k. Safety systems and parametric values of action setpoints

1. Control (of flow paths, etc.)

2. Liquid waste disposal

a. Sources, flow paths, etc.

b. Holdup and/or retention

c. Radiation monitoring

d. Safety systems and parametric values of action setpoints

e. Control (of flow paths, etc.)

N. Experiments

1. Effect on the reactor power level and other systems

2. Normal and abnormal variations (cause, effect, corrective action)

o. Computer

1. Modes of operation

2. Control allowed

3. Information displayed 
Sample Study Questions

1. Discuss the response of the reactor power level, inlet-coolant temperature controller, system pressure, and production of steam (as a function of time) when one or more control rods drop.

2. Discuss the changes in the various instrument readouts when there is a loss of one or more primary coolant pumps.

3. Discuss the changes in the various instrument readouts when there is a loss of electrical power.

4. Discuss the changes in the various instrument readouts when there is a luss of the feedwater pumplag system.

5. Discuss the changes in control room readouts when there is a failure of the fuel cladding.

6. Discuss the changes in control room readouts when boiling occurs in the core.

7. Discuss the changes in control room readouts when there is a loss of the pressurizer pumps.

8. Discuss the changes in the control room readouts when there is a change in the electrical transmission load needed.

9. Discuss the changes in the control room readouts when there is a failure in the turbine-driven generator.

10. Discuse the changes in the control room readouts when there is a failure in the steam-driven turbine.

\section{$\underline{\text { References }}$}

1. Vendnr's 1iterature.

2. Safety analysis report.

3. Technical specifications.

4. Procedures manuals. 
Lesson Plan No. 10. Operational Safety

\section{Objective}

Operational safety is covered in greater depth in another section; however, its importance warrants reiteration. The primary objective of this lesson plan is to further indoctrinate the student with the relationship between safety and the operating characteristics of a nuclear facility. In essence, this section serves as a review of certain systems and reemphasizes associated safety parameters. The senior operator candidate should thoroughly understand the reasons for each safety parameter, safety limit, safety procedure, safety test, and safety report.

\section{Plan Outline}

A. License requirements by the NRC prior to construction and/or. operation of the reactor

1. Site requirements

2. Fnvironmental impact

B. Engineered safeguards (brief review)

1. Containment spray and isolation systems

2. Annulus ventilation system

3. Emergency core cooling system

4. Ice condenser system

5. Air return fans

6. Control. and safety systems

7. Diesel-operated electrical systems

8. Battery-operated electrical systems

9. Chemical addition systems

10. Stack filtering systems

11. Fire protection system

12. Shielding 
C. Summary of emergency cooling requirements

1. Reactor core

2. Steam generator

3. Steam-driven turbine

4. Pressurizers

5. Pumps

6. Heat exchangers

7. Experiment installations

8. Other components and/or systems

D. Characteristics of safe operating personnel,

1. Procedure oricnted

2. Safety-oriented (from training programs, testing programs, safety meetings, and safety literature)

E. Radiation and contamination monitoring

1. Health physics

2. Gaseous waste

3. Liquid waste

4. Solid waste

5. Exposure control (dose limits)

F. Surveillance requirements

1. Operational safety revlew committees

2. Reactor coolant system inspection and testing

3. Containment spray system tests

4. Building containment tests

5. Emergency core-cooling tests

6. Ice condenser system tests

7. Steam isulation valve tests

8. Feedwater eyctom tooto

9. Emergency electrical power system tests

10. Facility radiation monitoring system tests

11. Fire protection system tests

G. Internal and external distribution of literature on operational experiences

H. Plant and building evacuation criteria

I. Training programs for operating personnel 
Sample Study Questions

The questions provided in Sect. VIII (General Operating Characteristics) should be reviewed.

1. In regard to the annual release rate of gaseous waste from this facility, explain the terms in the following equation:

$$
\left[8.74 \times 10^{-7} \frac{\mathrm{sec}}{\mathrm{m}^{3}} \times \Sigma \frac{\Phi}{(\mathrm{mpc})}\right] \leqslant 1.0 .
$$

2. Discuss the limitations and precautions during fuel handing.

3. Discuss the preparations that must be made before a refueling sequence is performed.

4. Discuss any three incidents that have occurred in a nuclear facility, and describe the precautions taken at this facility to ensure against the recurrence of similar situations.

\section{References}

1. Vendor's literature.

2. Safety analysis report.

3. Technical specifications.

4. Procedures manuals. 
SECTION XV. FUEL HANDLING AND CORE PARAMETERS

Contents

Introduction . . . . . . . . . . . . . 306

Lesson Plan No. 1. Fuel . . . . . . . . . . . 307

Lesson Plan No. 2. Core Loading . . . . . . . . 309

Lesson Plan No. 3. Fuel Handling . . . . . . . . . . . 311

Lesson Plan No. 4. Reactivity Worths .......... 313

Lesson Plan No. 5. Heat Transfer . . . . . . . . . 314

Lesson Plan No. 6. Boiling and Rupture Detection . . . . . 317

Introduction

The purpose of this section is to outline the depth of knowledge of fuel handling procedures and core parameters required of the senior operator. This includes knowledge of criticality problems in the fuel storage area as well as within the reactor.

Reactivity addition problems may be caused by a variety of actions by the operator or by various equipment malfunctions. To eliminate these problems, safeguards are built into the reactor and procedures are written with limitations upon actions by the operacors. The sentur operator shuuld have sufficient knowledge of the hazards involved so that he will be able to recognize them and understand the need for and application of the preventive measures. 
Lesson Plan No. 1. Fuel

\section{Objective}

The student should learn the physical properties of the fuel and the design criteria of the fuel and limitations upon operation due to these criteria.

\section{Plan Outline}

A. Fuel enrichment and loading

1. Active core
a. Equivalent diameter
b. Active fuel height
c. Length-to-diameter ratio
d. Total cross-sectional area

2. Reflector thickness and composition

3. Moderator volume and distribution

4. Fuel assemblies
a. Number
b. Rod array
c. Rods per assembly
d. Rod pitch
e. Overa11 dimensions
f. Fuel weight
g. Cladding weight
h. Total weight
i. Number of grids per assembly
j. Number of guide thimbles
k. Size of guide thimbles

5. Fuel rods
a. Number
b. Outside diameter
C. Clad thickness
d. Clad material 
6. Fuel plates
a. Weight of material per plate
b. Enrichment
c. Distribution within plate
d. Number of plates per assembly
e. Clad material
f. Clad thickness

7. Fuel pellets
a. Material
b. Density
c. Fuel enrichments
d. Diameter
e. Length

8. Burnable poison
a. Material
b. Amount
c. Distribution
d. Effectlve 11fetime

B. Fuel rod design criteria and limits

1. Fucl tempcraturc
a. Melting point
b. Nominal full-power tompcrature

2. Gladding temperature
a. Corrosion control
b. Chemical reactions
c. H̃ot spots
d. Thermal expansion
e. Internal gas pressure
t. Fatigue limit
g. Transient limitations

\section{Sample Study Questions}

1. Explain the purpose of incorporating a burnable poison within the fuel plate or rod. What advantages do some types of burnable poison have over others? 
2. Why must fuel and burnable poison distribution within the fuel plate be specified and controlled?

3. Explain the purpose of multiple concentrations of fissionable material within the core. What tolerances are provided in a core loading?

Lesson Plan No. 2. Core Loading

Objective

This lesson should teach the student the possible hazards involved in loading the reactor core, recognition of these hazards, necessary preventive measures, and appropriate actions to be taken if an abnormal condition should occur during the core loading.

\section{Plan Outline}

A. Responsibility

1. Intt1al core loading

2. Subsequent core loadings

3. Limitations of responsibility and authority

4. Alternate core loadings

B. Standard procedures

1. Containment status

2. Radiation level monitoring

3. Core subcritical multiplication plot

4. Operability of residual heat removal system

5. Liquid control system monitoring and limitations

6. Communication between control room and refueling crew

7. Component identification and records 
8. Fuel accountability

9. Minimum instrumentation

10. Source requirements

11. Operability of containment ventilation and purging system

12. Flux mapping

C. Refueling equipment

1. Refueling platform with interlocks

2. Auxiliary hoists

3. Grapples

4. Fuel tools

5. Huel bundie samplers

6. Structural component tools

7. Reflector tools

8. Fuel servicing tools

9. Record-keeping forms and their use

10. Core component accountability

11. Control rod tools

12. Instrument handling tools

13: Crid tools

14: Equipment prcloading tcoting

15. Safety considerations in handling spent fuel

D. Abnormal condition proccdures

1. Abnormal increase in overall neutron count rate and limitations

2. Abnormal increase in neutron count rate in any individual monitor and limitations

3. Mechanical damage to fuel assemblies and rods during loading and unloading

E. Postloading testo

1. Pressure tests

2. Mechanical and electrical tests on control rod drive mechanisms

3. Time response tests on control rods and trip circuits

4. 'lrip circuit testing 
5. Liquid control system concentration during tests

6. Nuclear flux mapping system tests

7. Control rod calibrations

Sample Study Questions

1. List the electrical and mechanical interlocks associated with the refueling platform and auxiliary which prevent unsafe actions by the operators. What is each of these designed to prevent?

2. Communication between the control room and the refueling crew is required. Why is this so? What possible hazards make this necessary?

3. How can there be an abnormal increase in neutron count rate in an individual monitor while the overall reactor count rate remains normal?

4. What possible hazards are involved in dropping an irradiated fuel assembly? What immediate actions should be taken if this occurs?

Lesson Plan No. 3. Fuel Handling

\section{Objective}

The trainee should learn (1) the responsibilities and limitations of authority of the senior operator during fuel handling, (2) procedures which ensure safety during fuel movement, and (3) limitations that prevent the possibility of criticality while fuel is in storage. 
Plan Outline

A. New fuel

1. Responsibility and authorization

2. Inspection requịrements

3. Testịng requirements

4. Dimensional tests

5. Quality assurance program

6. Health physics coverage

7. Fue1 transfer (internal and external)

8. Storage requirements

a. Criticality prevention

b. k-effective of stored array

c. Mechanical damage prevention

d. Accountability procedures

e. Records of location and identification marks

f. Auditing

g. Limitations

B. Irradiated fuel

1. Responsibility and authorization

2. $\Lambda$ fterheat removal requirements (in-core as well as in storage)

3. Criticality prevention

4. Personnel exposure prevention

5. Storage requirements

a. Mechanical damage prevention

b. Accountability

c. Records of location

d. k-effective of storage facility

e. Auditing

f. Water level above fuel

6. Health physics coverage

7. Shipping for disposal

a. Shlpping casks (design, safety considerations, license limitations) 

b. Decay time
c. Heat removal
d. Shielding
e. Transportation

\section{Sample Study Questions}

1. What three main hazards are associated with the handling of reactor fuels?

2. What provisions are made to maintain adequate water shielding above the stored irradiated fuel?

3. How is criticality prevented in the new fuel storage vault?

4. What procedures cover fuel assembly substitution during core loading if the scheduled assembly is mechanically damaged? What authority does the senior operator have to make these substitutions?

Lesson P1an No. 4. Reactivity Worths

Objective

The trainee should learn the effects of various core loading upon the k-effective of the reactor and the effects of all variable parameters upon the safety of the reactor.

\section{Plan Outline}
A. Fuel (new and used)
B. Burnable poison (other than boron)
C. Xenon and samarium 
D. All fission products

E. Experiments

F. Control-rod differential and integral worths

G. Shutdown margins

H. Maximum reactivity insertion rates of control rods

I. Excess reactivity distribution

J. Liquid control system worth

K. Fixed poison strips

\section{Sample Study Questions}

1. What is meant by control-rod shutdown margin?

2. Why is it important that the insertion rates of control rods be maximized during reactor design?

3. What pussible effects can result from misoperation of control rods? What safeguards prevent these misoperations?

4. How can experiments affect reactivity? What measures are taken to gain prior knowledge of these effects?

Lesson Plan No. 5. Heat Transfer

\section{Objective}

This lesson should familiarize the trainee with design data that influence safe and efficient reactor operation.

\section{Plan Outline}

A. General

1. Design heat loads in
a. Fue1
b. Control rods 
c. Reflector

d. Structural components

2. System pressure

3. Normal operating pressure

4. Design coolant flow rates

a. Total

b. Through fuel coolant channels

c. Between fuel assemblies

d. Through experiment facilities

e. Through reflector

f. Through control regions

5. System pressure drop

6. Coolant temperatures
a. Vessel inlet
b. Vessel outlet
c. Fuel outlet

B. Fuel region

1. Geometry and dimensions

2. Total heat transfer area

3. Active core volume

4. Heat load

5. Power density

6. Heat flux

a. Hot spot

b. Burnout

c. Average

7. Coolant flow rate

8. Coolant velocity

9. Pressure drop across fuel region

10. Temperatures
a. Inlet
b. Outlet
c. Oxide-water interface
d. Metal-oxide interface (nominal and maximum)
e. Fuel rod (nominal and maximum) 
C. Experiment region

1. Geometry and dimensions

2. Heat load

3. Heat flux

4. Coolant flow rate

5. Coolant velocity

6. Pressure drop

7. Temperatures

a. Inlet

b. Ont1et.

b. Control region

1. Geometry and dimensions

2. Heat load

3. Heat generation rate

4. Heat flux (nominal and maximum)

5. Coolant flow rate

6. Coolant velocity

7. Pressure drop

8. Temperatures

a. Inlet

b. Outlet

c. Surface

d. Interior

E. Reflector region

1. Geometry and dimensions

2. Heat load

3. Heat gencration rate

4. Heat fl11x

5. Cuolaul velucily

6. Coolant flow rate

7. Pressure drop

8. Temperatures
a. Inlet
b. Outlet
c. Surface
d. Interior 
Sample Study Questions

1. A blocked coolant channel can cause excessive temperature buildup within a fuel element. What precautions are taken to prevent this from happening?

2. Explain how coolant channel design can affect the overall power level limitation.

Lesson Plan No. 6. Boiling and Rupture Detection

\section{Objective}

The trainee should learn (1) to detect coolant boiling in the reactor so that power reduction may be effected prior to fuel cladding rupture (applicable to research reactor), (2) to recognize the possible causes of boiling and thus prevent its occurrence, (3) to detect cladding failure and to control fission product release, and (4) to operate the reactor in such a manner as to prevent cladding rupture.

\section{$\underline{\text { Plan Outline }}$}

A. Boiling and burnout

1. Incipient bolling temperature

2. Bolling detection

3. Boiling temperature calculations

4. Calculated hot-spot heat flux

5. Hot spot at incipient boiling power level

6. Burnout power level

7. Burnout fuel temperature

8. Burnout cladding temperature

9. Burnout cladding-coolant interface temperature

10. Flux mapping procedures 
B. Rupture detection

1. Fission product detection in coolant

2. Instrument response to boiling and clad rupture

3. Identification and location of clad rupture

4. Controlling fission product release by flux depression method

\section{Sample Study Questions}

1. What are the first indications of the onset of boiling in a research-type reactor?

2. What instruments would give the first indications of a cladding failure?

3. Why must control-rod manipulations be made according to a prescribed program? What results could be expected if this program is disregarded?

4. Explain the method used to minimize the release of fission products into the coolant in a water-cooled power reactor.

5. What methods can be used to locate a ruptured fuel element? Explain the reasons for using each of these. 
SECTION XVI. RADIOACTIVE MATERIAL HANDLING, DISPOSAL, AND HAZARDS

\section{Contents}

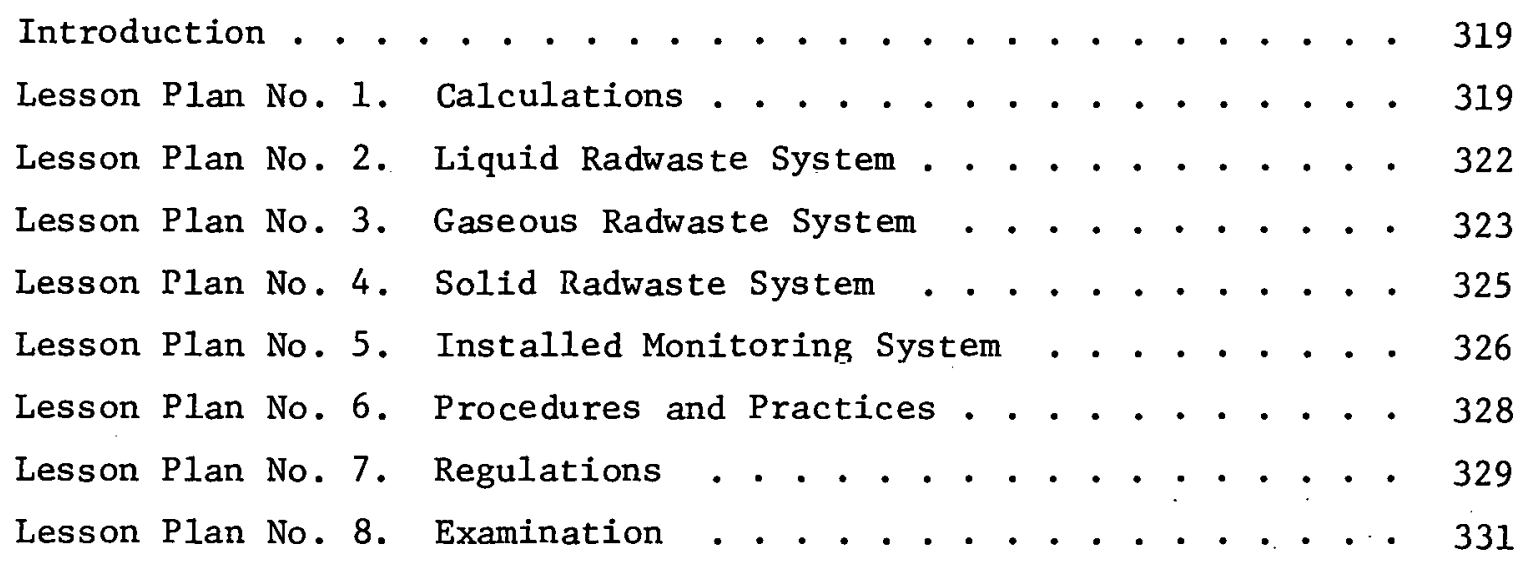

\section{Introduction}

The objective of this section is to outline the depth of understanding required of a senior operator concerning the handling, disposal, and hazards of radioactive material. Knowledge is required of the provisions of $10 \mathrm{CFR}$, Part 20, and facility regulations; the processing and disposal systems of the facility; and techniques for calculating decay rates, dose-distance relationships, the conversion of radiation intensities to rems, and similar types of calculations.

Lesson PIan No. 1. Radiation Calculations and Heallh Physics Considerations

\section{Objective}

The objective of this lesson plan is to review the calculational techniques related to the inverse square law, decay rates, half-thicknesses, 
etc. The senior operator is expected to perform calculations using the various laws and to be able to use various "rule-of-thumb" methods applicable to operational problems.

\section{$\underline{\text { Plan Outline }}$}

A. Activity buildup and decay

1. Activity buildup equation

$$
\frac{\mathrm{dn}}{\mathrm{dt}}=\Sigma \Phi-\lambda \mathrm{N}
$$

2. Radioactive decay

$$
\begin{aligned}
& \frac{\mathrm{dn}}{\mathrm{dt}}=-\lambda \mathrm{N}_{0} \\
& \mathrm{~N}(\mathrm{t})=\mathrm{N}_{\mathrm{O}} \mathrm{e}^{-\lambda t}
\end{aligned}
$$

3. Half-life

$$
t_{1 / 2}=\frac{\ln 2}{\lambda}=\frac{0.693}{\lambda}
$$

4. Definition of curie and microcurie

B. Radiation attenuation

1. Invelse squale law

$$
I_{1} d_{1}^{2}=I_{0} d_{0}^{2}
$$

2. Half-value thickness of shielding

C. Dose calculations

1. Dose rate $X$ time $=$ dose

2. Rad, rem, and $\mathrm{RBE}$ relationship

3. $6 \mathrm{CiE}=\mathrm{R} / \mathrm{hr}$ at $1 \mathrm{ft}$

4. Accumulative dose $5(\mathrm{~N}-18)$

5. Problcmo eombining cffcets of time, diotanec, and shiclding

D. Diulugical tadialiun efrecls

E. Situations where alpha, beta, gamma, or neutrons may occur.

F. Radiation characeristics of radioisotopes

G. Chemical and phyeical properties of radioieotopes which cauee problems at a power reactor

H. Situations where radiation or contamination may occur

I. Difficulties of detection 
Sample Study Questions

1. What is the half-life of an isotope having a decay constant of $0.5 \mathrm{dis} / \mathrm{sec}$ ?

2. What dose rate would you expect $10 \mathrm{ft}$ from a $10-\mathrm{C} i$ source emitting gamma rays of $1.25-\mathrm{MeV}$ energy?

3. An alpha emitter indicated an activity of $4000 \mathrm{dis} / \mathrm{sec}$. How many curies of activity is this?

4. A gamma emitter indicated a dose rate of $10 \mathrm{rems} / \mathrm{hr}$ at $1 \mathrm{ft}$. If 2 in. of lead is placed around the: emitter, what will the dose rate be at $1 \mathrm{ft}$ ?

5. Does the biological effect of a 100-rem dose depend on whether it is a neutron or gamma dose? Explain.

6. What are the most vulnerable parts of the body with respect to external radiation damage? Why are they considered the most vulnerable?

7. Discuss situations in which the presence of important radioisotopes might be undetected. What precautions should be taken?

\section{$\underline{\text { References }}$}

1. S. Glasstone and A. Sesonke, Nuclear Reactor Engineering, D. Van Nostrand, Inc., Princeton, N.J., 1963.

2. S. D. Sheppard, Reactor Operator Study Handbook (Progrommed Instmution Version). Vol. IV - Heat Theory and. Fluid Flow, ed. C. D. Cagle, ORNL/TM-2034, Oak Ridge National Laboratory, Oak Ridge, Tenn., December 1968.

3. H. J. Stoever, Engineering Thermodynomics, John Wiley \& Sons, Inc., New York, 1951. 
Lesson Plan No. 2. Liquid Radwaste System

\section{Objective}

This lesson should provide an understanding of the components and equipment, sources of activity, treatment methods, and disposal of liquid wastes generated in the plant. The breadth of knowledge should exceed that of an operator (e.g., the senior operator should be familiar with the design bases and reasons for design changes, and he should display a thorough knowledge of the interrelationship of ocher systems).

\section{Plan Outline}

A. System description

1. Review of flow diagram

2. Component characteristics

3. Design parameters

B. Collection systems and sources

1. Normal flow and activicy

2. Munlturlng

3. Abnormal conditions of flow or radiuactivity

4. Cunlrol hecessary

c. 'lreatment system and components

1. Equipment for treating waste

2. Normal parameters and limits

3. Abnormal parameters and constderations

D. Disposal

1. Sampling and analysis technique

2. Calculations to determine appropriate release rates

3. Valving and conditions required before release

4. Precautions

5. Restrictions applicable to releases 
Sample Study Questions

1. Sketch a simple flow diagram of the liquid radwaste system, and include the main collection points and sources.

2. Describe the monitoring associated with liquid waste and its purpose.

3. What are the major contaminants in the liquid radwaste system? Describe their source and the methods used to treat each significant contaminant.

4. What are the limitations imposed for liquid radwaste effluents from the plant?

\section{$\underline{\text { References }}$}

1. Safety analysis report.

2. Vendor's manuals.

3. Procedures manuals.

4. Technical specifications.

Lesson Plan No. 3. Gaseous Radwaste System

\section{Objective}

This lesson should provide an understanding of the components and equipment, sources of activity, treatment methods, and disposal of gaseous wastes generated in the plant. The senior operator should be thoroughly familiar with the design bases and the interrelationships with other systems.

\section{Plan Outline}

A. System description

1. Flow diagram 
2. Component characteristics

3. Design parameters

B. Collection systems and sources

1. Normal flow and activity

2. Monitoring (including efficiency)

3. Abnormal conditions, interpretation, and corrective action

C. Treatment system and components

1. Component characteristics

2. Norma1 parameters and limits

3. Abnormal conditions and corrective actions

4. Presaltions

D. Disposal

1. Monitoring and sampling techniques

2. Abnormal conditions and corrective actions

3. Restrictions applicable to releases

4. Precautions

\section{Sample Study Questions}

1. Sketch a flow diagram of the gaseous radwaste treatment system; label all major components.

2. Provide a list of the monitors and their setpoints associated with the gaseous radwaste system.

3. What are the principal isotopes in gaseous releases from this plant? What are their half-lives and their relative amounts of importanre?

4. What are the limitations imposed on the gaseous effluents from Llie plant?

\section{References}

1. Safety analysis report.

2. Vendor's manuals.

3. Procedures manuals.

4. Technical specifications. 
Lesson Plan No. 4. Solid Radwaste System

Objective

This lesson should provide an understanding of the equipment and methods for treating and disposing of solid radwaste. The senior operator should be familiar with 'other systems.

\section{Plan Outline}

A. System description

B. Sources

1. Cleanup sludge

2. Spent resins

3. Miscellaneous

C. Treatment system and components

1. Operation

2. Control over contamination

3. Segregation of different types of waste

D. Disposal

1. Stonrage prosedures and restrictions

2. Disposal procedures and limitations

Sample Study Questions

1. What are the sources and expected annual quantities of solid materials?

2. What different types of waste may be expected, and what is the basis for segregation?

3. What are the limitations imposed for storage of solid radwaste?

4. What are the requirements for disposal of solid wastes? 


\section{References}

1. Safety analysis report.

2. Procedures manuals.

3. Technical specifications.

4. Applicable governmental regulations.

Lesson Plan No. 5. Inetulled Monitoring Systems

Objective

This lesson should provide a thorough understanding of the installed monitoring systems for detecting radioactivity. The student is expected to know the setpoints at which monitors alarm, the reasons for these setpoints, the significance of alarms, and the location of the monitors.

\section{$\underline{\text { Plan Outline }}$}

A. Area radiation monitors

1. Location

2. Types of monitors, sensitivity, limitations

3. Setpoints

4. Significance of alarms

B. Environmental monitors (description and purpose)

C. Off-gas radiation monitors

1. Looation

2. 'lypes of monitors, sensitivity, limitations

3. Setpoints

4. Significance of alarms

D. Ventilation exhaust monitors

1. Location

2. Types of monitors (sensitivity, 1imitations) 
3. Setpoints

4. Significance of alarms

E. Stack monitors

1. Location

2. Type of monitors, sensitivity, limitations

3. Setpoints

4. Isotopes which might be released and reaction of monitor

5. Significance of alarms

F. Liquid radwaste monitors

1. Location

2. Type of monitors, sensitivity, limitations

3. Setpoints

4. Isotopes which might be present and reaction of monitors

5. Significance of alarms

6. Action required to interpret alarms and abnormal behavior

Sample Study Questions

1. What limitations are imposed if the stack effluent monitors are inoperative?

2. What occurs if the ventilation system monitor setpoint is actuated?

3. Discuss the significance of an area radiation alarm on the refueling.floor with the reactor at full power.

\section{$\underline{\text { References }}$}

1. Safety analysis report.

2. Procedures manuals.

3. Technical specifications.

4. Applicable governmental regulations. 
Lesson P1an No. 6. Procedures and Practices

\section{Objective}

This lesson should provide an understanding of the procedures required to safely handle radwastes and to provide practice in the manipulation of radiation detection devices.

\section{$\underline{\text { Plan Outline }}$}

A. Review of procedures applicable to

1. Liquid radwaste

2. Gaseous radwaste

3. Solid radwaste

4. Refueling

B. Radiation monitoring techniques

1. Manipulation of all portable radiation detection devices

2. Limitations and applicability of portable radiation detection devices

C. Decontamination techniques

1. Methods to localize contamination

2. Different cleaning techniques

3. Discipline needed to prevent spread of contamination

4. Monitoring during decontamination

\section{Sample Study Questions}

1. Describe the systems, procedures, monitoring, 1imitations, and precautions for handling liquid and gaseous waste.

2. What types and amounts of solid waste might be expected each year from a power station, and what handling, storage, and disposal techniques are used for each type?

3. Describe the method for calculating the liquid activity release rate. 
4. Describe how the demineralizer resin removal is accomplished and the precautions associated with its disposal.

5. What are the precautions necessary in refueling and in handing spent fuel?

6. What factors must be considered in shipment of spent fuel?

7. What situations which might be encountered at a reactor require certain monitoring instruments in preference to other instruments?

8. Under what conditions are personnel allowed to enter high-radiation areas?

9. What types of portable instruments would you use when entering the primary containment as soon as possible after shutdown?

10. Discuss a situation in which contamination might be spread if precautions were not taken.

11. Discuss procedures necessary to prevent the spread of contamination.

12. Explain the precautions and procedures for exiting an area which has a high surface contamination level.

13. Discuss the need for counting smear samples. What areas should be smeared, and with what frequency?

\section{References}

1. Procedures manuals.

2. Vendor's training manuals.

3. Technical specifications.

Lesson Plan No. 7. Regulations

\section{Objective}

This lesson should provide an understanding of the facility regulations, technical specifications, administrative controls, and $10 \mathrm{CFR} 20$ related to the handling and disposal of radioactive materials. 
Plan Outline

A. Facility regulations

1. Limiting conditions for radwaste release

2. Surveillance requirements on effluents

3. Requirements in event of abnormal occurrence

4. Personnel exposure limits

5. Radiation and contamination zone limits

B. 10 CFR 20 regulations

1. Limiting conditions for radwaste release

2. Persumel expusule linits

3. Definition of radiation areas and high-radiation areas

\section{Sample Study Questions}

1. What is the difference between a radiation area and a highradiation area?

2. What is the $10 \mathrm{CFR} 20$ limit for a whole-body dose received in one quarter?

3. What is the limit for unidentified activity that can be discharged in water to an unrestricted area?

4. What are the requirements for reporting an overexposure of personnel to radiation?

5. What is the facility's maximum allowed annual average gaseous effluent release rate?

\section{References}

1. Technical specifications.

2. Procedures manual.

3. "Standards for Protection Against Radiation," Code of Federal Regulations 10, Part 20, U.S. Government Printing Office, Washington, D.C. 
Lesson Plan No. 8. Examination

Objective

This lesson should review the information presented in the previous lesson plans and provide practice in taking examinations.

Plan Outline

This lesson plan should consist of a 1- to 2-hr written or oral examination. Questions for the examination may be taken from those of previous lesson plans and be supplemented by those prepared by the instructor.

Sample Study Questions

1. Does the biological effect of a 100-rem dose depend on whether it is a neutron or gamma dose? Explain.

2. Explain how you would decontaminate a small tool which is emitting 50 millirems/hr of gamma radiation at contact.

3. What are the most vulnerable parts of the body with respect to external radiation damage? Why are they considered the most vulnerable? 
SECTION XVII. ADMINISTRATIVE PROCEDURES, CONDITIONS, AND LIMITATIONS

Contents

Introduction . . . . . . . . . . . . . . . . 332

Lesson Plan No. 1. Regulatory Controls and Limitations . . . 333

Lesson Plan No. 2. Technical Specifications . . . . . . . . 334

Lesson Plan No. 3. Assignment of Authority and Responsibility . 336

Lesson l'Lan No. 4. Keview and Audit . . . . . . . . . . . . 337

Lesson Plan No. 5. Facility Administrative Policies and

Plucedules . . . . . . . . . . . . . . . 338

Lesson Plan No. 6. Records and Audits . . . . . . . . . . 340

\section{Introduction}

Numerous administrative controls are imposed upon the operators of a nuclear facility from the issuance of a construction permit through the life of the facility. The objective of this section is to acquaint the student with the administrative, procedural, and regulatory factors controlling the operation of the facility, including the organizational and administrative systems and the various authorities and organizations through which the facility is licensed, constructed, operated, and maintained.

Some of the administrative controls originate with government agencies and apply to all reactor facilities, whereas others might develop as a result of specific design features of the reactor facility and its location. 
Lesson Plan No. 1. Regulatory Controls and Limitations

Objective

This lesson should familiarize the student with the administrative controls and regulations imposed upon the facility by governmental agencies. The student should be especially cognizant of his responsibilities in operating the facility within limitations of Section 10 of the Code of Federal Regulations and any applicable state and local regulations.

\section{Plan Outline}

A. $10 \mathrm{CFR} 20$ (Standards for Protection Against Radiation)

1. Exposure of individuals to radiation in restricted areas

2. Determination of accumulated dose

3. Permissible levels of radiation in unrestricted areas

4. Concentrations in effluents to unrestricted areas

5. Surveys

6. Personnel monitoring

$\%$ Caution signs, labels, and signals

B. 10 CFR 50 (Licensing of Production and Utilization Facilities)

1. Requirement of license and exceptions

2. Standards for license

3. Limitations and conditions of 1icense

4. Allocation of special nuclear material

5. Inspection, records, and reports

6. Amendment of license

C. $10 \mathrm{CFR} 55$ (Operator's Licenses)

1. Requirements for approval of application

2. Ticensing of operational personnel

3. Retraining of operational personnel 
D. 10 CFR 70 (Special Nuclear Material)

\section{Licenses}

2. Acquisition, use, and transfer of special nuclear material

3. Reports, records, and inspections

4. Modification and revocation of licenses

E. 10 CFR 100 (Reactor Site Criteria)

1. Factors to be considered when evaluating sites

2. Determination of exclusion area, low-population zone, and population center distance

F. State and local limitations and regulations

\section{Sample Study Questions}

1. What are the requirements for monitoring personnel exposure to radiation in a restricted area?

2. What is the maximum permissible radiation dose to the whole body in any one quarter?

3. What is the formula for calculating the maximum permissible accumulated whole-body occupational dose?

4. What are the requirements for manfpulating the controls of a nuclear reactor?

5. What are technical specifications, and why are they provided?

Lesson Plan No. 2. Technical Specifications

\section{objective}

This lesson should familiarize the student with (1) safety limits and maximum safety settings, (2) minimum conditions for operation, (3) surveillance requirements, (4) design features, and (5) administrative controls essential to safe operation of the facility. The student should learn what action should be taken if a safety limit is exceeded. 
Plan Outline

A. Safety limits and maximum safety system settings

1. Normal operating limits

2. Maximum safety limit

3. Action if safety limit is exceeded

B. Minimum conditions for operation

1. Lowest functional capability or performance levels of equipment for safe operation

2. Minimum number of personnel for various phases of operation

3. Action taken if minimum conditions of operation are not met

C. Surveillance requirements

1. Tests

2. Calibrations

3. Inspections

D. Design features

1. Examination of all equipment and materials associated with each barrier with respect to

a. Whether a change in design would affect any technical specification

b. Whether any margin of oufcty aooociated with any technical specification would be affected

c. Whether the equipment or its performance is covered in any other technical specification

E. Administrative controls

1. Organization

2. Procedures

3. Logs and records

4. Review and audit

5. Reports to NRC 


\section{Sample Study Questions}

1. What is the purpose of a safety limit?

2. What action should be taken if a safety limit is exceeded?

3. What are maximum safety system settings, and how are they related to safety limits?

4. What are the minimum conditions for normal operation?

5. What action should be taken if the minimum conditions for operation cannot be met?

6. What is the procedure for reporting operation in excess of a safety limit?

Lesson Plan No. 3. Assignment of Authority and Responsibility

\section{Objective}

This lesson should familiarize the student with the organizational system and the lines of authority which have been established for implementing administrative and procedural items that affect the operation of the facility. This section focuses primarily on the assignment of authority and responsibility in approving all types of changes to items such as procedures, design, and specifications.

\section{Plan Outline}

A. Lines of authority

1. Organization chart

B. Authority to approve changes

1. In operating procedures

2. In maintenance procedures 
3. In design

4. In technical specifications

5. By issuing new operating procedures

6. By issuing new maintenance procedures

7. By issuing temporary procedures

Sample Study Questions

1. By what authority are permanent changes made in the operating procedures?

2. Who has the authority to approve deviations from standard operating procedures?

3. By what authority are changes in design effected?

Lesson Plan No. 4. Review and Audit

\section{Objective}

Each reactor facility shall establish review and audit programs to verify that operation of the plant is consistent with the policy and rules, approved operating procedures, and license provisions; to review important proposed plant changes, tests, and procedures; to verify that unusual events are promptly reported investigated, and corrected; and to detect trends that may not be apparent to a day-to-day observer. This lesson should familiarize the student with the various types of reviews and audits that will be conducted routinely to assure facility management that operations are being conducted in a safe and approved manner. 
Plan Outline
A. General
B. Administration of the independent review and audit programs
C: Subjects requiring independent review
D. Independent audit
E. On-site review organization
F. Quality assurance program

Sample Study Questions

1. List the committees that have been established to conduct routine review?

2. What is the purpose of the review committees?

3. How often will independent audits of the nuclear power plants be conducted?

Lesson Plan No. 5. Facility Administrative Policies and Procedures

\section{Objective}

This lesson should familiarize the student with the rules of practice and operating and maintenance procedures of the facility. The senior operator should know the general plant procedures, standard practice procedures, standing orders, requirements for security and visitor control, etc. Upon completion of this lesson, the trainee should have a full understanding of how the general plant policies and administrative procedures supplement the nuclear plant procedures. 
Plan Outline

A. Rules of practice

1. Responsibilities and authorities

2. Procedure adherence

3. Standing orders

4. Special orders

5. Equipment control and work permit procedure

6. Maintenance

7. Surveillance schedul,e

8. Plant security and visitor control

9. Radiation safety

B. Operating and maintenance procedures

1. Procedure scope

2. Procedure content

3. System procedures

4. General plant procedures

5. Maintenance procedures

6. Health physics procedures

7. Instrument calibration and test procedures

8. Chemical-radiochemical control procedures

9. Emergency procedures

10. Materials control procedures

\section{Sample Study Questions}

1. Who has the authority to issue work permits? What are the requirements of issuing work permits?

2. What is the plant policy on admitting visitors?

3. What action should be taken if there is a fire alarm in the reactor building?

4. List six examples of potential emergencies for which procedures are written and for which Immediate action is indicated? 
Lesson Plan No. 6. Records and Audits

\section{Objective}

This lesson should familiarize the student with the logs, records, and audits which are routinely maintained and conducted to assure that adequate information and documentation is kept on all phases of the operation.

Plan Outline

A. Logs and records

1. uperacton

2. Ma1ntenance

3. Changes

4. Tests

5. Inspections

6. Calibrations

7. Incidents

8. Fuel storage and handling

9. Accumulated radiation dose

1U. Keviews

B. Review and audit

1. Operations

2. Maintenance

3. Equipment

4. Personnel

C. Quality assurance program

1. Procedures

2. Records

3. Audits

D. In-service surveillance programs

1. Type

2. Frequency

3. Evaluations 


\section{Sample Study Questions}

1. What type of information should be recorded in the shift operating log?

2. What records are kept on radiation exposure of personne1?

3. What records are normally kept as part of the quality assurance program?

4. Who is responsible for maintaining inspection records on pressure vessels?

5. What records should be available for auditing the plant maintenance program? 


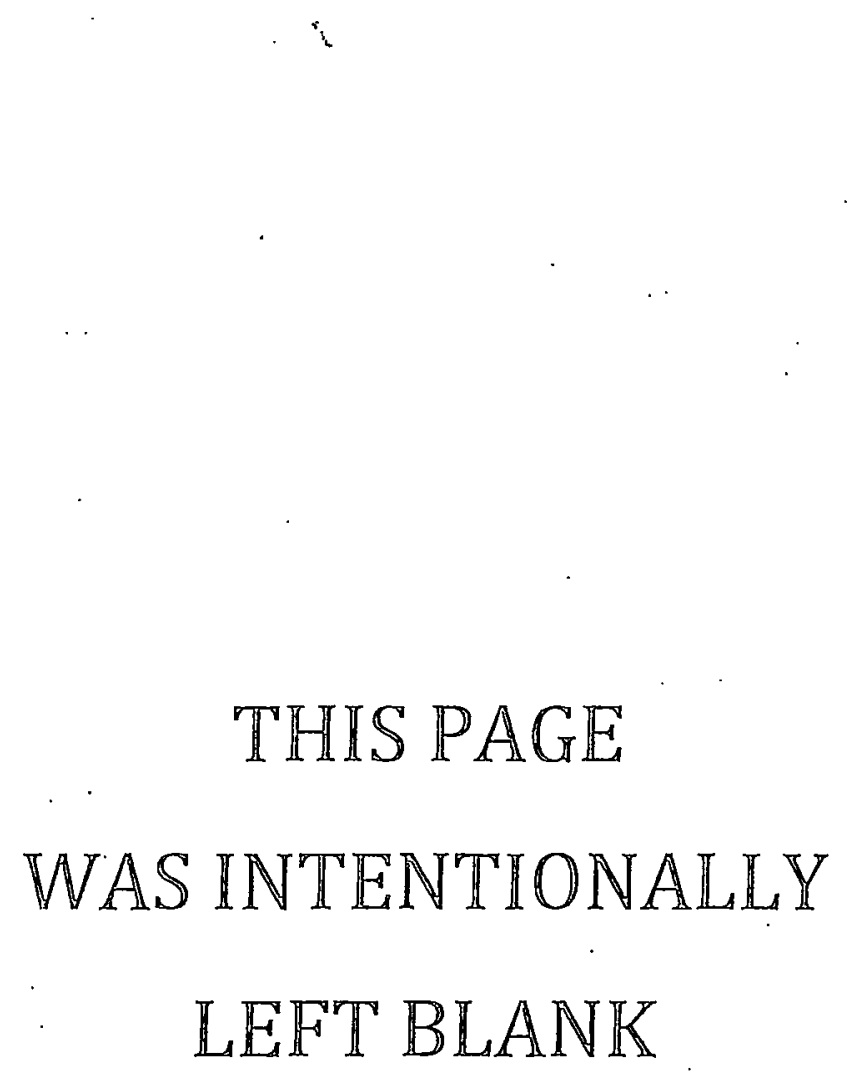


APPENDIX A

BIBLIOGRAPHY FOR TRAINING GUIDE

General

American Nuclear Society, USA Standard - Selection and Training of Nuclear Power Plant Personnel, Hinsdale, Ill.

J. L. Anderson and W. G. Counsil, "Training of Personnel to Operate the Millstone Point Company Nuclear Boiling Water Reactor Power Plant," Trans. Am. NucZ. Soc. 13: 456 (1970).

A. L. Babb, N. J. McCormick, and G. L. Woodruff, "Experience with a Televised Nuclear Engineering Seminar Program," Trans. Am. Nucl. Soc. 11: 44 (1968).

A. E. G. Bates, "Training Nuclear Power-Plant Operators with Computerized Simulators," Nucl. Safety 10: 405-11 (1969).

R. R. Beach, "Comprehensive Training Programs for the Nuclear Plant Staff," Trans. Am. Nucl. Soc. 12: 14-15 (1969).

R. J. Bogisich, "Training of Replacement Operators at the Vallecitos Nuclear Center," Trans. Am. Nucl. Soc. 14(1): 318-19 (1971).

P. A. Burt, "Observed Deficiencies in Training Programs, Paper 4 in Symposium on Training of Nuclear Facility Personnel, Gatlinburg, Tenn., Aprit 1971, Conf-7 10416.

S. H. Cantone, "Training of Replacement Operators - Indian Point Plant," Trans. Am. Nucl. Soc. 14(1): 317 (1971).

N. B. M. Clack, "Practical Training of Naval Engineer Officers as Nuclear Submarine Power Plant Operators," Proc. Inst. Mech. Eng. (Lond.) 183: 8-11 (1968-69).

J. M. Collins and J. Connelly, "CP and L's Reactor Operator Requalification Program," Trans. Am. Nucl. Soc. 18: 284 (1974).

P. F. Collins, "AEC Examination Results," Paper 3 in Symposium on Training Nuclear Facility Personnel, Gatlinburg, Tenn., April 1971, Conf-7 10416.

P. F. Collins, "Operator License Examinations Using Nuclear Power Plant Simulators," Trans. Am. Nucl. Soc. 13: 804-05 (1970).

P. F. Collins and J. J. Holman, "Operator Requalification," Trans. Am. Nucl. Soc. 18: 284-85 (1974). 
Commonwealth Edison Co., Dresden Nuclear Power Station, Units 1 and 2, Operator Retraining Program, Docket No. 50 010, Chicago, Apr. 10, 1970.

Commonwealth Edison Co., Dresden Nuclear Power Station, Unit 2, Operator Retraining Program, Docket No. 50 237, Chicago, Apr. 10, 1970.

Connecticut Yankee Atomic Power Co., Connecticut Yankee Atomic Power Plant, Operator Retraining Program, Docket No. 50 213, Hartford, Apr. 10, 1970.

Consolidated Edison Co. of New York, Inc., Indian Point Station, Unit No. 1, Operator Retraining Program, Docket No. 50 003, Mar. 19, 1970.

Consumers Power Co., Big Rock Point Nuclear Plant, Operator Retraining Program, Docket No. 50 155, Jackson, Mich., Apr. 10, 1.970.

W. G. Counsil, "Simulator Experience by Utilities," Paper 11 in Symposizm on Training of Nuclear Facility Personnel, Gatlinburg, Tenn., April 1971, Conf-7 10416.

W. G. Counsil, "Training of Personnel to Operate the Millstone Point Company Nuclear Boiling Reactor Power Plant," Trans. Am. Nucl. Soc. 13: 803 (1970).

Dairyland Power Cooperative, La Crosse Boiling Water Reactor, Operator Retraining Program, Docket No. 1155 or 50 407, La Crosse, Wis., May 21, 1970.

J. N. Davis, "Test Reactor Operating Crew Training," Trans. Am. Nucl. Soc. 14 (Supp1 2): 48 (1971).

J. C. Deddens, "PWR Simulator Training," Nucl. News 12(11): 50-53 (1969).

J. C. Deddens, "Simulator Training of Nuclear Power Plant Operators," Proc. Am. Power Conf. 31: 90-98 (1969).

R. W. Deutsch, "Academic and Laboratory Courses for Nuclear Power Plant Personnel," Nucl. News 14(9): 47-50 (1971).

R. W. Deutsch, "Staffing Tomorrow's Nuclear Plants," Power Eng. 75(3): 58-60 (1971).

Directorate of Regulatory Standards, Personnel Selection and Training. Safety Guide, WASH-1226-8, Washington, D.C., Mar. 10, 1971.

F. C. Duvall, How to Staff and Train for Nuclear Power, NUS Corp., Washington, D.C.

F. C. Duvall, "Requalification: A New Dimension in Training," Trans. Am. NucZ. SOC. 18: 283-84 (1974).

F. C. Duval1, "Staff Planning for Nuclear Projects," Paper 15 in Symposium on Training of Nuclear Facility Personnel, Gatlinburg, Tenn., April 1971, Conf-7 10416. 
D. R. Edwards, A. E. Bolon, and A. E. Elliot, "Educational Uses of the University of Missouri-Rolla Reactor," Trans. Am. Nucl. Soc. 15(Supp1. 1): 19 (1972).

J. H. Ferguson, R. L. Gridley, and G. C. Masche, "Nuclear Power Plant Simulation Applied to Reactor Operator Training," Trans. Am. Nucl. Soc. 10(Supp1.) : 37 (1967).

J. L. French, "Operating Retraining Program," Trans. Am. NucZ. Soc. 14(Supp1. 2): 51 (1971).

J. L. French and J. D. Grady, "Biennial Retraining Program for Licensed Operators," Trans. Am. Nucl. Soc. 18: 282-83 (1974).

R. L. Gridley, "Organization of Two-Year Retraining Program for Licensed Personnel at Operating Nuclear Power Plants," Trans. Am. Nucl. Soc. 14 (Supp1. 2) : 52 .

R. L, Gridley, W. H. Guppy, and K. T. Perkins, "BWR Simulator Training," Nucl. News 12(11): 53-56 (1969).

R. L. Gridley, W. H. Guppy, and K. T. Perkins, "Experience in the Use of a BWR Nuclear Power Plant Training Simulator," Proc. Am. Power Conf. 31: 99-103 (1969).

S. Grimes, "Operating Experience with the Cardinal Plant Training Simulator," Trans. Am. Nucl. Soc. 13: 802 (1970).

W. H. Guppy and G. C. Masche, "Nuclear Plant Training," Power Eng. 72(7): 38-41 (1968).

W. H. Guppy and G. C. Masche, "Nuclear Power Plant Operator Training and Qualification," Proc. Am. Power Conf. 30: 336-46 (1969).

T. P. Hamrick, "The Development of a Self-Study Program for Certifying and Retraining Reactor Operations Staff at ORNL," Paper 16 in Symposium on Training Nuclear Facility Personnel, Gatlinburg, Tenn., April 1971, Conf-7 10416 .

J. A. Hancock, "Custom-Tailored Nuclear Training," Power Eng. 72(2): 31-35 (1970).

D. F, Hang, "Continuing Education in Nuclear Engineering - Progress and Problems," Trons. Am. Nucl. Soc. 12: 435-36 (1969).

D. F, Hanlen, "Modular Concepts Approach for Individual Training Needs of Reactor Plant Personnel," Trans. Am. Nucl. Soc. 13: 804 (1970).

D. F. Hanlen, G. N. Hamilton, and E. G. Taylor, Westinghouse Reactor Evaluation Center, Reactor Operator Training Manual, WCAP-2713 (rev.), Westinghouse Electric Corp. Pittsburgh, Pa., October 1967.

W. C. Harrison, "Industrial Preferences for Nuclear Engineering Manpower," Trans. Am. Nucl. Soc. 14(2): 759-60 (1971). 
L. H. Heider and E. W. Jackson, "Training of Replacement Operators at Yankee Rome," Trons. Am. Nucl. Soc. 14(1): 319-20 (1971).

Idaho Nuclear Corp., Reactor Training, IN-1228, Idaho Falls.

R, Jaerschky and H, D. Martin, "Simulator Training of Operating Personnel for Nuclear Power Plants. Development and Methods in the U.S.A.,"

Atomuirtsch. Atomtech. 15: 329-30 (1970).

Jersey Central Power and Light Co., Oyster Creek Nuclear Generating Station, Unit No. 1, Operator Retraining Program, Docket No. 50 219, Morristown, N.J., Apr. 3, 1970.

W. P. Johnson, "The Yankee Companies' Experience with Staffing and 'Iraining of Nuclear Power Plants," Trans. Am. Nucl. Soc. 12: 15 (1969).

C. F. Jones, "Staffing Nuclear Plants," Power Eng. 72: 47-49 (1968).

R. C. Knoble, "I'raining Perspective on the Use of the BWR Simulator," Trans. Am. Nucl. Soc. 13: 802-03 (1970).

B. V. Koen, "Evaluation of an Introductory Nuclear Engineering Course Taught by a Self-Paced Method,"Trans. Am. Nucl. Soc. 13: 24 (1970).

S. J. Kovacs, "On the Job Training," Paper 12 in Symposium on Training of Nuclear Facility Personnel, Gatiinburg, Tenn., April 1971, Conf-7 10416.

D. S. Lewis, "Operational Staffing and Training Problems for the Startup of N Reactor," Trans. Am. Nucl. Soc. 10 (Supp1.): 35-36 (1967).

R. L. Long and M. L. Lee, "Nuclear Engineering Education from a Utility Viewpoint," Trans. Am. Nucl, Soc, 14(2): 760-61 (1971).

G. C. Masche, "Training Program for Replacement Operators," Trons. Am, Nucl. Soc. $14(1): 319$ (1971).

S. A. McGuire and J. G. Martin, Nuclear Training for Latin America - at Home or Abroad," Trans. Am. Nucl. Soc. 15(2): 638 (1972).

Niagara Mohawk Power Corp., Nine Mile Point Nuclear Station, Unit No. 1 , Operator Retraining Program, Docket No. 50 220, Syracuse, N.Y., Apr. 15, 1970.

"Nuclear Training Center Uses Digital Simulation," Elec. World 170(4): 24-25 (1968).

Pacific Gas and Electric Co., Humboldt Bay Power Plant, Unit No. 3, Operator Retraining Program, Docket No. 50 133, San Francisco, Apr. 10, 1970. 
J. L. Penkala, "Role of Universities in Training Nuclear Facility Personnel," Paper 7 in Symposium on Training of Nuclear Facility Personnel, Gatlinburg, Tenn., April 1971, Conf-7 10416.

Philadelphia Electric Co., Peach Bottom Atomic Power Station, Unit 1, Operator Retraining Program, Docket No. 50 171, Apr. 7, 1970.

Power Reactor Development Co., Enrico Fermi Atomic Power Plant, Unit 1, Operator Retraining Program, Docket No. 50 016, Detroit, Apr. 22, 1970.

Preparation and Training of Experts in the Nuclear Field. Proceedings of the 15th Nuclear Congress of Rome, Mar. 12-13, 1970, Rome-Comitato Nazionale Energia Nucleare, 1971.

G. A. Reed, "Staffing and Training for Nuclear Power," Power 112(5): 88-91 (1968).

F. J. Remick and J. L. Penkala, "Role of the University in Training Nuclear Power Plant Operators," Trans. Am. Nucl. Soc. 12: 14 (1969).

Rochester Gas and Electric Corp., Robert E. Ginna Nuclear Power Station, Unit 1, Operator Retraining Program Description, Docket No. 50 244, Apr. 10, 1970.

M. A. Schultz, "Use of Simulation Plus Real Steam Turbine for Teaching Theory and Operation of a Pressurized Water Reactor," Nucl. Technol. 10(3): 380-90 (1971).

S. D. Schuman, Description of Westinghouse Reactor Operator Training Program, WCAP-7170, Westinghouse Electric Corp., Pittsburgh, February 1968.

S. D. Schuman, "Westinghouse Nuclear Training Center at Zion, Illinois," Proc. Am. Power Conf. 31: 84-89 (1969).

Southern California Edison Co., San Onofre Nuclear Generating Station, Unit 1, Operator Retraining Program, Docket No. 50 206, Los Angeles, Apr. 8, 1970.

A. Tachibana, "Simulator for BWK I'ype 'l'suruga Nuclear Yower Station," Hitachi Hyoron 52: 412-18 (1970).

USAEC, Division of Nuclear Education and Training, Nuclear Education and Training Frograms of Potential Interest to Utilities, Washington, D.C., 1968.

USAEC, Division of Nuclear Education and Training, Utility Staffing for Nuclear Power, WASH-1130, Washington, D.C., July 1969.

Yu, V. Vinogradov et al., "Nuclear Power Plant Simulator Based on a Complex Computex System," At. Energy (USSR) 26: 537 (1969). 
L. D. White, Jr., "Retraining Experience at R. E. Ginna Station," Trons. Am. Nucl. Soc. 14(Supp1. 2): 51-52 (1971).

Yankee Atomic Electric Co., Yankee Nuclear Power Station, Operator Retraining Program, Docket No. 50 029, Westboro, Mass., Apr. 10, 1970.

\section{Section II}

A. Glassner, Introduction to Nuclear Science, Van Nostrand Rheinhold Co., Cincinnati, 1969.

G. C. Masche, Physics for Reactor Operators, API0-1038, General Electric Co., San Jose, Calif., April 1966.

\section{Section VI}

Bhabha Atomic Research Centre, Introduction to Radiation Protection, BARC/1-292, Bombay, India, 1974.

C. W. Easley, Basic Radiation Protection. Principles and Organization, Gordon and Breach, Science Publishers, Inc., New York, 1969.

A. Glassner, Introduction to Nuclear Science, Van Nostrand Rheinhold Co.. Cincinnati, 1969.

J. C. Hart, "Three-Part 36-Week Training Program for Nuclear Facility Health Physicists," Paper 10 in Symposium on Training of Nuclear Facility Personnel, Gatlinburg, Tenn., April 1971, Conf-7 10416.

D. G. Jacobs, Sources of Tritium and its Behavior upon Release to the Environment, USAEC, Washington, D.C., 1968.

P. N. Krishnamoorthy, "Radiological Protection Problems in the Developing Countries," Health Phys. 21(2): 163-71 (1971).

G. C. Masche, Physics for Reactor Operators, APIO-1038, General Electric Co., San Jose, Calif., April 1966.

R. F. Meeks, Contamination Control Monual, General Electric Co., St. Petersburg, F1a., Apr. 1, 1974. 
D. G. Miller, Radioactivity and Radiation Detection, Gordon and Breach, Science Publishers, Inc., New York, 1972.

J. J. Moe et a1., Radiation Safety Technician Training Course, ANL-7 291 (rev. 1), Argonne National Laboratory, Chicago, May 1972.

K. Z. Morgan and J. E. Turner, ed., Principles of Radiation Protection: A Textbook of Health Physics, John Wiley \& Sons, Inc., New York, 1967.

W. D. Norwood, Health Protection of Radiation Workers, Charles C. Thomas, Publishers, Springfield, Ill., 1975.

W. C. Reinig and G. E. C. Kauffman, "Radiation Protection Training of Industrial Employees," Health Phys. 13: 223-25 (1967).

M. Sarram, "Problems of Radiological Safety Near the Research Reactor of the Tehran University," Radioprotection 9(3): 211-20 (1974).

S. D, Soman and K. C. Pillai, "Radiation Hazards," Sci. Today (Bombay) 9(3): 26-27 (1974).

S, D. Swisher, "A Shift Supervisor's Introduction to Practical Local Meteorology," Nucl. Safety 10 431-36 (1969).

H, Uchida, "Philosophy of Nuclear Safety in Japan," At. Jpn. 18(5, Supp1. 1): 4-9 (1974).

J. E. Wade and G. E. Cunningham, Radiation Monitoring: A Progromed Instruction Book, USAEC, Washington, D.C., 1967.

J. Weber and C. E' Kausmussen, Radiation Frotection. Introduction to Radiation Hygiene, Delftse Uitgeversmaa Tschappij, Delft, 1974.

\section{Section VII}

D. C. Bauer, Practical Control Procedures for Xenon Spatial Oscillations, vols. I and II, Carnegie-Mellon University, Pittsburgh, 1972.

D. C. Bauer, C. G. Poncelet, and A. J. Impink, "Practical Xenon Spatial Control. Problems and Opportunities in Load Follow," Trans. Am. Nucl. Soc. $15(2): 888$ (1972).

C. J. Bridgman and R. S. Booth, "Different Approach to the First Course in Reactor Nuclear Physics," Trans. Am. NucZ. Soc. 11: 45-46 (1968).

Carolina Power and Light Co., H. B. Robinson Unit 2. Axial Xenon Oscillations, Raleigh, N.C., Oct. 16, 1972. 
W. R. Corcoran, "Damping of Xenon Oscillations in the Maine Yankee Reactor," Nucl. Technol. 22(2): 252-62 (1974).

W. R. Corcoran et al., "Damping of Xenon Oscillations in the Maine-Yankee Reactor," Troons. Am. Nucl. Soc. 17(1): 27-29 (1973).

F. J. Frank, D. P. Felentzer, and J. C. Lee, Measured Characteristics of Xenon-Induced $X-Y$ Oscizlations in the $H$. B. Robinson Unit 2 Nuclear Power Plant, WCAP-8118, Westinghouse Electric Corp., Pittsburgh, April 1973.

A. Glassner, Introduction to Nuclear Science, Van Nostrand Rheinhold Co., Cincinnati, 1961.

E. Greenspan, "Source-Multiplication Reactivity," NucZ. Sci: Eng. 56(1): 103-06 (1975).

A. J. Impink, Jr., and A. A. Bassioni, "Automatic Optimal Suppression of Xenon Oscillation," Trans. Am. Nucl. Soc. 18: 307-08 (1974).

S. Ina, H. Yoshikawa, and J. Wakabayashi, "Simulation Study of System for Diagnosis of Nuclear Reactor Operation," J. Nucl. Sci. Technol. 11(7): 275-83 (1974).

L. W. Lau, Elements of Nuclear Reactor Engineering, Gordon and Breach, Science Publishers, Inc., New York, 1974.

G. C. Masche, Physics for Reactor Operators, APIO-1038, General Electric Co., San Jose, Calif., April 1966.

A. F. McFarlane, "Physics of Operating Pressurized Water Reactors," Nucl. App Z. Technol. 9: 634-39 (1970).

D. H. Owens, Optimization of Xenon Control Margins During Power Moneuvers, AEEW-R-868, Atomic Énergy Establishment, Winfrith, England, April 1973.

R. J. Tuttle, "Delayed-Neutron Data for Reactor-Physics Analysis," Nucl. Sci. Eng. 56(1): 37-71 (1975).

F. A. Valente, ed., A Manual of Experiments in Reactor Physics, Macmillan Co.. 1963.

Section VIII

G. G. Abbey, "Development of Large Scale Operational Simulators for Power Operator Training," Trans. Am. Nucl. Soc. 21(1): 975-77 (1974). 
W. G. Counsi1, "Simulator Experience by Utilities," Paper 11 in Symposium on Training of Nuclear Facility Personnel, Gatlinburg, Tenn., Apriz 1971, Conf-7 10416.

J. C. Deddens, "PWR Simulator Training," Nucl. News 12(11): 50-53 (1969).

F. P. Demello and R. J. Mills, "Specifying Training Simulators for Power Plant Operators," Instrum. Power Ind. 15: 31-36 (1972).

R. L. Gridley, W. H. Guppy, and K. T. Perkins, "BWR Simulator Training," NucZ. News 12(11): 53-56 (1969).

S. Grimes, "Operating Experience with the Cardinal Plant Training Simulator," Trans. Am. Nucl. Soc. 13: 802 (1970).

R. C. Knoble, "Training Perspective on the Use of the BWR Simulator," Trans. Am. Nucl. Soc. 13: 802-03 (1970).

P. L. Pfennigwerth and B. Minkler, Heat Transfer and Fluid Flow with Applications to Pressurized Water Reactors, vol. 1, WAPD-TM-1000, Bettis Atomic Power Laboratory, Pittsburgh, January 1971.

M. A. Schultz and W. F. Eckley, "Use of a Simulation Plus Real Steam Turbine for Teaching Theory and Operation of a Pressurized Water Reactor," Nucl. Technol. 10(3): 380-90 (1971).

B. S. Shiralkar, L. E. Schnebly, and R. T. Lahey, Jr., "Variation of the Vapor Volumetric Fraction During Flow and Power Transients," Nucl. Eng. Des. 25(3): 350-68 (1973).

\section{Section IX}

G. G. Abbey, "Development of Large Scale Operational Simulators for Power Operator Training," Trans. Am. Nucl. Soc. 21(1): 975-77 (1974).

J. A. Ayres, ed., Decontomination of Nuclear Reactors and Equipment, The Ronald Press Company, New York, 1970.

C. A. Baird and J. E. Behen, Jr., "Automation Solves Winter Cooling Tower Problems," Power Eng. $79(5)$ : 36-39 (1975).

P. Cohen, Water Coolant Technology of Power Reactors, Gordon and Breach, Science Publishers, Inc., New York; 1969.

W. R. Corcoran et al., "Damping of Xenon Oscillations in the Maine Yankee Reactor," Nucl. Technol. 22(2): 252-62 (1974). 
W. G. Counsil, "Simulator Experience by Utilities," Paper 11 in Symposium on Training of Nuclear Facility Personnel, Gatlinburg, Tenn., April 1971, Conf-7 10416.

J. C. Deddens, "PWR Simulator Training," Nucl. News 12(11): 50-53 (1969).

F. P, Demello and R. J. Mills, "Specifying Training Simulators for Power P1ant Operators," Instrum. Power Ind. 15: 31-36 (1972).

K. H. Fischer et al., Radiation and Radiation Measuring Techniques in Nuclear Power Plants, Elitera, Berlin, Fed. Rep. Germany, 1974.

R. L. Gridley, W. H. Guppy, and K. T. Perkins, "BWR Simulator Training," Nuc2. News 12(11): 53-56 (1969).

S. Grimes, "Operating Experience with the Cardinal Plant Training Simulator," Tiurls. An. NueZ. Suce. 13: 802 (1970).

R. C. Knoble, "Training Perspective on the Use of the BWR Simulator," Trans. Am. Nucl. Soc. 13: 802-03 (1970).

H. Mende, "Development and Current Technical Status of Decontamination Eyaporators," Kerntechnik 16(4): 170-77 (1974).

A. Roffman et al., State of the Art of Saltwater Cooling Towers for Stecm Electric Generating Plants, WASH-1244, Westinghouse Electric Corp., Pittsburgh, February 1973.

G. 0. Schrecker, S. L. Williams, and F. M. Shofner, "Atmospheric Dispersion of Cooling-Tower Blowdown," in Environmental Effects of Cooling Systems at Nuclear Power Plants, International Atomic Energy Agency, Vienna, February 1975.

M. A. Schultz and W. F. Eckley, "Use of a Simulation Plus Real Steam Turbine for Teaching Theory and Operation of a Pressurized Water Reactor, "Nucl. Technol. 10(3): 380-90 (1971).

C. P. Straub, Low-Level Radioactive Wastes: Their Handling, Treatment, and Disposal, ÜSAEC , Washington, D.C̈., University Microfilms OP 55507, 1964.

I. Vladea, "The Most Important Parameters Which Decide the Behaviour of the Wet Cooling Tower," Brennst.-Waerme-Kraft 26(6): 244-49 (1974).

\section{$\underline{\text { Section X }}$}

J. M. Harrer and J. G. Beckerley, Nuclear Power Reactor Instrumentation Systems Handbook, vol. II, USAEC, 1974. 
F. Szabo et al., "Role of a Research Reactor in Science Technology and Education in Hungary," p. 326 in Conf-7 10901, June 1971.

\section{Section XI}

J. F. Boland, Nuclear Reactor Instrmentation (In-Core), Gordon and Breach, Science Publishers, Inc., New York, 1970.

H. Dahse, "Special Requirements of the Instrumentation in Nuclear Power Stations and Nuclear Processing Plants," Kerntechnik 16(10): 449-54 (1974).

J. M. Harrer and J. G. Beckerley, eds., Nuclear Power Reactor Instmumtation Systems Handbook, vols. I and II, Argonne National Laboratory, Chicago, 1973.

S. Takamatsu, Reactor Instrumentation. Report to the Government of Argentina, International Atomic Energy Agency, Vienna, Apr. 24, 1970.

P. Timmerman, Instruction Systems and Administrative Procedures in Nuclear Reactor Plants, RISO-M-809, Danish Atomic Energy Commission, Risoe, Oct. 3, 1968.

J. E. Wade and G. E. Cunningham, Radiation Monitoring: A Progrommed Instruction Book, USAEC, Washington, D.C., 1967.

\section{Section XIII}

W. K, Anderson and J. S. Theilacker, Neutron Absorber Materials for Reactor Control., USAEC, Waohington, D.C., 1962.

D, C. Bauer, Practical Control Procedures for Xenon Spatial Oscillations, vols. I and II, Carnegie-Mellon University, Pittsburgh, 1972.

D. C. Bauer, C. G. Poncelet, and A. J. Impink, "Practical Xenon Spatial Control. Problems and Opportunities in Load Follow," Trans. Am. Nucl. Soo. 15(2): 888 (1972).

C. J. Bridgman and R. S. Booth, "Different Approach to the First Course in Reactor Nuclear Physics," Trans. Am. Nucl. Soc, 11: 45-46 (1968).

Carolina Power and Light Co., H. B. Robinson Unit 2. Axial Xenon Oscillations, Raleigh, N.C., Oct. 16, 1972. 
W. R. Corcoran, "Damping of Xenon Oscillations in the Maine Yankee Reactor," Nucl. Technol. 22(2): 252-62 (1974).

W. R. Corcoran et a1., "Damping of Xenon Oscillations in the Maine-Yankee Reactor," Trans. Am. Nucl. Soc. 17(1): 27-29 (1973).

F. J. Frank, D. P. Felentzer, and J. C. Lee, Measured Characteristics of Xenon-Induced $X-Y$ Oscillations in the $H . B$. Robinson Unit 2 Nuclear Power Plant, WCAP-8118, Westinghouse Electric Corp., Pittsburgh, April 1973.

E. Greenspan, "Source-Multiplication Reactivity," Nucl. Sci. Eng. 56(1): 103-06 (1975).

A. J. Impink, Jr., and A. A. Bassioni, "Automatic Optimal Suppression of Xenon Oscillation," Trans. Am. Nucl. Soc. 18: 307-08 (1974).

S. Ina, H. Yushikawd, and J. Wakabayaohi, "Simulation Study of system fur" Diagnosis of Nuclear Reactor Operation," J. Nucl. Sci. Technol. 11(7): 275-83 (1974).

L. W. Lau, Elements of Nuclear Reactor Engineering, Gordon and Breach, Science Publishers, Inc., New York, 1974.

D. H. Owens, Optimization of Xenon Control Margins During Power Maneuvers, AEEW-R-868, Atomic Energy Establishment, Winfrith, England, April 1973.

R. J. Tuttle, "Delayed-Neutron Data for Reactor-Physics Analysis," Nucl. Sci. Eng. 56(1): 37-71 (1975).

F. A. Valente, ed., A Manual of Experiments in Reactor Physics, Macmilian Co., 1963.

\section{Section XIV}

G. G. Abbey, "Development of Large Scale Operational Simulators for Power Operator Training," Trans. Am. Nucl. Soc. 21(1): y/b-i'i (1974).

W. G. Counsil, "Simulator Experience by Utilities," Paper 11 In Symposium on Training of Nuclear Facility Persurrtel, Gutlinburg, Tenn., April 1871, Conf-7 10416.

J. C. Deddens, "PWR Simulator Training," Nucl. News 12(11): 50-53 (1969).

F. P. Demelio and R. J. Mills, "Specifying Tralning Simulators for Power Plant Operators," Instrum. Power Ind. 15: 31-36 (1972). 
R. L, Gridley, W. H. Guppy, and K. T. Perkins, "BWR Simulator Training," Nucl. News 12(11): 53-56 (1969).

S. Grimes, "Operating Experience with the Cardinal Plant Training Simulator," Trans. Am. Nucl. Soc. 13: 802 (1970).

R. C. Knoble, "Training Perspective on the Use of the BWR Simulator," Trans. Am. Nucl. Soc. 13: 802-03 (1970).

M. A. Schultz and W. F. Eckley, "Use of a Simulation Plus Real Steam Turbine for Teaching Theory and Operation of a Pressurized Water Reactor," Nucl. Technol. 10(3): 380-90 (1971).

\section{Section XV}

T. Downs and J. T. Wood, "Detection and Location of Failed Fuel," J. Brit. Nuc Z. Energy Soc. 12(4): 437-42.

A. R. Kaufmann, Nuclear Reactor Fuel Elements, Metallurgy and Fabrication, John Wiley \& Sons, Inc., New York, 1962.

J. A. L. Robertson, Irpadiation Effects in Nuclear Fuels, Gordon and Breach, Science Publishers, Inc., New York, 1968.

W. D. Wilkinson, W. F. Murphy, and W. J. McGonnagle, Nuclear Reactor Metal.7.urgy, Van Nostrand Rheinhold Co., Cincinnati, 1958.

\section{Section XVI}

J. W. Barnes, Storage of Radioactive High-Level Waste, ARH-SA-162, Atlantic Richfield Hanford Co., Richland, Wash.

D. G. Jacobs, Sources of Tritium and its Behavior upon Release to the Environment, USAEC, Washington, D.C., 1968.

P. N. Krishnamoorthy, "Radiological Protection Problems in the Developing Countries," Health Phys. 21(2): 163-71 (1971).

D. G. Miller, Radioactivity and Radiation Detection, Gordon and Breach, Science Publishers, Inc., New York, 1972. 
K. Z. Morgan and J. E. Turner, eds., Principles of Radiation Protection: A Textbook of Health Physics, John Wiley \& Sons, Inc., New York, 1967.

J. E. Wade and G. E. Cunningham, Radiation Monitoring: A Progrommed Instruction Book, USAEC, Washington, D.C., 1967.

\section{Section XVII}

C. D. Becker and T. O. Thatcher, compilers, Toxicity of Power Plant Chemicals to Aquatic Life, WASH-1249, USAEC, Washington, D.C., June 1973.

W. G. Belter, "Management of Waste Heat at Nuclear Power Stations, its Possible Impact on the Environment, and Possibilities of its Economic Use," Environmental Effects of Cooling Systems at Nuclear Power Plants, International Atomic Energy Agency, Vienna, February 1975.

Consumers Power Corp., Quality Assurance Program Manual for Nuclear Power Plants. Vol. III. Procedures for Operations, CPC-1, Jackson, Mich., May 1975.

B. Cook and A. K. Biswas, "Beneficial Use for Thermal Discharges," Survey of Possibilities in Canada, Information Canada, Ottawa, 1974.

D. W. Crancher, D. J. Higson, and L. H. Keher, Safety and E'nvironmental Aspects of Nuclear Energy, Australian Atomic E'nergy C'ommission, Conf-7 $10511,1971$.

Duke Power Company, Duke Power Company l'opical Report: Quality Assurarce Progrom, Charlotte, N.C., Feb. 14, 1975.

R. F. Foster, Nuclear Power and PolZution, BNWL-SA-5184, Battelle Pacific Northwest Laboratories, Richland, Wash., 1974.

S. R. Hanna and J. Pell, coordinators, Cooling Tower Environment - 1974 (AEC Symposium Series), USAEC, Winter 1974-75.

K. Hornyik, "Tritium Generation in the Coolant-Moderator of Pressurized Water Reactors," Nucl. Sci. Eng. 49(3): 247-54 (1972).

International Atomic Energy Agency, Physical-Chemical Effects of Cooling Systems and Thermal Discharges on the Environment, Thermal Discharges at Nuclear Power Stations, Vienna, 1974.

L. D. Jensen, "Effects of Thermal Discharges into Surface Waters," in Human and Ecological Effects of Nuclear Power Plants, ed. L. A. Sagan, Charles C. Thomas, Publishers, Springfield, I11., 1974. 
W. A. Jester, "Environmental Impact of Electrical Power Generation: New Educational Minicourse," Trans. Am. Nucl. Soc. 18: 31-32 (1974).

L. M. Johnson, "Consultant's View: Nuclear Industry's Quality Personnel Needs and Qualifications," Trans. Am. Nucl. Soc. 21: 84 (1975).

H. Kiefer, "Catastrophic Protection Training at the Gundremingen Nuclear Power Plant - Experience and Theory," pp. 261-72 in GeselZschaft fur Kernforschung M. B. H., Karlsmihe (West Germany), Conf-6 90540.

Nuclear Safeguards, McGraw-Hill, Inc., New York, 1974.

T. H. Pigford, M. J. Keaton, and B. J. Mann, Environmental Effluents from Waste Heat Rejection, NP-20456, University of California, Berkeley, 1974.

J. A. Powers and L. R. Norderhaug, "Materials and Plant Protection Standards: Revisited," Nucl. Mater. Manage. 3(4): 31-35 (1975).

L. 0. Ramsett and G. C. Vellender, "Quality Assurance Requirements Associated with a Spare Parts Program," Trans. Am. Nucl. Soc. 19: 333 (1974).

D. I. Ray, Importance of Nuclear Safeguards, Atomic Industrial Forum, Inc., New York, 1975.

R. L. Rinne, Nuclear Energy Technology Transfer: The Security Barriers, SAND-75-8685, Sandia Laboratories, Albuquerque, August 1975.

S. E. Rippon, "Public Acceptance of Nuclear Power: A Worldwide Problem," Conadian Nuclear Association 14th Annual Intemational Conference, Montreal, Conada, Jumo 8-12, 1074, vol. 0, 1974.

R. M. Rotty, Waste Heat Disposal from Nuclear Power Plants, NOAA-TM-ERLARL-47, Nat1onal Oceanic and Atmospheric Administration, Silver Spring, Md., September 1974.

L. A. Sagan, ed., Human and Ecological Effects of Nuclear Power Plants, Charles C. Thomas, Publishers, Springfield, Ill., 1974.

V. Schultz and F. W. Whicker, compilers, Ecological Aspects of the Nuclear Age: Selected Readings in Radiation Ecology, USAEC, Washington, D.C., 1972.

R. J. Squires, "Quality Assurance in Operations," Trans. Am. Nucl. Soc. 19: 357 (1974).

O, R. Surgen and R. E. Martin, "Nuclear Power Plant Quality Assurance Records," Trans. Am. Nucl. Soc. 19: 328-29 (1974). 
USAEC, Directorate of L1censing, Quality Assurance During the Operations Phase, REG/SRP-17.2, Washington, D.C., 1974.

E. A. V1erzba and M. H. PhIl1ps, Jr., "Implementation of the Operational Quality Assurance Program," Trans. Am. Nucl. Soc. 21(Suppl. 1): 2 (1975).

Virginia Electric and Power Co., Quality Assurance Progran: Operations Phase, Topical Report, NP-20528, Richmond, July 1, 1975.

J. S. W11llams, Jr., and S. Sp1gel, Socio-Economic Impact of Estuarine Thermal PolZution, Completion Report, PB-236 034, Metrostudy Corp., Washington, D.C., 1974.

D. W, W11son, "Facllity Security: Does the Shoe Fit the Foot?," Trans. Am. NucZ. Soc. 21: 126 (1975).

J. S. Young, "Menhaden and Power Plants: A Growlng Concern," Mar. Fish. Rev. 36(10): 19-23 (1974).

\section{Section XVIII}

W. K. Pohl, "Catastrophic Protection Training at the Gundremmingen Nuclear Power Plant - Planning, Operating Sequence, and Experfence," pp. 246-60 in Bayerisches Staatsministerium des Innerm, Monich (West Germany/Oberste Baubehoerde), Conf-6 90540 .

S. D. Swisher, "A Shift Supervisor's Introduction to Practical Local Meteorology," Nucl. Saf'ety 10: 405-11 (1969).

P. Timmermann, Instruction Systems and Administrative Procedures in Nuclear Reactor Plants, RISO-M-809, Danish Atomic Energy Commission, Risoe, Oct. 3, 1968. 


\title{
INTERNAL DISTRIBUTION
}

\author{
1. A. E. G. Bates \\ 2. C. D. Cagle \\ 3. W. R. Casto \\ 4. B. L. Corbett \\ 5-34. J. A. Cox \\ 35. W. H. Culbert \\ 36. T. P. Hamrick \\ 37. S. S. Hurt, III \\ 38. R. V. McCord \\ 39. K. H. Poteet \\ 40. Central Research Library \\ 41. Document Reference Section \\ 42-44. Laboratory Records Department \\ 45. Laboratory Records, ORNL R.C. \\ 46. Patent office \\ 47. Research and Technical Support Division, ORO \\ 48-74. Technical Information Center
}

